


\section{La presente obra está bajo una licencia de:}

\section{http://creativecommons.org/licenses/by-nc-sa/3.0/deed.es MX}

\section{Atribución-No Comercial-Licenciamiento Reciproco 3.0 Unported}

Eres libre de:

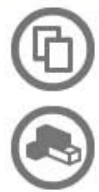

copiar, distribuir y comunicar públicamente la obra

hacer obras derivadas

Bajo las condiciones siguientes:

Atribución - Debes reconocer la autoria de la obra en los términos

especificados por el propio autor o licenciante.

No comercial - No puedes utilizar esta obra para fines comerciales.

D Licenciamiento Reciproco - Si alteras, transformas o creas una obra a

partir de esta obra, solo podrás distribuir la obra resultante bajo una licencia

igual a ésta.

\section{Esto es un resumen fácilmente legible del: texto legal (de la licencia completa)}

\section{En los casos que sea usada la presente} obra, deben respetarse los términos especificados en esta licencia.

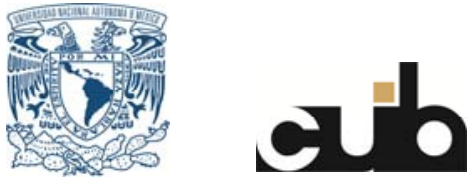


Enseñanza virtual sobre la organización de recursos informativos digitales 


\section{COLECCIÓN}

SISTEMAS BIBLIOTECARIOS DE INFORMACIÓN Y SOCIEDAD

Centro Universitario de Investigaciones Bibliotecológicas 


\title{
Enseñanza virtual sobre la organización de recursos informativos digitales
}

\author{
Roberto Garduño Vera
}

Universidad Nacional Autónoma de México 2005 


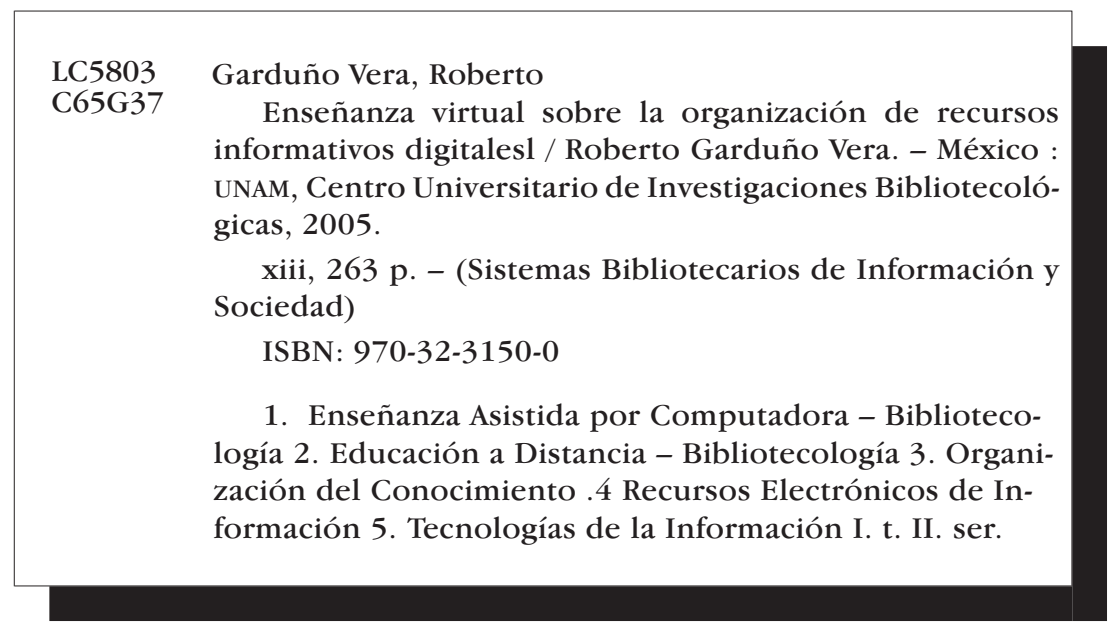

Diseño de portada: Mario Ocampo Chávez

Primera edición 2005

DR (C) UNIVERSIDAD NACIONAL AUTÓNOMA DE MÉXICO

Ciudad Universitaria, 04510, México D.F.

Impreso y hecho en México

ISBN: 970-32-3150-0 


\section{Contenido}

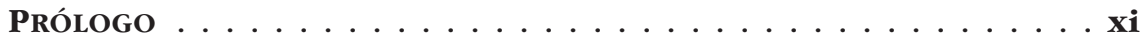

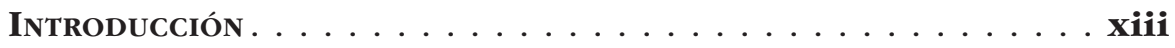

\section{Capítulo I \\ LA EDUCACIÓN VIRTUAL FRENTE A LOS EFECTOS \\ DE LAS TECNOLOGÍAS DE INFORMACIÓN Y COMUNICACIÓN}

Educación a distancia y educación virtual: una aproximación conceptual . . . . . . . . . . . 3

Componentes fundamentales de la educación a distancia $\ldots \ldots . . . .12$

Aproximación a las teorías y estrategias de aprendizaje en los sistemas a distancia . . . . . . . . . . . . . 15

Constructivismo, tutoría y educación virtual $\ldots \ldots \ldots . \ldots 21$

La educación virtual ante las tecnologías de información y comunicación . . . . . . . . . . . . . . . . . . 29 


\section{Capítulo II \\ MATERIALES DIDÁCTICOS Y SOPORTES DE CONTENIDO \\ EN LA EDUCACIÓN VIRTUAL}

Materiales didácticos: un acercamiento teórico $\ldots \ldots 43$

Desarrollo de materiales didácticos para la educación virtual . . . . . 51

Desarrollo de materiales didácticos y derechos de autor . . . . . . 58

Tecnologías de información y comunicación en el desarrollo de materiales didácticos . . . . . . . . . . . . . 66 65

Tendencias en el desarrollo de software educativo . . . . . . . 68

Instrucción Asistida por Computadora . . . . . . . . . . 68

Programas tutoriales . . . . . . . . . . . . . . 73

Simulaciones y micromundos $\ldots \ldots \ldots \ldots \ldots \ldots \ldots \ldots \ldots \ldots$

Hipertexto-hipermedia $\ldots \ldots \ldots \ldots \ldots \ldots \ldots$

\section{Capítulo III}

ENSEÑANZA VIRTUAL SOBRE LA ORGANIZACIÓN DE RECURSOS INFORMATIVOS DIGITALES

La bibliotecología como disciplina de referencia $\ldots \ldots . \ldots 85$

La comunicación en la educación virtual en bibliotecología . . . . 92

Educación virtual del bibliotecólogo ante la globalización

y la sociedad de la información . . . . . . . . . . . . . 95

Hacia un perfil del bibliotecólogo frente a la educación virtual $\cdots 98$

Educación especializada del bibliotecólogo . . . . . . . . 105

Formación especializada en temas bibliotecológicos $\ldots \ldots$

Tendencias actuales sobre la organización de recursos

informativos digitales . . . . . . . . . . . . 118

El documento como objeto digital . . . . . . . . . . . . . 121

El hipertexto en la organización de objetos digitales . . . . . . . . 126

Retos para los bibliotecólogos en la organización de recursos

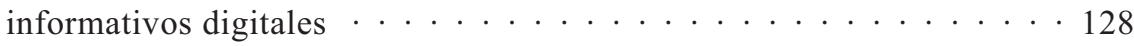




\section{Capítulo IV \\ ELEMENTOS BÁSicos PARA EL dISEÑO DE UN MODELO PARA \\ LA ENSEÑANZA VIRTUAL SOBRE LA ORGANIZACIÓN DE RECURSOS INFORMATIVOS DIGITALES}

Aproximación a la idea de modelo teórico . . . . . . . . . . 135

Las nociones de modelo educativo y de modelo académico . . . . . . 139

Modelo académico para la enseñanza virtual sobre la organización de recursos informativos digitales: una especialización como ejemplo . . . . . . . . . . . . . . . . . 143

Temas relevantes para la enseñanza virtual sobre la organización de recursos informativos digitales . . . . . . . . . . . 154 Avances del control bibliográfico y la normalización en los albores del siglo XXI . . . . . . . . . . . . . . . . . . . 154

Vigencia u obsolescencia de los formatos bibliográficos . . . . . . 160

Bases de datos bibliográficos y catálogos públicos en línea

(OPAC's) : ¿viejos problemas o novedosas soluciones? . . . . . . . 163

Promesas del paradigma metadatos . . . . . . . . . . . . . 170

El tesauro en la recuperación de documentos digitales . . . . . . . 177

Redes de telecomunicación y transmisión de documentos digitales. . . . . . . . . . . . . . . . . . . . . 179

Fundamento de la especialización sobre la organización de recursos informativos digitales . . . . . . . . . . . 181

Módulos de la especialización … . . . . . . . . . . 185

Módulo I. Normalización de la información digital y gestión de contenido mediante bases de datos, lenguajes de marcado e hipertexto . . . . . . . . . . . . . . . . . . . . . . . . . . . 186

Módulo II. Formatos Bibliográficos Internacionales: MARC 21 y representación de documentos digitales . . . . . . . . . . . . . . . 187

Módulo III. Metadatos en la representación de recursos informativos digitales y acceso a la información vía Internet . . . . . . . . . . . . . . . . . . . . . . . . . . . . . . . . . . . 188

Módulo IV. El tesauro en el medio digital . . . . . . . . . . . . . . . . . . 189

Módulo V. Elaboración de un trabajo de investigación . . . . . . . . 190

Requisitos y figuras del programa académico . . . . . . . . . . . . . . . 190

Representación gráfica de la especialización ․ . . . . . . . . . 198 


\section{Capítulo V \\ Plataforma de APOYO A la ENSEÑANZA VIRTUAL \\ SOBRE LA ORGANIZACIÓN DE RECURSOS \\ INFORMATIVOS DIGITALES}

Internet en la educación virtual . . . . . . . . . . . . . 203

Internet y los nuevos procesos en la educación virtual . . . . . . 210

Lo virtual en la educación . . . . . . . . . . . . . . . . . 213

Interactividad en la web y educación virtual . . . . . . . . . 217

Estructura del aula virtual de apoyo a la especialización sobre

la organización de recursos informativos digitales . . . . . . 222

Software y desarrollo del aula virtual y de la biblioteca

digital de apoyo . . . . . . . . . . . . . . . . . . . . . . . . . . . . . . . . . . . . .

Estructura lógica del aula virtual . . . . . . . . . . . . . . . . 229

Estructura lógica de la biblioteca digital y sus servicios en la

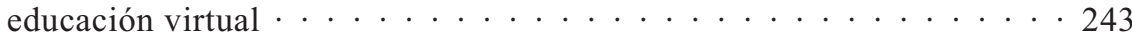

REFLEXIONES FINALES $\ldots \ldots \ldots \ldots \ldots \ldots \ldots$

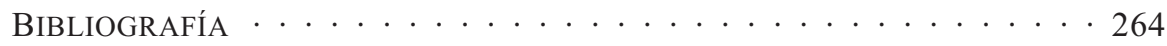




\section{ÍNDICE DE FIGURAS}

Figura 1

Lineamientos para la elaboración de material didáctico $\ldots \ldots . . .52$

Figura 2

Flujograma para la producción académica $\ldots \ldots \ldots$

Figura 3

Diálogo didáctico mediado en la educación a distancia $\ldots \ldots .78$

Figura 4

Problemas de actualidad en torno a la educación

virtual en bibliotecología . . . . . . . . . . . . . . 92

Figura 5

Temas relevantes en torno a la organización de

recursos informativos digitales .................. 130

Figura 6

Dimensiones esenciales del modelo de la

educación a distancia .

Figura 7

Sistema de la Especialización Sobre la Organización

de Recursos Informativos Digitales . . . . . . . . . . . . . . . 199

Figura 8

Estructura lógica del aula virtual $\ldots \ldots \ldots \ldots$

Figura 9

Plataforma del aula virtual $\ldots \ldots \ldots \ldots \ldots \ldots$

Figura 10

Herramientas del aula virtual $\ldots \ldots \ldots \ldots \ldots$

Figura 11

Actores del aprendizaje a través del aula virtual

y figuras complementarias . . . . . . . . . . . . . 238 
Figura 12

Funciones del alumno a distancia $\ldots \ldots \ldots \ldots$

Figura 13

Funciones del tutor a distancia $\ldots \ldots \ldots \ldots \ldots$

Figura 14

Funciones del bibliotecólogo en la educación

virtual . . . . . . . . . . . . . . . . . . . . . . . 240

Figura 15

Funciones del administrador del aula virtual . . . . . . . . 241

Figura 16

Estructura fundamental de la biblioteca digital . . . . . . . 254

Figura 17

Recuperación de la información digital

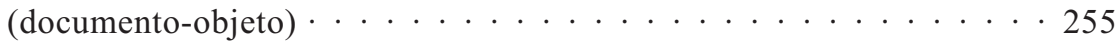




\section{PRÓlogo}

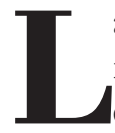

a obra de Roberto Garduño que, por medio de las presentes líneas tengo el honor de presentar a la comunidad científica, es el fruto más granado de su investigación doctoral y, además, constituye una enorme y auténtica encrucijada disciplinar. Pero este último aserto merece una explicación.

En efecto, en En señanza virtual sobre la organización de recursos informativos digitales, se dan cita una serie de problemas y de cuestiones que el autor, tras su oportuna y atinada reflexión, nos ofrece en forma de soluciones y aun de nuevas vías de discurso y de profundización. Como se sabe, las disciplinas documentales y los profesionales del documento son considerados en ocasiones como entes mutantes. Y esta expresión, que mueve a la sonrisa y que comparten sólo los recientes campos del saber, significa que el cambio es el fenómeno en que se mece el qué, el por qué y el para qué de los bibliotecólogos y documentalistas. Y nos referimos, específicamente, a tres tipos de cambio: El cambio social, derivado de las crecientes y cambiantes necesidades de la información experimentadas por los ciudadanos incluso en las sociedades menos avanzadas; el cambio tecnológico de permanente evolución y arraigo en las variadas costumbres de los ciudadanos, y el cambio resultante, esto es, el cambio documental o bibliotecológico que se observa, de modo sintético, en diversas notas como el acercamiento cada vez más intenso del hombre y la computadora, el homo documentalis o protagonista de la autodocumentación, frente al homo documentator o bibliotecólogo/ documentalista del futuro presente, y la presencia de la socialización 
del saber en brazos de la biblioteca virtual y digital, de la biblioteca mágica y emergente.

El cambio tecnológico al que aludimos se manifiesta también en otros aspectos que han ocupado a nuestro admirado colega. De un lado, el desarrollo de la enseñanza virtual. Ello ha comportado numerosas reflexiones sobre su concepto y sobre la naturaleza de los adecuados materiales didácticos. Del otro lado, la forzosa obligación de preparar permanentemente al profesional del documento ante el reto representado por el cambio en la naturaleza del quehacer bibliotecario y documental. De aquí arranca el núcleo de la obra que presentamos y que, por consiguiente, se afana en proponer un modelo de enseñanza virtual encaminado al estudio y experimentación de los recursos informativos digitales en la materia aludida. La plataforma informática resultante es analizada con todo detalle de tal manera que se convierte, de hecho, en un modelo crítico y consolidado y de previsible aplicación.

En suma, el libro redactado por el doctor Garduño Vera, uno de los más eminentes investigadores del Centro Universitario de Investigaciones Bibliotecológicas (UNAM), contribuye, entre otros aspectos, al mejor conocimiento de las claves de la sociedad de la información, al desarrollo eficaz de la nueva metodología didáctica para la formación de los profesionales del documento y, específicamente, a la enseñanza de los recursos informativos digitales como instrumento básico para la citada formación.

José López Yepes

Catedrático de Biblioteconomía y Documentación, Facultad de Ciencias de la Información Universidad Complutense de Madrid 


\section{Introducción}

Ta educación a distancia es un campo de conocimiento privilegiado para comprender los desafíos actuales ante los procesos que se han generado con los desarrollos y aplicaciones alcanzados por las Tecnologías de la Información y Comunicación (TIC) en las sociedades modernas. En el área educativa, es indispensable estudiar las repercusiones del uso de la Internet en la educación a distancia, las propuestas teóricas que se discuten ahora en cuanto a interactividad y navegación, así como las perspectivas sociales e institucionales que se esperan en el siglo XXI de la educación basada en tecnologías de red.

La sociedad de la información y del conocimiento ha producido cambios sustanciales dirigidos al ejercicio profesional y construido escenarios de vinculaciones, relaciones y acciones que afectan a la sociedad en su conjunto; al mismo tiempo, ha generado retos para la educación virtual adaptada a las nuevas realidades tecnológicas, lo que requiere que los diseñadores de propuestas educativas a distancia, autores de contenido, asesores y tutores, cuestionen, por una parte, los alcances de los modelos que diseñan y, por otra, la conveniencia de los contenidos educativos y las prácticas pedagógicas que requieran utilizar.

En la actualidad, la Internet representa una realidad tecnológica relevante en el diseño de propuestas educativas virtuales para cualquier disciplina, de ahí que resulte conveniente considerar diversos aspectos de su desarrollo y de su aplicación en la educación del presente siglo. En este contexto, el desarrollo del conocimiento y la tecnología 
son fenómenos fundamentales que la educación debe enfrentar en todos sus niveles.

Así, el modelo propuesto por la educación a distancia exige tomar en cuenta una serie de variables, con el fin de incidir eficientemente en la comunicación educativa entre los actores del aprendizaje. Entre las variables se encuentran la institución responsable de la propuesta educativa, el programa de estudio, el perfil del egresado, el mercado laboral, el desarrollo planificado de materiales didácticos (tomando en cuenta teorías del aprendizaje), la distribución del material a través de medios que favorezcan el aprendizaje independiente y colaborativo. Cabe destacar la tutoría como elemento determinante del diálogo académico; asimismo, la evaluación de contenidos y de los aprendizajes son dimensiones de suma importancia en dicha modalidad.

Por todo lo anterior, este libro tiene como intención primordial analizar las principales características, posibilidades y retos que implican los diversos aspectos teóricos de la educación a distancia y que ha heredado la educación virtual, con el propósito de hacerlos visibles en el diseño teórico de un Modelo $^{1}$ de enseñanza virtual, cuya estructura general comprende un modelo académico ${ }^{2}$ y la estructura lógica de una "plataforma tecnológica" de apoyo, la cual se estructura con base en un "aula virtual" ${ }^{3}$ y una "biblioteca digital", ${ }_{4}^{4}$ a través de

1 Se entiende por modelo el conjunto estructurado de propiedades, principios, reglas, métodos y contenidos orientados a instrumentar el proceso de enseñanza-aprendizaje a distancia, en torno a los fenómenos involucrados en la organización de recursos informativos digitales.

2 El modelo académico se enfoca principalmente a identificar las características del plan de estudios, las relaciones entre los actores del proceso educativo y el papel asignado a cada uno de ellos.

3 Se entiende por aula virtual el espacio simbólico de investigación, estudio y actualización en técnicas y metodologías que requieren de la enseñanza virtual para ser aplicados en propuestas educativas a distancia.

4 La biblioteca digital (BD) es "sistema conformado por colecciones de objetos y procesos interactivos". Arias O., José et al.. "El desarrollo de las estructuras de la biblioteca digital". 2000, p. 5. En el presente libro la BD se propone como apoyo documental para la especialización sobre la organización de recursos informativos digitales. Respecto de la BD los siguientes autores proponen ideas interesantes: Deegan Marilyn y Simon Tañer, Digital futures: strategies for the information age, 2002, p. 225-231. 
las cuales se sustentan los procesos de interactividad entre alumnos, asesores y tutores, así como la administración de las diversas actividades de enseñanza-aprendizaje. Con el fin de comprender cabalmente la lógica de dicho modelo, se ejemplifica con el diseño teórico de una especialización sobre la organización de recursos informativos digitales, orientada a profesionales en bibliotecología, documentación y disciplinas afines en ejercicio. Por ello, su consecuencia va desde la presentación de acercamientos teóricos y conceptos hasta propuestas para implementar dicha especialización. Así, esta obra parte de la siguiente problemática.

El constante desarrollo de la ciencia y la tecnología en las diversas áreas profesionales ha propiciado una acelerada generación de conocimiento, situación que dificulta su estudio permanente en niveles óptimos de aprendizaje. En este sentido, se percibe que los fenómenos surgidos con las TIC y los requerimientos del mercado laboral han dado lugar a la formación de profesionales de alto nivel. Asimismo, en nuestros días se advierte una tendencia encaminada a incidir en una mayor preparación de recursos humanos, propiciada por la orientación a lo global, a democratizar la educación y a las posibilidades que otorgan los constantes desarrollos tecnológicos.

En los medios bibliotecarios se ha atendido esta tarea, principalmente de forma presencial mediante licenciaturas, maestrías, doctorados, diplomados y cursos cortos de actualización; sin embargo, se observa que son escasas y, en muchos países latinoamericanos, inexistentes aun en estos días, propuestas educativas a distancia que aludan a la organización de recursos de información digital en el nivel de especialización.

Asimismo, la generación de documentos digitales crece significativamente, lo cual exige la formación de recursos humanos de alto nivel con capacidad para apropiarse de la teoría relacionada con la organización de este tipo de recursos informativos, aplicación de modelos para la organización de documentos de esta naturaleza y desarrollar destrezas en el uso de las tecnologías que requieren el desarrollo de sistemas de información normalizados. Todo ello con la finalidad de facilitar la gestión de servicios documentales, de acuerdo 
con los intereses informativos de la sociedad de nuestro tiempo y en diversos entornos sociales.

Proponer el diseño teórico de un modelo para la enseñanza de una especialización sobre la organización de recursos informativos digitales responde al requerimiento de colaborar en la preparación de cuadros altamente calificados que asuman tareas sociales urgentes y necesarias, relacionadas con la organización de documentos digitales. En tal modelo se sugiere el estudio de temas inherentes a la organización de recursos informativos digitales, tomando como base los fenómenos de mayor relevancia que han generado las nuevas propuestas de normalización documental y los recientes avances de las tecnologías de la información y comunicación.

Son evidentes las diferencias entre catalogar registros bibliográficos y representar información digital para incorporarla en sistemas de metadatos, en bibliotecas digitales o en repositorios de objetos de aprendizaje. En este sentido, resulta indispensable estudiar y reflexionar sobre los modelos normativos que, junto con tecnologías de información y comunicación, están sujetos a cambios constantes que afectan las actividades que requiere la sistematización documental, cuyo propósito debe seguir siendo facilitar la recuperación y el uso de la información por parte de la sociedad.

Asimismo la selección y descripción normativa de recursos digitales disponibles en la Internet se vuelve más urgente, debido sobre todo a los aspectos siguientes: crecimiento exponencial de la información en línea; existencia de una tipología documental múltiple; inestabilidad de los recursos informativos a causa de las continuas actualizaciones, dada su disponibilidad temporal y el requerimiento de fiabilidad que busca el usuario final. A lo anterior habría que agregar los nuevos desarrollos generados por los formatos bibliográficos, los digitales, la generación constante de software para la gestión de documentos digitales y los avances alcanzados en los protocolos de comunicación para redes de teleproceso.

En consecuencia, en los albores del siglo XXI, las tareas sustantivas de los bibliotecarios se orientarán hacia los desarrollos tecnológicos mencionados en líneas atrás. Al respecto, en este libro se considera que la selección apropiada del formato digital y la reorientación o 
generación de la normalización, necesarias para representar recursos documentales en sistemas de metadatos, en bibliotecas digitales y el software de gestión, se perfilan como tareas urgentes para los sectores bibliotecarios, ${ }^{5}$ pero también serán tareas importantes para adelantos tecnológicos más recientes y la proyección de escenarios sociales en los que incida el trabajo relacionado con la organización de documentos digitales.

La problemática que plantea la enseñanza de la organización de recursos informativos digitales se incrementa frente al hecho de que las TIC cambian constantemente, y ante la demanda creciente por parte de los sectores bibliotecarios sobre propuestas educativas que aborden fenómenos emergentes. Por ello es necesario incidir en la búsqueda de un modelo educativo que concuerde con las características de lejanía y situación laboral de los alumnos potenciales. Así pues, consideramos que la educación a distancia, por las características que la definen, puede ser idónea para sustentar el diseño de propuestas educativas en distintos niveles.

En este sentido, cabe mencionar que, después de los años noventa, la educación a distancia se vinculó estrechamente con el uso de las TIC, así como con el desarrollo de medios didácticos para difundir información y conocimiento. Al respecto, coincidimos con Amador Bautista cuando afirma que:

[...] estos procesos de cambio tecnológico están contribuyendo a la transformación de la sociedad de la comunicación en una sociedad de la información. Sin embargo, la carencia de una historia escrita de la educación y la formación a distancia [...], vinculada al desarrollo de los medios y tecnologías de información y comunicación, representan un vacío significativo en un momento de grandes transformaciones mundiales. ${ }^{6}$

5 R. Lafuente López y Roberto Garduño Vera. Lenguajes de marcado de documentos digitales de carácter bibliográfico, México: UNAM, CUIB, 2001, p. 59.

6 Rocío Amador Bautista. "Educación y formación a distancia en México. Crónica de una historia no escrita" en Educación y formación a distancia. Prácticas, propuestas y reflexiones, México: Universidad de Guadalajara, 2001, p. 15. 
Así, en la emergente sociedad de la información y del conocimiento, la educación virtual se sitúa en las TIC. El ciberespacio es el escenario de comunicación interactivo y comunitario. La aparición y desarrollo de este nuevo contexto propicia la generación de propuestas educativas complejas, en las que la construcción del conocimiento entre los actores del proceso educativo se perfila como la principal potencialidad y el nuevo desafío. Con base en esto, se puede decir que atañe a la bibliotecología procurar un proceso permanente de formación, ya que con la penetración de las TIC la vigencia de los conocimientos en el área será cada vez más corta, situación que necesariamente redundará en los procesos educativos y en el ejercicio profesional.

También destaca que la consecuencia inmediata traerá consigo cambios sustantivos en los modelos estructurales de las sociedades y de las instituciones educativas. En este contexto, la bibliotecología requiere diversificar sus campos de conocimiento; desarrollar nuevas alternativas educativas, tomando en cuenta los avances del conocimiento de la disciplina y las demandas de los mercados laborales; incorporar el uso de TIC para la producción y la difusión de nuevo conocimiento; innovar sus métodos y técnicas de enseñanza-aprendizaje, además de continuar con la investigación básica y aplicada. Por ello la especialización sobre la organización de recursos informativos digitales intenta incursionar en varios de estos aspectos.

Asimismo, es evidente la necesidad de recursos humanos con un alto nivel de especialización para elaborar estudios específicos y de amplio espectro orientados a la organización de documentos digitales. Tal conocimiento debe reflejar las necesidades informativas de los usuarios en forma local, regional y nacional, y proyectar sistemas de información normalizados que contemplen el máximo aprovechamiento de los recursos documentales del país de que se trate y en diversos entornos geográficos.

En definitiva, para que la teoría de la educación a distancia y su aplicación en la especialización mencionada sea alcanzable se debe investigar en torno a la educación de esta naturaleza y su vinculación con la educación virtual, los hechos y fenómenos que atañen a la disciplina bibliotecológica y, principalmente, lo relacionado con la organización 
de recursos informativos digitales, las diversas estrategias del proceso de enseñanza aprendizaje, la importancia de los materiales didácticos y la apropiación de las TIC. Igualmente, dada la orientación de la educación superior de buscar alternativas para hacer llegar propuestas educativas a una mayor población, la educación a distancia constituye una posibilidad atractiva para tal fin. Así, considerando lo señalado, este libro se estructura en cinco capítulos y en unas reflexiones finales.

El primer capítulo, titulado: "La educación virtual frente a los efectos de las tecnologías de información y comunicación", se ocupa, entre otros aspectos, de realizar una aproximación a los conceptos y elementos teóricos fundamentales inherentes a la educación a distancia, se valora su utilidad y se plantean interrogantes para estimular la investigación en temas de análisis de los diversos fenómenos generados, principalmente por la irrupción de las TIC en la educación de esta naturaleza. Respecto de lo exhaustivo y genérico de los conceptos existentes, se utilizan principalmente la educación a distancia y la virtual, debido a que son los términos que se han estudiado a profundidad y tienen un uso amplio en los medios educativos, además, explican de la mejor manera el propósito de este libro.

El segundo capítulo, "Materiales didácticos y soportes de contenido en la educación virtual", tiene como propósito desarrollar un acercamiento a los fundamentos teóricos y metodológicos relativos a la generación de materiales didácticos para la educación a distancia, la situación de los derechos de autor en el desarrollo de los mismos, la evolución de los soportes de contenido, la orientación de la generación de software educativo y las características que presentan las TIC aplicadas en la educación virtual.

Este capítulo se ocupa, por una parte, de las bases teóricas para que, en su momento, administradores de propuestas educativas virtuales valoren la conveniencia en cuanto al desarrollo de materiales de instrucción y, por otra parte, los autores de contenido cuenten con elementos teóricos y metodológicos fundamentales para estudiar las diversas tareas que exige el desarrollo de material didáctico de apoyo para el aprendizaje virtual. Los dos primeros capítulos proporcionan marcos de referencia para sustentar diversos aspectos teóricos 
vinculados con la bibliotecología en general, y en particular con la enseñanza sobre la organización de documentos digitales.

El tercer capítulo, "Enseñanza virtual sobre la organización de recursos informativos digitales", parte de la bibliotecología como disciplina de referencia y se analizan diversos fenómenos relacionados con su posible enseñanza virtual. El propósito de esto es fundamentar, a partir del cuerpo de conocimientos de la bibliotecología, la propuesta teórica de una especialización sobre la organización de recursos informativos digitales, por lo tanto, se reflexiona desde una perspectiva histórica en torno a la educación especializada y se aluden los fenómenos de estudio que se contemplan en dicha especialización. Las preguntas de mayor relevancia y a las cuales se intenta dar respuesta a lo largo de este capítulo son las siguientes: ¿desde una perspectiva metodológica, cómo pueden enseñarse en forma virtual temas relacionados con la organización de recursos digitales? ¿qué fenómenos propios de la organización de recursos informativos digitales han de considerarse para su enseñanza virtual?

En el cuarto capítulo, "Elementos básicos para el diseño de un modelo para la enseñanza virtual sobre la organización de recursos informativos digitales", se habla de la estructura del modelo académico que se propone para sustentar la especialización sobre la organización de recursos informativos digitales. Se parte de la noción de modelo teórico, de modelo educativo y modelo académico. Se aluden las características fundamentales de la educación a distancia, con la finalidad de identificar los ejes que sustentan el modelo teórico que se presenta en este capítulo, como la institucionalización de la propuesta, estructura del programa académico; se argumenta y reflexiona sobre los fenómenos seleccionados para su estudio en la especialización; se determinan los actores del aprendizaje; se destacan los requerimientos del material didáctico; se acude a la normatividad para la acreditación, etcétera.

Este capítulo contiene una acentuada influencia en México, debido a que 1 . se propone a un organismo mexicano como institución sede para que, en su momento, se analice la posible implementación de la especialización que se propone, y 2 . la estructura de la plataforma tecnológica se desarrolló y probó en una dependencia perteneciente a la 
UNAM. Sin embargo, el modelo académico, el aula virtual y muchos de los aspectos tratados tienen validez en el marco internacional.

En el quinto capítulo denominado "Plataforma tecnológica de apoyo a la enseñanza virtual sobre la organización de recursos informativos digitales"; se reflexiona en torno al uso de la Internet en la educación virtual, se discuten las propuestas teóricas sobre la interactividad y la navegación en la educación virtual, las perspectivas sociales e institucionales que se esperan de la educación de esta naturaleza en el siglo XXI. Estos aspectos sirven de base para sustentar la estructura de una plataforma tecnológica de apoyo a la especialización sobre la organización de recursos informativos digitales. El diseño teórico se planeó con base en un aula virtual y una biblioteca digital; se asume que la primera constituye el espacio simbólico a partir del cual se incide con técnicas y metodologías que requiere la enseñanza virtual, para lograr una interacción y navegación de calidad entre los actores del aprendizaje, la entrega de materiales didácticos y el uso de la biblioteca digital.

En las "Reflexiones finales" se destacan las experiencias obtenidas a través de la investigación y el requerimiento del estudio permanente respecto de fenómenos relevantes en torno a la organización de recursos informativos digitales, por su trascendencia en la disciplina y en el ejercicio profesional de los bibliotecólogos. El diseño y desarrollo del aula virtual permitió generar un espacio de investigación, estudio y actualización de técnicas y metodologías requeridas por la enseñanza virtual y su aplicación, a partir de redes telemáticas, como la vía básica para la comunicación y la interacción entre los actores del aprendizaje. Tanto el modelo académico, como la plataforma tecnológica sirven de base para estructurar propuestas educativas virtuales en varios niveles educativos en el campo de la bibliotecología y en otras disciplinas.

Por lo expuesto hasta aquí, este libro se dirige principalmente a profesionales y estudiantes en bibliotecología, pues, a partir de la bibliotecología, se propone un modelo teórico para la enseñanza virtual sobre la organización de recursos informativos digitales. Para ello se toman como base diversas dimensiones emanadas de la educación a distancia y se reflexiona sobre los efectos de la tecnología 
en la educación virtual. En este contexto, la bibliotecología funge como disciplina de referencia y la educación a distancia, como la de apoyo. No obstante, consideramos que esta obra también será útil a profesionales de otras áreas de conocimiento, interesados en el diseño de propuestas educativas virtuales y a posibles tutores y autores de contenido para escenarios virtuales de aprendizaje. 
I

La educación virtual frente a los efectos de las tecnologías de información y comunicación 



\section{EDUCACIÓN A DISTANCIA Y EDUCACIÓN VIRTUAL: UNA APROXIMACIÓN CONCEPTUAL}

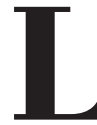

a educación a distancia resulta un campo apropiado para comprender los desafíos actuales de las entidades educativas frente a la sociedad de la información y el conocimiento, así como ante las tecnologías y nuevos escenarios que reclama la sociedad actual. El constante debate en torno a la teoría que ha prevalecido en la educación a distancia a lo largo del tiempo y la aparición del ciberespacio y lo virtual han inducido al estudio permanente de estos fenómenos, con el fin de analizar la conveniencia de la teoría que subyace en la educación a distancia y la teoría que se gesta para aplicarla en entornos virtuales de aprendizaje.

Así, en cualquier disciplina se observa que los modelos educativos a distancia que utilizan o no tecnologías de información y comunicación procuran sustentar teóricamente las propuestas educativas que generan. Un aspecto relevante se refiere a la creación de escenarios virtuales colaborativos de enseñanza-aprendizaje, basados en dinámicas de construcción grupal de conocimiento. Por ello es menester considerar que las comunidades en que se adopta el aprendizaje de esta naturaleza tienen el compromiso de participar activa y planificadamente atendiendo aspectos teóricos, intenciones educativas específicas y marcos pedagógicos compartidos. 
Por lo anterior, conviene contemplar que la educación a distancia es una expresión imprecisa a la que se pueden atribuir (y de hecho se atribuyen) muy diversos sentidos. ${ }^{1}$ El estudio de la teoría de la educación a distancia (EAD), los elementos que se precisan para llegar al aprendizaje de esta naturaleza y la utilidad de las TIC representan fenómenos de análisis necesario para comprender con certeza las posibilidades que puede tener la $\mathrm{EAD}$ en la educación del nuevo siglo. Se parte del hecho de que el estudio de los conceptos y elementos teóricos fundamentales de la EAD permiten comprender la importancia de esta modalidad educativa, valorar su utilidad y formular interrogantes para motivar la investigación en temas que traten de explicar los diversos fenómenos generados, principalmente por la irrupción de las TIC en la educación virtual.

En cuanto a los procesos de aprendizaje a distancia, García Aretio señala que para llegar a dicho tipo de aprendizaje, "[...]se precisan instituciones, equipos y personas que diseñen, desarrollen y controlen determinados procesos que ayuden a los estudiantes a alcanzar sus expectativas". ${ }^{2}$ El creciente interés generado por el estudio y aplicación de la EAD ha suscitado que, en los últimos años, sea desbordante la literatura generada, sea formato impreso o digital. En ésta se evidencia el intento de encontrar los conceptos apropiados que agrupen la esencia de esta modalidad educativa.

Así, diversos autores coinciden en que el término educación a distancia involucra desde el campo de estudio de la educación por correspondencia (basada en texto impreso), hasta la educación virtual (o educación en línea), que se apoya en medios generados a través de TIC. En ambos casos, la noción de la separación del profesor y del alumno es una constante. Sin embargo, diversos teóricos e instituciones prefieren el término aprendizaje a distancia, debido a que su énfasis radica en el alumno, más que en el proceso educativo.

1 Lorenzo García Aretio. La educación a distancia: de la teoría a la práctica, España: Ariel Educación, 2001, p. 11.

2 Ibíd., p. 11. 
Se puede señalar que la diferencia entre educación a distancia y aprendizaje a distancia es un asunto de énfasis, debido a que no existe hasta nuestros días, acuerdos en los medios académico sobre cual término es el más apropiado. ${ }^{3}$

Con la aplicación de tecnologías en la EAD la situación conceptual se ha complicado aún más, de ahí que en los últimos años se ha intentado generar conceptos que expliquen de manera apropiada el uso de las tecnologías recientes en esta modalidad. Hoy existe una amplia gama de conceptos orientados a explicar y fundamentar las características relacionadas con la separación de los sujetos del acto educativo, la entrega de materiales didácticos, los procesos de la comunicación, aspectos relacionados con la educación a distancia, con la educación virtual (e-learning) y con diversas formas de aprendizaje. La dificultad de encontrar definiciones universalmente aceptadas hasta ahora sigue siendo un asunto irresuelto, sin embargo, varios especialistas de prestigio, han asumido el reto de proponer definiciones al respecto que, a su juicio, explican la esencia de dichas formas de enseñar y de aprender.

Lo más novedoso y significativo de algunas definiciones consiste en destacar las bondades de las TIC en la interacción y "navegación" de los sujetos del aprendizaje en entornos virtuales, así como en la entrega de materiales didácticos en línea, siendo la Internet la protagonista en estas actividades. Entre los términos más frecuentemente utilizados destacan los siguientes: la educación a distancia se refiere a una "[...]metodología de enseñanza en la que las tareas docentes acontecen en un contexto distinto de las discentes, de modo que éstas resultan respecto de las primeras, diferenciadas en el tiempo, en el espacio o en ambas dimensiones a la vez". ${ }^{4}$ A mayor abundamiento, Peña Borrero afirma que "[...]la educación a distancia es una metodología de enseñanza que se caracteriza por la interposición de formas mediadoras entre docentes y estudiantes, para trascender las

3 Ibid., p. 11.

4 J. Sarramona, citado por Lorenzo García A. La educación a distancia: de la teoría a la práctica, Barcelona: Ariel, 2001. p. 27. 
limitaciones de tiempo y espacio propios de la enseñanza directa o presencial y abrir así el ámbito de influencia de la educación". 5

Por otro lado, el aprendizaje distribuido tiene características en común con el aprendizaje abierto y flexible, al mismo tiempo implica el uso de TIC para el desarrollo y entrega de los cursos. El aprendizaje sincrónico se refiere a la interacción en tiempo real entre los actores del aprendizaje; En cambio, el aprendizaje asincrónico implica comunicación en tiempo diferido, lo que igualmente determina obtener respuestas en tiempos distintos. En ambos casos, las interacciones con el aprendizaje por lo general se realizan a través de la comunicación asistida por computadora.

Los términos teleaprendizaje, teleformación y e-learning tienden a utilizarlos con mucha frecuencia diversos autores e instituciones en el marco internacional. Así, Collins señala que teleaprendizaje se refiere a la "[...] conexión entre personas y recursos, a través de las tecnologías de la comunicación con un propósito de aprendizaje". ${ }^{6}$ En cuanto a la teleenseñanza, Tiffin afirma que es "[...]la posibilidad de simular la presencia física, sin que ésta exista realmente, así como facilitar la interacción entre estudiantes y profesores". ${ }^{7}$ Respecto de la teleformación, FUNDESCO señala que "[...] es un sistema [para impartir] formación a distancia, apoyada en TIC, que combinan distintos elementos pedagógicos $[\ldots] .{ }^{8}$ Se puede observar que en éstos es común el prefijo tele-, que incluye un sentido de distancia a la palabra que le precede, no obstante, en la actualidad, casi siempre implica el uso de redes telemáticas. ${ }^{?}$

5 Luis Alberto Peña Borrero. Planeación de programas de universidad abierta y a distancia, Bogotá: IFCES, 1983. p. 9.

6 B. Collis. Tele-learning in a digital world: the future of distance learning, London : International Thompson Computers Press, 1996. p. 9.

7 John Tiffin y Lalita Rajasingham. En busca de la clase virtual: la educación en la sociedad de la información, Barcelona: Paidós, 1997, p. 235.

8 FUNDESCO. Teleformación: un paso más en el camino de la formación continua, Madrid : FUNDESCO, 1998, p. 56.

9 Mariano Sanz Prieto. Teleeducación entornos de aula virtual. en Temas [2002], p.12. 
La educación virtual frente a los efectos de las tecnologías de información ...

Por su parte, Urdan y Weggan definen e-learning como "[...]el desarrollo de contenidos a través de cualquier medio electrónico, incluyendo Internet, Intranet, Extranet, satélites, cintas de audio y video, televisión interactiva y CD-ROM". ${ }^{10}$

Recientemente aparecieron los términos universidad virtual y educación virtual, los cuales se introdujeron para representar la versión más moderna de la educación a distancia. Con esto se pretende explicar, desde el punto de vista físico, que la universidad y las aulas pueden reemplazarse con entornos virtuales mediante TIC, lo cual, de nuevo, remite al uso de Internet como medio principal de comunicación. Este aspecto se corrobora en esta definición: la educación virtual, es un método de enseñanza no presencial, basado en las nuevas tecnologías de la información "[...]utilizando como herramienta fundamental el soporte informático, sin prescindir ni atenuar la relación profesor-alumno, pues la comunicación se mantiene y fomenta mediante la red". ${ }^{11}$

Un aspecto relevante de carácter terminológico y su definición se encuentra en las denominaciones que distintos países han dado a estas instancias. Sobre esto, John Daniel ha observado que "Francia, Irán y España se centran en la expresión educación a distancia o enseñaza a distancia [...], India, Indonesia, Corea Tailandia y Reino Unido se refieren a sus instituciones como universidades abiertas". ${ }^{12}$ Más allá del mero término, este autor señala que "[...]el concepto de universidad virtual, actualmente tan de moda, que se limita a poner en conexión, mediante nuevos sistemas, universidades ya existentes, será un fracaso si no es capaz de suscitar el compromiso individual de los alumnos y el personal de plantilla en que se fundamenta una

10 T. Urdan y C. Weggan citados por Carlos Marcelo [et al.] Formando teleformadores: diseño y desarrollo de un curso online utilizando WebCT. [en línea]

http://s.es/idea/mie/pub/marcelo/Formando\%20Teleformadores.pdf [consultada: 15/04/03]

11 Enciclopedia de pedagogía. España: Espasa, 2002, p.1039.

12 John Daniel. "¿Va a ser la macrouniversidad el modelo de formación académica superior en el nuevo milenio?”. en La educación a distancia en tiempos de cambios: nuevas generaciones, viejos conflictos / coords., Eustaquio Martín Rodríguez y Manuel Ahijado Quintillán. Madrid: Ediciones de la Torre, 1999, p. 29-30. 
comunidad académica". ${ }^{13}$ En este contexto, conviene señalar que la educación virtual debe evitar caer en la tentación de utilizar las tecnologías de vanguardia, sólo por su disponibilidad, más que por su real efectividad en los aprendizajes a distancia.

En los últimos años, un rubro que ha suscitado mucha discusión en los medios académicos especializados se refiere a la aplicación de las TIC en la educación virtual. Esto ha mostrado el requerimiento de revisión y, en su caso, adecuación o generación de fundamentos teóricos que sustenten con mayor precisión el marco conceptual de la educación virtual. La reflexión se ha orientado, entre otros aspectos, en torno a la implantación en la sociedad de tecnologías debido a que: "[...] sus efectos y alcances, no sólo se sitúan en el terreno de la información y comunicación, sino que lo sobrepasan para llegar a provocar y proponer cambios en la estructura social, económica, jurídica, política, [educativa; lo anterior se debe] a que no sólo se centran en la captación de la información, sino también, y es lo verdaderamente significativo, a las posibilidades que tienen para manipularla, almacenarla y distribuirla". ${ }^{14}$ Tales acciones inciden directamente en la educación en sus diversos niveles y modalidades, por ello, antes de continuar analizando los efectos que han ocasionado dichas tecnologías en la educación, sería importante tomar en cuenta algunos aspectos.

El significado del verbo educar se refiere al desarrollo de las facultades intelectuales y morales de los individuos, de determinado proceso educativo; su sentido lógico indica la búsqueda de formas y medios que den respuesta a dos preguntas fundamentales: ¿para qué educar? y ¿cómo bacerlo? Al proporcionar las posibles respuestas a estas interrogantes es factible contemplar algunos aspectos señalados por Cruz Rincón:

La educación es un proceso, individual y colectivo al servicio de la continuidad, la actualización y la renovación de una determinada cultura. El proceso educativo, en cuanto dinámica cultural, debe

\section{Ibíd., p.33.}

14 Julio Cabrero Almenara. "Nuevas tecnologías, comunicación y educación", en EDUTEC. Revista electrónica de tecnología educativa, núm.1, feb. 1996. [en línea] http://uib.es/depart/gte/revelec1.html/ [consultada: 20/10/03] 
propiciar la elaboración y el dominio en los grupos de nuevos modelos de indagación de la realidad, de modelos valorativos y normativos para la acción y de formas de comunicación y expresión que afiancen la vinculación y cohesión del grupo o la comunidad. ${ }^{15}$

Por lo anterior, los fines que se planteen en torno a la educación requieren de fundamentos teóricos en los que se distinga la coherencia y la razón de ser de las acciones concretas que se quieran desarrollar, con fundamento en determinada propuesta educativa. Así, la investigación, el estudio, la generación e implementación de modelos educativos son tareas permanentes de educadores, pedagogos y estudiosos de la educación en todos sus niveles, quienes han generado teorías y modelos que, por su naturaleza, constituyen marcos a considerar en cualquier proyecto educativo.

En este sentido, el modelo de la educación formal o presencial contempla impartir conocimiento en los entornos físicos de una institución escolar, tiempos y edades predeterminados para el aprendizaje, métodos de enseñanza y contenidos de planes y programas de estudio, cuya actualización se realiza, por lo general, sin considerar tiempos preestablecidos. Sin embargo, Peña Borrero afirma que, “[...]aunque en un principio los estudiosos de la educación no formal insistieron demasiado en identificarla con aquella que se hace al margen de cualquier institución escolar, la experiencia ha demostrado que se puede hablar de proyectos de educación no formales adelantados por estas instituciones y que las modalidades así llamadas no formales tienden a institucionalizarse". ${ }^{16}$ Él argumenta que la "[...] universidad abierta designa una serie de cambios en el orden cualitativo, que no se restringen, como en el de universidad a distancia, a la cobertura espacial, un aspecto apenas de la apertura. Universidad abierta señala una finalidad, universidad a distancia se refiere más a un

15 Jaime Cruz Rincón, citado por Miguel Ángel Casas Armegol. Universidad sin clases: educación a distancia en América Latina, Caracas: Kapeluz, OEA-UNA, 1987, p. 33 .

16 Luis Alberto Peña Borrero. Planeación de programas de universidad abierta y a distancia: factores críticos para la toma de decisiones, Colombia: ICFES, Ministerio de Educación Nacional, 1983,. p. 9. 
medio". ${ }^{17}$ De lo anterior se infiere que puede existir determinada universidad abierta, sin que necesariamente sea a distancia; asimismo también puede existir una universidad a distancia que se limite a ser abierta sólo en el sentido en que amplía su espacio de acción mediante el uso de medios didácticos. En este contexto, se entiende como “[...]los apoyos de carácter técnico que facilitan de forma directa la comunicación y la transmisión del saber, [que debe estar] encaminado a la consecución de los objetivos de aprendizaje". ${ }^{18}$

Así, la universidad a distancia se ha orientado al entorno de las estrategias, lo cual exige, entre otros aspectos, fundamentos teóricos que expliquen, determinen y posibiliten su desarrollo y aplicación. Al respecto, Casas Armegol, al referirse a la educación superior a distancia, señala que:

[...]debe considerarse como una innovación tecnológica que se apoya en fundamentos teóricos, comunes y necesarios para comprender cualquier proceso educativo. Sin embargo, existe un conjunto de determinantes que proporcionan a esta modalidad educativa cierta singularidad que tipifica y justifica el empleo de determinadas estrategias y metodologías. ${ }^{19}$

Al respecto, la teoría indica que la educación a distancia representa un intento fundamentado de tecnología educativa en términos teóricos, estructuras organizativas, metodologías de enseñanza, metodologías para el diseño de materiales de instrucción, medios de comunicación, financiamiento, institucionalización, consecuencias sociales, etcétera. Así, diversos aspectos ya señalados se corroboran en el modelo de la Open University de Gran Bretaña, liberado en 1969, considerada una de las experiencias en educación superior más exitosas y relevantes en el marco internacional, con reconocimiento por parte de estudiosos de las áreas educativas como la experiencia pionera en la modalidad de la educación a distancia.

Otro matiz relevante de este modelo lo constituyen los materiales didácticos, que han requerido de una alta inversión tecnológica, de

17 Ibid., p. 9.

18 Lorenzo García Aretio,. Op. cit., p. 170.

19 Miguel Casas Armegol. Op. cit., p. 33. 
conocimiento especializado y la presentación de los medios en que se han desarrollado: textos impresos, pruebas de evaluación académica, guías para programas de radio y televisión, bibliografías complementarias, discos, audiocientas, diapositivas, guías, notas y tutoriales automatizados. Sin embargo, los especialistas en educación también reconocen la importancia de instituciones educativas ${ }^{20}$ como las siguientes: Centre National d'Enseigment a Distance (CNED) de Francia; University of South Africa (UNISA); Universidad Nacional de Educación a Distancia (UNED) de España; China TV University System (CTVU); Universidad Oberta de Cataluña, Universidad Pompeau Fabra (ambas en Barcelona, España); Universidad Nacional a Distancia de Costa Rica; Universidad Nacional Abierta de Venezuela; Universidad de Athabasca, Canadá; Universidad para todos los Hombres, en Israel, entre otras.

En cuanto a México, destacan el Sistema de Universidad Abierta (SUA) de la Universidad Nacional Autónoma de México, la Coordinación de Universidad Abierta y Educación a Distancia (CUAED) de la Universidad Nacional Autónoma de México; el Sistema de Educación a Distancia (SEAD) de la Universidad Pedagógica Nacional; el Sistema Abierto de Enseñanza (SEA) del Instituto Politécnico Nacional); la Universidad Virtual del Instituto Tecnológico de Estudios Superiores de Monterrey, etcétera.

En 1996, la fuente College degrees by mail, ${ }^{21}$ especializada en cursos ofrecidos a distancia por correo electrónico como soporte principal de comunicación, registró cien escuelas acreditadas en Estados Unidos que ofrecen programas a distancia en los niveles de bachillerato, maestría y doctorado en diversas áreas del conocimiento. Respecto del área de bibliotecología y ciencias de la información, sólo Syracuse University registra un programa de posgrado en Library

20 Para una mayor información sobre algunas de las instituciones mencionadas, véase John Daniel. ¿"Va a ser la macro-universidad el modelo de formación académica superior en el nuevo milenio?" en La educación a ... Op. cit., pp. 27-42.

21 John Bear y Mariah Bear. College degrees by mail: and modem 100 acredited schools that other bachelor's, master, doctorates and law degrees by bome study, Berkeley, California: Ten Speed, 1999, p. 89. 
Sciences. Esto refleja la falta de ofertas de esta naturaleza en los campos de la bibliotecología y la documentación.

Por otra parte, un denominador común de los programas de educación a distancia es el uso de medios didácticos, cuya constante fundamental se debe a que representan uno de los instrumentos básicos de comunicación con los estudiantes. Esto convierte a los medios en herramientas de mucho valor, ya que de éstos depende un alto porcentaje del éxito en el proceso de aprendizaje. Con el advenimiento de las TIC, la educación virtual ha enriquecido sus posibilidades comunicativas entre el tutor y el estudiante; en consecuencia, se observa que las tecnologías de información y comunicación facilitan y enriquecen el proceso educativo.

Tal afirmación se sustenta en los siguientes aspectos: lo virtual es aquello que está implícito, lo que es de facto. Como concepto se define así: "Virtual, frecuentemente en oposición a efectivo o real; que tiene existencia aparente y no real". ${ }^{22}$ En este mismo sentido, se ha escrito que lo virtual se relaciona con lo "[...] efectivo, aparente, irreal. Que existe en esencia o en sus efectos, aunque no en forma real y verdadera". ${ }^{23}$ A mayor abundamiento, Maestre Yenes señala que lo virtual es:

[...]la forma de funcionar basada en las tecnologías de la información y de las comunicaciones en la que se simula el mundo real dando una serie de prestaciones y funcionalidades que permiten en gran medida obtener los mismos servicios y prestaciones que se obtendrían en aquel $[\ldots]$ utilizando las posibilidades que proporciona Internet. ${ }^{24}$

Así, aquí entendemos que la educación virtual trata de incidir en el uso creciente de las TIC, avivar el interés de los tutores al ofrecerles un nuevo modelo de gestión educativa, centrado en la comunicación y en el aprendizaje. Esto implica fomentar el estudio independiente y

22 Diccionario de la Lengua española / Real Academia Española. 22a ed., Madrid: Real Academia de la Lengua Española, 2001, p. 2095.

23 Javier L. Collazo. Diccionario enciclopédico de términos técnicos: inglés-español español-inglés, México : McGraw-Hill, 1988, p. 1709.

24 Pedro Maestre Yenes. Diccionario de gestión del conocimiento e informática, Madrid: Fundación DINTEL, 2000, p. 240. 
el aprendizaje en colaboración, la interacción académica efectiva entre tutor-alumno y alumno-tutor, utilizando diversos canales de comunicación, siendo la Internet el predominante, pues facilita tal comunicación y la generación de entornos virtuales de aprendizaje. No obstante, recordemos que en esta obra se utilizan principalmente los términos educación a distancia y educación virtual por ser de uso generalizado.

\section{COMPONENTES FUNDAMENTALES DE LA EDUCACIÓN A DISTANCIA}

Comúnmente, el carácter innovador de la educación a distancia se genera, según Holemberg, a través de los siguientes aspectos: "Las ideas básicas de que el aprendizaje puede ocurrir sin la presencia del profesor y el soporte dado a los estudiantes pueden ser adaptados a sus estándares de conocimientos y el uso consistente de medios nocontiguos, tanto para la presentación de la materia de aprendizaje como para la comunicación resultante". ${ }^{25}$ Así, el uso de estos métodos es determinante en la estructura y estilo de la comunicación (conversación didáctica), uso apropiado de recursos disponibles, adaptación de la propuesta educativa a las condiciones de vida de los estudiantes, aspectos que determinan la identificación de situaciones específicas de enseñanza-aprendizaje, todo encaminado a obtener la mayor efectividad posible para los actores del aprendizaje.

En este tipo de modelo, la sustitución presencial del maestro es un factor determinante, debido a que, al no poder darse la comunicación presencial inmediata, la interacción entre tutores, asesores y alumnos debe establecerse a través de medios de comunicación para incidir en el aprendizaje. Este aspecto determina una alta planificación de la comunicación, en la que las actividades determinan la forma de aprender a distancia de los estudiantes.

25 B. Holemberg, citado por Miguel Ángel Casas Armegol. Op. cit. p. 42. 
En suma, los componentes esenciales de la educación a distancia son la población masiva de estudiantes, predominantemente adulta; la separación física entre docente y estudiantes, parcial o total durante el proceso de aprendizaje; necesidad, esporádicamente, de contactos cara a cara; brindar atención preponderante al desarrollo de materiales didácticos; uso de medios particulares de comunicación entre estudiantes y "tutores", ${ }^{26}$ la responsabilidad del aprendizaje se centra en el alumno, proclividad al uso creciente de TIC; utilización de redes académicas de aprendizaje, así como de una institución sede que reúna requisitos de infraestructura académica, administrativa y normativa; requiere evaluación permanente de procesos de diseño, producción, distribución, uso de contenidos, componentes pedagógicos, vías de comunicación, calidad de la interactividad y evaluación de los resultados del aprendizaje de los alumnos. Todas estas características son determinantes en la educación de esta naturaleza, por lo tanto, en el modelo teórico que se propone en este trabajo, la enseñaza virtual sobre la organización de recursos informativos digitales, se consideran antecedentes para trazar su estructura y rescatar lo esencial de la educación a distancia y su relación con el uso de las TIC. Cabe resaltar que, en relación con espacio y tiempo, el uso de éstas da por resultado que el proceso de enseñanza-aprendizaje, sea flexible con el fin de ampliar el ámbito de comunicación entre tutores y estudiantes. Por lo tanto, el tiempo de enseñanza y aprendizaje se da en cualquier lugar y en el momento que sea propicio para el estudiante, esto ha impulsado un cambio radical, como han observado Rumble y Harry al comentar que:

Con la eliminación de los salones de clases, seminarios, bibliotecas, y ubicando al estudiante en la casa, las Universidades de Enseñanza Superior a Distancia (UDT), han presentado el cambio más radical al concepto tradicional. ${ }^{27}$

26 La figura del tutor en la educación a distancia respecto del proceso de enseñanza-aprendizaje es determinante, puesto que su función es motivar y facilitar los aprendizajes.

27 Rumble y Harry, citado por Miguel Ángel Casas Armegol. Op.cit. p. 43. 
Así, uno de los atractivos de la educación virtual para los planificadores y diseñadores de propuestas educativas de esta índole es el hecho de que más personas, ubicadas en diferentes entornos geográficos, tienen acceso a la educación en el momento en que su situación personal se lo permita.

En cuanto a la desaparición de la biblioteca, observación hecha por Rumble y Harry, no obstante que se entiende que no formaliza una característica de la educación a distancia, la incorporación de la biblioteca como apoyo informativo a propuestas de educación virtual presupone analizar y planear cuidadosamente las particularidades de los servicios de información dirigidos a este tipo de educación. Esto con el propósito de que la biblioteca realmente se convierta en un medio innovador de servicios de información, acorde a la educación virtual contemplando las necesidades de información de la propuesta educativa que sea. Con tales posibilidades adjudicadas a la biblioteca digital, estos aspectos han cobrado mucho interés entre los medios bibliotecarios y documentalistas; sin embargo hasta ahora, es muy escaso el estudio de esta entidad dirigida a cursos virtuales.

Por otra parte, cabe señalar que la cobertura geográfica como objetivo para acceder a lugares remotos no es un fin en sí mismo en la educación virtual, más bien se trata de una propuesta educativa dirigida a potenciales estudiantes, considerando, entre otras variables, su situación laboral y familiar. Esto tendría o representaría un contenido social relevante porque, al trascender distancias, se brinda la oportunidad a determinadas comunidades de educarse, lo cual estaría en relación directa con su motivación para buscar el progreso gracias a una mayor y mejor preparación académica.

Sobre las estructuras curriculares Holemberg y Casas opinan que existe una "[...] tendencia a estructuras curriculares [dúctiles (módulos-unidades)] que permiten una mayor flexibilidad para ajustarse a 
las características de la población estudiantil". ${ }^{28}$ Estos autores observan que son "[...]cursos que intentan ser autoinstruccionales, mediante un diseño sistemático, destinados y adaptados a las distintas peculiaridades de la población a la que van dirigidos, con énfasis en el que aprende, más que en el que enseña". ${ }^{29}$ Su intención es lograr la autosuficiencia y se fundamentan en textos de autoinstrucción para que el estudiante sea su propia guía en el proceso de aprendizaje. Estos cursos suelen producirse fundamentalmente en forma impresa y se complementan con otros medios, como la televisión (en circuito cerrado o abierto), audiovisuales y, muy recientemente, computadoras conectadas a la Internet.

En consecuencia, los aspectos ya señalados son parte de la teoría que sustenta el desarrollo de material de instrucción en cualquier propuesta educativa a distancia. No obstante, para el desarrollo del contenido y la planeación de estrategias de aprendizaje, conviene considerar las teorías orientadas al desarrollo de material didáctico. Se otorga bastante importancia a este aspecto porque tales materiales, en opinión de García Aretio, “[...]se configuran como una columna vertebral de cualquier sistema de educación a distancia”. ${ }^{30}$

Asimismo, la teoría insiste en que, para darles validez académica resulta conveniente que los programas de educación a distancia sean institucionalizados, es decir, un programa así requiere, entre otros aspectos, de una planeación apropiada y el vínculo de sus líneas de enseñanza con un determinado organismo preexistente o de nueva generación, dedicado al tema. De ahí que la influencia que ejerza determinada institución educativa en la planeación o diseño de los materiales didácticos determina el éxito o fracaso de la propuesta educativa que se persiga.

28 B. Holemberg, Kaye y Casas, citados por Lily Stojanovic. "Teorías en la educación universitaria a distancia de América Latina: exploración sobre la utilización de bases teóricas en la producción de materiales de instrucción", en Revista de Tecnología Educativa, 1988, vol. 10, no. 4, 1998, p. 273.

29 Ibid., p. 273.

30 García Aretio, Op. cit., p. 190. 
La educación virtual frente a los efectos de las tecnologías de información ...

\section{APROXIMACIÓN A LAS TEORÍAS Y ESTRATEGIAS DE APRENDIZAJE EN LOS SISTEMAS A DISTANCIA}

El éxito en los procesos de aprendizaje puede garantizarse aun más cuando se sustenta con teorías de enseñanza-aprendizaje. En este sentido, una teoría del aprendizaje es descriptiva en sus propósitos para explicar cómo ocurre el aprendizaje; en cambio, la teoría de la enseñanza es prescriptiva, en el sentido en que establece reglas, condiciones del medio y ordenación de los elementos que en la enseñanza permitan transmitir conocimientos y habilidades, a fin de conseguir, efectivamente resultados de aprendizaje. En consecuencia, la teoría de la instrucción debe servir de modelo para alcanzar objetivos de carácter instruccional de naturaleza diversa y complejidad. Así, el modelo instruccional contempla la "[...]teoría que analiza, explica y regula [norma] el proceso didáctico o instructivo”. ${ }^{31}$

Las investigaciones en psicología instruccional han reforzado el requerimiento teórico para optimizar los procesos de la instrucción. La intencionalidad de la psicología educativa es abarcar categorías en cuanto a objetivos educativos, características y desarrollo de los estudiantes, naturaleza del proceso de aprendizaje, métodos de enseñanza y su evaluación, entre otros. Al respecto, Merril señala que una teoría de la instrucción " [...] consiste en la identificación de las partes componentes de un sistema instruccional y en la descripción de los principios utilizados por dichos componentes para seleccionar, modificar y disponer de la información y conocimientos de los resultados, así como producir los tipos particulares de respuestas del que aprende". ${ }^{32}$

En cambio, la práctica de la educación a distancia de la escuela constructivista ha tenido mucha aceptación particularmente en los principios de la actividad del aprendizaje; asimismo, las teorías de la motivación y la personalidad han repercutido en dicha práctica. En este ámbito, Moor hace énfasis en que:

31 Diccionario de las ciencias de la educación, México: Santillana, 1995, p. 962.

32 M.D.Merril, citado por Lily Stojanovic. Op. cit, p. 279. 
[...] deben ser considerados los métodos, ya que la separación física de los estudiantes y profesores en la fase interactiva, así como la preactiva, se realiza mediante elementos impresos, mecánicos o electrónicos. 33

Por su parte, Stojanovic, estudiosa de las teorías relacionadas con el modelo de organización avanzado de Ausubel y el modelo de enseñanza de Gagné, señala que la teoría del primero "[...]asume que el proceso de la instrucción está fundamentalmente controlado por el docente, lo cual permite que la comunicación simultánea entre estudiante y docente no resulte imprescindible y, por otra parte, tome en cuenta las características del estudiante en la preparación del material didáctico". ${ }^{34}$ La especificidad de este modelo radica en que cada unidad de aprendizaje debe ir precedida de un organizador avanzado que permita relacionar el contenido por aprender, con el previamente aprendido. Los aspectos de relación que analizan mediante conceptos inclusores, y por comparación éstos deberán contribuir a que el material didáctico sea conceptualmente claro y que contenga una organización lógica del contenido por aprender. Igualmente habrá que agregar que cada unidad debe contener, repasos, resúmenes, ejercicios y otros indicadores que reflejen la consolidación del material.

En cuanto al modelo de enseñanza de Gagné, enfatiza los eventos de la instrucción e intenta, según Stojanovic: "[...]vincular [...] una serie de fases que se dan durante el proceso de enseñanza-aprendizaje, en el cual se van distinguiendo una serie de eventos externos que constituyen la instrucción, y provocan en el individuo procesos internos que originan el aprendizaje". ${ }^{35}$ Así, esta teoría propone un marco de referencia en el que el aprendizaje se halla en función de lo que la instrucción logre o no cuando se contempla el conjunto de procesos en secuencia para el establecimiento y retención de distintos tipos de aprendizaje.

33 Moor, citado por Lily Stojanovic. Op. cit., p. 274.

34 Lily Stojanovic. "Teorías en la educación universitaria a distancia de América Latina: exploración sobre la utilización de bases teóricas en la producción de materiales de instrucción”, en Revista de Tecnología Educativa, 1988, vol. 10, no. 4, pp. 283- 284.

35 Ibid., p. 284. 
En este sentido, la utilidad de la teoría de la educación a distancia se evidencia en cómo se deduce " [...] una forma de educación en la que la instrucción oral tiene un papel de subordinación y se concentra en periodos intensivos externos. Entre estos periodos, el estudiante trabaja individualmente en casa, pero tiene la posibilidad de consultar al maestro por teléfono, por carta [o por Internet]". ${ }^{36}$ En definitiva, la educación a distancia propone un modelo cuyos medios didácticos subordinan la comunicación entre los actores del aprendizaje y el plan de estudio; constituye una metodología que incide en propuestas educativas en cualquier nivel y facilita la entrega de contenidos a poblaciones ubicadas en diversos entornos geográficos, cuando se dificulta la relación presencial entre tutores-alumnos.

Así, la educación a distancia conlleva una estructura claramente tipificada, de la que derivan diversas posibilidades orientadas a incidir en el acto educativo. No obstante, se debe tener presente la existencia de limitaciones que afecten su realización. Entre las más frecuentes y reiterativas, destacan la retroalimentación (feed-back) que puede ser lenta y repercute en los aprendizajes, el material didáctico, las evaluaciones y en la autodisciplina que ha de observar el estudiante a distancia. Llegar a poblaciones masivas (industrialización del aprendizaje) provocaría la deserción o el fracaso de los estudiantes a distancia debido a la poca o nula atención personalizada que recibirían estos alumnos. Actualmente, las TIC limitan el acceso a grandes sectores de potenciales estudiantes debido a que la oferta educativa vía Internet exige disponer de la infraestructura necesaria para cursos de esta naturaleza.

Por todo lo anterior, antes de planificar cualquier programa para educación a distancia, debe considerarse que la teoría recomienda entender la estructura de esta metodología, para identificar las posibilidades u ofertas de esta clase de educación en sus distintos niveles. En consecuencia, tiene sentido recordar que la educación a distancia surgió en los países más avanzados, a partir de una creciente demanda educativa, lo cual ocasionó que pudiera ser cubierta con los sistemas

36 Ibid., p. 67. 
de enseñanza presencial. Asimismo, tal demanda educativa coincidió con una serie de innovaciones tecnológicas aplicadas en distintos procesos y servicios, que propiciaron su surgimiento. Estas innovaciones se refieren a la generación de modelos de organización, generación de nuevos medios para la comunicación masiva, desarrollo de técnicas de impresión, de teorías educativas y modelos para el manejo de la información, entre otras.

Estos fenómenos repercutieron determinantemente en la comunicación humana en todos sus aspectos, y la educación, como una forma particular de aquélla, recibió también el impacto de estos fenómenos. Así, en los últimos años, el desarrollo de las TIC se ha expandido hacia la planeación y organización de propuestas educativas a distancia, y ciertamente algunos aspectos de mayor impacto, como la interactividad, la navegación y el diseño de medios didácticos apoyados en dichas TIC.

De aquí ha derivado una tendencia a reconstruir o generar modelos educativos basados sobre todo en la convergencia tecnológica. En ese sentido, las TIC ofrecen múltiples posibilidades para establecer procesos de comunicación y para elaborar materiales didácticos. Pese a los avances tecnológicos, para que la educación a distancia continúe en su objetivo de ser propositiva, considera las características del modelo de la enseñanza tradicional con el fin de comprender las diferencias estructurales entre ambas formas de comunicación educativa. En la educación tradicional ${ }^{37}$ la comunicación tiene estas características: profesor y estudiantes se encuentran cara a cara en el mismo espacio y tiempo. La voz y la expresión corporal del profesor son los medios de comunicación por excelencia. Se llama presenciales a estos medios porque restringen la comunicación al aquí y ahora. Otros medios visuales o sonoros son poco utilizados en la clase convencional, y sólo sirven como ayuda didáctica para complementar la acción del profesor. El código en la enseñanza convencional es la comunicación oral, acompañada de gestos, movimientos e inflexiones de la comunicación no verbal.

37 La exposición de las particularidades generales de la educación tradicional y de la educación a distancia se fundamenta en Peña Borrero, Op. cit., p. 19. 
En esto último se observa que la relación presencial de los sujetos del aprendizaje propicia el diálogo personalizado o en grupo inmediatamente. En cambio, en la educación a distancia, tutores y estudiantes no están físicamente presentes en el mismo espacio o tiempo. Para que la comunicación se produzca, han de generarse elementos mediadores entre los dos polos del acto educativo. En consecuencia, la voz y el esquema corporal se sustituyen con otros medios no presenciales o tendrían que registrarse en soportes sonoros, visuales o multimedia para transmitirlos luego a otro espacio y tiempo diferentes. Los medios no son simples apoyos didácticos, sino portadores de contenido de ayuda tutoria. En la comunicación educativa a distancia, los contenidos del aprendizaje se convierten en el medio dominante por excelencia, el manejo adecuado del discurso académico será uno de los aspectos fundamentales que deben resolver quienes lo comunican.

Los códigos de la radio, la computadora o de la televisión, cuando registran voz o imágenes, tienen una estructura propia, distintos de la situación en la que la voz y la figura corporal del profesor se reciben directamente. La relación no presencial o indirecta de los que se comunican condiciona una forma de diálogo que, por no acontecer en el aquí y ahora, puede denominarse diálogo diferido. En otras palabras, el comunicador debe concluir un mensaje completo y esperar un tiempo para recibir la comunicación de retorno, de forma similar como ocurre en el diálogo epistolar.

Así, queda de manifiesto la importancia que otorga la educación a distancia al uso de medios de comunicación; en la interacción de los sujetos del aprendizaje, debido a que en la estructura didáctica de aquélla, el medio se constituye como un elemento condicionante, ya que a partir del mismo derivan las variables fundamentales que la tipifican como una forma de tecnología educativa.

Resulta necesario, pues, considerar varios aspectos teóricos relativos a los procesos de enseñanza-aprendizaje, pues éstos condicionan un alto porcentaje del éxito en la totalidad del modelo educativo a distancia. Por lo tanto, es indispensable que, en el diseño de propuestas educativas de esta naturaleza, adoptar posturas o tomar decisiones, definiciones y demás de las teorías pedagógicas. En este caso, el modelo teórico relacionado con la Enseñaza virtual sobre la 
Organización de Recursos Informativos Digitales, se propone la teoría constructivista, por la riqueza de sus enfoques y amplia aceptación. A continuación se abordan aspectos relevantes relacionados con dicha teoría.

\section{CONSTRUCTIVISMO, TUTORÍA Y EDUCACIÓN VIRTUAL}

La teoría y la experiencia en la educación en sus diversos niveles han hecho patente, a través del tiempo, la generación de distintas formas de pensamiento y nuevas maneras de ejecutar el acto educativo. En estas épocas, la educación a distancia ha observado la necesidad de estructurar planes curriculares flexibles, con el fin de ofrecer a los sujetos del aprendizaje alternativas educativas que respondan a sus requerimientos de formación. En este contexto es determinante contemplar referentes teóricos en el proceso de enseñanza-aprendizaje. No obstante, de las teorías que fundamentan la construcción del conocimiento, aquí se rescatan los postulados constructivistas para explicar aspectos fundamentales del proceso de enseñanza-aprendizaje, como el estudio de los adultos, las estrategias y las actividades de aprendizaje, la enseñanza individualizada, los materiales y medios didácticos, la evaluación y funciones de la tutoría en los sistemas a distancia.

Se dice que no obstante lo útil de las teorías del aprendizaje, se debe tener presente que su concepción se manifiesta en forma distinta en los escenarios donde se adopta la educación a distancia. En consecuencia, se advierte que la orientación de las teorías del aprendizaje han recibido la influencia de los ambientes sociales y el contexto económico del país donde se utiliza. Sin embargo, esta teoría determina la existencia de procesos eminentemente activos en la construcción del conocimiento, en los que el actor cognoscitivo rebasa, mediante su labor constructiva, lo que le ofrece su entorno, aspecto atractivo para los diseñadores de programas de educación a distancia.

Este modelo teórico sostiene que el alumno construye su peculiar modo de pensar y conocer de un modo activo, resultante de la interacción entre sus capacidades innatas y la exploración ambiental que 
La educación virtual frente a los efectos de las tecnologías de información ...

realiza por medio del tratamiento de la información que recibe del ambiente. ${ }^{38}$ Sobre esto, Díaz Barriga considera de suma importancia

[...] revalorar el papel del docente, no sólo en sus funciones [de que es] transmisor del conocimiento, guía o facilitador del aprendizaje, sino más bien como mediador del mismo, resaltando el papel de la ayuda pedagógica que presta reguladamente al alumno. 39

Por otra parte, otros especialistas concuerdan en que a la escuela constructivista concurren diversas corrientes asociadas a la psicología cognoscitiva, como el enfoque psicogenético de Piaget, la teoría de los esquemas cognoscitivos, la teoría de Ausubel relacionada con la asimilación y el aprendizaje significativo, la psicología de Vygotsky, entre otras. En este sentido, García Olvera señala que "[...] dichas teorías comparten el principio de la actividad constructivista del alumno en la realización de los aprendizajes escolares". ${ }^{40}$ En esta misma línea, Díaz Barriga señala: "[...] es mediante la realización de aprendizajes significativos que el alumno construye significados, los cuales enriquecen su conocimiento del mundo físico y social, potenciando así, su crecimiento personal". ${ }^{41}$

En este aspecto, el constructivismo considera que el modo como se adquiere el conocimiento puede ser por recepción, descubrimiento, incorporación a la estructura cognoscitiva del alumno a través de la repetición y por el valor significativo que tiene para este. Se advierte que dichas situaciones no son estáticas, más bien se interrelacionan para identificar matices de lo que ocurre en el proceso de enseñanza-aprendizaje; por lo tanto, es deseable considerar la estructura cognoscitiva del alumno en cuanto a sus conocimientos previos, vocabulario y marco de referencia personal, ya que estos aspectos revelarían sus niveles de conocimiento intelectual.

38 Diccionario de las ciencias de la educación, p. 315.

39 Frida DÍaz Barriga. "El aprendizaje significativo desde una perspectiva constructivista", en EDUCAR oct./dic. 1993, p. 24.

40 Guillermo García Olvera. "Propuesta para elaborar programas de actualización a distancia para egresados de escuelas mexicanas de bibliotecología”, México: El autor, 2000. p. 24 Tesis (Maestría en Bibliotecología) UNAM, FFyL, Posgrado en Bibliotecología.

41 Diaz Barriga, Op. cit., p. 24. 
Algunos teóricos insisten en la relevancia de los contenidos didácticos y el conocimiento. Sobre este asunto, la autora citada sugiere, con base en la teoría constructivista, los principios de la instrucción y del material didáctico orientado a sistemas a distancia: "El aprendizaje se facilita cuando los contenidos se presentan al alumno convenientemente organizados, con una secuencia lógica-psicológica apropiada". ${ }^{42}$ También afirma que "[...] es conveniente delimitar intencionalidades y contenidos de aprendizaje en una progresión continua que respete niveles de inclusividad, abstracción y generalidad". ${ }^{43}$

En cuanto a las estrategias de aprendizaje, -entendidas como comportamientos planificados que seleccionan y organizan mecanismos cognitivos y afectivos para enfrentar problemas específicos y globales de enseñanza-aprendizaje-, se ha señalado que "[...]son las responsables de facilitar la asimilación de la información que llega del exterior al sistema cognitivo del sujeto, lo que supone gestionar y monitorizar la entrada, etiquetación-categorización, codificación, almacenamiento, recuperación y salida de los datos". ${ }^{44}$ Las estrategias de aprendizaje cubren amplias gamas relativas a la memorización, procesos cognitivos complejos, planificación, control y evaluación del desarrollo de tareas de instrucción.

La importancia de las estrategias de aprendizaje, tanto para la práctica educativa como para la teoría psicológica, se vinculan desde el momento en que el sujeto relaciona conocimiento previo con nuevo conocimiento, para poder lograr un proceso constructivista. "Aunque la adopción del enfoque constructivista no siempre supone un abandono total de los supuestos asociacionistas tradicionales, parece claro que las teorías psicológicas del aprendizaje se orientan cada vez más al análisis de la interacción de los materiales de aprendizaje y

42 Ibid., p. 33.

43 Ibid., p. 33.

44 Carlos Monereo,. "Macroestrategias de enseñanza: aplicación en la preparación de servicios de información”, España: Universidad de Barcelona, 2000. [Documento mimeografiado]. 
los procesos psicológicos". ${ }^{45}$ Por lo anterior, el docente no debe buscar solamente proporcionar conocimientos y asegurarse de obtener resultados, sino que además debe fomentar estrategias de aprendizaje orientadas a lograr los productos planeados.

Históricamente, la relación entre teoría y praxis de la educación a distancia ha sido el indicador constante en su evolución. Así, en décadas recientes, con el uso masivo de TIC, los diseñadores de propuestas educativas virtuales atienden lo teórico y lo pragmático incorporando innovaciones tecnológicas de vanguardia que respondan eficazmente a la navegación, la interacción y la representación del conocimiento. Sobre esto, Barberá señala que "[...]la revisión constante de la multiplicidad de aplicaciones en educación a distancia y de sus concreciones en la práctica, permite intuir la dificultad de encontrar aproximaciones teóricas que expliquen globalmente este fenómeno $[\ldots]$ ". 46

La composición multifactorial y dinámica de la educación a distancia permite comprender el reto de incidir en un enfoque teórico capaz de explicar, generalmente, la heterogeneidad de su práctica o realizar prospectivas óptimas del proceso de enseñanza-aprendizaje para este ámbito. En cuanto a lo anterior, Barberá afirma que "[...]probablemente no podemos esperar que una sola teoría resuelva de manera definitiva el fundamento de la práctica y de la investigación, como si la relación entre teoría y práctica fuese unidireccional o simple". ${ }^{47}$

De ello se infiere que ninguna teoría alcanza la totalidad de niveles de análisis y de factores incidentes en la materialización final de cualquier proceso de formación a distancia. En consecuencia, los enfoques existentes serán necesariamente parciales y complementarios. Por lo tanto, cada teoría proporciona parámetros diferentes para la

45 Juan Ignacio Pozo. "Estrategias de Aprendizaje", en Desarrollo psicológico y educación II: psicología de la educación / comp. C. Coll. Madrid: Alianza, [s.f.]. [p.v.]

46 Elena Barberá, et. al. La incógnita de la educación a distancia, Barcelona: ICE Universitat Barcelona, Horsori, 2001, p. 36.

47 Ibid., p. 37. 
comprensión de aspectos específicos de cada situación en que se concrete el proceso de enseñanza-aprendizaje en la educación virtual. Hoy, los modelos educativos a distancia y virtuales en bibliotecología y otras disciplinas que utilizan TIC se apoyan, por lo general, en principios constructivistas. La intención es sustentar teóricamente la creación de contextos colaborativos de enseñanza y aprendizaje basados en dinámicas de construcción grupal de saberes culturales.

En este contexto, señala Barberá, cuando “[...]las situaciones educativas a distancia se producen en contextos constructivistas, el profesor deja de tener un rol periférico y pasa a tener un papel preminente en el proceso didáctico". ${ }^{48}$ Así, las TIC y los principios constructivistas facilitan el desarrollo y la acción en escenarios colaborativos de enseñanza y aprendizaje, centrados en dinámicas de construcción conjunta de saberes inherentes a determinada comunidad educativa.

En este sentido, cabe reconocer que las tecnologías de red han propiciado un cambio sustantivo en el panorama de la educación virtual, no obstante, su potencialidad en los aprendizajes será más visible en los próximos años. Respecto de este asunto, advierte Barberá que "[...]la incorporación de la tecnología a un determinado sistema de enseñanza a distancia comporta automáticamente la adopción de una concepción constructivista de enseñanza y aprendizaje". ${ }^{49}$ En relación con esto, Kaye concuerda y dice: "[...] los contextos y las comunidades donde se forman procesos de aprendizaje colaborativos no surgen espontáneamente en el seno de las redes electrónicas, al igual que las demás, las comunidades virtuales requieren una implicación activa y planificada en el marco de unas intenciones educativas concretas y de unos compromisos pedagógicos compartidos". ${ }^{50}$

Esto obliga a la reflexión sobre la navegación y la interacción que hoy ofrecen los entornos virtuales para la enseñanza y el aprendizaje; el uso de la Internet en la educación a distancia pone énfasis en estas dimensiones. Así, todo análisis al respecto debe contemplar

48 Ibid., p. 79.

49 Ibid. p. 69.

50 A. Kaye, citado por Elena Barberá. La incógnita de la educación a distancia, Op. cit., p. 36. 
un conjunto de principios, sobre los cuales Barberá argumenta que pueden ser

- Los modelos de educación a distancia se estructuran sobre la base de los principios de racionalización del trabajo, es decir, en función de estrategias de planificación, organización, sistemas de evaluación y control de calidad destinadas a conseguir el mayor grado de eficiencia posible.

- La división del trabajo también se considera cosustancial a la educación a distancia.

- La mecanización. Cualquier sistema de educación a distancia precisa un medio tecnológico que posibilite la comunicación en el proceso de enseñanza aprendizaje.

- La producción masiva. La capacidad de proporcionar formación a grupos numerosos de estudiantes. ${ }^{51}$

Con el uso de las TIC en la educación virtual, estos principios permanecen vigentes. Asimismo, la teoría constructivista apoya la planeación y práctica de tales principios. La tutoría en la educación virtual es un campo en que el constructivismo y otras teorías inciden, por ejemplo, en corroborar la concordancia entre la presentación de los objetivos de aprendizaje, los avances del aprendizaje del alumno, la forma como está aprendiendo y el tiempo que utiliza para ello. Asimismo, dicha teoría es un buen apoyo para corroborar si determinado programa y el respectivo material didáctico están correctamente diseñados. En este sentido, cabe señalar que un material didáctico mal elaborado propicia confusión y retraso en el estudiante; en consecuencia, el tutor debe subsanar esa deficiencia con recomendaciones dirigidas al alumno. Una estrecha comunicación tutor-estudiante permite aclarar dudas, minimizar defectos del material didáctico y maximizar las metas personales que se ha propuesto el alumno. La motivación, combinada con refuerzo de conocimiento y énfasis en técnicas de estudio, posibilita un mejor tránsito de los estudiantes que cuenten con materiales de aprendizaje defectuosos.

51 Elena Barberá, Op. cit. pp. 40-41. 
La actividad del tutor cubre una amplia gama de funciones: desde la aclaración de dudas derivadas de imprecisiones u omisiones de los materiales didácticos o, en su caso, deficiencias en la formación del estudiante. En este sentido, el tutor se supedita a la idea de aconsejar, sugerir, insinuar, influir en el ánimo del alumno, por tanto, el tutor es parte esencial del diseño de un modelo de educación virtual, en razón de que su función no radica tanto en el sentido de mostrar o demostrar los contenidos temáticos (acción que recae en los materiales didácticos), sino en su capacidad para sugerir al estudiante alternativas en el desarrollo de su proceso de enseñanza-aprendizaje.

En este sentido, la teoría constructivista indica los métodos y técnicas que sean el punto de partida para controlar las circunstancias en las que puede encontrarse el alumno en un momento dado y aprovecharlas para su perfeccionamiento profesional. Así, el tutor tiene la oportunidad de ser el enlace entre los alumnos, el curso y los materiales y medios didácticos, por lo tanto, se halla en una situación privilegiada para identificar las principales áreas de dificultad, fundamentalmente de los sistemas de comunicación y de los materiales didácticos. Se prevé la relación tutor-alumno en los siguientes aspectos: motivar y reforzar las actitudes del alumno hacia el autoaprendizaje, valiéndose de los ejercicios que el alumno debe resolver; dar seguimiento a las tareas de autoaprendizaje, mediante orientación y control de los resultados que obtiene, sugiriendo actividades tendientes a desarrollar aquellas habilidades didácticas, así como orientar individualmente a lo largo del proceso de aprendizaje.

En cuanto al uso de las TIC, lo atractivo para los sujetos del aprendizaje respecto del uso del correo electrónico y las listas de discusión, consiste en que permiten crear ambientes de pertenencia a una comunidad o un ambiente digital de comunicación en múltiples direcciones: alumno-institución, alumno-alumno, alumno-tutor; además de que pueden presentarse varios tipos de participación: enviando-recibiendo mensajes o bien simplemente leyendo los mensajes. Si consideramos los señalamientos anteriores, conviene que las actividades de la tutoría virtual se planeen a partir de los siguientes elementos: 
1. Claridad en la presentación de los mensajes didácticos o de la información necesaria para el desarrollo del curso.

2. Procesos de retroalimentación con objeto de contar con mecanismos de control útiles para la evaluación de la eficacia del proceso de enseñanza-aprendizaje.

3. Medios de interacción, como seminarios virtuales programados, videoconferencias, encuentros de estudiantes, entre otros.

4. Uso de medios de comunicación interactiva, como el chat.

5. Utilización de medios auditivos y visuales no sólo para transmitir mensajes didácticos, sino también para proporcionar elementos que induzcan a la comunicación entre los sujetos participantes en el proceso de aprendizaje.

6. Servicios de información bibliográfica, noticiosos y de seguimiento del calendario del curso.

Con base en lo anterior, resulta factible referirse a la frialdad que se adjudica a las propuestas educativas a distancia, aspecto que se acentúa con la incorporación de las TIC. Esto puede subsanarse con un modelo correctamente diseñado, en el que se contemple la incorporación de tutores interesados en el alumno como un todo. Un rubro teórico importante de la tecnología educativa es el de la formación integral del tutor que atenderá programas por Internet, esto implica incidir en una pedagogía que sea "[...] ]autoinstructiva, interactiva, personalizada y que a su vez incida en el aprendizaje, los medios y la metacognición". ${ }^{2}$ Estos fenómenos de estudio y de investigación se hallan ahora en plena discusión en los medios educativos y tecnológicos.

52 Antonio J. Colom C., en su obra Pedagogía tecnológica para la educación a distancia, propone demostrar por qué la pedagogía que él llama tecnológica es el constructo teórico más pertinente y que mejor se adapta al desarrollo de la educación a distancia. 


\section{LA EDUCACIÓN VIRTUAL ANTE LAS TECNOLOGÍAS DE INFORMACIÓN Y COMUNICACIÓN}

Un hecho relevante respecto de estas tecnologías y que atañe a la educación virtual, tuvo lugar en 1994, cuando Bill Gates, propietario y director de Microsoft manifestó su visión del futuro tecnológico en el que las computadoras y las redes de comunicación respaldarán todas las actividades humanas, y donde las escuelas virtuales serán el común denominador del sistema educativo en los umbrales del siglo XXI.

Esta visión futurista se ha vuelto realidad, gracias a que los sistemas tecnológicos de comunicación e información transforman los procesos y las prácticas tradicionales de la educación a distancia y la socialización del conocimiento, mediante innovaciones que han modificado las formas de producción, distribución, apropiación, representación, significación, interpretación de la información, el conocimiento y el saber. Sin embargo, se advierte la necesidad del requerimiento social de un cambio cultural que incida en el reconocimiento de estas TIC como medios que facilitan la adquisición de conocimiento a través de un aprendizaje dinámico, integral y significativo para el estudiante, aspecto que debe reflejarse en su vida profesional y personal.

Así, las TIC plantean nuevos retos a la educación virtual, pues entre otras cosas, a las transformaciones tecnológicas operadas en el campo de las telecomunicaciones y la computación, que han generado cambios en las sociedades en cuanto a las formas de trabajo, maneras de interacción y comunicación de grandes sectores sociales, así como en la forma de acceder a la información en un mundo globalizado. Sobre esto último, Castells señala que las TIC han promovido un cambio de paradigmas, cuyas características serían:

- Las tecnologías son para "actuar" sobre la información, que es el insumo de aquéllas.

- Como la información es parte integral de toda actividad humana, todos los procesos de nuestra existencia están moldeados por el nuevo medio tecnológico. 
La educación virtual frente a los efectos de las tecnologías de información ...

- La interacción que propicia la red, mediante una lógica de intercambios, da lugar a una complejidad de interacciones y a un desarrollo impredecible.

- Las TIC son muy flexibles y permiten reconfigurar y modificar las organizaciones e instituciones, rasgos decisivos de una sociedad cambiante.

- Las TIC ofrecen una convergencia creciente (microelectrónica, telecomunicaciones, optoeléctrica y computadoras) de tecnologías específicas en un sistema altamente integrado. ${ }^{53}$

En este entorno, la información constituye el ingrediente esencial a partir del cual la sociedad participa en procesos de cohesión, globalización, informatización, educación y generación de conocimiento. En las últimas décadas, han surgido ideas que consideran el uso de las TIC en propuestas educativas virtuales, como el medio idóneo para democratizar la educación mediante la prestación de servicios educativos globalmente. Sin embargo, conviene reconocer que el camino que exige recorrer el mundo tecnológico es largo y muy accidentado, principalmente para los países donde la cultura informática apenas inicia; se utilizan restringidamente los sistemas de información automatizados y los modelos educativos evidencian graves atrasos. Asimismo, se advierte que el uso de las TIC enfrenta nuevos métodos de trabajo a los actores de la planeación y desarrollo educativo, entre otros aspectos; incluye inversión en infraestructura tecnológica; planificación apropiada a la calidad académica que se persiga; actualización permanente de la planta académica; preparación de autores de material didáctico, formación de tutores, orientada a la comunicación educativa en entornos virtuales de aprendizaje.

La creación de programas de esta naturaleza requiere de una apropiada comprensión y explicación de los conocimientos, hechos y fenómenos de la disciplina en que se planee la propuesta educativa, de un replanteamiento de estrategias del proceso de enseñanza-aprendizaje y la apropiación de TIC que se requiera utilizar. Por ejemplo, un tema relevante que debe examinarse en la enseñanza virtual en

53 Manuel Castells.."La era de la información: economía, sociedad y cultura", en La Sociedad Red, México : Siglo XXI, Editores, 1999, p. 94. 
bibliotecología tiene que ver con la edición en línea, cuyo objetivo es hacer llegar a la sociedad un producto digital cuyo formato se asemeje a una monografía, una revista o el periódico. En este sentido, el registro, compilación, proceso y transmisión de información vía redes de comunicación tiende a separarse de las formas y estructuras propias de la comunicación impresa, ya que la comunicación vía redes posibilita la presentación de documentos, cuya navegación y posibilidades de lectura proporcionan una amplia gama de opciones para el alumno, en tanto que no lo circunscribe a un solo documento, sino a variadas formas de relación entre los contenidos de distintos textos.

Por otra parte, las redes de información cada vez abren más posibilidades al acceso de un universo de información inimaginado, reducen los límites de fronteras a altas velocidades y con una cobertura universal que satisface las más sofisticadas necesidades de un usuario que se halle casi en cualquier punto geográfico del planeta. En este sentido, la Internet representa una realidad tecnológica relevante en el diseño de propuestas educativas virtuales en cualquier disciplina, por lo que, conviene tomar en consideración diversos aspectos de su desarrollo y aplicación en la educación del siglo actual.

Así, las universidades enfrentan el reto de mantenerse a la vanguardia en cuanto al uso de TIC, fortalecer el rigor académico, la libertad de cátedra, la libertad de investigación, revalorar su función docente frente a la globalización y la sociedad de la información y del conocimiento. Las universidades públicas reflejan una mayor competitividad al ampliar sus actividades extramuros (fuera de su país y una competencia con universidades privadas y universidades vinculadas con el sector empresarial). Sin embargo, cobertura y calidad académica siguen siendo desafíos para las universidades, ya que enfrentan el reto con nuevas formas de abordar la educación virtual. Especialistas de esta disciplina han señalado que uno de los retos de mayor urgencia es lograr una práctica pedagógica que haga un uso más eficiente de los recursos, los tiempos, los modos, los espacios para aprender y, desde luego, aprovechar al máximo las TIC. 
Sobre esto, Contreras señala: “[...]a lo largo del siglo XX [...] se han enfrentado dos corrientes pedagógicas que aglutinan enfoques ideológicos y culturales [...] la escuela tradicional y la escuela nueva, mismas que se proyectan en todos los niveles educativos, desde el básico hasta las universidades". ${ }^{4}$ Contreras Mayén afirma que "[...]las aportaciones de la pedagogía, la psicología y la sociología educativa [...] han puesto en evidencia que los teóricos de la educación no previeron la vertiginosa aceleración del cómputo y las telecomunicaciones, y su impacto en la vida de las sociedades de fin de siglo, lo cual renueva la discusión pedagógica, debido a que la misma tecnología de información y comunicación anida en sí, nuevos modelos de vida, de trabajo y en consecuencia de educación". ${ }^{55}$

En este siglo, la discusión sobre la educación virtual adquiere importancia singular en el marco internacional, un ejemplo es la relevancia que le concede la Conferencia Mundial sobre Educación Superior, convocada por la UNESCO. En el marco de acción prioritaria, la Conferencia puntualiza que "[...]se deberá generalizar en la mayor medida posible la utilización de las nuevas tecnologías, para [...] reforzar el desarrollo académico, ampliar el acceso, lograr una difusión universal, extender el saber y facilitar la educación durante toda la vida. Todo esto mediante la creación o reforzamiento de redes académicas que permitan aprovechar las ventajas de la tecnología reconociendo las necesidades nacionales y locales". ${ }^{56}$ Asimismo, las redes de telecomunicación han creado nuevos espacios para la transmisión de flujos de

54 Rita Contreras Mayén. "Reflexiones en torno al uso de la tecnología de la información en el terreno educativo", en Soluciones Avanzadas: tecnologías de información y estrategias de negocios, jun. 1997, vol. 5, no. 46, p. 10. Refiere que la escuela tradicional concentra en el maestro conocimiento y aprendizaje. En la nueva escuela, el estudiante construye su conocimiento basado en sus intereses de aprendizaje.

55 Ibid., p. 10.

56 La Educación Superior en el Siglo XXI -Líneas estratégicas de desarrollo- Una propuesta de la ANUIES. Documento aprobado en la XXX Sesión Ordinaria de la Asamblea General, Universidad Veracruzana e Instituto Tecnológico de Veracruz, Ver, 1999, p. 2. 
información, modificando hábitos y estableciendo nuevas formas de documentos digitales, necesarios para la educación virtual.

Pese a los buenos deseos de universidades y organismos internacionales, es interesante corroborar que una de las principales dificultades a que se enfrentan al implantar las TIC, provienen del factor humano, con poca disposición a enfrentar el cambio, particularmente cuando se trata de nuevo conocimiento; este hecho se presenta con mayor frecuencia en generaciones adultas, poco interesadas en el uso de tales tecnologías. Esto representa un reto para la educación virtual, ya que su objetivo de dirigirse principalmente a la población adulta utilizando tecnologías actuales.

Por incidir en gente adulta y por el requerimiento de utilizar tecnologías de información y comunicación, las universidades de hoy reconocen que deben preparar a las nuevas generaciones desde una perspectiva orientada a la reflexión, la autoformación y la apropiación de tecnologías que faciliten el logro de aprendizajes dinámicos, versátiles. Sin embargo, el uso apropiado de las TIC es también un asunto que atañe a los docentes para la consecución de los objetivos de su programa académico. Se reconoce que lo anterior ha sido un problema presente de manera permanente en los sistemas educativos. Sin embargo, los esfuerzos que se hagan al respecto permitirá a los egresados afrontar las exigencias actuales del mercado laboral, el cual precisa de profesionales de alto nivel y con apropiación de tecnologías de información y comunicación.

Por lo anterior la universidad virtual tiene como propósito atender las tendencias de globalización y económicas y plantea cambios en los modelos de enseñanza. "Las ventajas de la universidad virtual son amplias y variadas, y se consolidan cada vez más a partir del crecimiento de Internet". ${ }^{57}$ Sin embargo, la educación virtual tiene pocos años de existencia por lo tanto, en los inicios del siglo XXI educadores y universidades someten a discusión cuestiones como las siguientes: ¿Cómo se logra un aprendizaje integral a través de la interactividad y la navegación en red?, ¿Las teorías que históricamente ha

57 Contreras Mayén, Op. cit., p. 12. 
utilizado la educación a distancia, responden al aprendizaje virtual?,¿Cómo se aborda el proceso educativo y el uso apropiado de la información frente a los retos de la globalización y el constante desarrollo tecnológico?, ¿Qué papel deben asumir las universidades y las bibliotecas digitales frente a las exigencias de la educación en línea?, ¿Cómo incide la tecnología de información y comunicación en la organización, la transferencia, el acceso y la recuperación de contenidos y flujos de recursos digitales para la educación virtual?. En términos de competencia ¿Qué representa para las universidades la educación virtual, el teleaprendizaje y la educación en línea?

Algunas respuestas a los cuestionamientos mencionados pueden estar en las experiencias relacionadas con el uso de medios en la educación, en este sentido; "[...]cabe mencionar que la frustrada experiencia de introducir medios audiovisuales en la enseñanza durante los años setenta no tomó en cuenta la necesidad de transformar los métodos y técnicas de enseñanza para aprovechar certeramente la tecnología disponible en [esa] época". ${ }^{5}$

Si aprendemos de esta historia, se comprenderá, ciertamente que en la actualidad el uso de tecnologías requiere transformar modelos educativos y métodos de enseñanza-aprendizaje, con el fin de utilizar adecuadamente la tecnología disponible y darle su valor y justa dimensión. "Hoy en día las condiciones han cambiado considerablemente y se espera que la introducción de tecnologías de información y comunicación en el terreno educativo atienda las necesidades reales de tutores y estudiantes, aceptando el hecho de que la institución escolar fungirá como coordinadora y ya no como rectora del proceso enseñanza-aprendizaje". 59

El cambio más importante radica en que el peso de la calidad de la educación y el ritmo de aprendizaje dejará de ubicarse en las escuelas y pasará a manos del estudiante, aunque esto parece enfatizar el individualismo, propiciará lo opuesto. "Las redes de computadoras están generando las llamadas comunidades virtuales de aprendizaje, donde el conocimiento se vuelve colectivo y el estudiante se hace

58 Ibid., p. 14.

59 Ibid., p. 14. 
cargo de su propia educación, interactuando con el entorno en el que se desenvuelve". ${ }^{60}$

Por otra parte, la industria tecnológica ha visto en la educación virtual una posibilidad interesante, por ello ha generado una oferta en aumento de software educativo, aplicaciones multimedia, tecnología de comunicación vía redes, plataformas e-learnig orientadas a la formación en línea. Sin embargo, “[...] ]el papel de las empresas tecnológicas suele reducirse a considerar donaciones a precios preferenciales para el sector educativo. [...], pero no hay proyectos formales de apoyo a la investigación pedagógica y su alineación a TIC". ${ }^{61}$ De lo anterior se infiere que la lenta respuesta del sistema educativo en consumir tecnología como herramienta de apoyo presenta al sector educativo no tan atractivo en términos de mercado, como sí lo es el sector financiero. De allí que los esfuerzos de investigación de la industria tecnológica no se enfoquen tan intensamente al sector educativo.

Aun así, la educación virtual requiere de apoyos tecnológicos para solventar la comunicación educativa entre el alumno y el tutor, en este sentido, las redes de teleproceso facilitan el franqueo de las distancias y constituyen una plataforma sólida para el soporte de las herramientas y materiales didácticos, así como para facilitar la interacción con el alumno a distancia. De la armonía plena entre estos elementos depende que la dispersión geográfica entre los participantes no sea un obstáculo, sino al contrario, que se torne en una posibilidad de enriquecimiento, intercambio y aportación de conocimiento para el programa educativo específico.

En este contexto, la necesidad de resolver problemas relacionados con la educación en sus diversos niveles y modalidades se ha considerado medular por parte de diversos organismos internacionales. La UNESCO, la Asociación Internacional de Universidades y otros organismos de esta naturaleza han propiciado la investigación en torno a la problemática relacionada con la educación abierta, a distancia y virtual en diversas disciplinas. Hace poco, esta asociación realizó un

60 Roberta S Matthews., citado por Contreras Mayén, Op. cit., p. 15.

61 Contreras Mayén, Op. cit., p. 12. 
estudio comparado de universidades de reconocimiento mundial en este tipo de educación por su relevancia, los resultados del estudio fueron publicados por la UNESCO. ${ }^{62}$ De los veinte puntos que resumen las aportaciones de mayor importancia de esa investigación, para efectos de este trabajo, se incluyen, por su relevancia, los siguientes:

- Existe una correlación interesante entre igualdad, cantidad y calidad en la educación superior y, más específicamente, en la educación superior a distancia. Operar a gran escala e incorporar a un mayor número de estudiantes proporciona a las universidades una base financiera sólida que permite diseñar condiciones de convivencia a pequeña escala, para el encuentro entre estudiantes y académicos. Las finanzas sanas permiten grandes inversiones en materiales de alta calidad y estudios de alto nivel[...].

- Es esencial contar con planes de estudio flexibles y modulares para promover y consolidar el aprendizaje de por vida, y permitirle a los estudiantes escoger los programas que les gustaría seguir [...].

- Muchos universitarios que optan por un grado académico con la intención de realizar estudios de posgrado prefieren planes de estudio disciplinarios especializados, antes que programas amplios, aun en las universidades de educación a distancia. Esto evidencia la supremacía de las disciplinas en la educación superior.

- Las universidades deben estar alertas a los cambios en su entorno y responder rápidamente a un mercado de trabajo y consumo cambiantes. La colaboración exitosa entre empresas, industria y universidades arroja siempre beneficios recíprocos. Esto ayuda a que las universidades revitalicen su misión académica, amplíen el universo de usuarios, mejoren su base financiera y fortalezcan su responsabilidad social.

- La experiencia acumulada por las universidades de educación a distancia muestra la importancia del aprendizaje y la interacción

62 Sarah Guri-Rosenblit. Distance and campus universities: tension and interactions. A comparative study of five countries, [s.p.i.]; UNESCO, International Association of Universities and Elsivier Science Ltd. IAU Press Perganon, 1999. Traducción del capítulo final, pp. 240-242, de Tito Mejía Esparragoza. 
social $[\ldots]$. Las tecnologías avanzadas permiten incrementar la intensidad del intercambio entre los estudiantes, y entre éstos y el personal académico. En el futuro, la educación superior a distancia proporcionará aún mayores oportunidades para llevar a cabo diálogos interpersonales y trabajo en equipo.

- Desarrollar material para estudios de alto nivel requiere de una enorme inversión en capital humano, tiempo y dinero, pero genera grandes beneficios para el aprendizaje de los estudiantes.

- La incorporación de una amplia variedad en el tipo de estudiantes obliga a las universidades a poner mayor atención en los procesos de enseñanza y aprendizaje y a buscar formas efectivas de mejorar ambas tareas, aspectos que hasta ahora han sido ampliamente relegados.

- Probablemente, el personal académico de apoyo a los estudiantes será una parte integral de los cuerpos docentes en muchas universidades. En consecuencia, la responsabilidad de la enseñanza tradicional se dividirá entre diferentes grupos: tutores, consejeros, especialistas en Internet, diseñadores de programas de computación, especialistas en tecnología educativa, personal para almacenamiento de datos, etcétera.

- Las nuevas TIC interactivas poseen un enorme potencial para mejorar los medios de aprendizaje en los sistemas de educación a distancia, así como para promover el aprendizaje social. Sin embargo, su aplicación requiere de altas inversiones [...]. Los altos costos de ciertas tecnologías avanzadas podrían justificarse al quedar probada su eficiencia educativa o su capacidad de agregar una nueva dimensión, la interactividad, por ejemplo, en la educación a distancia.

- Por su naturaleza, la educación a distancia fácilmente trasciende las fronteras nacionales y llega a un amplio número de estudiantes en todo el mundo. La infraestructura de las universidades de educación a distancia les permite extender su colaboración internacional entre diferentes sistemas de educación de esta clase, y entre las universidades, el mundo de los negocios y las empresas. 
Los resultados del estudio citado han sido considerados por universidades de varias naciones, han tomado en cuenta las experiencias del entorno internacional para incidir en propuestas que operan actualmente en México y en otros países. También han surgido instituciones coordinadoras de sistemas y programas de educación abierta y a distancia en los niveles de educación básica, media superior y superior.

Así, en el siglo XXI se advierte que la modernización de la educación es uno de los proyectos relevantes de las naciones, pues hay cabida para programas globales en los que está presente la aplicación de políticas gubernamentales orientadas a efectuar cambios estructurales, económicos y constitucionales que den coherencia a la participación educativa en un mundo globalizado. Hoy se percibe un mayor interés de organismos nacionales e internacionales respecto de la educación a distancia por las repercusiones que tendría en las sociedades. La investigación de los fenómenos relacionados con aquéllas, ha cobrado mayor apogeo a raíz de la incorporación de las TIC, lo cual representa nuevas exigencias para estudiar temas que atañen a la teoría de la educación en entornos virtuales de aprendizaje.

Finalmente, se puede señalar que en lo expuesto hasta aquí queda de manifiesto que toda propuesta educativa virtual debe tener presente que comprender la teoría que subyace en la educación a distancia es determinante, debido a que de esta manera se incidirá en propuestas educativas bien fundamentadas y evitar los errores cometidos en diversas iniciativas de esta índole.

Asimismo, la sola exposición de la teoría redunda en un valioso discurso puesto que es el resultado de la reflexión de estudiosos, a lo largo de la existencia de la educación a distancia y el advenimiento de la educación virtual. Sin embargo, sin dejar de reconocer lo anterior, en este escrito se insiste en proponer un modelo teórico dirigido a la enseñanza virtual de una especialización sobre la organización de recursos informativos digitales, a partir de la cual se rescatan diversos aspectos teóricos expuestos en este capítulo.

Igualmente es importante señalar que en el diseño de propuestas educativas que atiendan un modelo de educación virtual se manifiesta la necesaria concurrencia de especialistas en educación, pedagogía, 
psicología, tecnologías de la información, telecomunicaciones, medios de comunicación, diseñadores gráficos, y, naturalmente, de especialistas en el ámbito del conocimiento específico en el que se diseñe la oferta educativa. Esto evidencia el carácter multidisciplinario que exige el diseño de propuestas educativas de esta naturaleza.

Por lo tanto, es necesario que las instituciones educativas asuman el compromiso de atender los requerimientos que conlleva incidir en programas de educación virtual, como una alternativa que favorezca el cumplimiento de los objetivos de educar a la mayor cantidad de la población sin importar dónde se encuentre. En lo anterior, las disciplinas también deben colaborar desde el lugar que les corresponde. En el campo de la bibliotecología se reconoce que hace falta incidir en los medios bibliotecarios con propuestas de educación virtual que favorezcan su preparación permanente. Las tecnologías más recientes facilitan el diseño y desarrollo de propuestas educativas que conduzcan a tal preparación, empero, es conveniente tomar en consideración lo dicho por Bates cuando señala que "[...]la elección apropiada del uso de las tecnologías dependerá del contexto particular en que éstas se apliquen". ${ }^{63}$

Cabe recalcar que los diversos parámetros teóricos y metodológicos utilizados en propuestas educativas sustentadas en la educación virtual son determinantes, tanto en su diseño como en su ejecución, por ende, es recomendable profundizar en los aspectos relacionados con el desarrollo de material didáctico, debido a que esta tarea tiene un papel preponderante en esa modalidad. En consecuencia, en el siguiente capítulo se abordan aspectos relacionados con el desarrollo de materiales didácticos y el uso de medios portadores de contenidos.

63 A. W. Bates. La tecnología en la enseñanza abierta y la educación a distancia, México: Editorial Trillas, 1999, p.15. 
II

Materiales didácticos y soportes de contenido en la educación virtual 



\section{MATERIALES DIDÁCTICOS: UN ACERCAMIENTO TEÓRICO}

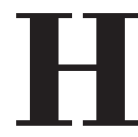

istóricamente la educación a distancia ha manifestado que materiales y soportes de contenido son elementos inseparables y necesarios en la educación de este tipo, debido a que representan uno de los enlaces de comunicación de mayor importancia entre quien enseña y quien aprende. Por lo anterior, en este capítulo me propongo analizar los fundamentos metodológicos de mayor relevancia relacionados con el desarrollo de materiales didácticos, la evolución de los soportes de contenido, la orientación de la generación de software educativo y las características que presentan las TIC aplicadas en el desarrollo de materiales multimedia y plataformas tecnológicas. Estos temas son fundamentales en la educación a distancia, pues presentan, en conjunto, los medios de comunicación entre los sujetos del aprendizaje, con el propósito de concretar el diálogo académico. Se entiende que el desarrollo de materiales didácticos exige a los autores de contenidos asumir una postura de articulación teórica como principio para su elaboración.

Las TIC han enriquecido las formas de realizar dichas tareas, gracias a la convergencia tecnológica de las telecomunicaciones con otros medios educativos, como la informática, cuyo objetivo es incidir en acciones vinculadas con el desarrollo de software educativo, 
sistemas multimedia, hipertexto e hipermedia, a fin de enriquecer las modalidades de los aprendizajes a distancia. De este modo, aquí se intentará dar respuesta a las siguientes preguntas: ¿es conveniente el uso de metodologías para el desarrollo de materiales didácticos? ¿qué teorías del aprendizaje son las más apropiadas para guiar la elaboración de contenidos? ¿es la Internet un medio apropiado para el manejo de contenido en propuestas de educación virtual?

Así, el desarrollo de materiales didácticos de apoyo en el proceso de enseñanza-aprendizaje en la educación virtual es una de las tareas fundamentales que otorgan identidad a esta modalidad, dada la relevancia que en este modelo educativo se reconoce aquélla. Se advierte que el uso intensivo de medios de instrucción tiende a condicionar los objetivos y temas de los programas, por ello, la identificación y el tratamiento de los mensajes docentes son tareas de gran valor, ya que se requiere discriminarlos y estructurarlos de tal forma que se registren con facilidad, contemplando las características particulares de los medios portadores que se requiera emplear.

En consecuencia, las tareas que exige el diseño de materiales de instrucción y el hecho de que el estudiante es el sujeto principal del proceso de aprendizaje, exige tomar en cuenta, como expresa Peña Borrero: "[...]la formulación de objetivos, el análisis estructural de las tareas de aprendizaje, la selección de estrategias y medios adecuados para el logro de los objetivos, la combinación de éstos de modo que constituyan un todo integrado y el diseño de mecanismos que sirvan para recibir la información de retorno y evaluar permanentemente a los estudiantes". ${ }^{1}$ Asimismo, el empleo de modelos dirigidos al desarrollo de materiales didácticos presupone acudir al conocimiento y a la aplicación de un conjunto de principios normativos, derivados de las teorías del aprendizaje, con los cuales se intenta volver más eficiente el proceso de elaboración de los materiales.

1 Luis Alberto Peña Borrero. Planeación de programas de universidad abierta y a distancia: factores críticos para la toma de decisiones, Colombia : ICFES, Ministerio de Educación Nacional, 1983, p. 37. 
Una característica peculiar respecto de los materiales de instrucción que se emplean en la educación a distancia es su alto grado de estructuración pedagógica, ya que su finalidad consiste en reforzar los aprendizajes. Sin embargo, la búsqueda de un conocimiento más significativo consideraría los contenidos didácticos, que también deben ser objeto de un ordenamiento lógico, y permitir, con fundamento en bibliografías complementarias, la búsqueda de información adicional sobre los temas de estudio por parte del alumno.

Esto cobra sentido porque la estructuración pedagógica de los materiales es uno de los requerimientos de la comunicación didáctica en la educación a distancia. Tal aspecto indica que ha de eliminarse cualquier tipo de ambigüedad,sea de estructura o de contenidos, al brindar al estudiante un discurso accesible para su aprendizaje y que, además, lo orille a la reflexión y a la búsqueda de más información sobre el tema de estudio, redundando en que sea un reto para todo autor de este tipo de materiales.

Se advierte que las tareas mencionadas se facilitan si se acude a modelos de diseño instruccional que respondan a preguntas de este tipo: ¿cómo se plantean objetivos de aprendizaje? ¿cómo se presenta el ordenamiento lógico de contenidos? y ¿cómo se diseñan secuencias de aprendizaje que permitan a los estudiantes corroborar sus avances y detectar las fallas de su aprendizaje? Sobre esto Chan Núñez acota: "El proceso de enseñanza tiene como fin la formación de personas con capacidad para analizar, problematizar y actuar sobre su realidad y, por tanto, contribuir positiva y eficazmente en un proyecto social participativo". ${ }^{2}$ En este sentido, se entiende que el aprendizaje se califica como productivo cuando el alumno es capaz de generar ideas, desarrollar y resolver problemas, habilidades que lo vuelven útil en la sociedad y en el grupo profesional al que pertenece. Sin embargo, habrá que contemplar que los alumnos de programas a distancia, por su condición de adultos, exigen contenidos de aprendizaje que proporcionen no sólo la explicación de fenómenos;

2 Ma. Elena Chan Nuñez et al. "Guía para la elaboración del paquete de materiales didácticos orientados al aprendizaje independiente”. en Estudio Independiente, México: ILCE, 1997, p. 260. 
sino también su posible solución, aplicación y vinculación con los problemas que se les presentan ante una situación laboral o cuando se enfrentan a problemas propios de su vida cotidiana.

Por lo tanto, este tipo de alumnos se somete principalmente a dos tipos de procesos educativos: a) el informativo, que consiste en el cúmulo de conocimientos identificados a través de la actividad relacionada con la organización curricular, y $b$ ) el formativo, a través del cual el sujeto realiza la aplicación del conocimiento adquirido en la solución de problemas específicos. En consecuencia, en el desarrollo de materiales didácticos deben considerarse múltiples características pedagógicas, por ejemplo:

- Epistemológica: la que atañe a la actitud en torno a la construcción del conocimiento y que lleva a asumir una postura de articulación teórica para la formulación de la propuesta misma y como principio central de la lógica que se recomienda para la elaboración de los materiales. Actitud con la que se asume un sentido de totalidad relacional, en la que los objetos de conocimiento no están predeterminados de antemano.

- Teórica: se asumen dos vertientes principales para la concepción de aprendizaje: la constructivista y la histórico-cultural. En ambas subyace una postura epistemológica abierta y organicista, de la que derivan conceptos como el de la problematización y la noción de integridad de las actividades y productos que se construyen por medio del desarrollo de las unidades didácticas. El enfoque comunicacional sociocultural se articula dentro de la perspectiva teórica desde el cual se considera la cultura como el elemento fundamental de toda significación, haciendo énfasis en el papel de los educandos, en tanto receptores activos que usan, significan y se apropian de los contenidos que son codificados por el elaborador del material de apoyo. ${ }^{3}$

Por lo tanto, la función del autor de materiales didácticos es de suma importancia, pues es él quien debe determinar los medios idóneos para socializar los contenidos y comunicar la información

3 Ibíd., pp. 261-262. 
pertinente en el aprendizaje. En este sentido, la función de la información es fungir como base de conocimiento para lograr que los estudiantes lleguen a la construcción de estructuras de pensamiento y a la resolución de problemas. Algunas tareas académicas de importancia del autor de contenidos para la educación virtual serían estas:

- Seleccionar la información relevante al fenómeno de estudio que se pretenda abordar

- Determinar formas de procesamiento de la misma, como resúmenes, ensayos y demás géneros textuales

- Identificar casos de estudio, con los cuales el alumno encuentre formas de relacionarse con diversos fenómenos de aprendizaje.

- Presentar opciones para el manejo y análisis de contenidos, orientados a lograr conocimiento significativo en los estudiantes.

- Proponer lecturas complementarias que garanticen la profundización en temas desarrollados en el contenido fundamental de los materiales didácticos.

En cuanto a estos aspectos mencionados, la teoría sobre el desarrollo de materiales didácticos indica la conveniencia de considerar básicos al análisis de los objetivos generales y específicos de la propuesta educativa de que se trate, atendiendo la vinculación temática que tengan las partes que estructuren el plan de estudios, los requisitos de ingreso y egreso del programa, así como evidenciar el conocimiento que el sujeto logre asimilar mediante la evaluación. La evidencia de ésta en el aprendizaje se fundamenta en resultados como los que se enuncian ahora:

Productos elaborados sobre la información. Permiten evaluar el grado de apropiación de la información sugerida por el docente, sobre todo la evidencia de lectura, capacidad de análisis y síntesis. Entre estos productos destacan las fichas de trabajo, reseñas, ensayos, cuadros sinópticos, análisis de contenido, etcétera. [Con este tipo de productos se evidencia que el estudiante trabajó con la información y la organizó en determinada manera. Se pueden identificar capacidades o habilidades cognitivas como la síntesis, el análisis y la valoración de los contenidos]. 
Productos elaborados para constatar la aplicación de la información. Con éstos el sujeto se fundamenta en las fuentes informativas, pero desarrolla propuestas, analiza situaciones reales, resuelve casos, presenta un informe de investigación o un proyecto específico. En esta clase de productos no sólo se verifica el manejo de contenido, sino también las habilidades cognitivas de transferencias de la información, toma de decisiones, sentido crítico, deducción, inducción, etcétera. ${ }^{4}$

Estos aspectos conducen a corroborar el grado de aprendizaje logrado, mostrar si las habilidades programadas se alcanzaron y si hubo pertinencia en los contenidos y actividades de aprendizaje. La evaluación adquiere mayor sentido si se toma en cuenta el perfil de los egresados, el que determina las habilidades que se espera logren los estudiantes con base en contenidos, actividades, fuentes de información y productos elaborados por aquéllos.

En propuestas educativas a distancia, las actividades ya citadas cuentan con apoyo estratégico de los materiales didácticos, comúnmente integrados a partir de fuentes de información y guías de aprendizaje elaboradas ex profeso. A su vez, las fuentes de información se desarrollan utilizando diversas modalidades:

La compilación. Selección de materiales existentes (aclarando que puede ser cualquier tipo de material o la combinación de varios: impreso, auditivo, visual o de software), cuya función es la transmisión informativa de los contenidos señalados en el programa, considerando que esa recopilación no obsta limitación para la búsqueda de información en otras fuentes, que, como parte de las actividades de investigación, habría de realizar el estudiante.

El diseño de un libro ex profeso. Uno o varios especialistas en el campo específico del curso elaboran a petición de los responsables del programa académico.

Uso de publicaciones comerciales. Se editan para atender a destinatarios con necesidades e intereses diversos, por lo cual es importante

$4 \quad$ Ibid., pp. 264-265. 
hacer un análisis muy crítico en la selección de este tipo de fuentes como material de estudio. ${ }^{5}$

La antología. Otra forma del material didáctico se refiere a este tipo de textos, que consisten en la recopilación de documentos selectos y representativos para el estudio de un campo temático específico. Su elaboración exige el análisis y la selección de documentos, así como un ordenamiento determinado. Dicho tipo de obra las realizan profesionistas especializados en la propuesta educativa de que se trate; idealmente se recomienda que se forme un grupo interdisciplinario o multidisciplinario para garantizar la relevancia de los contenidos y el desarrollo de las actividades de aprendizaje que conduzcan al alumno virtual a la práctica del estudio independiente.

Sobre lo antes mencionado, Morales Campos señala: “[...]el entorno local y virtual a partir de las telecomunicaciones, las redes y la web nos ponen ante un amplísimo universo de datos y de información que se ha de estructurar y organizar para contar con un fácil acceso a ellos. La convivencia natural de la información impresa y electrónica nos obliga a dar un tratamiento adecuado a cada uno: los libros, las revistas electrónicas, enriquecidos con contenidos multimedia, se tienen que estudiar para su administración, su conservación y su acceso a la información que contienen". ${ }^{6}$ No obstante, para que dichas fuentes se utilicen en programas de educación virtual se requiere, además, de la intervención de autores de contenido para depurar las que garanticen una mayor relevancia dentro de la propuesta educativa en cuestión, de lo contrario, el alumno a distancia estará frente a un alud de información que, más que apoyar su aprendizaje, ocasiona una saturación informativa en detrimento de su avance educativo.

Por ello, en el diseño de materiales de instrucción y en el desarrollo de actividades de aprendizaje, así como en la selección de lecturas complementarias, los autores de contenido suelen apoyarse en la concepción constructivista del aprendizaje, considerando para tal proceso una actividad de reconstrucción y reestructuración, es decir,

5 Ibid., pp. 268-269.

6 Estela Morales Campos. Infodiversidad, globalización y derecho a la información, Buenos Aires: Sociedad de Investigaciones Bibliotecológicas, 2003, p. 75. 
el nuevo conocimiento se construye a partir del conocimiento adquirido previamente a la propuesta educativa específica. Por tanto, el alumno es quien construye su propio conocimiento, gracias a su participación en actividades planificadas y sistematizadas, orientadas a propiciar en ése, ejercicios mentales que lo orienten a la construcción de su propio conocimiento, tomando como base principal los materiales de instrucción, las lecturas complementarias y las actividades de aprendizaje individuales y colectivas.

Las características del proceso de enseñanza-aprendizaje que puede darse con fundamento en la concepción del constructivismo se relacionan con a) el modo como se adquiere el conocimiento (por medio de la percepción y el descubrimiento) y b) a la forma como se incorpora el conocimiento en la estructura cognoscitiva del alumno, que puede ser por repetición y significativo.

Uno de los postulados de esta teoría señala que la estructura cognoscitiva del alumno tiene una serie de antecedentes y conocimientos previos, un vocabulario y un marco de referencia personal, lo cual indica aspectos relacionados con su madurez intelectual. Por lo tanto este aspecto es de sumo valor para cualquier autor de material instructivo orientado a la educación virtual.

Varios autores han señalado que los medios didácticos son la unión entre las palabras y la realidad, en tanto que su ordenación representa tareas complejas, pues se trata de estructurar los contenidos curriculares que den coherencia al proceso de enseñanzaaprendizaje en forma mediatizada. En consecuencia, al desarrollar los materiales didácticos, se han de tomar en cuenta sus objetivos, según los cuales, señala EDUCADIS (proyecto argentino en educación a distancia), consisten en:

- Favorecer la autonomía, requisito indispensable en un sistema a distancia.

- Despertar curiosidad científica en el destinatario, motivar para seguir estudiando y mantener la atención.

- Relacionar la experiencia, los conocimientos previos con los nuevos que se proponen.

- Facilitar el logro de los objetivos propuestos en el curso. 
- Presentar la información adecuada, esclareciendo los conceptos complejos o ayudando a esclarecer los puntos más controvertidos.

- Poner en marcha el proceso de pensamiento en el destinatario, proponiendo actividades inteligentes y evitando, en lo posible, aquellas que estimulen sólo la retención y la repetición.

- Propiciar la creatividad. ${ }^{7}$

Conforme a lo ya mencionado, se observa que el valor del material didáctico de apoyo a propuestas educativas a distancia es de fundamental importancia, debido a que se estructuran contenidos que atienden la temática de estudio, teorías de aprendizaje, perfil de los alumnos, etcétera. El requerimiento de una estructura planificada desde el punto de vista pedagógico, responde al hecho de que en esta modalidad no tiene cabida el currículum oculto, ya que dichos materiales se convierten en los medios de comunicación inmediata para los actores del aprendizaje; por lo tanto, es esencial lograr que el alumno tenga el mínimo de dudas de los temas de estudio.

\section{DESARROLLO DE MATERIALES DIDÁCTICOS PARA LA EDUCACIÓN VIRTUAL}

En la elaboración de los materiales de instrucción, conviene pensar en la calidad académica y pedagógica que se quiera lograr con los productos finales, así como la variedad, alcance y complejidad de los medios por emplear. Asimismo, los recursos humanos y la disponibilidad financiera son determinantes en los distintos niveles de esta actividad, pues contar con especialistas de distintas disciplinas garantiza el logro de productos de mayor calidad. En cuanto a la conformación de grupos interdisciplinarios, resulta determinante en la consecución de esa calidad. Asimismo, el proceso de elaboración de materiales didácticos para la EAD adopta características particulares, según el marco teórico que las sustente. Varios autores se han ocupado de

7 EDUCADIS. "Materiales y medios didácticos". Servicios asociados para la educación a distancia. Argentina, 2000. [en línea]

http://www.educadis.com.ar/mymath.htm [consultada: 25/09/03] 
proponer lineamientos metodológicos para la elaboración de materiales de esta naturaleza. EDUCADIS sugiere una metodología para la elaboración de materiales didácticos orientados a la educación a distancia, algunos de estos elementos se describen a continuación.

\section{Figura 1}

Lineamientos para la elaboración de material didáctico

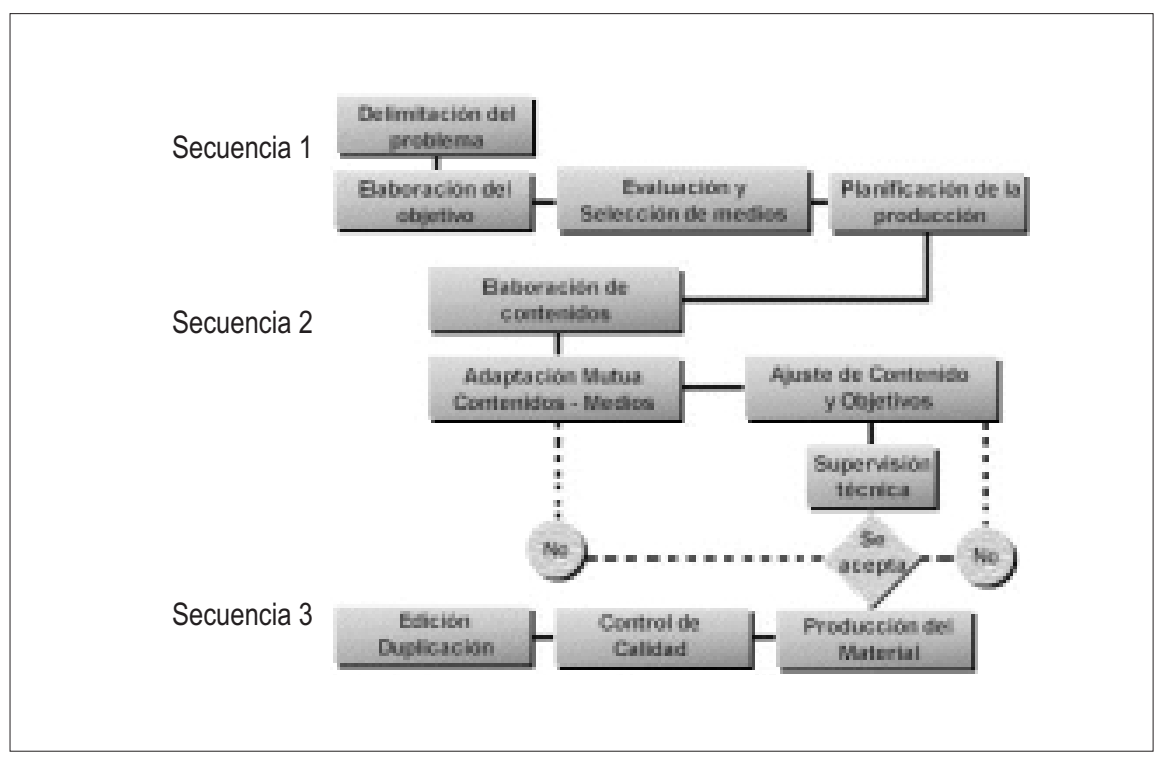

Fuente: Diagrama basado en EDUCADIS. http://www.educadis.com.ar/mymat.html

\section{Secuencia 1}

Delimitación del problema. Definir con claridad el problema que se abordará en el material implica tener la visión global de la propuesta educativa, tanto desde el punto de vista de las necesidades institucionales, como de la información a desarrollar y desde las características de los destinatarios y su contexto.

Elaboración de Objetivos. En función del problema definido, se procede a establecer con precisión qué se propone lograr con los 
materiales por producir. La relación entre los objetivos y la solución del problema debe ser clara.

Evaluación y selección de medios. Los criterios relevantes tendrán que ver básicamente con la naturaleza de objetivos y contenidos.

Planificación de la producción. Después de seleccionar los distintos medios, se procede a la planificación de su producción, pensando en los requerimientos temporales y materiales de cada medio, las etapas del modelo de producción, tiempos y responsables.

\section{Secuencia 2}

Elaboración de contenidos. En función de la propuesta educativa, el autor de contenidos procede a su desarrollo; para ello seguirá las orientaciones generales del proyecto y las pautas específicas que el equipo productor requiera. Debe recordar el objetivo previsto, con contenidos, proporcionar ejemplos y explicaciones adicionales, sugerir bibliografía que los complemente.

Adaptación mutua de contenidos y medios. En esta etapa del proceso de producción, se procede a adaptar los contenidos a la forma del lenguaje del medio o los medios seleccionados, previendo la función que cumplirá dentro del programa.

Ajuste de contenidos-objetivos. En esta tarea la coordinación del programa procederá a supervisar lo realizado a fin de determinar su coherencia interna. Se cotejarán los contenidos con los objetivos propuestos. Si hay coherencia, el proceso continúa en el paso siguiente, de lo contrario se volverá a la instancia anterior y se deberán proponer los ajustes necesarios.

Preproducción del material. En esta etapa se da la estructura definitiva del material, de acuerdo a las características propias del medio usado, se presentan los contenidos, actividades, problemas, etcétera. Este paso estará a cargo del diseñador didáctico, guionista de audio y video, entre otros.

\section{Secuencia 3}

Supervisión técnico-académica. En esta etapa se realiza una nueva revisión de lo hecho para comprobar que durante el diseño de los materiales no se hayan producido distorsiones en los contenidos, 
especialmente en la traducción de éstos al lenguaje propio de cada medio. También se controla que la conversación didáctica sea adecuada para el destinatario. Si esto se cumple, el proceso continúa en el paso siguiente, de lo contrario se regresa al anterior.

Producción del material En esta etapa se procede a la producción técnica del material, de acuerdo a las características específicas y propias del medio seleccionado. Esto estará a cargo de los productores que, según el medio, serán editores, diseñadores gráficos, productores de radio y televisión (sitios web, plataformas para el desarrollo de aulas, bibliotecas y hemerotecas virtuales).

Control de calidad. Es el último control del material antes de que lo reciba el destinatario. La coordinación técnica del programa realiza una revisión crítica, con parámetros de calidad, estilos, lenguajes, diseños, etcétera. Pasa luego al diagnóstico de expertos, quienes con una mirada externa y especializada, juzgan tanto la calidad académica como técnica del material.

Edición. Una vez concluidos los controles de calidad y aceptado el producto final como material apto para el aprendizaje, se procede a su edición en formato impreso o digital.

Asimismo, conviene enfatizar que la supervisión de la generación de objetivos en el desarrollo de contenido es determinante. Si el aprendizaje implica una modificación en algún aspecto de la conducta, los objetivos expresan entonces las modificaciones que se prevén como resultado del proceso de enseñanza-aprendizaje. Plantear objetivos puntual y coherentemente facilita la identificación de los cambios que se quieran observar en la conducta de los alumnos como resultado del proceso de aprendizaje, los cuales se advierten en tres áreas fundamentales:

- Área cognoscitiva: son los comportamientos relativos a los procesos mentales o intelectuales de los alumnos.

- Área afectiva: comportamientos relativos a las actividades, sentimientos y valores de los alumnos. 
- Área psicomotriz. comportamientos que representan las habilidades neuromusculares o físicas e incluyen diferentes grados de destreza física. ${ }^{8}$

Se tiene en mente que un objetivo es la expresión clara y precisa de las metas por alcanzar mediante ciertas acciones, en un campo determinado y en un tiempo preestablecido, por tanto, su función principal es delimitar la amplitud y profundidad con que se aborda determinado campo de conocimiento. En consecuencia, afecta las actividades de aprendizaje y desarrollo de contenidos, debido a que a partir de sus objetivos es factible definir el grado de detalle con que se elaborará el contenido, en qué aspectos del discurso académico se pondrá énfasis, cómo se relacionarán entre sí y qué utilidad tendrá en el aprendizaje de los alumnos a distancia.

Con lo antes expuesto, se advierte que la elaboración de los materiales didácticos implica un seguimiento metodológico estricto. En todo caso, la calidad y exactitud de los contenidos determinan el éxito de la propuesta educativa prevista y, en consecuencia, justifica la insistencia de algunos autores respecto de la conformación de grupos interdisciplinarios para realizar esta tarea.

Si se toma como referente determinado método o una combinación de éstos para el desarrollo de materiales didácticos, sería de mucho valor para los autores de contenido, sin embargo, convendría incluir otros referentes, que quizás enriquecerían la metodología al realizar dicha tarea. En este sentido, vale la pena recordar que por tradición, en las universidades europeas a distancia, los materiales impresos se consideran desde hace por mucho tiempo, la base para el desarrollo de materiales didácticos y, más recientemente, también para la educación virtual. A partir de éstos han surgido propuestas que se han enriquecido con el advenimiento de las TIC. Así, el desarrollo de material didáctico impreso para la $\mathrm{EAD}$ se orientó principalmente a la redacción de textos de ensenanza programada y guías de autoaprendizaje.

Con el texto de enseñanza programada se busca que a partir de éste, el alumno planee su ritmo de aprendizaje. Estos textos se han

8 Unidad de autoenseñanza: redacción de objetivos de aprendizaje, México: UNAM, 1998, [p.v.]. 
utilizado desde los años sesenta; sin embargo, hacia los ochenta, al parecer influyó en ellos la corriente industrial de la educación. Uno de sus exponentes, Peters, advierte: “[...]la enseñanza-educación a distancia es un método de impartir conocimiento, habilidades y actitudes, $[. .$.$] principalmente para el objetivo de reproducir materiales$ de enseñanza de alta calidad lo cual hace posible instruir a un gran número de estudiantes al mismo tiempo [...]". 9

Respecto de las guías de autoaprendizaje, se intenta que el estudiante relacione su conocimiento previo, derivado de lo que sabe sobre la materia que estudiará, con la idea de que lo enriquezca con el nuevo conocimiento que adquirirá. Para ello se le proporcionan actividades de aprendizaje mensurables en la evaluación; al final de la guía se le proporciona un estudio de caso que deberá resolver según los conocimientos adquiridos. El desarrollo de este tipo de material atiende, por lo general, la teoría constructivista. Así, la guía de autoaprendizaje se elabora tomando como base fundamental los siguientes aspectos:

1. Análisis del programa correspondiente a un curso.

2. Elaboración de la guía de estudio.

3. Elección y análisis de las lecturas recomendadas como complemento de la guía.

Conviene advertir que en la elaboración del material didáctico para la educación a distancia, sea impreso o digital, no se sigue un modelo homogéneo, más bien los autores de contenido se enfrentan a diferentes modelos, postulados, requisitos, exigencias, procesos y a la obtención de determinados resultados, atendiendo los requerimientos de los cursos que se quieren ofertar.

Por tanto, se consideró adecuado presentar, de grosso modo, la propuesta de María Elena Chan, relacionada con el mismo tema. Ella propone un diagrama de flujo para la elaboración de guías de autoaprendizaje. Sobre esto, ha tenido reconocimiento y uso principalmente en universidades a distancia de América Latina, aspectos que se ilustran en el siguiente diagrama:

9 O. Peters, citado por García Aretio. La educación a distancia:..., Op. cit. p. 27. 
Figura 2

Flujograma para la producción académica

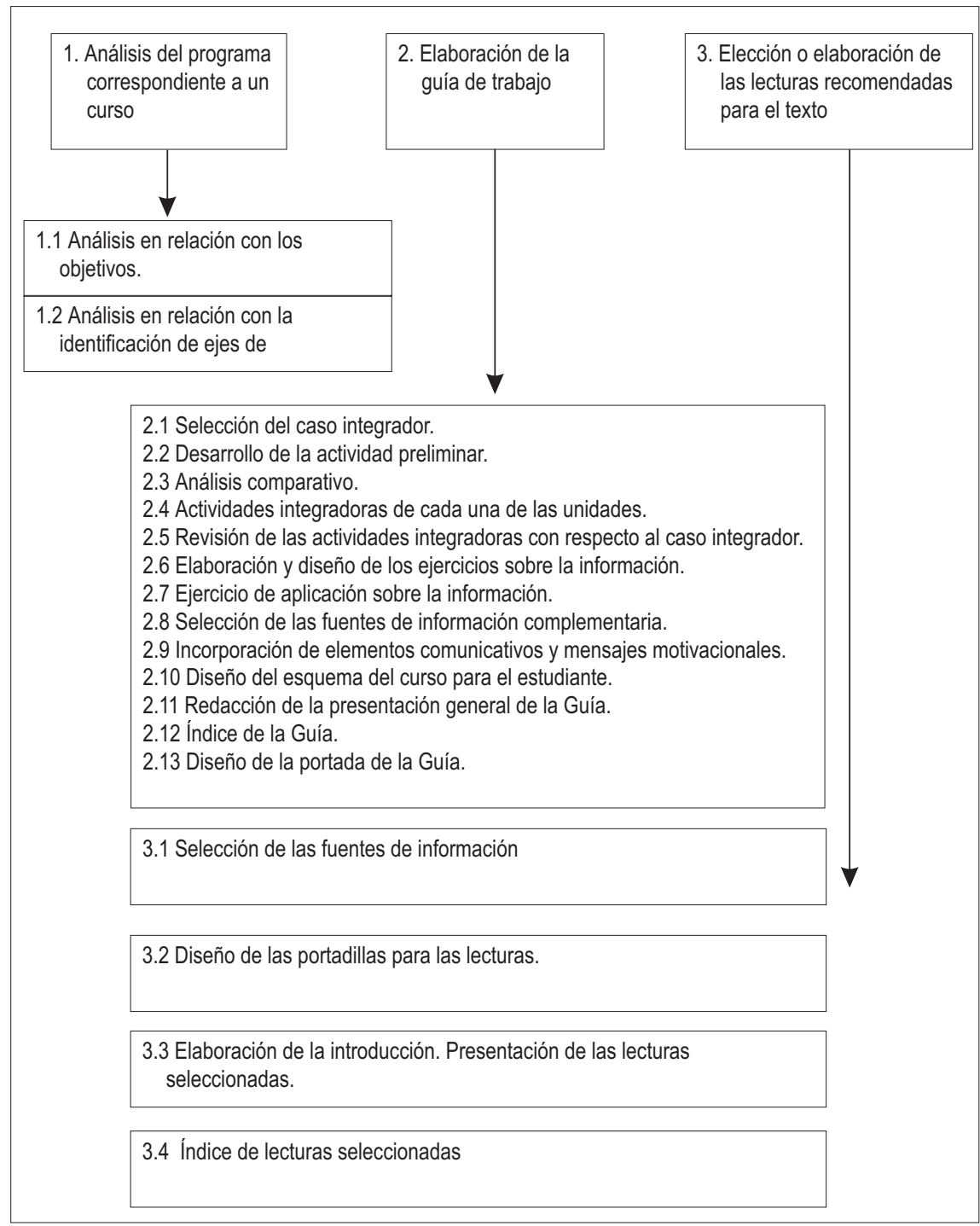

Fuente: M.E. Chan Nuñez, [et al.]. "Guía para la elaboración del paquete de materiales didácticos orientados al aprendizaje independiente”, en Estudio Independiente, México: ILCE. 
Cualquier tipo de material didáctico que se intente desarrollar, además de emplearlo, implica problemáticas de autoría derivadas del contenido y del medio a utilizar, por ello es conveniente prever ciertos aspectos sobre los derechos de autor.

\section{DESARROLLO DE MATERIALES DIDÁCTICOS Y DERECHOS DE AUTOR}

Históricamente, los derechos de autor, los derechos de copia y la propiedad intelectual han despertado severos debates y generado legislaciones, normas y reglamentos, cuyos propósitos han sido proteger a los autores del uso que se da a sus obras. Tal tema no está exento de dificultades, pues cada nación tiene particularidades legales al respecto. Sobre este asunto, Goldstein dice que:

[...]la protección debe de ser capaz de atender intereses públicos y privados que en esta materia están en juego y que dependen de diversos factores no sólo sociales y económicos, sino asimismo jurídicos y de política jurídica que con los años se entrecruzan y se condicionan recíprocamente. ${ }^{10}$

En cuanto al derecho de autor, ${ }^{11}$ la legislación mexicana contempla la protección de las obras literarias, músicales, dramáticas, dancísticas, pictóricas o de dibujo, escultóricas y plásticas, caricaturas, historietas, arquitectónicas, cinematográficas, radiales, televisivas, programas de cómputo, fotográficas y obras de arte aplicado que incluyen el diseño gráfico o textil. Tocante a las obras de compilación,

10 Paul Golstein. El copyright en la sociedad de la información / int. y trad. María Luisa Llobregat Hurtado, Alicante: Publicaciones Universidad de Alicante, 1999, p. 15

11 El artículo 11 de la Ley Federal de Derecho de Autor señala que: "es el reconocimiento que hace el Estado a favor de todo creador de obras literarias y artísticas, para que goce de prerrogativas y de privilegios exclusivos". Para mayor información, véase Ley Federal del Derecho de Autor [en línea] http:/www.impi.gob.mx/web/docs/marco_j/index_marco_j.html [consultada: 15/03/04]. 
se incluyen las enciclopedias, antologías y bases de datos; estas últimas son de particular interés para autores de contenido y encargados de antologías para la educación virtual, por lo tanto, conviene revisar las particularidades legales que las protegen de su uso ilegal.

El derecho de autor contempla dos aspectos inseparables: "[...]el derecho moral y el patrimonial; mientras que el primero es irrenunciable, el segundo puede ser transmitido como cualquier otro derecho económico". ${ }^{12}$ la diferencia existente entre los sistemas jurídicos mundiales se fundamenta en que "[...] el derecho continental europeo [...] protege el derecho moral y patrimonial; por su parte, el common law, o derecho anglosajón, sostenido básicamente por Inglaterra y Estados Unidos [...] pone el acento en el derecho patrimonial y deja a la decisión tribunalicia la solución de cualquier inequidad respecto de la persona humana. Es de este modo como al primero se le denomina derecho de autor y al segundo copyright (derecho de copia)". ${ }^{13}$ En este sentido, la ley mexicana sobre este mismo asunto pone especial énfasis en los autores como personas físicas, a quienes reconoce derechos básicos perpetuos e inalienables.

Con el advenimiento de documentos digitalizados, digitales y la información disponible en entornos de redes de teleproceso, la situación del derecho de autor, el derecho de copia y el derecho a la información ${ }^{14}$ se ha complicado, generando nuevos problemas, que en muchos casos no se encuentran previstos en las legislaciones. Sin duda, la cuestión sobre tales derechos es sumamente compleja, por tanto, el propósito de este apartado consiste en examinar generalizaciones al respecto y hacer unas reflexiones útiles para autores de

12 Mabel Goldstein. Derechos de autor, Buenos Aires: Ediciones la Rocca, 1995, p. 41.

13 Ibid.

14 El derecho de autor en jurisprudencia se considera el término genérico que contempla los derechos concedidos a los autores de obras literarias, artísticas, científicas, etc. El derecho de copia (copyright) se ocupa de los aspectos económicos o patrimoniales para la explotación de la obra intelectual y de las fotocopias ilícitas. La propiedad intelectual se refiere al conjunto de normas jurídicas que regulan lo concerniente a patentes, marcas, derechos de autor, etc. Jurídicamente es la noción más amplia que abarca los derechos de autor y los de propiedad industrial. 
contenido y desarrolladores de antologías empleadas en la educación virtual, así como para alumnos y usuarios de información contenida en distintos medios. De los autores sobre educación a distancia consultados sólo mencionan el derecho de autor superficialmente, incluso en ocasiones ni siquiera lo aluden, por lo que se consideró conveniente retomarlo por la cuestión del desarrollo de materiales didácticos.

Con frecuencia se dice que los materiales didácticos para la educación virtual representan una dimensión necesaria de dicha modalidad, en consecuencia, independientemente del tipo de material que se realice, se ha de acudir a fuentes documentales impresas o digitales para sustentar conceptos, teorías, vertientes ideológicas, modelos y demás. No obstante; al atender los términos del derecho de autor conforme lo requiera el contenido del material didáctico conviene prever que la producción y difusión de documentos digitales de carácter científico por las redes de teleproceso ha ocasionado varios problemas en cuanto a la calidad de su contenido y la visión económica de editores y libreros, que por lo general, se orienta a propósitos de carácter financiero. Esto se traduce en desventajas para los autores de materiales didácticos, por lo tanto, la biblioteca tiene que prever alternativas para el derecho de autor y los costos de fotocopia.

En este incipiente siglo XXI se advierte que las redes de teleproceso han revolucionado el acceso, consulta, navegación y uso de diversas obras, ya que cada vez más autores de contenido, de antologías y alumnos tienen libre acceso a la información disponible vía Internet. Hoy, las TIC borran las fronteras de distancia y tiempo para recuperar información de circulación libre. Sin embargo, los actores de los procesos educativos virtuales, creen que se distinguen dos tipos de la información disponible en la red: la gratuita y la remunerada.

Esta última es, por lo general, la que produce la investigación y, en consecuencia, ofrece calidad de contenido; se controla por medio de software, que funge de interfaz en el almacenamiento y recuperación de la documentación en línea. Este tipo de información se vincula con el comercio electrónico, consistente en la contratación de servicios de información vía red, lo que conlleva a la recuperación de documentos digitales, mediante una remuneración económica que 
libera la obtención del documento específico. No obstante, día con día aparecen nuevos programas de cómputo para la protección de contenidos académicos y de investigación de alto nivel; no obstante, la piratería de información es un asunto cotidiano.

Desde los noventa, cuando se incrementaron las propuestas educativas virtuales, hubo mayor incertidumbre del futuro de los derechos de autor y los derechos de copia, o bien de las obras disponibles en diversos medios tecnológicos. Las figuras de los titulares de esos derechos y sus representantes, los maestros, investigadores y alumnos, se tornan vulnerables ante aspectos no previstos por la normatividad legal vigente, que pretende que el material protegido no se use sin autorización. Sin embargo, los autores de material didáctico para la educación virtual (potenciales poseedores de derechos de autor y derechos de copia), requieren normas de seguridad para acceder libremente a las fuentes documentales necesarias para las tareas relacionadas con desarrollo de contenidos. Para los derechos de autor relativos al uso de documentos digitales conviene mantener excepciones que aún tienen los impresos, siempre y cuando el uso de recursos informativos digitales se dirija a la investigación y a la educación sin fines de lucro.

Ante la necesidad de usar información digital, disponible en los entornos de red; es indispensable revisar y proponer marcos jurídicos nacionales e internacionales orientados a proteger los derechos de autor, los de copia y los derechos de los usuarios, en este caso, los autores de contenido.

Los derechos de autor no deben ser obstáculo para la creación de materiales para la educación virtual, ya sea en el desarrollo de textos ex profeso, en la preparación de antologías, en el desarrollo de recursos multimedia o en el uso de lecturas complementarias. Se dice que para no cometer infracciones en materia de propiedad intelectual en la educación virtual cuando se usan medios digitales, se han de atender los siguientes derechos:

1. El derecho a la reproducción de un trabajo.

2. El derecho a la preparación de trabajos derivados

3. El derecho a la distribución de copia y su venta.

4. El derecho a la presentación de un trabajo. 
5. El derecho a la exhibición y publicidad de un trabajo. ${ }^{15}$

Para ahondar más en este asunto, Dietz afirma que "[...] el concepto tradicional del derecho de autor no es anacrónico, pero sí corre el riesgo de fracasar si no va hasta el final de su propia lógica, que es la de un sistema jurídico que asegure la protección global del autorcreador". ${ }^{16}$ Sin embargo, habrá que atender el uso justo de las obras publicadas, sin soslayar los intereses de autores, editores, usuarios y bibliotecas. El derecho de autor debe armonizar el uso correcto de la información impresa y la documentación digital, estableciendo una distinción entre la propiedad material del soporte y la propiedad inmaterial del contenido.

En el caso de México, tales asuntos son objeto de análisis en el Instituto Mexicano de la Propiedad Intelectual (IMPI) y el Instituto Nacional de Derecho de Autor (INDA) instancias cuya función es la protección de la propiedad intelectual, basadas en la Ley Federal de Derechos de Autor, la cual "[...] contempla disposiciones importantes para combatir la piratería y la competencia desleal, [...] vigilar y sancionar aquellas conductas violatorias de algún derecho de autor o de derechos conexos, que impliquen alguna infracción en materia de comercio $[\ldots]]^{\prime 1}{ }^{17}$

La participación de México en la Organización Mundial de la Propiedad Intelectual (OMPI) ha fructificado en algunos tratados, entre los que destacan el Tratado de la OMPI sobre derechos de autor y derechos conexos (1999) y el Decreto del Tratado de la OMPI sobre Derechos de Autor relacionado con las publicaciones en Internet (2002).

15 “Copyright issues in Digital Distance Education". [en línea] http://www.tbr.state.tn.us/general_counsel/ip/Copyrigth\%in\%20in\%DE.htm [consultada:09/03/04]

16 Adolf, Dietz, citado en “Derecho de autor e industrias culturales”. Barra Mexicana, Colegio de Abogados, A.C. [en línea] http://www.google.com.mx/search?q= cache:hg6mX54OJscJ:www.bma.org.mx/ publicaciones/ediciones/nuevas/derecho /derechode.html+dietz+derecho+ autor $\&$ hl $=$ es\&ie $=$ UTF- 8 [consultada: 12/03/04]

17 Instituto Mexicano de la Propiedad Industrial, Informe anual 1999, México: El Instituto, 2000, p. 16. 
Este último decreto publicado en el Diario Oficial de la Federación del 15 de marzo de 2002, instituye las pautas internacionales con la finalidad de impedir el acceso no autorizado y la utilización indebida de las obras disponibles en red. Las facultades, estructura y disposiciones del decreto se enmarcan en que los autores dispondrán del amparo jurídico en cada uno de los estados contratantes, en contra de la distribución, alquiler comercial y comunicación al público de sus obras en los entornos digitales. ${ }^{18}$

Asimismo, el surgimiento de las "sociedades del conocimiento" como una expresión de los logros del desarrollo de la sociedad de la información, edificará necesariamente sus cimientos en los derechos humanos y en la libertad de expresión; en este sentido, el derecho a la educación y los derechos culturales se perfilan como esenciales, ya que "[...] el acceso a la información y al conocimiento del dominio público, con fines educativos y culturales deberá ser lo más amplio posible. La información tendrá que ser de alta calidad, diversificada y fiable, $[\ldots] " . .19$

No obstante lo complejo que resulta lo relacionado con el derecho de autor, se reconoce que en México se han hecho esfuerzos para avanzar al respecto, con el propósito de estar alertas en la actividad global de este asunto. Sin embargo, conviene preguntarse, ¿cómo pueden evitar infracciones los autores de material didáctico para la educación virtual y los alumnos de este tipo de programas educativos que requieren el uso de la información? En materia legislativa, se han establecido limitaciones y excepciones al derecho de autor; en ese sentido, a las bibliotecas y a otras unidades de información no lucrativas se han otorgado prerrogativas legales para reproducir determinadas obras con fines de consulta, asimismo tienen facultades para negociar con las editoriales los pagos de regalías justas para el uso de obras impresas y de documentos disponibles en medios digitales.

18 Jesús Francisco García Pérez. "Los derechos de autor, el entorno digital y los usuarios”, (Tesis de Maestría en Bibliotecología). México: FFyL, UNAM, 2004.

19 UNESCO, Consejo Ejecutivo. Contribución de la UNESCO a la cumbre mundial sobre la sociedad de la información, París: UNESCO, 2003, p. 2. 
De esta manera, las bibliotecas tradicionales y digitales se nutrirán de los avances que logre la sociedad del conocimiento con las nuevas propuestas legales sobre el derecho de autor, el derecho de copia y el derecho a la información, para incorporar los beneficios relacionados con el uso de recursos informativos digitales de obras protegidas o puestas en línea y así generar servicios informativos digitales. Una posibilidad para evitar infracciones en el derecho de autor consiste en que las bibliotecas operen con base en sitios protegidos para los autores, los tutores y los estudiantes, con el fin de obtener gratuitamente los documentos de su interés. En el desarrollo de servicios bibliotecarios, dirigidos a estos sujetos, es preferible estrechar vínculos con el programa educativo, el sustento bibliográfico que tengan las actividades de aprendizaje y la valoración de necesidades de información que exijan los distintos actores del aprendizaje.

Con esto quiero enfatizar que la vinculación de la biblioteca con autores de material didáctico, con tutores y alumnos de programas educativos virtuales, debe conducir a que ésta, los proteja de posibles violaciones del derecho de autor y el derecho de copia, situación que conlleva a que los bibliotecarios se comprometan en una permanente actualización de las disposiciones vigentes sobre derechos de autor y derechos de copia. En este sentido, cada actor del aprendizaje estará involucrado en lo que realmente le corresponde. Sin embargo, en los debates sobre estos asuntos hasta hoy, no se ha llegado a consensos y soluciones concretas. La situación se complica aún más con los recursos informativos digitales en entorno de red, debido a que las TIC plantean nuevas medidas legales. Se puede señalar que hasta nuestros días, la ley mexicana sobre derechos de autor en medios digitales es ambigua en varios aspectos, situación que presenta desventajas en cuanto a la orientación mundial de los flujos de información vía redes de teleproceso.

En este sentido, los bibliotecarios deben hacer conscientes a los autores de material didáctico, tutores y alumnos de propuestas educativas virtuales acerca de la conveniencia de su asesoría, con el fin de evitar cualquier anomalía legal derivada del derecho de autor o del derecho de copia. De ahí que en toda propuesta de servicios bibliotecarios, entre la que se incluye la asesoría sobre derechos de autor, es 
necesario reflexionar sobre el futuro de la documentación digital, ya que parece tener posibilidades de rescatar uno de los principios del derecho de autor y del derecho de copia: poner en contacto a los autores y sus lectores, sin el embrollo de leyes inconclusas o sin actualizar, así como el proteccionismo excesivo de editores y libreros. En este sentido, legisladores, editores, autores de contenido, bibliotecarios y especialistas en información, tienen mucho que aportar en pro de los derechos de autor y el derecho de copia aplicados en la elaboración de materiales didácticos y en la consulta de recursos informativos digitales dentro de la educación virtual del presente siglo.

\section{TECNOLOGÍAS DE INFORMACIÓN Y COMUNICACIÓN EN EL DESARROLLO DE MATERIALES DIDÁCTICOS}

Con la aparición de las TIC, han tenido efecto diversas transformaciones en las tareas del diseño y desarrollo de materiales didácticos para la educación virtual. El uso de las TIC se orienta principalmente a fortalecer la comunicación entre el tutor y el alumno, y en el diseño de materiales didácticos atractivos y con posibilidades de interacción.

Aún así, la proliferación de tecnologías exige un análisis cuidadoso del posible uso que se les dará. Es conveniente que su evaluación se oriente sobre todo a su función pedagógica, relacionada con los requerimientos educativos determinados por la población de alumnos a los que enfoca la oferta educativa. Según EDUCADIS "[...]los medios visuales, auditivos, audiovisuales e informáticos imponen ciertas características a los mensajes". ${ }^{20}$ Esto se refleja en las diferencias existentes entre un material impreso y su transmisión a través de un video, por televisión o Internet. En cada caso, la relación de los destinatarios con los medios asume características distintas, lo que condiciona la estructura de los contenidos.

Una característica de los medios audiovisuales es su inmediatez, la redundancia y repetición, inapropiados para los medios impresos.

20 EDUCADIS, Op. cit, http://www.educadis.com.ar/mymath.htm 
Esto es así porque mientras los medios audiovisuales se distribuyen en el tiempo haciendo más lógica la reiteración, los impresos lo hacen en el espacio al permanecer fijos y completos en el tiempo, los mensajes escritos hacen que la redundancia y la repetición sean consideradas tediosas cuando no incorrectas. 21

Asimismo, difiere en la manera en que las personas inciden en los distintos medios, por ejemplo, leer un texto impreso determina el dominio de habilidades lectoras, se puede interrumpir la lectura en el momento que se desee, o iniciar la relectura inmediata de las partes del texto que más llamó la atención. En cambio, para la lectura en una computadora, implica habilidades de apropiación de tecnologías de información, habilidades de lectura en pantalla y manejo de hipertexto para, en su momento, llevar a cabo la lectura no secuencial, sin perder el contenido integral del documento digital. En consecuencia, el desarrollo de material didáctico en formato digital supone prever un alto grado de interacción con el alumno, en comparación con el texto impreso.

Con base en lo anterior, se puede señalar que una apropiada selección de contenidos y de medios tecnológicos portadores del mismo debe considerar, entre otras variables, las siguientes:

1. Objetivos de la propuesta educativa.

2. Características de los contenidos a transmitir.

3. Perfil de los alumnos en cuanto a hábitos, destrezas y conocimientos tecnológicos requeridos por la propuesta educativa.

4. Facilidades de uso que ofrecen los medios a los destinatarios y la tecnología destinada al curso en cuestión.

En cuanto a los recursos tecnológicos, convendría que la institución sede realice un estudio de los medios disponibles para su uso en el proyecto de educación virtual, debido a que los diseñadores de programas de esta naturaleza omiten o soslayan que la función pedagógica no se puede atribuir a un solo medio. Esto se advierte en diversas propuestas educativas en operación que optan por la combinación de medios. Sobre esto EDUCADIS responde:

21 Ibid., http://www.educadis.com.ar/mymath.htm 
[...]respecto a la cobertura geográfica y poblacional que alcanzará el proyecto, hay que tener en cuenta que proyectos multitudinarios con una gran dispersión geográfica tendrán más necesidad de incorporar medios masivos y de gran alcance que aquellos proyectos acotados en el espacio y en la población. ${ }^{22}$

También la duración del programa es un criterio de selección de los medios apropiados para la propuesta educativa de que se trate. La experiencia indica que en cursos de larga duración se justifica la elección de medios complejos, pues su uso intensivo amortiza el costobeneficio de la inversión, tanto tecnológica como económica. En cambio, en un programa de corta duración, conviene recurrir a medios poco costosos (por ejemplo, los impresos). Se debe hacer énfasis en que una apropiada selección de los medios por emplear en determinada propuesta educativa virtual tiene que contemplar que no será pertinente la elección de ninguno que no garantice el logro de los objetivos planteados, o que no se adapte a la idiosincrasia y disponibilidad tecnológica de los destinatarios. Hoy, los medios de uso más frecuente en la educación a distancia son los que se enuncian enseguida:

\section{Impresos}

Guías de autoaprendizaje, manuales, fotografías, láminas y demás. Por su versatilidad y bajo costo, estos materiales son los más utilizados en la educación a distancia, sin embargo, con el advenimiento de tecnologías de red, en diversos países han disminuido su uso. Auditivos.

Generalmente son programas de radio, audiocasetes, audioconferencias, teléfono y fax. En la educación a distancia, la audioconferencia (telefonía analógica) se considera la forma más rudimentaria de las telecomunicaciones con fines pedagógicos en entornos virtuales.

\section{Audiovisuales}

Programas de televisión, videos y videoconferencias. Videoconferencias

Utiliza cámaras de video y monitores en cada centro enlazado, por

22 Ibid., http://www.educadis.com.ar/mymath.htm 
lo tanto, los participantes pueden verse y escucharse en tiempo real, es factible mostrar imágenes relacionadas al tema tratado. En general, esta tecnología resulta cara y defectuosa ya que se proyectan imágenes de baja definición, aun cuando los tecnólogos argumentan que los defectos actuales de la videoconferencia mejorarán notablemente con el uso masivo de Internet 2.

\section{Informáticos}

Se refieren al software educativo, tutoriales y sistemas multimedia. Tecnologías de información y comunicación.

Se relacionan con la Internet (aulas virtuales, correo electrónico, foros de discusión, web, chat, videoconferencia digital, televisión interactiva, etcétera.)

Estos medios se emplean en diversas propuestas educativas a distancia, aunque los materiales impresos siguen teniendo mucha aceptación en sistemas de educación a distancia, dada su facilidad de manipulación y los costos, que por lo general son más bajos comparados con las exigencias de otros medios. En consecuencia, los que han surgido o se han enriquecido con el advenimiento de las TIC experimentan nuevas aplicaciones, de las que ya se cuenta con experiencias significativas, algunas relacionadas con el software educativo y los desarrollos de aulas virtuales orientados a la educación en línea; por lo tanto, son fenómenos que estarán presentes con mayor énfasis en la educación del siglo que comienza.

\section{Tendencias en el desarrollo de software educativo}

\section{Instrucción asistida por computadora}

Desde que se iniciaron las aplicaciones de software educativo en la enseñanza, se han explorado múltiples formas de presentar y comunicar los contenidos del aprendizaje, la corriente relacionada con la Instrucción Asistida por Computadora. IAC. (Computer Assisted Instruction, CAI) ha recorrido un largo camino y, en consecuencia, ha acumulado mucha y muy útil experiencia para nuevos desarrollos y aplicaciones. La generación de programas de cómputo de esta naturaleza se ocupa de la construcción de esquemas lógicos versátiles, 
cuyo propósito principal consiste en incidir en un aprendizaje interactivo y participativo, en el que el alumno sea el elemento principal en la construcción de su aprendizaje; rasgos que se perciben en los primeros desarrollos de tutoriales influidos por una orientación de carácter psicológico.

Okuyama señala que la IAC vuelve a los estudiantes más entusiastas en sus actividades, ayudándoles a disfrutar de éstas; posibilita que estudien conforme a su propio grado de progreso; favorece la retroalimentación de lecciones previas para estudiar nuevamente y asegurar la asimilación de aquéllas. ${ }^{23}$ Gurdak añade que en la enseñanza de esta naturaleza: el estudiante aprende a enseñarse, el estudiante progresa a su propio ritmo, el instructor se convierte en un conductor [...], en lugar de un lector o abastecedor de información, el instructor genera más interacción con los estudiantes antes que una relación con todo el grupo. ${ }^{24}$

En cuanto a las características de mayor relevancia de los programas de software educativo que utilizan como apoyo la computadora, Hannafin y Peck aportan la clasificación del cuadro mostrado en la página siguiente (Cuadro 1).

En relación con la clasificación anotada, diversos estudiosos han señalado que estos principios son limitados. También se dice que los esquemas actuales sobre el aprendizaje como un hecho (conductismo) y el aprendizaje como proceso (cognoscitivismo) son ya precarios para modelar el aprendizaje particular de los sujetos. Así, en relación con la identificación de los tipos de programas de uso educativo, varios autores coinciden en señalar que la clasificación de los programas de esta naturaleza no es tarea fácil por la carencia de parámetros apropiados que permitan clasificar de manera ampliamente aceptable. No obstante, Rosas aporta una clasificación y explicación

23 K. Okuyama, citado por Leobardo Rosas, El cómputo en la enseñanza (diplomado). La computadora en actividades docentes, México: UNAM, DGSCA, 1998, p. 14.

24 D. M. Gurdak, citado por Leobardo Rosas. El cómputo en la enseñanza (diplomado). La computadora en actividades docentes. México: UNAM, DGSCA, 1998, p. 15. 


\begin{tabular}{|c|c|c|}
\hline \multicolumn{3}{|c|}{$\begin{array}{l}\text { Cuadro } 1 \\
\text { Caraterísticas de programas educativos en computadora }\end{array}$} \\
\hline \multicolumn{3}{|c|}{$\begin{array}{l}\text { CARACTERISTICAS DE PROGRAMAS } \\
\text { EDUCATIVOS EN COMPUTADORA }\end{array}$} \\
\hline Principios conductistas & Principios cognoscitivistas & $\begin{array}{l}\text { Otros principios } \\
\text { emanados del con- } \\
\text { ductismo y del cog- } \\
\text { noscitivismo }\end{array}$ \\
\hline $\begin{array}{l}\text { Contigüidad. La respuesta debe seguir } \\
\text { al estímulo sin demora. }\end{array}$ & $\begin{array}{l}\text { Orientación y recuerdo. El apren- } \\
\text { dizaje involucra la síntesis de in- } \\
\text { formación previa que debe ser } \\
\text { recuperada para la memoria } \\
\text { activa. }\end{array}$ & $\begin{array}{l}\text { Tiempo académico } \\
\text { de aprendizaje. El in- } \\
\text { cremento de tiempo } \\
\text { que un estudiante } \\
\text { sostiene vinculación } \\
\text { activa en actividades } \\
\text { instruccionales pro- } \\
\text { vechosas puede } \\
\text { generar mayor } \\
\text { aprendizaje. }\end{array}$ \\
\hline $\begin{array}{l}\text { Retroalimentación y reforzamiento. El } \\
\text { conocimiento acerca de lo correcto de } \\
\text { la respuesta contribuye al aprendizaje. }\end{array}$ & $\begin{array}{l}\text { Individualización. El aprendizaje } \\
\text { puede ser más eficiente cuando } \\
\text { la instrucción se adapta a las ne- } \\
\text { cesidades y perfiles de los apren- } \\
\text { dizajes individuales. }\end{array}$ & \\
\hline $\begin{array}{l}\text { Indicación y desvanecimiento. El apren- } \\
\text { dizaje puede lograrse conduciendo al } \\
\text { estudiante hacia la respuesta deseada } \\
\text { bajo condiciones de guía o indicación } \\
\text { decreciente. }\end{array}$ & & \\
\hline
\end{tabular}

Fuente. HANNAFIN, M. J. y K.L. Peck. The design, development and evaluation of instructional software, New York: USA, Macmillan/Collier Macmillan.

de los diferentes usos educativos de la computadora, que en este apartado se describen como de gran relevancia:

1. Herramientas de productividad.

2. Programas secuenciales sin interacción.

3. Programas secuenciales con interacción. 
4. Programas de estructura ramificada y cíclica.

5. Simuladores.

6. Mecanismos robóticos. ${ }^{25}$

Cada uno de estos usos tiene características particulares que inciden en el acto educativo, por lo tanto se incluye una explicación mínima a partir de lo expuesto por Rosas:

Herramientas de productividad

Se estructuran por medio de diferentes programas de aplicación, diseñados para resolver problemas específicos o para automatizar tareas, tales como procesadores de texto, manejadores de bases de datos, hojas de cálculo, programas estadísticos, programas de gráficos y programas de dibujo, entre otros.

Programas secuenciales sin interacción

Su finalidad es sólo presentar información en una secuencia lineal preestablecida, como presentaciones de diapositivas, diaporamas y video. Emplear la computadora de esta forma generalmente es incorrecto, ya que su utilidad educativa es pobre y hasta ahora es un recurso costoso en relación con otros medios.

Programas secuenciales con interacción

Presentan información estructurada linealmente, buscando la interacción con el usuario; este tipo de programas pertenecen a los denominados "pasa páginas", presentadores y programas de ensenanza programada.

Los Pasa páginas

Despliegan información en forma lineal, se avanza de pantalla en pantalla, la información puede estar constituida por texto, imagen, sonido, animación y/o video. Su uso es generalmente individual, plantea necesidades amplias de equipo de computo. En cuanto a las diapositivas y el video se puede señalar que han logrado gran aceptación debido a que facilitan la integración de diversos recursos:

25 L. Rosas. El cómputo en la enseñanza, La computadora en actividades docentes. México: UNAM, DGSCA, 1998. p. 10-14. [La explicación de cada tipo de programas se basó principalmente en Rosas, para mayor abundamiento al respecto se recomienda sea consultado]. 
texto, imagen, sonido, animación, video, a partir de la misma herramienta. Esto hace que se considere como una alternativa accesible en costo para el desarrollo de material audiovisual.

Programas de estructura ramificada y cíclica

Presentan información siguiendo rutas múltiples a través de la navegación de contenidos, a estos programas pertenecen los tutoriales de navegación libre y los programas de hipertexto. La navegación libre supone una visión estructurada del conocimiento del usuario, por lo que su diseño consume una cantidad de tiempo considerable. Los tutoriales de navegación libre utilizan herramientas variadas y buscan generar situaciones en las que el alumno debe resolver determinados problemas.

\section{Simuladores}

Como su nombre lo indica, simulan situaciones o fenómenos para que el usuario interactúe u obtenga datos sobre éstos; su uso es múltiple, ya que pueden utilizarse ante grupos o bien integrarse a sesiones de programas tutoriales.

\section{Mecanismos robóticos}

Se trata de un conjunto de programas y mecanismos conectados a la computadora para proporcionar información en tiempo real; permiten la manipulación directa y la retroalimentación inmediata.

No obstante el intenso movimiento en el desarrollo de software de uso educativo, se dice que la investigación realizada en torno al aprendizaje, poco es lo que se sabe de éste para que se incorpore efectivamente en entornos virtuales. En cuanto a este planteamiento, cabe señalar que hoy existen diversos proyectos de investigación en inteligencia artificial y sistemas expertos. La intención pedagógica de estas tecnologías intenta incidir en un aprendizaje interactivo y de mayor participación en el que el alumno sea el sujeto principal en la construcción de su aprendizaje (aprendizaje autónomo). Ésta y otras posibilidades de software se examinan en los apartados que siguen.

\section{Programas tutoriales}

La enseñanza virtual utiliza tutoriales con la idea de explotar las facilidades de cómputo en los procesos de aprendizaje individual o 
grupalmente, tal propósito es de sumo interés por la facilidad de operar tutoriales en un sinnúmero de computadoras, propiciando así la interactividad entre los contenidos del aprendizaje y los alumnos. Las facilidades de las TIC han hecho posible que los tutoriales estén disponibles en la Internet. Sin embargo, la comunicación entre usuario y tutorial exige la programación de la interfaz que hace posible la interacción entre el alumno y los contenidos por aprender. El diseño de la interfaz hombre-máquina requiere pensar en las relaciones entre ergonomía (hombre-máquina) a nivel de hardware y de software (programación y comunicación). La ergonomía en el hardware se refiere a la selección de los dispositivos de entrada/salida y al diseño de formas de uso, suministro y obtención de resultados a partir de la computadora. En este sentido, la ergonomía en programación se aplica a la especificación de los elementos del procesador y de las tareas de soporte. La ergonomía en la comunicación informática alude al diseño de los ambientes por donde transitará el alumno. Así, con base en la interfaz, la comunicación se realiza a través de la interactividad mediante elementos textuales, gráficos y sonoros.

Hasta hoy un porcentaje importante en el desarrollo de software educativo corresponde a los llamados tutoriales. Estos programas intentan reproducir la forma de enseñanza basada en el diálogo con un tutor, a través de preguntas que propicien la reflexión en el alumno, que construya por sí mismo las respuestas correctas y obtenga conocimiento significativo a partir del aprendizaje de los contenidos objeto de estudio. Así, las actividades se controlan con la computadora, a partir de la cual resulta factible implantar esquemas de aprendizaje complejo y de mejor adaptación para el alumno, utilizando interfaces para el diagnóstico y la corrección de errores en las fases de respuesta y reaprendizaje, lo cual evita que se acumulen los errores.

En la producción de tutoriales se emplean diversas estrategias, sin embargo, éstas son válidas si se logra un buen programa de esta naturaleza, en cuyo caso debe permitir, según Vaquero Sánchez, alcanzar una serie de objetivos pedagógicos fundamentales:

1. Tomar en cuenta las diferencias individuales entre alumnos.

2. Ofrecer orientación inmediata a las respuestas, de acuerdo al principio de actividad, intentando cautivar la atención del alumno. 
3. Sustituir al profesor en las tareas más rutinarias, permitiéndole dedicar más tiempo al alumno[...]. ${ }^{26}$

El enfoque cognitivo difiere del conductista en que su objetivo es una descripción cualitativa de los procesos involucrados en la conducta cognitiva del individuo. Esta descripción se materializa en programas de cómputo que simulan aspectos de la conducta del sujeto, especificándose en estas simulaciones tanto las estructuras de datos, como los algoritmos con los que se reproducen los procesos cognitivos del ser humano.

Los programas de este tipo basados en inteligencia artificial suelen adoptar la forma de tutoriales, en los que el alumno toma la iniciativa. Además, la comunicación con la computadora se realiza en un subconjunto más o menos amplio del lenguaje natural:

Las diferencias de mayor evidencia con respecto a los programas tutoriales convencionales, radican en que en su diseño conduce a que el alumno proporcione la respuesta correcta mediante una serie de estímulos. En cambio, un programa tutorial inteligente intenta simular alguna de las capacidades cognitivas del alumno y utilizar los resultados de esta simulación como base de las decisiones pedagógicas a tomar. ${ }^{27}$

En cuanto al modo de aprendizaje, existe la tendencia actual a producir tutoriales que aprovechan las técnicas de control de la iniciativa, desde las totalmente conductistas, hasta las de libre iniciativa del alumno, con representación y explotación de todo tipo de conocimiento. Los resultados del paradigma constructivista en la investigación psicopedagógica e informática son alentadores, puesto que permiten vislumbrar nuevos enfoques del aprendizaje y la representación de contenidos.

26 Antonio Vaquero Sánchez. "Las TIC para la enseñanza, la formación y el aprendizaje" [en línea].

http://www.ati.es/PUBLICACIONES/novatica/1998/132/anvaq132.html [consultada:18/06/03]

27 Ibid. 


\section{Simulaciones y micromundos}

Esta denominación corresponde al concepto de entornos libres en los que el control de la totalidad del proceso de aprendizaje corresponde al alumno, a diferencia de los tutoriales, en los cuales la computadora controla gran parte del proceso de aprendizaje. En este tipo de software, la máquina se usa para crear un entorno simulado o un micromundo que el alumno debe descubrir o aprender a utilizar, mediante la exploración y la experimentación de ese entorno. En estos programas, la computadora funge como herramienta a disposición del alumno para potenciar el desarrollo de sus habilidades cognitivas.

Para los investigadores que defienden este enfoque "[...]la revolución educativa se basa tanto en la capacidad de la computadora para procesar conocimiento, como en los cambios que su utilización [...]puede provocar en la mente del alumno". ${ }^{28}$ Así, los educadores han advertido que la simulación en el proceso de aprendizaje es imprescindible, principalmente cuando se trata de generar habilidades en determinados aspectos disciplinarios, por ejemplo, desarrollo de habilidades en la catalogación y clasificación de recursos digitales, diseño de sistemas de metadatos, desarrollo de estructuras de tesauros, manejo de estructuras de lenguajes de marcado, etcétera.

\section{Hipertexto - bipermedia}

Las técnicas de creación de programas educativos basados en hipertexto y en hipermedia indican que para alcanzar el objetivo en el proceso de aprendizaje se necesita acceder adecuada y oportunamente a la información y al conocimiento. Se comenta que el aprendizaje a través de hipermedia es eminentemente constructivista, lo cual determina que el alumno tenga iniciativa para explotar entornos de conocimiento en presentaciones atractivas y dinámicas, sin embargo, Vaquero objeta que: "[...] ]el acceso libre a la información contenida en un entorno de hipermedia presenta el problema de que el alumno se pueda perder, sin saber por dónde proseguir su itinerario de acceso a dicha información." ${ }^{29}$ Sin embargo, esta afirmación aliente a los diseñadores

28 Ibid.

29 Ibid 
de hipertexto e hipermedia en busca de soluciones tecnológicas y de lógica algorítmica que eviten construir un laberinto, en lugar de un sistema estructurado de acuerdo al aprendizaje que se persiga, lo cual implica pensar en el diseño, en múltiples ligas que permitan llegar al conocimiento de manera lógica y consistente. Los sistemas de esta naturaleza -apuntan otros especialistas- constituyen un excelente laboratorio para las teorías cognitivas y para encontrar nuevos problemas en los que se centra la investigación en ciencia cognitiva, algunos de hecho se relacionan con el aprendizaje constructivista. Se observa que las tecnologías del hipertexto e hipermedia han logrado aplicaciones interesantes para la educación virtual.

Se entiende, pues, que el creciente uso de las TIC en la enseñanza virtual es complejo, por lo que los resultados que se esperen de aquéllas deben ser a largo plazo y en el marco de la revolución tecnológica que transforma a toda la sociedad. La tendencia actual en la educación virtual es que la información con valor académico de apoyo a la enseñanza se halle disponible en la Internet. Aun así, la información se requiere para múltiples propósitos sociales, uno de los principales, la educación.

Otros autores abundan en que, en un futuro cercano, el desarrollo de la telemática facilitará más la transmisión vía redes de teleproceso de multimedios en tiempo real. Sobre esto, Loyo Varela ha señalado que "[...] con la utilización de agentes cooperativos implantados en computadoras, multimedios y [...] sistemas de enseñanza asistida por computadora, se incrementará la participación interactiva y la interacción directa de los actores del proceso de enseñanza-aprendizaje". ${ }^{30}$ Estos propósitos se perfilan en la tecnología más reciente relacionada con objetos de aprendizaje.

Por lo anterior, se dice que las TIC ofrecen diversas posibilidades para el diseño de materiales didácticos docentes y de investigación. Esto pone de manifiesto que la incorporación de las TIC en la educación virtual es el requerimiento de una adecuación teórica dirigida

30 C. Loyo Varela y V.G. Sánchez. "La telemática y la educación a distancia”, en Soluciones Avanzadas, ago. 1995, vol. 4, no. 24, [en línea]

http://www.lania.mx/nivel2/divulgacion.html [consultada:10/01/04] 
sobre todo al desarrollo de conceptos, definición de estructuras y normas para la construcción de materiales didácticos con los que se garantice el aprendizaje y la adquisición de conocimiento significativo por parte del alumno. Tales propósitos se entienden en función de la construcción de modelos integrales en línea, en tanto dispongan de bases de conocimiento flexibles y que muestren el uso pertinente de la teoría subyacente en la educación virtual. Nos percatamos que esta clase de educación requiere de investigación que le ayude a lograr el tan deseado diálogo académico de calidad y avanzar hacia la formación de un alumno más autónomo. En ese sentido, coincidimos con García Aretio cuando opina que el "[...]diálogo didáctico mediado" 31 requiere enfatizar la necesaria comunicación entre los sujetos del aprendizaje y los tutores, conduciendo al uso, entre otros recursos, de soportes de contenido. El cuadro mostrado en la página siguiente (Figura 3) refleja sucintamente la diversidad de medios que empleados en programas de educación virtual, algunos de éstos utilizados actualmente por diversas instituciones educativas en el marco mundial.

En la parte superior del cuadro se ilustra el Diálogo simulado asíncrono, a través del cual se establece la primera comunicación de doble vía entre la institución que enseña a través de los materiales y el estudiante que aprende. Así, la primera diseña y produce los materiales de instrucción, el contenido puede almacenarse en medios impresos, de audio (radio), de video (televisión), informáticos o en soporte web. Una vez producidos, se realiza su distribución. El diálogo simulado no coincide en el tiempo del estudio de los materiales didácticos ni en la emisión del mensaje ni en la respuesta del receptor.

En cambio, como se ilustra en la parte inferior del esquema, el Diálogo real síncrono-asíncrono, a través de los materiales y la disposición de diversos canales de comunicación, se encuentra disponible para los estudiantes permanente, abierta y flexiblemente, el estudiante no se limita a responder, sino que también pregunta o inicia determinado diálogo con el apoyo de un tutor. Así, el diálogo real

31 García Aretio, Op. cit., p. 41. 
Figura 3

Diálogo didáctico mediado en la educación a distancia

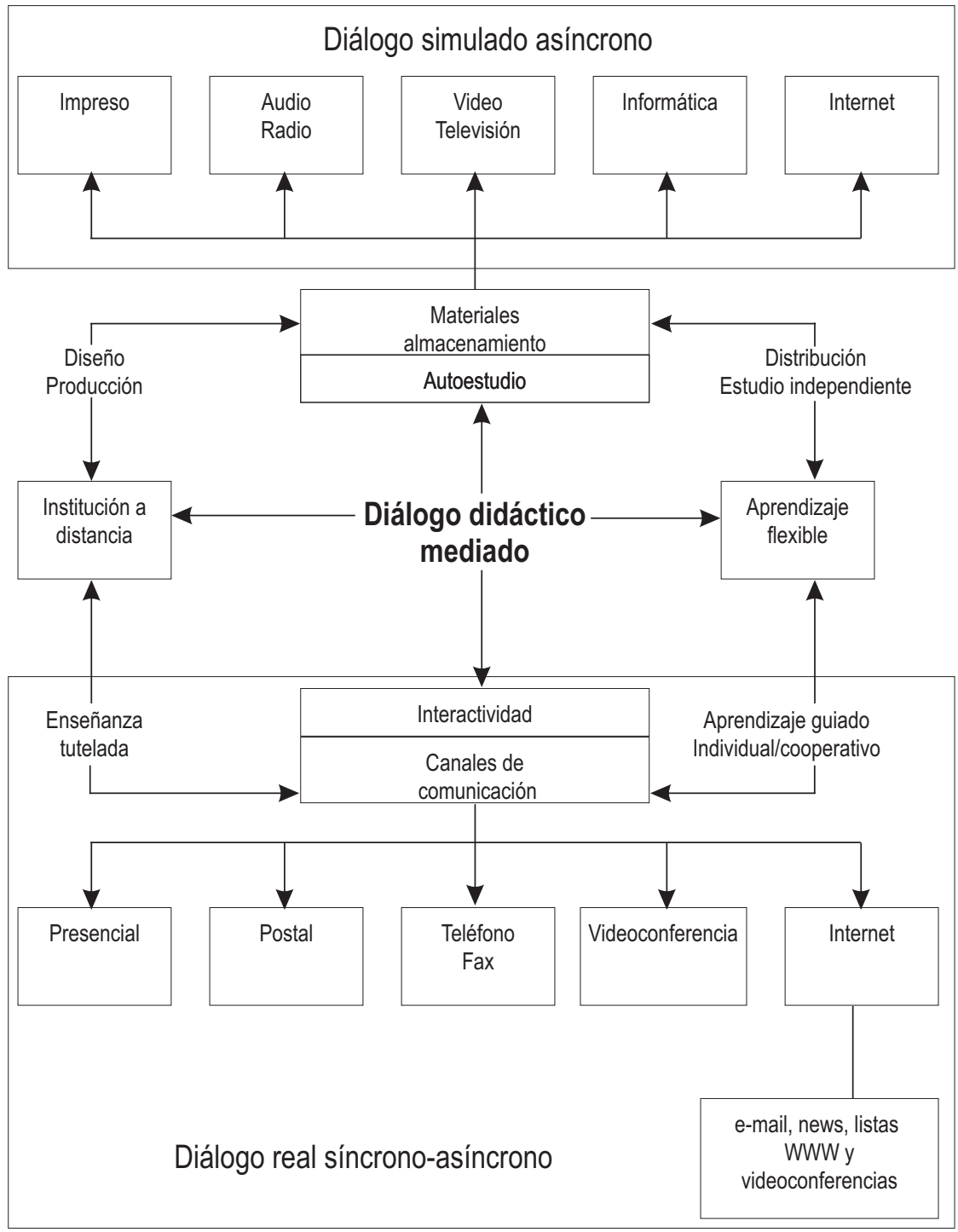

Fuente: Lorenzo García Aretio. La educación a distancia: de la teoría a la práctica. España: Ariel Educación, 2001, p. 110. 
puede producirse de forma síncrona (presencial, telefónica, videoconferencia, chat) o asíncrona (correo electrónico, fax, Internet). En definitiva, este diálogo didáctico mediado intenta producir un aprendizaje guiado por el docente y, según los casos, compartido con los pares utilizando tecnologías interactivas.

En este tipo de diálogo el conocimiento en el aprendizaje colaborativo se concibe como constructo social, retomado desde la interacción social de todos los miembros de la comunidad de aprendizaje. La teoría del diálogo didáctico mediado basa su propuesta en la comunicación a través de los medios, que, cuando se trata de los materiales, se apoya en el autoestudio; si se trata de las vías de comunicación, en la interactividad vertical y horizontal tutor-alumno o bien alumno-alumno.

En este contexto, las TIC ofrecen un gran potencial en el desarrollo de materiales didácticos para la educación virtual, entre las que se encuentran las redes de datos, con una repercusión notable en la comunicación; las redes digitales de apoyo a los flujos de información locales e internacionales orientados a servicios de datos integrados y las bibliotecas digitales, entre otros.

Respecto de la informática, se advierte un notable avance en hardware y software, también los recursos informáticos de memoria y velocidad para la presentación de información gráfica de todo tipo, la producción de imágenes estáticas o animadas, escenas animadas, la aplicación de sonido, voz o cualquier medio de comunicación procesable por un sistema informático. De igual modo el desarrollo de interfaces usuario-máquina se orientan cada vez más a facilitar la comunicación y el uso de la información a los sujetos ubicados en diversos entornos geográficos.

Antes de los años noventa, el concepto multimedia tuvo como fundamento la enseñanza basada en el uso de diversos recursos, como texto, voz, música, imágenes (fijas o en movimiento) mediante recursos aislados como el audio, el video y la computadora. De entonces a la fecha se denomina multimedia a la integración de diversos recursos en un solo medio o plataforma, por ejemplo, la generación de aulas virtuales en donde se incorpora material didáctico que contenga texto, 
gráficos, imágenes y sonido. La comunicación en forma interactiva enriquece los procesos educativos de los sujetos del aprendizaje.

Igualmente el ideal tecnológico de lograr la estructura de la web semántica, que se propone realizar que las páginas web dejen de ser cadenas de caracteres para las computadoras y se conviertan en textos provistos de semántica. De volverse realidad en el futuro inmediato conllevaría a nuevos replanteamientos en los aprendizajes y el saber, en consecuencia, instituciones, tutores y alumnos continuarán permanentemente en la línea de la educación para toda la vida, principio surgido en el seno de la UNESCO.

El largo camino que han recorrido las universidades en la oferta de programas de educación a distancia y su corto andar en la educación virtual, les ha otorgado experiencia de toda laya. El desarrollo de contenidos didácticos, luchar para que la modalidad a distancia se reconozca y respete en la sociedad, y la aventura en el uso de medios de toda clase; asimismo, se ha constatado que el uso de contenidos y de medios de alta calidad propicia el diálogo académico entre los sujetos del aprendizaje, la interacción se dinamiza entre el estudiante, el material didáctico y el tutor; se amplía el horizonte y el nivel del proceso de enseñanza-aprendizaje adquiere mayor nivel académico.

Sin embargo, un asunto sin resolver por las instituciones de EAD tiene que ver con la búsqueda de un alumno con alto nivel de autonomía, se argumenta que con base en materiales de instrucción y los diversos medios de comunicación es factible formar alumnos con estándares elevados de autonomía; empero, en muchos casos se ha interpretado que esa "autonomía" se ve más bien como pretexto para que instituciones y tutores eludan responsabilidades de atención personalizada o grupal de los alumnos. En todo caso, los hechos revelan que los alumnos a distancia requieren de una comunicación constante con sus tutores, de lo contrario caen en situaciones de soledad e impotencia por no poder resolver dudas en el inmediato corto plazo. Lo anterior incide en la tentación de desertar del programa por falta de atención o de motivación, tareas que son inherentes a los tutores de cualquier propuesta educativa virtual. 
El concepto de alumno autónomo, afirma Ross, “[...]implica cambios en el sistema personal de valores (apertura a las ideas nuevas y replanteamiento de las anteriores), en los comportamientos (automotivación) y el desarrollo de nuevas capacidades (para organizar el tiempo, para adquirir técnicas de estudio, para comprender el porqué de las dificultades, para adquirir un pensamiento crítico y lateral, así como técnica de investigación y de trabajo en bibliotecas)" ${ }^{32} \mathrm{Se}$ puede decir al respecto que esta búsqueda de ideales está presente en la historia de la $\mathrm{EAD}$, pues diversos estudiosos de reconocido prestigio han externado su opinión y preocupación por incidir planificadamente en lograr alumnos autónomos, sin menoscabo de su nivel académico. Esto, naturalmente, conlleva, entre otros aspectos, a la toma de decisiones institucionales que privilegien la elaboración de materiales de instrucción de buena calidad y la efectividad pedagógica frente a la conveniencia administrativa.

La institución sede de programas virtuales debe comprometerse en solventar tales problemas y prepararse más y más para avanzar hacia el logro del alumno autónomo, aspecto que aun con los apoyos didácticos cada vez más sofisticados y los diversos canales tecnológicos de comunicación existentes, representa un reto complejo.

Finalmente, quiero subrayar que en este capítulo se corroboró que la educación a distancia apela a diversos aspectos para llegar al aprendizaje significativo de los actores que participan en la misma. A lo largo del tiempo, el desarrollo de materiales didácticos y de soportes de contenido ha mostrado características específicas, atendiendo a las épocas en que aparecieron, del soporte impreso, ahora vivimos el soporte digital y su uso en la Internet. La educación virtual utiliza plataformas que posibilitan el control de la matrícula, la tutoría a distancia en tiempo real o diferido, la entrega de materiales didácticos, la realización y entrega de las evaluaciones, la supervisión de las sesiones de aprendizaje, etcétera. Aun así, conviene preguntarse: ¿cómo se puede

32 Paul Ross. "Hacia una autonomía del alumno: nueva pauta para medir los logros de una institución de enseñanza abierta", en La educación a distancia en tiempos de cambios: nuevas generaciones, viejos conflictos, Madrid: Ediciones de la Torre, 1999, p. 45. 
incorporar la educación virtual a la enseñanza de la organización de recursos informativos digitales?. Su respuesta exige, indispensablemente, en principio, un acercamiento teórico de la educación bibliotecológica, considerando su vinculación con los requerimientos sociales y culturales del país de que se trate. Dicha tarea comprende la calidad sustentada en la enseñanza inter y multidisciplinaria, así como en la investigación científica; asimismo contemplar la innovación educativa a largo plazo es impostergable para insertar a los egresados en la competitividad que exige la internacionalización de la educación superior y la movilidad de profesionales, teniendo siempre en mente, entre otros aspectos, el desarrollo cultural y la cooperación en un mundo globalizado.

La enseñanza virtual y las TIC plantean nuevos fenómenos de estudio para la bibliotecología, puesto que las transformaciones tecnológicas operadas en el campo de las telecomunicaciones y la computación han generado cambios en las sociedades en sus formas de trabajo, maneras de interacción y de comunicación de grandes sectores sociales, así como en las necesidades del uso de información. De igual manera la bibliotecología, como cualquier otra ciencia, se halla frente al panorama y la oportunidad que le ofrece la educación virtual, por lo cual resulta indispensable, desde la investigación bibliotecológica, reflexionar y proponer nuevas formas de aprendizaje, basadas en tal modalidad educativa. Éstos y otros aspectos, se verán en el siguiente capítulo. 
III

Enseñanza virtual sobre la organización de recursos informativos digitales 



\section{LA BIBLIOTECOLOGÍA COMO DISCIPLINA DE REFERENCIA}

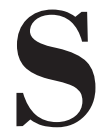

e asume que los elementos teóricos y metodológicos de la EAD revisados en los capítulos anteriores son inherentes a toda propuesta educativa relativa a la enseñanza en bibliotecología. Por lo tanto, en éste se reflexiona sobre los fenómenos relevantes de la disciplina, para estructurar un marco de referencia que dé sustento a la propuesta de la enseñanza virtual referente a la organización de recursos informativos digitales.

Se parte del hecho que la "[...]bibliotecología como disciplina autónoma existe desde el siglo XIX. No obstante, sus métodos, principios y teorías se enriquecen con diversidad de enfoques y diversidad de temas; primero, como una respuesta ante la revolución científica e industrial de finales del siglo XIX, y posteriormente como producto del estudio de los efectos de la revolución tecnológica de mediados del siglo XX [...]" ${ }^{1}$ A lo anterior, habrá que añadir que a finales del siglo XX e inicios del XXI los avances científicos y los desarrollos tecnológicos, han propiciado la aparición de nuevos fenómenos de estudio, repercutiendo en la enseñanza de esta disciplina.

1 Unam. Programa de Maestría y Doctorado en Bibliotecología y Estudios de la Información, México: UNAM, Facultad de Filosofía y Letras, División de Estudios de Posgrado, 1998, [en línea] http://www.filos.unam.mx:80/POSGRADO/programa/biblio.htm [consultada: 17/06/03]. 
Sin embargo, su propósito principal como "[...]ciencia que estudia el registro y flujo del conocimiento y de la información, así como la circulación social de los medios que la contienen para hacer posible su uso y organización", ${ }^{2}$ sigue vigente y puede aplicarse de manera cabal a su enseñanza presencial o a distancia. No obstante, su estudio, en cualquier modalidad educativa, exige meditar en el cúmulo de conocimientos de dicha disciplina y de su ejercicio. Por lo tanto, conviene tener presente que en la enseñanza de la bibliotecología deben atenderse sus fenómenos, principios y teorías, con la intención de que el alumno adquiera conocimiento sobre el desarrollo de la disciplina, los supuestos inherentes a ésta y el valor del conocimiento bibliotecológico en las sociedades usuarias de información.

Los fenómenos bibliotecológicos se presentan en entornos sociales específicos; y a través de su evolución se han generado instituciones sociales para la organización, preservación y difusión de la cultura -las bibliotecas- y que éstas, a lo largo del tiempo, han sido clasificadas en bibliotecas públicas, nacionales, universitarias, especializadas, centros de documentación o de información. Tal clasificación facilita definir precisamente las características de los servicios que proporcionan estas entidades. Asimismo, hay que considerar que desde hace algunos años, al referirse a aquéllas, suelen llamarse unidades de información. ${ }^{3}$ Con tal denominación, entre otros propósitos, se ha querido expandir la cobertura de acción del profesional con formación bibliotecológica.

Asimismo, las tareas de servicios bibliotecarios y de información realizados por cada tipo de biblioteca tienen incidencias sociales que se caracterizan atendiendo los escenarios sociales en los que se desenvuelven. Por ello, la clasificación citada facilita la identificación y

2 Ramiro Lafuente López y Estela Morales. "Reflexiones en torno a la enseñanza de la bibliotecología", en Investigación Bibliotecológica: archivonomía, bibliotecología e información vol. 6, no. 12, ene./jun. 1992, p. 25.

3 La denominación unidad de información abarca todo tipo de bibliotecas, centros de documentación, de información, archivos, editoriales, fuentes de información gubernamentales, asociaciones, etc. El término unidad de información, se usa en el Manual para sistemas y servicios de información de Pauline Atherton publicado por la UNESCO. 
precisión de las características y contenidos de los servicios dirigidos a grupos sociales específicos, atendiendo sus demandas y requerimientos de información. Los servicios bibliotecarios se generan a partir de la sistematización de colecciones documentales, siendo el catálogo el medio para la recuperación de documentos y, en consecuencia, el núcleo para establecer tales servicios.

Por otra parte, hay que advertir que la biblioteca digital, tendrá el requerimiento de considerar la evolución de los servicios bibliotecarios y de información, además de corresponder, de acuerdo a su naturaleza, con nuevos servicios y variados controles que contribuyan al acceso, la disponibilidad y el uso interactivo de la información digital.

Aun con la aparición de técnicas y tecnologías en distintas épocas, los propósitos de la bibliotecología -escribe Rodríguez Gallardo"[...]de preservar los registros de información y al mismo tiempo facilitar la consulta de los materiales, se mantienen como la base de la disciplina”. ${ }^{4}$ En ese sentido, este autor afirma que "[...] se podría senalar que, a lo largo de la historia, la bibliotecología ha sufrido cambios en su forma, más no en su fondo". 5

En consecuencia, la educación virtual de la bibliotecología exige pensar en que una formación adecuada del bibliotecólogo requiere de hábitos de autoaprendizaje orientados a determinado conocimiento teórico, equilibrado con su aplicación. Empero, aplicar la teoría no debe aprenderse como un conjunto de procedimientos memorísticos, repetitivos y mecánicos, desprovistos de toda cualificación, sino como un hacer del que se conoce el cómo y el para qué, lo cual implica, esencialmente, un dominio del conocimiento de los fenómenos bibliotecológicos, aspectos que deben plasmarse en discursos de los materiales didácticos por desarrollar para la enseñanza de dicha disciplina. Con ello se busca que el estudiante se oriente e incida en la adquisición de conocimiento significativo, reafirmando su valor a través de la aplicación en diversos aspectos de su vida profesional.

4 J. A. Rodríguez Gallardo, Formación bumanística del bibliotecólogo: hacia su recuperación, $2^{\mathrm{a}}$ ed., México: UNAM, CUIB, 2003, p. XI.

5 Ibid., p. XI. 
En este sentido, por ejemplo, no sería muy valioso que el alumno aprendiera los fundamentos de la organización documental en sí mismos, sino que los aprenda con la intención de comprender la aplicación de normas, reglas, formatos bibliográficos, formatos digitales, bases de datos, catálogos en línea, sistemas de metadatos, flujos de información, lenguajes documentales, etcétera, con el fin de que adquiera la teoría subyacente y las habilidades necesarias para su aplicación en la solución de casos concretos relacionados con la organización de recursos documentales que encontrará en el ejercicio de la profesión.

La enseñanza virtual de los principios y fundamentos se darían a través de guías de aprendizaje, videoconferencias, aulas virtuales y seminarios presenciales de corta duración, en los que se enseña al alumno no sólo a identificar los fenómenos bibliotecológicos, sino también a valerse de los conocimientos de otras disciplinas para comprender y explicar los objetivos de la bibliotecología. Este tipo de enseñanza requiere materiales de instrucción para apoyo del alumno y el tutor en la enseñanza de los elementos requeridos para abordar el estudio de aquellas cuestiones.

La enseñanza de la bibliotecología en ese sentido, implica buscar la formación de un alumno mediante el aglutinamiento de los conocimientos teóricos y aplicados disponibles con el fin de brindar una formación que permita ejercer la profesión en un ámbito laboral sujeto a constantes cambios. Se requiere, pues, de material didáctico que responda a la idea de que la enseñanza se realiza conforme a un orden de prioridades lógicas, de tal manera que al alumno se le proporcionen los conocimientos necesarios para comprender determinado fenómeno, así como plantearse problemas y solucionarlos. En consecuencia, el alumno a distancia requiere, indispensablemente, contar con conocimiento fundamental que le aporte elementos para comprender y explicar las interrelaciones de los fenómenos que se le enseñen.

La enseñanza virtual de la disciplina requiere de marcos referenciales para facilitar su concepción con el propósito de identificar los objetos y problemas de estudio. En consecuencia, si la bibliotecología como ciencia, estudia el registro, el flujo del conocimiento, de la información y la circulación social de los medios que la contienen 
para facilitar su uso y organización. El resultado será que el estudiante en bibliotecología tendrá que conocer los fenómenos siguientes:

a) Teoría bibliotecológica y avances del conocimiento en la materia.

b) Producción y circulación de los registros del conocimiento y de la información a las sociedades.

c) Tendencias y utilidad de las TIC en el ámbito bibliotecológico.

d) Uso de la información y los derechos de autor involucrados.

e) Flujos de la información en diversos entornos geográficos y sociedades.

f) Gestión de documentos en cualquier soporte, atendiendo a los escenarios y requerimientos de distintas comunidades de usuarios.

g) Usuarios de la información, etcétera.

En suma, incidir en una formación que contemple, entre otros objetivos, el estudio de los fenómenos ya señalados requiere, como afirman Lafuente y Morales, “[...]agrupar los fenómenos en áreas de conocimiento que permitan aglutinar, con propósitos didácticos, fenómenos afines o que sean necesarios como antecedente conceptual para la comprensión o explicación de otros fenómenos". ${ }^{6}$

Aun así, la agrupación de fenómenos de estudio implica reconocer que, dada la constante evolución del conocimiento, que en su momento se incorpora al cuerpo de conocimientos de la bibliotecología, no existe hoy una clasificación de éstos que se valide y de uso general. Más bien, existen propuestas al respecto, algunas han servido incluso como fundamento para continuar con el estudio del que debe tener la disciplina bibliotecológica por ejemplo, con la idea expresada por los especialistas ya citados, quienes afirman que: "[...]la organización de los conocimientos bibliotecológicos que tiene una mayor aceptación aún corresponde a los esquemas clásicos de la organización técnica de la biblioteca [...]: servicios, catalogación, clasificación, y usuarios". 7

En este sentido, Rodríguez Gallardo coincide y opina: “[...]la enseñanza impartida en la mayoría de las escuelas de bibliotecología, hasta ahora, ha propugnado la repetición de actividades técnicas y ha

$6 \quad$ Ibid., p. 25.

7 Ibid., p. 26. 
fomentado el uso de la tecnología, como si en ese uso se encontraran los paradigmas de la disciplina". ${ }^{8}$ No obstante, lo que sigue siendo atractivo es la incorporación de las TIC en la enseñanza de la bibliotecología y, al parecer, es un hecho irreversible. De ahí que concuerde con Rodríguez Gallardo cuando afirma que “[...]la educación bibliotecológica debe fortalecer el uso de la razón, como elemento indispensable para comprender la problemática de la disciplina". ${ }^{9}$ Estos señalamientos naturalmente son válidos en la enseña presencial y virtual en bibliotecología.

Si se toma en cuenta lo anterior, cabe subrayar que las posibilidades que ofrece la educación virtual de expandir la formación permanente de profesionales en bibliotecología, mediante la convergencia curricular, tecnológica y de materiales de instrucción en multimedia, plantea retos y expectativas de suma importancia para la disciplina. Algunas corresponden a la investigación con nuevas formas de enseñanza y teorías del aprendizaje emergentes para la enseñanza a distancia, que al analizar el potencial del uso de las TIC se incidirá en nuevas posibilidades de comunicación e interacción en el aprendizaje. Sobre esto último, Ríos Ortega señala que el currículo tiene que ser "[...] un practicum reflexivo, es decir, un conjunto de prácticas formativas para dotar a los estudiantes de hábitos de indagación y categorías de la disciplina complementarias para interpretar ampliamente sobre el valor cognitivo de las aplicaciones". ${ }^{10}$ A partir de estos enunciados, procede lo siguiente:

1. replantear la enseñanza de la bibliotecología para adecuarla a los nuevos fenómenos de la organización y difusión del conocimiento y la información y, por ende, validar, jerarquizar e interrelacionar el conocimiento bibliotecológico para lograr una adecuada organización pedagógica que establezca las pautas necesarias para

8 Ibid., p. 243.

9 Ibid., p. 243.

10 Jaime Ríos Ortega. "Modelos en conflicto en la formación del bibliotecólogo mexicano", en VIII Coloquio Internacional de Investigación Bibliotecológica, El medio digital en el siglo XXI: retos y perspectivas para los bibliotecólogos, México: UNAM, CUIB, 2000, (CD-ROM). 
transmitir al alumno una visión integradora del conocimiento bibliotecológico;

2. solucionar los problemas del orden en que deben agruparse los diversos fenómenos, conceptos, teorías y técnicas para señalar prioridades lógicas de enseñanza, basadas en la identificación de conceptos primarios y aumentar gradualmente la complejidad del manejo conceptual, de tal modo que el alumno sea capaz de manejar e interrelacionar los conceptos relativos a la explicación o comprensión de los fenómenos bibliotecológicos, materia de la enseñanza.

En este contexto, los programas de educación bibliotecológica a distancia deben prever las estrategias de enseñanza-aprendizaje que aseguren la preparación profesional con niveles óptimos de conocimiento tecnológico, acordes a los diferentes escenarios sociales, capacidad gerencial para el diseño, organización y provisión de servicios de información, dirigidos a distintos entornos sociales, considerando, entre otros fenómenos, lo global, aspecto que refleja la existencia de ambientes integrados.

En años recientes, se han detectado problemas que deben ser enseñados, por ejemplo, bibliotecas digitales, bibliotecas virtuales, desarrollo de colecciones digitales, organización de recursos digitales, sistemas de metadatos, lenguajes digitales, el tesauro en el medio digital, digitalización de documentos, construcción de sitios web, publicación electrónica, el libro digital, organización y preservación de la información en el medio digital, servicios de información digital, derechos de autor en el medio digital, objetos digitales, objetos de aprendizaje, etcétera.

El requerimiento de estudiar, entre otros fenómenos, los ya señalados antes se evidencian con mayor certeza cuando se hace referencia al documento digital. Varios especialistas han observado que se requiere establecer principios generales para la clasificación de una taxonomía de los documentos digitales, con el propósito de facilitar la construcción de principios para crear, organizar, difundir y gestionar colecciones digitales y el hipertexto, gracias a que las redes de telecomunicación han creado espacios novedosos para la comunicación de la información, estableciendo nuevas formas de documentos 
digitales. En el esquema subsiguiente se observan fenómenos de estudio que concurren en la enseñanza virtual en bibliotecología, por ser objetos de estudio que atañe al cuerpo de conocimientos de la disciplina.

Figura 4

Problemas de actualidad en torno a la educación virtual en bibliotecología

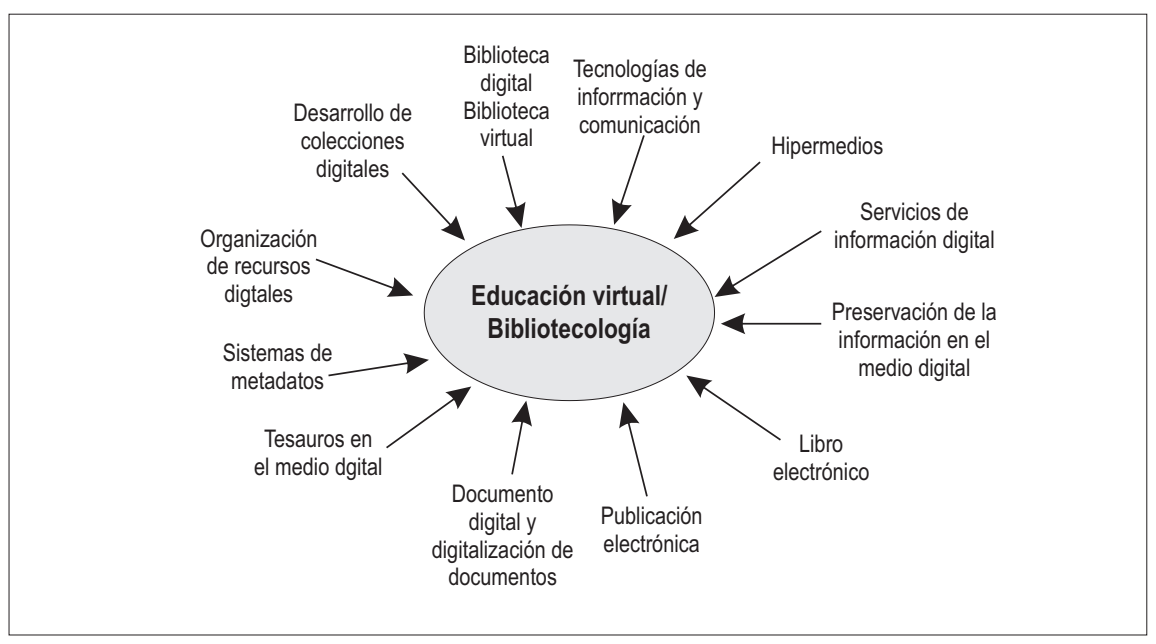

Los temas emergentes ilustrados en la gráfica no intentan ser exhaustivos, más bien son ejemplos de los que hay que percatarse ya que con los avances científicos y desarrollos tecnológicos se incrementan constantemente los fenómenos de estudio inherentes a la disciplina bibliotecológica.

\section{La comunicación en la educación virtual en bibliotecología}

A lo largo de su historia, la disciplina bibliotecológica ha generado teorías y métodos propios que la diferencian de otras disciplinas, sin embargo, acudir a otras áreas disciplinares ha propiciado el enriquecimiento de su cuerpo de conocimiento. Por lo tanto, en cualquier 
propuesta educativa relacionada con enseñanza virtual ha de pensarse que dichos aspectos son fundamentales cuando se propone el programa de estudios de que se trate. Los fenómenos surgidos con el constante desarrollo social y tecnológico reclaman su análisis para continuar enriqueciendo a la disciplina misma. Así, su enseñanza virtual plantea la siguiente interrogante: ¿cuáles son los rasgos generales característicos que han de considerarse en la enseñanza virtual de la bibliotecología? Recordemos que en los capítulos precedentes se examinaron los marcos teóricos relevantes de la EAD y que afectan su enseñanza virtual, empero, aquí se remarcan otros aspectos.

En la educación presencial, maestro y alumno tienen comunicación frente a frente, en el mismo espacio y tiempo. La voz y expresión corporal del primero son medios de comunicación dominantes, restringida al aquí y ahora. El código en la enseñanza convencional es el de la comunicación oral, acompañada de gestos, movimientos e inflexiones de la comunicación no verbal. La relación presencial de los actores del aprendizaje favorece el diálogo personalizado o en grupo inmediatamente. En cambio, en la educación a distancia, tutor y alumno no están presentes físicamente en el mismo espacio ni tiempo. En consecuencia, para que la comunicación educativa se genere, es necesario crear elementos mediadores entre los actores del aprendizaje. Así, la voz y los gestos corporales se sustituyen por contenidos de aprendizaje que se registran en medios sonoros, visuales, multimedios y digitales para transmitirlos en determinado espacio y tiempo diferentes. En la $\mathrm{EAD}$, contenidos y medios se convierten en el objetivo dominante por excelencia, el manejo adecuado del discurso docente será uno de los aspectos críticos que resolverán quienes lo transmitan. La relación indirecta de quienes se comunican crea una forma de diálogo que, por no ocurrir en un aquí y en un ahora, se ha denominado diálogo diferido.

En la enseñanza de la bibliotecología se ha de contemplar también que representar las TIC un nuevo paradigma, la comunicación a través de éstas facilita la explicación de los fenómenos disciplinarios que se quieran enseñar, además de la conveniencia de emplear tecnologías de red. La tecnología digital se concibe como de vanguardia en los procesos de comunicación, gracias a las posibilidades de la conexión a 
intrarredes y a redes de amplio espectro, aparte de las facilidades para transmitir conocimiento y saberes. En este contexto, las nociones de espacio, tiempo, conectividad, distribución de señal, distancia, interactividad, navegación, acceso a la información digital y costo-beneficio se vuelven esenciales. La influencia directa de las tecnologías frente a la comunicación se construye de varias formas: los signos y símbolos involucrados en los lenguajes pedagógicos, en los mensajes del aprendizaje y en la transmisión de señales a través de la Internet posibilitan hoy en día vías de comunicación más veloces y más ricas en contenidos.

Ante este panorama, la comunicación educativa y la innovación tecnológica resultan muy importantes para la noción de interactividad en red. Sobre esto, Fainholc ha señalado:

[...]la interactividad supone potenciar la comunicación y ello significa hacer partícipe y protagonista al otro de lo que cada cultura especifica como valioso de lo que tiene, piensa y siente, la elaboración de situaciones didácticas y la producción de material educativo para esos sistemas mediatizados que deberá posibilitar cada vez más el intercambio multidireccional de significados, si se trata de favorecer la reconstrucción autónoma del saber. ${ }^{11}$

Con lo anterior, queda de manifiesto que la educación virtual es una realidad; en consecuencia, la bibliotecología está comprometida a dar respuesta, entre otros, a cuestionamientos como éstos: ¿los administradores de programas en bibliotecología brindan atención a las dimensiones de la educación virtual como modelo alternativo?, ¿los docentes en bibliotecologia han tomado conciencia de lo que implica la educación virtual?, ¿estarán preparados para asumir tareas como tutores virtuales?, ¿los alumnos reales y potenciales en bibliotecología estarán conscientes de las repercusiones del aprendizaje virtual? Preguntas podríamos formularnos muchas más, sin embargo, a lo largo de los subsiguientes capítulos trataremos de dar respuesta a éstos y a otros cuestionamientos.

11 Beatriz Fainholc. La interactividad en la educación a distancia, Barcelona: Paidós, 1999, p.44. 


\section{Educación virtual del bibliotecólogo ante la globalización y la sociedad de la información}

La enseñanza virtual y las TIC plantean nuevos fenómenos de estudio para la bibliotecología, a causa, entre otros aspectos, de las transformaciones tecnológicas ocurridas en las telecomunicaciones y la computación, áreas que han generado cambios en las sociedades en cuanto a formas de trabajo, las maneras de interacción y comunicación de grandes sectores sociales, así como en las necesidades de uso de la información.

Por ello, el análisis de la enseñanza virtual en bibliotecología implica contemplar que la globalización ha penetrado en las sociedades para eliminar barreras de comunicación y facilitar los flujos de la información a través de la tecnología electrónica, la informática y las telecomunicaciones. Así, el estudio de la globalización y su repercusión teórica y aplicada en esta disciplina implica, por parte de los profesionales del área, el conocimiento y manejo de habilidades referidas a las particularidades tecnológicas de tales herramientas.

Efectivamente, lo global y lo tecnológico son inherentes al estudio de la bibliotecología, pues ambos fenómenos han externado el requerimiento de nuevos perfiles del bibliotecario que respondan al involucramiento de las TIC en esta disciplina y en su ejercicio. Baste señalar que la tecnología replantea la selección y adquisición de documentos impresos y digitales, sus formas de organización, requerimientos de su transferencia, la prestación de servicios de información y la atención al usuario final de los servicios bibliotecarios.

Por otra parte, se advierte que los fenómenos propiciados por las TIC presentan nuevos retos para esta disciplina y, por ende, para los sectores bibliotecarios y las unidades de información documental. Al mismo tiempo, las transformaciones tecnológicas han causado cambios en la sociedades en cuanto a las formas de trabajo y las maneras de interacción y comunicación entre los diversos sectores sociales. Además de que las redes de telecomunicación facilitan cada vez más el acceso a la información en un entorno global, reduciendo los límites espacio-temporales a gran velocidad, para facilitar la recuperación de información que requiere la sociedad actual. 
Evidentemente que las TIC han suscitado cambios significativos, ya que constituyen la base material de la sociedad de la información. Tal vez por eso el concepto sociedad de la información intenta describir un tipo de sociedad que, por un lado, ocupa un lugar histórico determinado y, por otro, presenta características que la distinguen de otras. En esta situación, el término información se vincula históricamente con la forma como ésta se genera, como se usa, las dinámicas que exige su flujo y las características de su influencia en la sociedad contemporánea, que la considera un recurso estratégico fundamental para su desarrollo.

Así, en este documento, se entiende por sociedad de la información ${ }^{12}$ el espacio social altamente dinámico, abierto, globalizado y tecnologizado, en el que el conjunto de relaciones sociales (acción e interacción de los individuos, procesos de producción material y espiritual) se apoyan y concretan por medio de la información, que es igualmente dinámica, abierta, globalizada, tecnologizada y mercantilizada. Cada comunidad, región o Estado puede tener su particular forma de organización social y transita por diferentes niveles de desarrollo y por los distintos tipos y niveles de ideología, economía, cultura y educación que practican, así como por la forma en que sus entes sociales generan, seleccionan, procesan, almacenan, buscan y usan la información. Esta última apreciación parecería adquirir dimensiones protagónicas y definitivas en la llamada sociedad de la información, que se apoya en dos vertientes fundamentales: la educación y la información sobre una estructura tecnológica.

Cabe subrayar que lo hasta aquí mencionado ha afectado a la sociedad en general, así como a la EAD. Aquí, se puede decir que a lo largo del siglo XX la EAD se vinculó estrechamente con el uso de las TIC y con el desarrollo de medios didácticos para promover el conocimiento. En este sentido, coincidimos con Amador Bautista cuando acota:

12 Esta visión de la sociedad de la información es la que se presentó en la investigación colectiva titulada "Hacia la Sociedad de la información en México", la cual se realiza en el Centro Universitario de Investigaciones Bibliotecológicas, UNAM, a partir de 1999. 
[...] ]estos procesos de cambio tecnológico están contribuyendo a la transformación de la sociedad de la comunicación en una sociedad de la información. Sin embargo, la carencia de una historia escrita de la educación y la formación a distancia [...], vinculada al desarrollo de los medios y tecnologías de información y comunicación, representan un vacío significativo en un momento de grandes transformaciones mundiales. ${ }^{13}$

En la sociedad de la información y del conocimiento, la educación virtual se ubica en las TIC. El ciberespacio es el escenario de comunicación interactivo y comunitario. La aparición y desarrollo de este nuevo contexto, propicia la generación de propuestas educativas complejas, en las que la construcción del conocimiento entre los actores del acto educativo se perfila como la principal potencialidad y el nuevo desafío. En este sentido, se menciona que atañe a los medios bibliotecarios procurar un proceso permanente de formación a raíz de que la penetración de las TIC y la vigencia de los conocimientos en el área será cada vez más corta, situación que repercutirá en los procesos educativos y en el ejercicio de la profesión.

Como consecuencia de lo anterior, habrá cambios sustantivos en los modelos estructurales de la sociedad y de las instituciones educativas. De ahí que la bibliotecología diversificará su campo de conocimiento, creará nuevas alternativas de formación para atender las demandas de los mercados laborales, incorporará el uso de las TIC para la producción y la difusión de nuevos conocimientos, innovará en sus métodos y técnicas de enseñanza-aprendizaje y continuará desarrollando la investigación básica y aplicada.

Imaginarse este escenario en la enseñanza de la bibliotecología, implica pensar en la formación de un profesional que identifique, detecte, organice, cree y difunda, a través de tecnologías de vanguardia, información especializada en áreas estratégicas para el desarrollo local, nacional, regional e internacional. Asimismo, se observa que la sociedad de hoy crea nuevas demandas de los servicios de información, resultando factores estratégicos determinantes que, en muchos casos, inciden en ventajas de competencia relativas a la toma

13 Rocío Amador Bautista, Op. cit., p. 15. 
de decisiones de distintos sujetos sociales, en los niveles macrosocial (en el plano de la globalización) y microsocial (en contextos nacionales o regionales).

\section{Hacia un perfil del bibliotecólogo frente a la educación virtual}

Las demandas antes descritas requieren la atención de un profesionista en bibliotecología con capacidad para identificar y caracterizar escenarios culturales, sociales y económicos en los que sea factible aplicar tecnologías de información y comunicación, realizar su gestión adecuada y diseñar sistemas de información acordes a los servicios que demanden sujetos específicos. En consecuencia, en cualquier programa sobre educación virtual en bibliotecología conviene recordar que los contextos sociales caracterizan la tecnología de aplicación, no al contrario; sin embargo, los hechos indican que la tecnología afecta directamente los escenarios sociales en que se inserta.

Un fenómeno representativo es Internet, en el que la ubicación espacial de la información tiene una existencia relativa. Empero, se advierte que parte de aquélla puede ser importante para determinados usuarios, por lo cual requiere recuperarse y organizarse apropiadamente para garantizar su permanencia y facilitar su consulta. En este sentido, para lograr esto, es determinante, como señala Sánchez y Pérez, "[...]la capacidad de la biblioteca y del profesional, de acceder, localizar y suministrar la información relevante y especializada en respuesta a los requerimientos específicos del usuario final". ${ }^{14}$ Con el uso de las TIC se vuelve necesario el aprendizaje de nuevos conocimientos y habilidades para el desarrollo de dichas tareas.

Aunado a lo anterior, la influencia de la globalización obliga a que la bibliotecología prepare profesionales con perfiles acordes a dicho fenómeno y a las exigencias de la sociedad actual. Sobre esto, las autoras citadas proponen cuatro saltos cualitativos, desde el punto de

14 Saadia Sánchez Vegas y Estrella Pérez, "Reflexiones sobre la formación de recursos humanos de cuarto nivel en el área de las ciencias de la información", en INFOLAC oct./dic. 1996, vol. 9, no. 4, p. 4. 
vista epistemológico, para configurar un posible perfil del egresado que demanda la sociedad actual, esos saltos serían estos:

- El primer salto cualitativo va del documento a la información.

- El segundo, del énfasis de los procesos de acceso y transmisión de la información, a un nuevo énfasis en los procesos comunicacionales al servicio de los usuarios finales.

- El tercero va de los servicios diseñados desde una perspectiva localista a una perspectiva cooperativista de servicios en redes.

- El cuarto apunta al dominio y conocimiento de los procesos cognitivos, comunicacionales y lingüísticos generados por el cambio de soporte de los documentos. ${ }^{15}$

Con base en estos elementos se puede decir que la educación virtual en bibliotecología debe prever las estrategias de enseñanza-aprendizaje que aseguren la preparación profesional en niveles óptimos de conocimiento tecnológico, acordes con los diversos escenarios sociales, capacidad gerencial para el diseño, organización y generación de servicios de información dirigidos a distintos entornos sociales. Así, los egresados de programas virtuales en bibliotecología deben asegurar la adquisición de conocimiento y habilidades para:

- Agregar valor, esto es, detectar, analizar, sintetizar, interpretar y evaluar información y conocimiento; desarrollar la capacidad de discernir problemas relevantes, un pensamiento crítico en relación con la información, su acceso, ordenamiento e investigación, desde una perspectiva inter y multidisciplinaria.

- Aprender técnicas que garanticen un uso eficiente y eficaz de las tecnologías para la comunicación interredes, así como la organización, procesamiento, acceso, transmisión y distribución de la información.

- Adquirir habilidades gerenciales que partan de principios de análisis, planificación, instrumentación y control articulados con programas y políticas destinados a alcanzar objetivos y metas específicas; estudio y manejo de los paradigmas organizacionales vinculados con el desarrollo de las TIC; funcionalidad del trabajo

15 Ibid., p. 5. 
en ambiente de redes, organización del trabajo bajo sistemas integrados.

- Adquirir liderazgo en contextos organizacionales cambiantes.

- Sociales, es decir, capacidad para la comprensión del entorno macrosocial de las exigencias de la realidad nacional en materia de información, además de diseñar políticas de información y tecnología enfocadas a esa realidad. ${ }^{16}$

Todo lo anterior determina el estudio de las novedades que ofrece el mercado del software y hardware para el desarrollo de sistemas integrales e integrados; la aplicación de la tecnología láser; las posibilidades de la tecnología CD-WARM; los avances en inteligencia artificial, las facilidades que ofrecen las redes de telecomunicación para acceder a sistemas globales de información, bibliotecas digitales, bibliotecas virtuales y de hipertexto o de hipermedios; además de las características, ventajas, desventajas y avances de los motores de búsqueda en la Internet.

A esto habría que añadir los servicios con posibilidades de desarrollo a través de intranets; los nuevos avances de los Open Systems Interconnection (OSI); las tendencias de la edición electrónica, las propuestas para la organización de la información digital disponible en redes, la orientación en la construcción de lenguajes documentales para la recuperación de información digital y otros. En consecuencia, los desarrollos tecnológicos exigen a los bibliotecarios una constante actualización y superación con el propósito de identificar, aprender, manejar y aplicar las tecnologías de mayor utilidad en los distintos sectores sociales para los cuales presta sus servicios.

El cúmulo de nuevos fenómenos de estudio para la bibliotecología conducen a Barberena a postular una búsqueda de identidad de los profesionales de la bibliotecología, manifiesta en diferentes formas:

- Cambios en los nombres de los planes de estudio.

- Impacto de las tecnologías.

16 Ibid., p. 7. 
- Amplitud en el horizonte laboral del bibliotecólogo (redes, administración de bases, análisis estadísticos, evaluación, diseminación y comercialización de la información).

- Nuevas disciplinas, algunas interdisciplinarias.

- Nuevos formatos.

- Nuevas modalidades de trabajo (a distancia, telecomunicación);

- Otros tipo de responsabilidades (protección de la información, derechos de autor, criptografía).

- Diferentes problemas de ambiente de trabajo (ergonomía, tensión).

- Nuevas comunicaciones y aplicación de formas conocidas de comunicación en el campo de la información (redes, intercambio de datos electrónicos, correo electrónico, telepedido). ${ }^{17}$

En años recientes, surgieron diversos objetos de estudio que se deben atender, por ejemplo, la organización de recursos informativos digitales, sistemas de metadatos, lenguajes digitales, el tesauro en el medio digital, bibliotecas digitales, bibliotecas virtuales, digitalización de documentos, construcción de sitios web, edición electrónica, organización y preservación de la información en el medio digital, servicios de información electrónica, sistematización de objetos de aprendizaje, etcétera.

En este sentido, Morales y Rodríguez, advierten una serie de fenómenos relacionados con el ejercicio profesional que merecen ser tomados en cuenta en cualquier proyecto de educación virtual en bibliotecología:

- Amplio desarrollo de ofertas de autoservicio de colecciones y procesos.

- Servicios de información remotos.

- Variedad de programas de ayuda al usuario [...].

- Una oferta variada y plural de la información que será impulsada por los desarrollos tecnológicos y limitada por aspectos económicos y políticos.

- Distinción y apoyo prioritario a la especificidad de la demanda y a la individualidad del usuario.

17 Elsa Barberena Blásquez, "Desafíos para la bibliotecología", en La bibliotecología en el México actual y sus tendencias, México: UNAM, DGB, 1992, p. 189-190. 
- Elaboración de publicaciones que serán producto de empaquetamiento o reempaquetamiento de la información [...].

- Innovaciones que permitan crear nuevos productos informativos y nuevas versiones de los ya existentes que faciliten la difusión y el acceso al conocimiento.

- Procesamiento de la información que propicie un valor agregado a la fuente primaria $[\ldots] .{ }^{18}$

Con todo lo anterior, se supondría que las bibliotecas y bibliotecarios proporcionen servicios de información sustentados en los siguientes aspectos:

- En una gran red global en línea de bibliotecas y de información.

- En interfaces múltiples y precisas entre bibliotecas y todo tipo de proveedores de información y de usuario.

- En una gran variedad de puertas de entrada y en "llaves" de acceso a la información.

- En la oferta de información y su acceso, a partir de la biblioteca y del trabajo bibliotecario de acopio, organización y análisis, pero proyectado y disponible fuera de la biblioteca.

- En un personal profesional que conozca y maneje el lenguaje del docente y del investigador, ya que es de uso común en las "transacciones" de la información, en especial en la biblioteca universitaria.

- En el control de calidad de los procesos y servicios, lo cual permitirá la fluidez y eficacia del intercambio de información, su acceso y su uso. La calidad será una alta prioridad en las bibliotecas. ${ }^{19}$

Sin duda, la incorporación de las TIC requiere por parte del alumno la apropiación de nuevos conocimientos y nuevas aplicaciones. En este sentido, la educación virtual en bibliotecología deberá propiciar la oferta educativa, entre otros temas, en normalización para la organización de recursos informativos digitales y facilitar la formación de bibliotecarios ubicados en distintas latitudes. Sin embargo, también es importante reconocer que, debido al acelerado desarrollo de la ciencia y la tecnología, en las diversas áreas del conocimiento ha proliferado este

18 La biblioteca del futuro /coord. Estela Morales Campos y Adolfo Rodríguez Gallardo. México: UNAM, DGB, 1996, p. 30.

19 Ibíd., p. 31. 
último, aspecto que dificulta que los respectivos profesionales se actualicen permanentemente en su disciplina. Así, el constante desarrollo tecnológico refleja la necesidad de formar profesionistas de alto nivel, para lo cual la educación virtual sería una alternativa a tales propósitos. La actualización constante en los nuevos conocimientos que se incorporan al cúmulo de conocimientos de la bibliotecología resulta hoy una tarea difícil de llevar a cabo. Sin embargo, se tiene que propiciar el aprendizaje de nuevos fenómenos, sin perder de vista la vastedad de conocimientos esenciales en bibliotecología.

Desde la perspectiva educativa, la formación de sujetos implica, la adquisición de conocimiento significativo de valor pleno cuando se relaciona o se aplica en un contexto laboral. Varios especialistas marcan la diferencia entre educación y formación, por ejemplo, Kenny y Reid opinan que "[...]la formación se orienta al trabajo más que a la persona". ${ }^{20}$ A este respecto Villagrá Rubio afirma que "[...]formación continuada y formación del personal son conceptos que, aunque suelen aparecer estrechamente relacionados [...] en ocasiones llegan a confundirse." 21 En esta misma línea, Conroy opina que la formación de sujetos es un recurso "[...]dirigido a potenciar la capacidad de una organización para cumplir su misión con mayor eficiencia y eficacia, mediante la capacitación de sus recursos humanos y la formación continuada, como las actividades de aprendizaje que los individuos realizan para desarrollarse personal y profesionalmente". ${ }^{22}$

De lo precedente se infiere que la educación bibliotecológica tiene como propósito esencial incidir en actividades de aprendizaje que conduzcan a la revisión o actualización de conocimientos teóricos,

20 J. Kenny y M. Reid, Training interventions. London : Institute of Personnel Management, 1986, p. 12.

21 La formación continuada de bibliotecarios y documentalistas: bases para una evaluación / informe elaborado por Ángel Villagrá Rubio, et al., Madrid: Federación Española de Sociedades de Archivística, Biblioteconomía y Documentación, 1996, p. 13.

22 Barbara Conroy. Human resources development for library personnel : a manual for programs of staff development and continuing education, Littleton, Col.: Libraries Unlimited, 1977, citado en La formación continuada de bibliotecarios y documentalistas: bases para una evaluación. p. 13. 
técnicos, métodos y destrezas que conduzcan a su perfeccionamiento, para influir directamente en una alta calidad del desempeño profesional. En el ámbito bibliotecológico y de la documentación, la Continuing Library Education Network and Exchange (CLENE) acota:

[...] el proceso de aprendizaje consiste en la actualización de conocimientos, técnicas y aptitudes previamente adquiridos por el individuo, lo que viene a suceder a la formación básica inicial, necesaria para la incorporación al marco profesional de los servicios bibliotecarios y de información. 23

Investigaciones realizadas en Estados Unidos sobre las expectativas de los empleadores del sector de información y documentación señalan: "[...]el empleador valora en el profesional candidato a un puesto de trabajo, cuatro características fundamentales: las de tipo personal, la formación básica, la formación especializada y los conocimientos y experiencias adquiridos en la práctica profesional". ${ }^{24}$ Convendría tener presente lo anterior en toda iniciativa orientada a propuestas educativas virtuales en bibliotecología.

En cuanto a los profesionales mexicanos, egresados de escuelas de bibliotecología y estudios de la información, se diría que es bajo el porcentaje de los que se ocupan permanentemente de su formación mediante programas de posgrados, especialización, diplomados y demás. Esta situación es más notoria en los profesionistas que laboran en unidades de información ubicadas en los estados de la república mexicana. Las razones son diversas, entre otras, porque la oferta de programas de educación se concentra principalmente en la ciudad de México, y en muchos casos las unidades de información del interior de la repúbica no cuentan, por lo general, con suficientes recursos humanos de alto nivel para desarrollar y aplicar programas de esta

23 NATIONAL COUNCIL ON QUALITY CONTINUING EDUCATION FOR INFORMATION, LIBRARY AND MEDIA PERSONNEL. A program for quality in continuing education for information, library and media personnel: policy statement and criteria for quality, Washington, D. C., Continuing Library Education Network and Exchange, 1980, p. 100.

24 Barbara M Preschel,. "Education of the information professional: what employers want", en Journal of the American Society for Information Science, 1988, vol. 39, no. 5, pp. 358-361. 
naturaleza. Asimismo, los recursos financieros son insuficientes para enviar a sus bibliotecarios en ejercicio a los sitios donde se ofrecen programas de esta naturaleza. Sin embargo, en la actualidad, existe entre los bibliotecarios profesionales una mayor necesidad de asistir a programas de educación, debido a la aparición de nuevo conocimiento que se incorpora al cúmulo de conocimientos de la disciplina bibliotecológica y a sus repercusiones en el ejercicio profesional.

Al mismo tiempo, se observa que el uso de las TIC ha propiciado un nuevo perfil cultural de los sectores sociales usuarios de información, expresada en una exigencia mayor en la selección (relevante y pertinente) de la información que se requiere. La interactividad en la web, el diseño y operación de sistemas documentales que faciliten cada vez más la recuperación de recursos de información son aspectos imprescindibles en los programas de educación bibliotecológica virtual ya que la sociedad así lo demanda.

En este sentido, se observa que el siglo XXI trae consigo nuevos conocimientos e innovaciones tecnológicas, lo que requiere que las unidades de información contemplen una reestructuración de sus actividades. En consecuencia, los profesionales bibliotecólogos tendrán que sortear desafíos para incorporar creativa y provechosamente las novedades tecnológicas a las diversas tareas de su campo, buscando siempre el beneficio social como corolario de su formación. Así, pues, es necesario subrayar que la educación virtual resulta de mucha utilidad en propuestas educativas en distintos niveles de la bibliotecología, como son las licenciaturas y maestrías. Empero, conviene no perder de vista las posibilidades de las especializaciones como uno de los niveles de posgrado.

\section{EDUCACIÓN ESPECIALIZADA DEL BIBLIOTECÓLOGO}

La formación del bibliotecólogo en América Latina ha manifestado, desde su origen, que las escuelas adscritas a facultades o universidades de perfil humanístico asumieron la preparación del personal que hasta nuestros días ha trabajado en bibliotecas, archivos, centros de información y documentación. No obstante, la tendencia predominante 
ha sido formar profesionales con atención especial en los procesos técnicos, más que en los servicios. Un porcentaje de $28 \%$ de los planes vigentes incluyen temas sobre el almacenamiento y la recuperación de la información por medios automatizados; $2 \%$ con los medios de comunicación, $1 \%$ con la micrografía y el $0,6 \%$ con la reprografía. ${ }^{25}$ De esto se infiere que la orientación principal de los planes y programa de estudio de las escuelas de bibliotecología y ciencias de la información de Latinoamérica tienen una alta tendencia hacia la organización documental y su recuperación, aspecto que en muchos casos ha sido criticado por diversos estudiosos de la enseñanza bibliotecológica. No obstante, la organización de recursos documentales es un área fundamental del cuerpo de conocimiento de la disciplina.

Por otra parte, las escuelas de bibliotecología y ciencias de la información de Latinoamérica, por lo general tienen infraestructuras tecnológicas insuficientes, en muchos casos incluso obsoletas, lo que entorpece la concreción del proceso de enseñanza-aprendizaje con óptima calidad, propiciando que numerosas dependencias académicas incorporen materias optativas sobre la enseñanza de las TIC y su aplicación en tareas bibliotecarias. Aun así, esta medida ha desequilibrado el aprendizaje, pues no todos los estudiantes optan por inscribirse a tales materias.

Los esfuerzos de las escuelas de bibliotecología y estudios de la información de América Latina por incorporar la enseñanza de las TIC en sus planes y programas revelan las desventajas puesto que los avances tecnológicos se diversifican y crecen aceleradamente, dificultando su incorporación a corto plazo en los planes y programas de estudio. Por otro lado, no se han dado acuerdos referente a los contenidos tecnológicos fundamentales y de actualización que deben incluirse en los planes de estudio, no obstante los esfuerzos explayados en diversos foros de la educación bibliotecológica,

25 R. Lafuente López, et al., Conocimiento y uso de las nuevas tecnologías de la información y la comunicación, Cuba: UNESCO, CRESALC, 1996, p. 28. (Documento Central, Comisión 4) 
como los externados en reuniones de investigadores y educadores Iberoamericanos en el área de la bibliotecología y ciencia de la información. ${ }^{26}$

Además en los últimos años, escuelas de bibliotecología de América Latina se han dado a la tarea de revisar sus planes y programas de estudio, a raíz de la aparición de nuevos fenómenos que requieren ser enseñados por la disciplina bibliotecológica. En el caso de México, sus escuelas de nivel superior o de posgrado han realizado un intenso trabajo de revisión, actualización y adecuación de sus planes y programas de estudio. Las dependencias que lo han hecho son el Colegio de Bibliotecología de la UNAM, Escuela de Bibliotecología e Información de la Universidad Autónoma de San Luis Potosí (UASLP), la Escuela Nacional de Biblioteconomía y Archivonomía (ENBA) donde operan las licenciaturas a distancia en bibioteconomía y archivonomía) y la Licenciatura en Ciencias de la Información Documental de la Universidad Autónoma del Estado de México. En posgrado, destacan la Maestría y el Doctorado en Bibliotecología y Estudios de la Información de la UNAM, así como la Maestría virtual que ofrece el Instituto Tecnológico de Estudios Superiores de Monterrey.

Se puede decir que en México existe interés por parte de los administradores de las escuelas de bibliotecología en retomar la revisión y actualización permanente de sus planes y programas de estudio, para incorporar nuevos elementos de esa disciplina, especialmente en la identificación de los fenómenos relevantes involucrados con la educación bibliotecológica surgidos con el uso de las TIC. Sin embargo, se observa que uno de los grados bastante descuidado por la bibliotecología en muchos países corresponde a las especializaciones, pese a que diversas universidades contemplan en sus legislaciones la posibilidad de impartir este nivel. En esta obra se privilegia la reflexión en torno del mismo y se propone un modelo teórico para la enseñanza virtual de una especialización sobre la organización de

26 Sobre los logros de esas reuniones, se puede obtener mayor información en: Reunión de Investigadores y Educadores de Iberoamérica y el Caribe en el área de la Bibliotecología y Ciencia de la Información / comp. Martha Alicia Añorve, et al. México: UNAM, CUIB, 1996. 387 p. (Memorias; 9). 
recursos informativos digitales, tratando de repercutir en un nivel fundamental para la bibliotecología, ya que todo indica que en el corto plazo la actividad bibliotecaria basada en especializaciones será un requerimiento indispensable de tal disciplina. En el mercado laboral se advierte que el profesional especializado se requiere en las unidades de información de organismos de investigación, en la iniciativa privada e industria en general, asimismo en tareas especializadas de organización, acceso y recuperación de documentos digitales y objetos de aprendizaje.

\section{FORMACIÓN ESPECIALIZADA EN TEMAS BIBLIOTECOLÓGICOS}

La orientación de la formación especializada en bibliotecología tiene como referente histórico principal Estados Unidos, dada la importancia que este país ha otorgado a la discusión de este tema. En España, las especializaciones se ubican en la educación universitaria y continua, mientras que en México se adscriben al nivel de posgrado. Asimismo, el tema de las especializaciones por materias ha sido de interés para la Federación Internacional de Bibliotecas (IFLA), la American Library Association (ALA), el Comité sobre Capacitación de la Special Library Association (SLA) y el American Documentation Institute (ADI), entre otros organismos.

Algunos datos relevantes sobre la discusión de la especialización en temas relacionados con la bibliotecología, se citan enseguida. En su época, "Melvin Dewey mostró interés en revisar las necesidades de las bibliotecas especializadas por materias con más o menos plenitud, de acuerdo con su importancia práctica", ${ }^{27}$ y en "[...]la reunión

27 S. K. Vann. Trainig for librarianship before 1923, Chicago: American Library Association, 1961, p. 31. 
anual de 1898 de la American Library Association (ALA) reivindicaba ya la necesidad de la instrucción profesional y de la formación a distancia”. ${ }^{28}$

Así, las bibliotecas especializadas en materias o disciplinas específicas surgieron a finales del siglo XIX, y tuvieron un incremento significativo a principios del XX. "Estas bibliotecas requirieron un nuevo tipo de bibliotecario, uno con las destrezas tradicionales del estudiante, o sujeto experto, y las habilidades técnicas bibliotecarias pensadas en las escuelas de bibliotecología". ${ }^{29}$ Plummber coincide con esta postura cuando "[...] discute la posibilidad de capacitación especializada para bibliotecarios por materias al [...] reconocer la demanda real de los negocios y la industria". ${ }^{30}$ Sin embargo, su única intención respecto de la especialización se refería a la catalogación. ${ }^{31}$ Este razonamiento reflejaba la poca proyección del crecimiento bibliotecario y la pobre disposición a aventurarse en nuevas áreas de conocimiento.

La crítica sobre el desdén o ignorancia de la especialización por materias fue ampliamente discutida en 1919, en la reunión de la ALA sobre capacitación en bibliotecas a lo largo de nuevas líneas y servicios especializados de biblioteca. Teóricos importantes de la época criticaron el desprecio de las escuelas hacia la especialización. En este contexto, Keogh observó dos necesidades interrelacionadas: "[...]bibliotecarios que deseaban volverse especialistas en materias y especialistas en materias que deseaban volverse bibliotecarios". ${ }^{32}$ Este autor sostenía que "[...]las escuelas no podrían ayudar ni a unos ni a otros, debido a su énfasis en las humanidades en requerimientos de admisión y en el trabajo de los cursos. Los empleos de bibliotecarios

28 Elizabeth Stone, citado en La formación continuada de bibliotecarios y documentalistas bases para una evaluación / Informe elaborado por Ángel Villagrá Rubio, et al., [Madrid]: FESABD, 1996, p. 15.

29 M. J. Zachert, citado por Robert V. Williams y Martha Jane K. Zachert, "Specialization in library education: a review of the trends and issues", en Journal of Education for Library and Information Science, spring 1986, vol. 26, no. 4, p. 216.

30 M. W. Plummber. "Specialization and grading in library schools", en ALA Bulletín jun. 1913, no. 7, pp. 343-347.

31 Ibid., p. 344.

32 Ibid., p. 344. 
especiales requerían de antecedentes de materias diversas, con una demanda creciente de conocimiento técnico". ${ }^{33}$

En la época posterior a la primera guerra mundial hubo en Estados Unidos un gran incremento en el número de negocios e industrias que reconocían sus necesidades en cuanto al manejo efectivo de la información. Como ha observado Rankin, "[...]la propuesta demandaba un programa completo y separado para bibliotecarios especiales, consistente en dieciocho temas: teoría, economía de negocios, estadística, psicología aplicada, mecanografía, edición, bibliografías especiales, principios de clasificación (con énfasis en sistemas específicos de materias), indexación de materiales, archivado, fuentes de información, investigación, relaciones públicas, adquisiciones y administración de bibliotecas especiales" ${ }^{34}$

En 1936, el Comité sobre Capacitación de la SLA, llevó a cabo el estudio de setecientos bibliotecarios especializados, cuyos resultados los analizó Jesse H. Shera: "[...]cerca del 50\% de los encuestados había tomado algunos cursos sobre bibliotecas escolares; la mayoría de ellos se hallaban decepcionados al respecto. Virtualmente, todos estaban convencidos de la necesidad de la especialización por materias". ${ }^{35}$ Así, Shera, en su investigación de 1965 señaló que "[...]las líneas de combate entre bibliotecarios y especialistas en materias han sido trazadas tan acuciosamente, que los valores mismos por los que la profesión se ha preservado se han visto seriamente amenazados". ${ }^{36}$

En Estados Unidos, durante los años posteriores a la segunda guerra mundial, a juicio de Williams, “[...]los programas de educación en bibliotecología fueron sometidos a un periodo de intenso escrutinio, tanto interno como externo, se analizó críticamente los supuestos y

33 Ibid., p. 166.

34 R. Rankin. "Training for the special librarian", en Special Libraries, nov. 1926, no. 17 , pp. 329-330.

35 J. H. Shera. "Training for specials: a prologue to revision", en Special Libraries may./jun. 1937 , no. 28 , pp. 139-144.

36 J. H. Shera. "The present state of education and training in documentation, information science, and special librarianship in the United States", en Proceedings of the 1965 Congress, International Federation for Documentation. Washington: American Documentation Institute and Macmillan and Co., [966, p. v. 
tendencias fundamentales en la educación profesional. Las conclusiones y recomendaciones trazadas iban a determinar, en lo principal, la dirección de la educación en bibliotecología durante los siguientes veinte años". ${ }^{37}$ Así, "[...] a principios de los cincuenta, las escuelas acreditadas parecían haber aceptado una orientación hacia los estudios de grado, con este movimiento, el debate cambió hacia la naturaleza del currículum "nuclear", en la medida en que la especialización podría ser adaptada a un año"38 y que "[...]hacia finales de los cincuenta los defensores de la bibliotecología especial parecieron haber triunfado, debido a que las escuelas se habían movido hacia los programas de nivel de grado, permitiendo asignaturas principales de cursos dedicados a la especialización". "Varios de estos aspectos influyeron en el desarrollo curricular en bastantes países latinoamericanos.

El logro aparente de los defensores de la especialización demostró no ser definitivo. "Aunque siendo inicialmente un pequeñísimo grupo, estos especialistas ganaron cifras significativas, volviéndose en 1970 más numerosos que los de la profesión bibliotecaria general." 40 Frecuentemente, -añade Williams “[...]compartiendo al menos algunos propósitos, valores y técnicas con los bibliotecarios, ellos eran del todo diferentes en su educación, con un mayor prestigio y con mejores salarios". ${ }^{41}$

Con la aparición de la tecnología del microfilme como un nuevo soporte para el control bibliográfico de reporte técnico, generado sobre todo por los científicos y sus artículos de revista, evidenciaron el requerimiento de los especialistas. En esta época, los reportes técnicos eran la novedad en cuanto a forma y contenido, Williams señala: "[...]había archivos masivos de información científica, series de

37 C. E. Carroll. The professionalization of library education, Metuchen, N.J.: Scarecrow Press, 1970, p.v.

38 Robert V. Williams y Martha Jane K. Zachert. Op. cit., p. 217.

39 Ibid., p. 217.

40 A. Debons, et al., The information professional: survey of an emerging field. New York: Marcel Dekker, 1981, citado por Robert V. Williams y Martha Jane K. Zachert. Op. cit., p. 223.

41 Robert V. Williams y Martha Jane K. Zachert. Op. cit., p. 223. 
tarjetas perforadas, dibujos de ingeniería, patentes y otros numerosos paquetes que no encontraban ordinariamente su lugar en las bibliotecas generales. El manejo de estas fuentes de información demandaba conocimiento de métodos de adquisición, de organización, y de acceso a dichas fuentes y, probablemente, lo que era más importante, conocimiento experto en su materia específica". ${ }^{42}$ En cierta medida, estos fueron los materiales que los bibliotecarios especializados ya habían aprendido a organizar y derivaron de los mismos el servicio de diseminación selectiva de la información. Así, los bibliotecarios especialistas propugnaban por una nueva denominación para caracterizar el modelo emergente de materiales, servicios intensivos y profesionales de la información con capacitación por materias y experimentación intensiva con métodos automatizados. Entre otros aspectos, estos sustentaron el surgimiento de los centros de información. En Estados Unidos, dos grupos llegarían a dominar las actividades del personal especializado y los ideales respecto a los servicios: la Special Libraries Association (SLA) y el American Documentation Institute (ADI). ${ }^{43}$ Los antecedentes de este último (fundado en 1937), se ubicaban en una tradición relacionada con la terminología, desarrollada para fines de información científica en Europa a principios del siglo XX. "Los miembros del ADI, lo mismo que los de la SLA, provenían de una amplia variedad de antecedentes en materias y profesionales". ${ }^{44}$

Rayward observa: "[...] en forma concomitante, el trabajo de los administradores de la información científica experimentó un cambio significativo: desde la documentación hacia la recuperación de la información, o desde el control de la información científica hacia el desarrollo de una ciencia de la información". 45 "Esta ciencia en evolución establecería por sí misma una diversidad de objetivos, algunos pragmáticos y bastante orientados a sistemas [de información]. Su

42 Ibid., p. 224.

43 Ibid.

44 B. Rayward. "Library and Information Science: an history perspective", en Journal of Library History spring 1985, no. 20, pp. 120-136.

45 Ibid., p. 128. 
principal objetivo dio como resultado el desarrollo de una serie de teorías que podrían utilizarse para explicar el desarrollo y el uso de la información y, finalmente, del conocimiento". ${ }^{46}$

Así pues, mientras ocurrían tales acontecimientos, la reacción de las escuelas de bibliotecología acreditadas se centraban, casi simbólicamente, en los nuevos desarrollos tecnológicos. Sin embargo, algunos autores coinciden en que la excepción fue la escuela de la Western Reserve University. "En 1950, dicha escuela había ofrecido el primer curso en documentación y en 1955 había establecido un centro de documentación. Durante este periodo recibió fondos para investigación sobre sistemas de recuperación de información". ${ }^{47}$

Por otra parte, la figura de Taube se considera de sumo valor, pues en 1950 impulsó y transformó el comercio en el manejo y producción de servicios de información mediante su empresa Documentation, Inc. "El reto estaba claramente definido, actuar como un agente catalizador en el desarrollo de una nueva profesión. Al mismo tiempo, redefinir y preservar los valores de la bibliotecología tradicional". ${ }^{48}$

Taube titubeaba acerca de que esto se realizara. Veía los esfuerzos hacia la unidad en la profesión como ocultadores de una dicotomía real en la función. "Yo diría que el bibliotecario público, con excepción de los servicios especializados en una biblioteca pública, no es un miembro de la misma profesión que el bibliotecario especial.”49 En este contexto, Taube veía más bien unidad entre los bibliotecarios especiales y los documentalistas.

Así, a la luz de las ideas de Taube, surgió “[...]un grupo profesional preocupado por la comunicación de información especializada, que insistiría sobre las currícula en las escuelas, currícula que incluyera lógica, semántica, edición e impresión, fotorreproducción, catalogación,

46 J. Shera y D. B. Cleveland. "History and foundations of Information Science", en Annual Review of Information Science and Technology, 1977, no. 12, pp. 111-151.

47 H. C. Wright. "Shera as a bridge between Libranship and Information Science", en Journal of Library History, spring 1985, no. 20, pp. 137-156.

48 M. Taube. "Implications for professional organization and training", en American Documentation aug. 1953, no. 4, pp. 122-125.

49 Ibid., p. 124. 
sistemas de comunicación y distribución". ${ }^{50}$ En esencia, un científico de la información es "[...] una persona que estudia y desarrolla la ciencia del almacenaje y la recuperación de la información, la idea de nuevos enfoques hacia los problemas de la información y que está interesado en la información en sí y por sí misma". ${ }^{51}$ Se ofrecieron los programas tanto de maestría como de doctorado. Ya en 1967, Slamecka señalaba que "[...] el programa se basó en la premisa de que el estudio de la información como fenómeno no se halla restringido a la bibliotecología, sino que es interdisciplinario." 52

Este nuevo programa educacional cristalizó la tendencia de los años setenta y principios de los ochenta, en asociación directa con la ciencia de la computación y la ingeniería de programas de cómputo. Los programas de sistemas de información se desarrollaron en respuesta a los desarrollos de hardware, software así como de los sistemas de información de décadas abteriores. "Los sistemas de información basados en máquinas de una naturaleza sin paralelo previo, se volvieron posibles". ${ }^{53}$ En los años ochenta, la aparición de "[...]la sociedad de la información presionó a las escuelas tradicionales de bibliotecología, debido a la idea de la gestión de recursos informativos (information resource(s) management IRM)".54 Los proponentes urgieron a que todas las disciplinas, ocupaciones y profesiones trabajaran en estos enfoques.

A principios de los años ochenta, fue obvio que las antiguas estructuras de la educación bibliotecológica, como las nuevas (en ciencias de la computación y negocios) eran inadecuadas para la sociedad de la información. El desarrollo de sistemas de información óptimos para satisfacer las necesidades de la creciente y compleja sociedad.

50 Ibid., p. 125.

51 D. M. Crosland. "Georgia tech and the NSF study grant for training personnel for scientific and technical libraries", en Special Libraries dec. 1962, no. 53, pp. 590-594.

52 V. Slamecka. "Graduate programs in information science at the Georgia Institute of Technology", en Special Libraries apr. 1968, no. 59, pp. 246-250.

53 Robert V. Williams y Martha Jane K. Zachert, Op. cit., p. 227.

54 M. L. Cohen. "Education for Law Librarianship", en Library Trends jan. 1963, no. 11, pp. 306-314. 
Los bibliotecarios especiales se dividieron en sus posibilidades o aptitudes y la necesidad de la educación disponible, muchos creyeron que resultaba más apropiada la capacitación en materias, seguida por el aprendizaje de las técnicas bibliotecarias. Pero quienes apoyaban la educación bibliotecológica, indicaban la necesidad de buscar formas de cooperación con las escuelas.

Así, el amplio reconocimiento social acerca de que Estados Unidos había ingresado en la era de la información obligó a centrar la atención en la necesidad del cambio, para ubicar juntos la educación tradicional en bibliotecología y los nuevos programas de información, para reexaminar la vocación subyacente de la profesión, para permitir la convergencia de las profesiones de la información, además de desarrollar nuevos tipos de educación.

El núcleo ahora incluye las técnicas para la automatización de los procesos bibliotecarios tradicionales y para búsqueda en línea de archivos bibliográficos. Por otra parte, la duración deseada del programa para el grado de maestría, el tiempo permitido para los estudios de especialización así como la naturaleza y responsabilidad del aprendizaje en el programa de grado, siguen siendo cuestiones irresueltas en diversos reglamentos universitarios. La capacidad de preparar estudiantes para el amplio espectro de los puestos de trabajo en la información especializada por materias, sobre todo, las que se han generado con las TIC, continúa sin una atención importante.

A lo largo de la historia de las especializaciones, se observa que los programas de educación bibliotecaria "[...]han confrontado el problema de preparar a los profesionales para el trabajo orientado a materias o a bibliotecas especiales". ${ }^{55}$ Varios especialistas señalan que la resistencia de los programas de educación bibliotecaria contra las demandas de los profesionales respecto de la especialización "[...]ha limitado la profesión a un ámbito de trabajo muy estrecho en la sociedad de la información de hoy". ${ }^{56}$ La resistencia de amplios sectores de profesionales en bibliotecología para aceptar la importancia de la educación especializada para la disciplina bibliotecológica y para la sociedad.

55 Robert V. Williams y Martha Jane K. Zachert, Op. cit., p. 215.

56 Ibid., p. 216. 
"Esta actitud contraria, tanto de los profesionales, como de los educadores, aun cuando ya no era dominante, ha sido evidente desde los primeros días de la educación profesional formal". ${ }^{57}$

Es probable que tal resistencia haya limitado la profesión bibliotecaria a formar profesionales especializados en las diversas actividades relativas a la documentación digital, las TIC y su incidencia en la sociedad de la información y del conocimiento. La resistencia a la especialización en materias ha limitado la cooperación entre disciplinas afines. En México, la tendencia de la Maestría en Bibliotecología y Estudios de la Información ofrecida por la UNAM tiene como una de sus metas incidir en especializaciones propias de la disciplina. Sin embargo, en varios semestres la dispersión y la limitante temática de las materias que se ofrecen ha repercutido en el objetivo de incidir en un alto nivel de especialización de sus egresados. No obstante, ante los cambios sustantivos en los modelos estructurales de las sociedades y de las instituciones educativas, la disciplina bibliotecológica tiene el compromiso de diversificar sus campos de conocimiento, crear nuevas alternativas de formación a partir del desarrollo del conocimiento de la disciplina y de otras disciplinas afines. Al igual que como ocurre con las demandas de los mercados laborales, así pasa con la incorporación de las TIC en la producción, gestión y difusión de nuevos conocimientos, en la innovación de sus métodos y técnicas de enseñanza-aprendizaje y con la continuidad de la investigación básica y aplicada. La posibilidad de una especialización sobre la organización de recursos informativos digitales debe incursionar en estos aspectos. Asimismo, resultan necesarios, en diversas naciones latinoamericanas, los recursos humanos con un alto nivel de especialización para elaborar estudios específicos y de amplio espectro orientados a la organización documental. Tal conocimiento debe reflejar las necesidades informativas de los usuarios en los niveles local, regional, y nacional además de proyectar sistemas de información normalizados que contemplen el máximo aprovechamiento de los recursos documentales del país en diversos entornos geográficos.

57 Ibíd., p. 215. 
Desde hace algunos años, México ha tenido el "[...]compromiso de modernizar el sistema educativo, por lo que algunas instituciones, entre ellas la Universidad Nacional Autónoma de México, han avanzado en su proceso de revisión y reformulación curricular [permanente]". ${ }^{58}$ Situación que naturalmente incluye las especializaciones, pues en dicha UNAM se imparten actualmente estudios de especialización en disciplinas como derecho, medicina, administración, ingeniería, etcétera.

Por otra parte, a la luz del Tratado del Libre Comercio de América del Norte (TLCAN) se ha puesto de manifiesto el requerimiento de preparar profesionistas capaces de solucionar problemas de información que atañen a la sociedad de hoy. Esto implica elevar la calidad de la enseñanza, diversificar los fenómenos de estudio de la bibliotecología e incidir en propuestas de especialización, acordes con un mundo globalizado y con el requerimiento de movilidad profesional más allá de las fronteras de Estados Unidos y Canadá. En este contexto, es alentadora la intervención de la Asociación Nacional de Universidades e Instituciones de Educación Superior (ANUIES) que en su XXVIII Asamblea General se comprometió a "[...]fortalecer y consolidar el sistema de educación superior, para lo cual se propuso impulsar y conformar el Sistema Nacional de Evaluación y Acreditación mediante estándares generales de calidad profesional [...]".59

A pesar de ello, hasta ahora no existe en el área bibliotecológica ninguna propuesta de especialización propiamente dicha en el nivel de posgrado, posibilidad que se encuentra sustentada en la normatividad de la UNAM y de otras instituciones de educación superior mexicanas; por lo tanto, consideramos de interés incidir en la especialización sobre la organización de recursos informativos digitales, pues es un área de conocimiento sustantivo de la bibliotecología y un fenómeno de estudio actual que atañe a todo tipo de unidad de información.

58 J. A. Rodríguez Gallardo, Op. Cit. p. 123.

59 Ibid., p. 124. 


\section{TENDENCIAS ACTUALES SOBRE LA ORGANIZACIÓN DE RECURSOS INFORMATIVOS DIGITALES}

El diseño de una propuesta de educación virtual sobre la organización de recursos informativos digitales implica tener en cuenta los diversos fenómenos que exigen su estudio, con el fin de que, a partir de aquéllos, se fundamenten los contenidos del diseño curricular. Los objetivos de la organización de recursos informativos digitales son reflejo de una necesidad humana de contar con los medios para acumular, organizar, recuperar y transmitir el conocimiento. Esto sólo se satisface con el desarrollo de herramientas normalizadas que garanticen efectividad en la organización y recuperación documental, con la idea de que la sociedad los use. En este sentido, las metas de la organización no configuran solamente una anticipación idónea de lo que se efectuaría, sino que además determinan requerimientos sociales en cuanto al uso de la información y su posible aplicación en situaciones humanas reales.

Por lo anterior, en la propuesta educativa virtual se ha de considerar que la sola actividad cognoscitiva de la historicidad, fenómenos, teorías, técnicas, métodos y tecnología orientados a la organización de recursos informativos digitales no revelan una repercusión social relevante en cuanto a las finalidades de dicha tarea; en consecuencia, conocer la organización documental y sus finalidades sociales se entiende como una unidad indisoluble.

La relación entre conocer acerca de la formación de colecciones documentales y la acción que representa la prestación de servicios derivados de su organización, mediante normas internacionales, requiere de la mediación de los fines que se persigan. La organización documental necesita medios e instrumentos para prestar servicios de información, y de condiciones que estimulen y faciliten el cumplimiento de esos objetivos, puesto que sólo se concretan o materializan con la práctica de la formación y organización de colecciones documentales, así como con la prestación de servicios de información específicos. 
En este sentido, se hace hicapié en que se ha señalado que la autonomía de la bibliotecología como disciplina se ubica en el siglo XIX, sin embargo, sus métodos, principios, teorías, temas de estudio, enfoques y corrientes se han desarrollado a lo largo del tiempo, y en todo esto ha estado presente el uso de tecnologías. Así, “[...]la revolución tecnológica de mediados del siglo XX, [enriqueció] las formas de registro documental, uso, difusión y preservación de la información y el conocimiento". ${ }^{60}$

Como ha sucedido en el devenir de los años, la organización del conocimiento, para su posterior localización y utilización, ha sido fundamental en el desarrollo cultural de la humanidad, pues la transmisión de información a individuos o grupos de una sociedad determinada es un fenómeno repetitivo temporal y espacialmente. Para realizar tal despliegue, ha sido indispensable que la información documental se mantuviera organizada para después recuperarla y difundirla en la sociedad y así después, propiciar la generación de nuevo conocimiento. De este modo, la organización de los registros gráficos, producto del quehacer intelectual humano ha sido una actividad constante en todas las épocas y en cualquier sociedad.

Por ello, se puede señalar que las reflexiones sobre la organización del conocimiento y del saber producidos por el hombre siempre han estado íntimamente vinculadas con el manejo y diseño de los procesos que los recogen.

Aristóteles desarrolló su clasificación de las ciencias como plan de construcción de su magna obra escrita, una auténtica enciclopedia. Los helenistas de la biblioteca de Alejandría se plantearon el problema de la organización de los documentos y de los saberes aportados por los sabios helenistas y sus predecesores en un todo organizado, con valor cognitivo $\mathrm{y}$, por tanto, predecible y recuperable.

60 UNAM. "Programa de Maestría y Doctorado en Bibliotecología y Estudios de la Información", Op. cit.,

http://www.filos.unam.mx:80/POSGRADO/programa/biblio.htm 
Ante la inmensa dispersión del saber, y su inabarcabilidad, los enciclopedistas propusieron una organización cuántica. ${ }^{61}$

Del mismo modo, a mediados del siglo XX, se creó el hipertexto, un sistema para el registro, organización y consulta de documentos, apoyado en el uso intensivo de las TIC, basado en la idea de que la mente humana funciona con base en asociaciones. La idea era hacer factible la disponibilidad universal del conocimiento y la democratización de la cultura.

Asimismo, en el siglo XX importantes organismos internacionales mostraron interés en la generación de programas y sistemas nacionales e internacionales de información, la cooperación bibliotecaria a partir de los productos emanados de la organización documental y la posibilidad de generar herramientas orientadas a lograr un uso más eficaz de la información en las sociedades. Dichos organismos han pugnado por orientar la organización documental mediante el uso de normas de cobertura internacional y el uso de TIC. En la difícil tarea de diseñar y mantener normas para la organización documental y su transferencia han participado activa e importantemente, durante el siglo XX y albores del XXI, diversos y muy prestigiados organismos, como “[...]la American Library Association, el Instituto Nacional Americano de Normalización (ANSI), UNESCO/UNISIST, la Federación Internacional de Asociaciones de Bibliotecas (IFLA), la Federación Internacional de Documentación (FID) y la Organización Internacional de Normalización (ISO)". ${ }^{62}$

Sus resultados se relacionan, entre otros desarrollos, con los formatos MARC, USMARC, UNIMARC, CCF y recientemente, con MARC 21. Las normas ISO aplicadas a la documentación, las Reglas de catalogación angloamericanas y las ISBD (International Standard Bibliographic Description) representan algunas de las herramientas normativas surgidas en el seno de éstos y otros organismos. Su finalidad ha sido facilitar el

61 Francisco Javier García Marco y Vannevar Bush, "El hipertexto y el futuro del documento", en Tendencias de la investigación en documentación / ed., Jesús Tramullas. Zaragoza, España: Seminario TID, 1996, p. 193.

62 R. Lafuente López y Roberto Garduño Vera. Lenguajes de marcado de documentos digitales de carácter bibliográfico, Op. cit, p. 35. 
desarrollo del ciclo del control bibliográfico que comprende las tareas de codificación, catalogación, clasificación, almacenamiento, recuperación, intercambio de la información y su utilización en las sociedades, en sus diversos entornos geográficos.

El panorama actual del manejo documental (registro, organización y recuperación) lo dominan sobre todo las tecnologías de las bases de datos, el hipertexto, las bibliotecas digitales y los sistemas de metadatos. No obstante la existencia de tecnologías como la inteligencia artificial y los sistemas expertos, los hechos muestran que los modelos de gestión de la información se organizan en función de la idea de las bases de datos y del hipertexto.

Sin duda, estas tecnologías han modificado la imagen tradicional del documento, los soportes de información, la forma de organizar los contenidos documentales y la manera de generar los servicios de información, incluso se han creado nuevas formas de registrar datos e información mediante estructuras lógicas diseñadas para su procesamiento automático, inconcebibles fuera del contexto tecnológico.

Ante este panorama generado por las TIC, organismos internacionales como los ya citados diversas unidades nacionales de información de reconocido prestigio, como la Biblioteca del Congreso de Estados Unidos, la Biblioteca Nacional de Canadá, la Biblioteca Británica, entre otras, así como diversos programas en educación bibliotecaria, documentalista y ciencias de la información, se han abocado a atender, desde donde les corresponde, los fenómenos que atañen a la organización de la información documental, en pro de las sociedades usuarias. Así, el modelo teórico orientado a la enseñanza virtual sobre la organización de recursos informativos digitales toma en cuenta los logros de esos organismos y la existencia de varios fenómenos que requieren atenderse con su enseñanza. Entre otros, los elementos que decíamos se consignan enseguida. 


\section{El documento como objeto digital}

Las tecnologías de bases de datos, hipertexto y sistemas de metadatos influyen ampliamente en la generación de modelos para la gestión de la información documental. Sin duda, estas tecnologías han renovado la idea tradicional de documento, pues no sólo los soportes de información denotan cambios, sino la forma misma de las tareas relativas a la organización, acceso, recuperación y estructuras de contenido de los documentos digitales. Así, han surgido tecnologías y formas para registrar datos e información mediante estructuras lógicas, diseñadas para su proceso automático, inconcebibles fuera del contexto de la informática.

La necesidad de estudiar, en forma virtual, éstos y otros asuntos, se observa con más certidumbre cuando se remite al documento digital. Varios autores han señalado que se requiere establecer principios generales para la clasificación de una taxonomía de estos documentos, con el propósito de facilitar la construcción de principios para crear, organizar, difundir y gestionar colecciones digitales. Esto se debe a que las redes de telecomunicación han creado novedosos espacios para la comunicación de información, estableciendo nuevas formas documentales. Así, se diría que las propiedades únicas de los documentos digitales, derivadas del uso de tecnologías digitales, determinan su naturaleza formal para el registro, transmisión y proceso de la información de esta índole. ${ }^{63}$

La introducción y uso de los documentos digitales en redes de telecomunicación no ha modificado grandemente las funciones tradicionales del documento, sino que éste actúa como una extensión del lenguaje para comunicar el pensamiento y facilitar la labor de la memoria. El documento digital se utiliza, pues, para comunicar, portar mensajes y discursos, bajo la tradicional forma del texto. En este sentido, el estudio de la normalización documental, de los formatos bibliográficos, de los lenguajes de marcado y de los sistemas de metadatos, entre otros fenómenos, es determinante, debido a su

63 Ibid., p. 5. 
trascendencia para registrar, organizar, clasificar y asociar documentos digitales.

Los documentos de esta naturaleza existentes en Internet presentan características inéditas en cuanto a estructura formal (denominada arquitectura del documento) y en cuanto a la generación de su contenido, principalmente en línea, aspecto que determina el uso necesario de las TIC. En este sentido, los documentos digitales se caracterizan por el manejo de bits-caracteres mediante impulsos electrónicos y magnéticos, en tal estado, adquieren semántica propia con el propósito de que el documento tenga sentido y utilidad para el usuario final.

Sobre estos asuntos, Schambler define el documento digital como "[...]la unidad flexible y dinámica, consistente en contenido no lineal, representado como conjunto de items de información, enlazados o almacenados en uno o más medios físicos o en red, creados y utilizados por uno o más individuos en el desarrollo de algún proceso o proyecto”. ${ }^{64}$ A mayor abundamiento, Fernández Hernández señala que "íntimamente relacionada con lo anterior se encuentra la integración semiótica, pues se desarrollan signos propios de los lenguajes tecnocientíficos, constituyendo un lenguaje semiótico digital y binario que se expresa en pixeles, bits, capacidad de memoria". ${ }^{65}$ Todo esto repercute, naturalmente, en el desarrollo del documento digital, en su organización, acceso y recuperación. En cambio, Codina cuando alude las características del documento digital, define las siguientes dimensiones

1. Navegación por la información. Opciones y elecciones sucesivas entre las alternativas y opciones del menú presentes en los documentos digitales. Esta navegación está relativamente condicionada por el autor del documento digital.

64 Linda Schamber. "What is a document? Rethinking the concept in uneasy and times", en Journal of the American Society for information science, v. 47, no.9, 1996, p. 669.

65 Patricia Fernández Hernández,. "Transferencia de información y educación a distancia", en X Encuentro internacional de educación a distancia: hacia la construcción de la sociedad del aprendizaje, México, (en prensa), 2003. 
2. El descubrimiento de relaciones. Se realiza en los sistemas de recuperación de información; no sólo conduce a la búsqueda del tema específico, sino a otros campos afines en los que también se habla información adecuada.

3. El establecimiento de filtros selectivos y personalizados sobre las características de la información que recibe a la medida específica de cada usuario[...]. ${ }^{66}$

Por otra parte, Hemingway considera que las ventajas de la información digital se manifiestan en estas dimensiones:

a) Acceso aleatorio. La información analógica es "lineal", mientras que la información digital es "aleatoria", lo que significa que la velocidad de acceso a la información en un medio digital es independiente de la cantidad de información que contenga.

b) Interacción, porque los medios digitales permiten la interacción en formas mucho más complejas e interesantes que los medios analógicos, que además resultan más pasivos.

c) Creación, además de coincidir con lo expresado anteriormente, esta propiedad explica que el usuario puede manipular o cambiar objetos, elementos o situaciones más fácil y rápidamente que con los medios analógicos. ${ }^{67}$

Las posibilidades de la elaboración del documento digital son múltiples, ya que las tecnologías de red brindan a un autor específico las facilidades para que plasme su conocimiento en determinado documento de esta clase, asimismo, otras alternativas son la colaboración de grupos especializados a través de redes académicas para elaborar documentos en grupo y las listas de discusión de temas específicos. Así, un solo documento se modificaría para obtener diversas versiones del mismo, enriquecer su contenido combinando textos, imágenes, sonido y voz, activar facilidades para su transferencia y prever el manejo de relaciones múltiples para una recuperación más exitosa.

66 Luis Codina. "El libro digital y la www", en Revista Española de Documentación Científica vol. 23, no.1, pp 61-92.

67 Hemingway, citado por Lluis Codina, en El libro digital... Op. cit., p. 70. 
En cuanto a su uso, se advierte una capacidad ilimitada de réplica, cuya posibilidad por parte del usuario de navegar e interactuar con el contenido total o con partes del mismo, facilidades para vincularse con otros documentos (bases de datos, catálogos públicos en línea, páginas web, portales y otros). Sin embargo, como las experiencias al respecto se encuentran en sus inicios, los cuerpos académicos cuidan la fiabilidad del contenido y su permanencia en red. Asimismo, se remite sus características cambiantes, situación que se cree se perfeccionará con el desarrollo de nueva tecnología para la publicación digital. Al respecto, Lafuente López abunda: “[...] el documento en ambientes digitales se adapta y modifica, de acuerdo a las necesidades o imposiciones de las nuevas tecnologías, lo que ha motivado que sea visto como un objeto único que representa nuevas realidades, usos y aplicaciones". ${ }^{68}$

En este sentido el documento visto como objeto se ha convertido en una línea de investigación en varias comunidades científicas, así, los campos de las TIC y de la normalización han puesto especial atención en el asunto. En cuanto a éste, Mireles Cárdenas ha dicho que: “[...]en la actualidad es frecuente encontrar el uso del término objeto para designar, no sólo las partes de un documento [...], sino aquello que por su continua transformación impide señalar las características propias y definidas de los fenómenos informativos que aparecen en pantalla de una computadora". ${ }^{69}$ A mayor abundamiento, Galloway entiende por objeto digital "[...]cualquier unidad de valor o descripción de contenido, datos textos, mundo URML (lenguaje de modelación de realidad virtual), imagen, texturas, movimiento, conducta o transformación". ${ }^{70}$

68 Ramiro Lafuente López. Biblioteca digital y orden documental. México, UNAM, CUIB, 1999. p. 18.

69 Celia Mireles Cárdenas. "Del documento al objeto digital”, en Investigación Bibliotecológica: Archivonomía, bibliotecología e información, ene./jun. 2003, vol. 34, no. 17. p. 96.

70 Alex Galloway. “¿Qué son los estudios digitales?”, [en línea] http://aleph-arts.org/pens/digitalstud.html [consultada: 15/05/03] 


\section{El hipertexto en la organización de objetos digitales}

Si se quiere, podemos recordar que las actuales formas de la tecnología de hipertexto tienen su antecedente en la propuesta que Nelson hiciera en 1965, al proponer un escenario fantástico al que denominó Xanadú, ${ }^{71}$ que pretendía se convirtiera en un archivo universal del conocimiento: un enorme sistema documental automatizado, en el que se almacenaría la totalidad de lo escrito por todos los autores de la humanidad, y en el cual los textos estarían conectados a partir de innumerables relaciones. Dicho archivo no residiría en una sola máquina, sino que los usuarios dispondrían de información en sus computadoras personales y cualquier trozo de información de sus documentos se unirían a los contenidos de otras máquinas mediante enlaces, por lo cual era necesario asignar a cada fracción de información una dirección única. "En Xanadú -escribe Nelson- nunca se borraría ningún documento, ni siquiera las versiones anteriores. Habría dos tipos de enlaces: unos dinámicos que conectarían con la versión más actualizada de una información, y otros serían fijos y quedarían anclados a una versión de un documento". ${ }^{72}$

La reflexión de Nelson sobre Xanadú parece similar al ideal generado hacia 1895 por Otlet (1868-1944) y La Fontaine (1853-1943) en cuanto a propugnar por el desarrollo de la bibliografía universal, orientada a la generación de un repertorio de todo tipo de impresos generados a partir del siglo $\mathrm{XV}$, de todas las materias y publicados en cualquier país del mundo. Este ideal ha pervivido en los medios bibliotecarios a lo largo del siglo XX y en los albores del XXI, aspecto que ha propiciado la generación de proyectos orientados al control bibliográfico en el seno de instituciones y asociaciones internacionales. Por todo ello, la visión de Otlet y de Nelson, especialistas de épocas distintas, debe recordarse en cualquier oferta educativa orientada a la organización de recursos documentales. Asimismo,

\footnotetext{
71 Para más detalles sobre Xanadú véase [el línea] http//www.polyester.com.au/xanadu/ [consultada: 25/06/03]

72 Theodor H. Nelson, citado por Lafuente y Garduño, Op cit., p. x.
} 
conviene contemplar que en los últimos años la idea del hipertexto se ha vuelto en una tecnología cuyos conocimientos se orientan a facilitar la organización de textos en segmentos que, explícitamente, se relacionan entre sí de diversas maneras para crear una estructura en forma de una red de relaciones de afinidad semántica.

La idea del hipertexto, relacionada con la organización documental por clases y combinadas según las necesidades de comprensión y sistematización de sus contenidos temáticos, es un concepto reciente en cualquier texto con referencias internas a otras partes del mismo. Igualmente, las notas al margen, estructura de citas y referencias bibliográficas se conciben como una estructura hipertextual. No obstante, a pesar de que la tecnología del hipertexto parte de antiguos conceptos, agrega nuevos conocimientos sobre la forma de estructurar el texto para interrelacionarlo y consultarlo automatizadamente, produciendo novedosas formas de construir, procesar y consultar textos digitales.

La tecnología del hipertexto es una forma de gestión documental, para lo cual la información se organiza por medio de una red de conceptos conectados con enlaces y se guarda en forma de estructuras de texto anotado. Como es sabido, los sistemas de hipertexto están formados tanto por programas de computadora como por conceptos, ideas y reglas para colocar etiquetas o notas que faciliten organizar y estructurar textos y gráficos. En general, estos sistemas los integra un subsistema de anotación, apoyado en una sintaxis que facilita la construcción del hipertexto, así como un subsistema de navegación que establece relaciones para consultar conjuntos de documentos. El desarrollo de la tecnología del bipertexto facilita el diseño y construcción de hiperdocumentos, concebidos como sistemas independientes entre sí, que integran texto, imágenes y sistemas de navegación por medio de ligas dentro del sistema. Los vínculos de textos se llevan a cabo con enlaces que definen las asociaciones entre los contenidos de aquéllos. Enlazar dos textos -escribe Frei- “[...]implica la creación de un concepto o una categoría que, desde luego, 
tiene una fuerte carga semántica", ${ }^{73}$ determinante para la consulta y comprensión de un hiperdocumento, pues este sistema de vinculación conceptual es el único elemento con que se cuenta para mostrar su contenido. "Como la base cognoscitiva de un hiperdocumento, se plantea sobre un mapa conceptual", ${ }^{74}$ al momento de utilizarlo, el usuario construye sus propios significados recorriendo los enlaces. De esta forma, el hiperdocumento se convierte en un juego de lenguaje por la relación entre términos y significados. Estas relaciones son posibles gracias a la característica geométrica de su estructura.

\section{RETOS PARA LOS BIBLIOTECÓLOGOS EN LA ORGANIZACIÓN DE RECURSOS INFORMATIVOS DIGITALES}

La acelerada socialización y comercialización de las redes de telecomunicación, sobre todo de la Internet, ha generado un alud de información relacionada con las bondades de las TIC en las bibliotecas y en otras unidades de información. De ahí que se enfaticen los beneficios que una infraestructura tecnológica adecuada produce en cuanto organización y eficiencia dirigidas para alcanzar un amplio acceso a los recursos informativos por medio de normas aceptadas en el marco internacional y en el uso de las TIC apropiadas para facilitar al usuario la ágil recuperación de la información requerida.

Sin embargo, el camino para volver realidad la organización documental digital no está libre de obstáculos técnicos y conceptuales, pero, sobre todo, es indispensable franquear la barrera de la enseñanza-aprendizaje del diseño, organización y manejo de los tipos de documentos sustentados en las TIC. El acelerado crecimiento cualitativo y cuantitativo de recursos digitales exige enfrentarse a formar recursos humanos en la selección y organización normalizada de objetos digitales, así como en su recuperación, por medio de las

73 H. P. Frei, "The use of semantic links in hypertext information retrieval", en Information Processing and Management, 1995, vol. 31, no. 1, p. 2.

74 Cliff Mcknight. Hypertext in context, Cambridge: Cambridge University Press, 1991, p. 74 . 
diversas posibilidades de las tecnologías actuales, con el propósito de facilitar su acceso a la sociedad de nuestros días.

Ante semejante panorama de implicaciones sociales del progreso tecnológico, la información representa un elemento clave para las sociedades, mientras que los bibliotecarios enfatizan su responsabilidad protagónica en la selección, organización, procesamiento y difusión de esta información, recurso esencial para el desarrollo social. Todo esto, ha generado una gran demanda de formación de recursos humanos relacionada con la organización de documentos digitales. En consecuencia, la enseñanza virtual sobre la organización de recursos informativos de esta naturaleza resolvería algunos aspectos de esa exigencia; de tal modo que la enseñaza de temas relacionados con la organización documental debe contestar cuestionamientos como éstos:

- ¿Qué aportes teóricos y aplicados ha generado el control bibliográfico a lo largo del siglo XX y albores del XXI?

- ¿El desarrollo de bases de datos bibliográficos determinó formas inéditas en la organización y recuperación documental?

- ¿El catálogo público en línea heredó las formas de organización y recuperación documental de las bases de datos bibliográficos o ha generado nuevas formas para la realización de tales tareas?

- ¿Los sistemas de metadatos representan propuestas novedosas para la organización de recursos informativos digitales?

- ¿Qué teoría sustenta la estructura de metadatos?

- ¿Existe la metodología y los instrumentos normativos para la construcción de sistemas de metadatos o han de generarse?

- ¿La normalización bibliográfica actual es susceptible de adecuación o se requieren nuevos modelos para la organización normativa de documentos digitales?

- ¿Se deben generar tesauros específicos para la recuperación de la información en el entorno digital?

Afrontar estos retos se traducen en explicar y construir nuevos enfoques en la organización de documentos digitales, en épocas en que los estudios son incipientes y resulta arriesgado, dadas las limitaciones tecnológicas y conceptuales del tema. No obstante, vale la pena examinar esos fenómenos para proponer, en su momento, alternativas para 
avanzar en la construcción de sistemas de información acordes a los requerimientos de información de la sociedad contemporánea.

Por todo esto, se observa que planear una propuesta educativa virtual sobre temas relativos a la organización de recursos informativos digitales representa múltiples dificultades, dada la desbordada concurrencia de fenómenos de estudio al respecto. Sin embargo, algunos temas más trascendentes serían de gran interés, como se representa en el siguiente esquema.

\section{Figura 5}

Temas relevantes de la organización de recursos informativos digitales

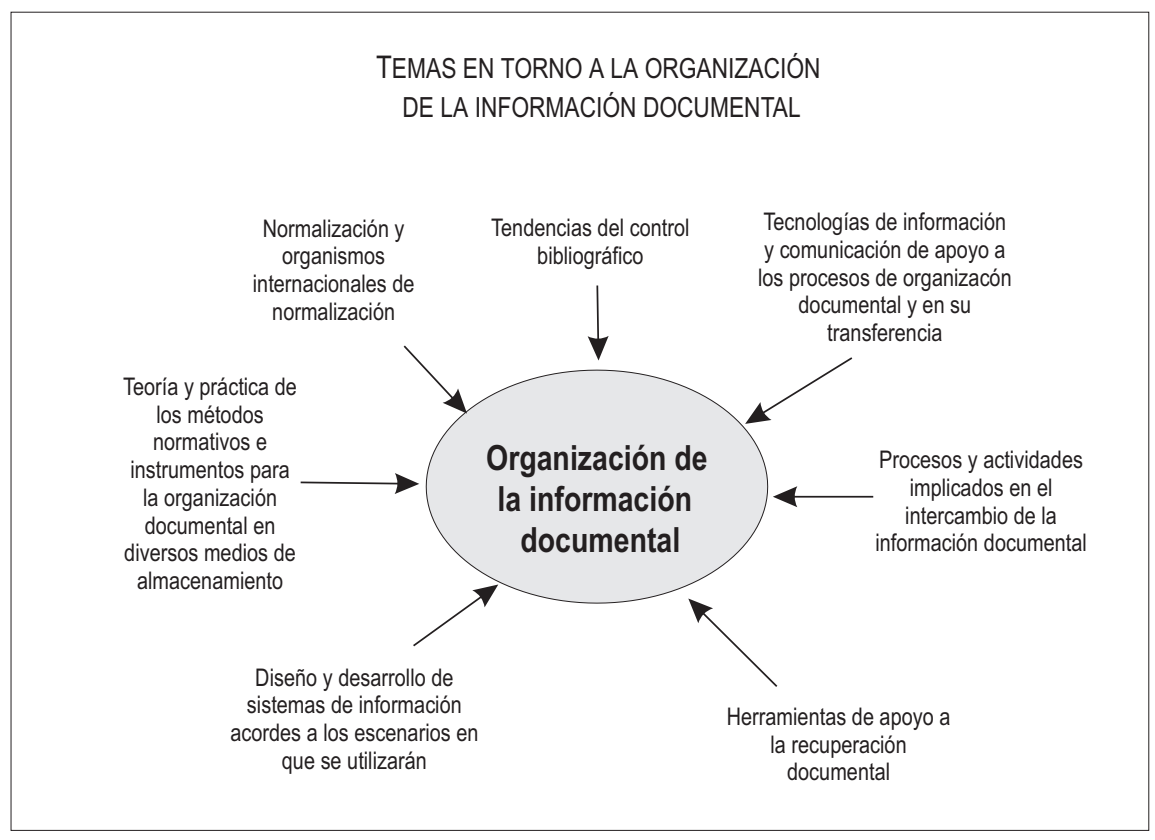

En este esquema se observa que los fenómenos de estudio que concurren en la organización de recursos informativos digitales son numerosos, lo que dificulta su examen, aun así, para identificar con precisión los objetos de estudio de mayor relevancia y actualidad, 
conviene señalar que existen diferencias fundamentales entre la organización documental y la búsqueda y recuperación de información en medios manuales y medios automatizados, así, la presencia de recursos de información almacenados, susceptibles de ser procesados en medios digitales, presentan nuevas y diferentes necesidades de enseñanza, lo que nos obliga a revalorar el método de enseñanza y, si se pretende que ésta sea virtual, las cosas se complican aún más. Por lo tanto, se requiere estudiar puntualmente las propuestas más recientes de los nuevos modelos normativos orientados a la representación de la información digital, con el fin de valorar su utilidad o, en su defecto, incidir en propuestas que garanticen estructuras para la representación documental, en un lenguaje accesible para el usuario final de la información. Esto también presupone el requerimiento de la compatibilidad de la organización del conocimiento de la biblioteca tradicional con el de la biblioteca digital y los sistemas de metadatos, para ofrecer a los usuarios una rica, organizada y eficiente información. No obstante la amplitud de la temática de la organización de recursos informativos digitales, consideramos que su aprendizaje virtual tiene que ver como esencia para su enseñanza los fenómenos más relevantes y actuales, tomando como referentes temáticos los siguientes: normalización de la información digital y gestión de contenido mediante bases de datos, lenguajes de marcado e hipertexto, los formatos bibliográficos internacionales (MARC 21 y representación de documentos digitales), los metadatos en la representación de recursos informativos digitales y el acceso a la información por Internet; por último, el tesauro en red, temas que, al igual que la estructura de la especialización sobre la organización de recursos informativos digitales que se propone, se desarrollan en el cuarto capítulo. 



\section{IV \\ Elementos básicos para el diseño de un modelo para la enseñanza virtual sobre la organización de recursos informativos digitales}





\section{APROXIMACIÓN A LA IDEA DE MODELO TEÓRICO}

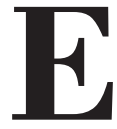

n este capítulo se revisan las variables fundamentales para estructurar un modelo académico teórico, cuyo propósito es ejemplificar, con base en una especialización sobre la organización de recursos informativos digitales, las características más relevantes de la educación a distancia, características relacionadas con la institucionalización de la propuesta educativa, la estructura del programa académico, el perfil del egresado, el desarrollo de material didáctico, la normatividad para la acreditación y demás. Cabe señalar que los temas de la organización de recursos digitales vistos en el capítulo anterior precedente, constituyen los referentes fundamentales para sustentar la estructura curricular de la especialización citada. Los elementos particulares de la educación virtual y los temas que se proponen para estructurar la especialización se complementan. El modelo teórico propuesto en esta obra comprende dos partes: el modelo académico y la estructura de una plataforma tecnológica de apoyo a la especialización, que igualmente incluye la estructura de una biblioteca digital. El primero se aborda en este capítulo, en tanto que la segunda se examina en el siguiente Así, en principio se parte del análisis de aspectos que formalizan teóricamente a los modelos.

El término modelo remite una amplia gama de tipologías y aplicaciones, cuyas particularidades que adopten se relacionan con la disciplina de la que se derivan. En consecuencia, la idea de modelo lo 
mismo alude a un conjunto de ideas abstractas, hasta cualquier representación tangible. Sin embargo, la palabra modelo indica la existencia de características y propiedades comunes determinadas por el modelo específico. Entre las disciplinas dedicadas al estudio de modelos destacan la filosofía de la ciencia, sociología, matemáticas, informática, bibliotecología, linguística, educación y otras. En este sentido, los filósofos de la ciencia subrayan la importancia de los modelos teóricos, indicando que su estudio aclara la estructura, la interpretación y el desarrollo del pensamiento científico. Desde una perspectiva filosófica, Achinstein identifica cuatro características de los modelos teóricos.

1. Un modelo teórico consiste en un conjunto de supuestos sobre algún objeto o sistema. Algunas veces, lo que se llama modelo, también recibe el nombre de teoría.

2. Un modelo teórico describe un tipo de objeto o sistema, atribuyéndole lo que se denominaría estructura interna, una composición o mecanismo que explique, al tomarlo como referencia, las diversas propiedades de ese objeto o sistema.

3. Un modelo teórico se considera una aproximación útil para ciertos propósitos.

4. Es frecuente que un modelo teórico se formule, desarrolle y llegue a denominarse tal con base en una analogía entre el objeto o sistema descritos por él y algún otro objeto o sistema diferente. ${ }^{1}$

Existe la creencia de que los modelos teóricos cubren las mismas funciones que las teorías relacionadas con fines de explicación, predicción, cálculo, sistematización, derivación de leyes, etcétera. En consecuencia, se infiere que la diferencia entre el uso de un modelo y el de una teoría no reside en la función para la que se emplee sino cómo se desempeña tal función. Sobre esto último, se ha señalado que los modelos teóricos proporcionan explicaciones basadas en supuestos posiblemente simplificadas, por lo que ha de tomarse en cuenta esta condición cuando se les compara con las teorías.

1 Peter Achinstein. Los modelos teóricos, trad. Madaleno Sancho, México: UNAM, Coordinación de Humanidades, 1987, pp. 7-9. 
En este contexto, Braithwaite afirma que "[...]de la explicación y la sistematización por medio de una teoría, se dice a menudo que son más profundas y penetrantes, por lo cual refleja la creencia de que los principios que constituyen una teoría son más exactos que los de un modelo y toman en cuenta más magnitudes conocidas. Otra postura al respecto revela que un modelo se propone siempre con referencia a alguna teoría, y que el modelo tiene la misma estructura formal que esa teoría". ${ }^{2}$ Con base en lo anterior se puede decir que los modelos son útiles para entender la problemática por medio de abstracciones que representen lo esencial de un problema o de un sistema para facilitar su comprensión, en ese sentido, la abstracción se refiere a la capacidad humana para manejar ideas complejas. Sobre esto mismo, y desde una perspectiva social, Landesheere observa que un modelo es un "[...]sistema de relaciones entre propiedades seleccionadas, abstractas, construido conscientemente con fines descriptivos de explicación o de previsión, y por ello totalmente dominable". ${ }^{3}$

Desde el enfoque informático, se dice que en el diseño de sistemas visuales se tienen que abstraer diferentes puntos de vista, construir modelos usando notaciones precisas y verificar que los modelos satisfagan los requerimientos del sistema. En ese sentido, Booch afirma que la notación:

- Sirve como lenguaje para comunicar las decisiones que no son obvias o que no pueden inferirse desde el código mismo.

- Proporciona la semántica, que es suficientemente rica para capturar todas las decisiones estratégicas y tácticas importantes.

- Ofrece una forma suficientemente concreta para los humanos para razonar y para manipular herramientas. ${ }^{4}$

2 R.B. Braithwaite, citado por Peter Achinstein. Los modelos teóricos... Op. cit p. 224.

3 Gilbert de Landesheere. Diccionario de la evaluación y de la investigación educativa, Barcelona: Oikos-Tau, 1985, p. 229.

4 Grady Booch, Object solutions, Redwood City, C. A.: Addison-Wesley, 1995, p. 15. 
Respecto de la disciplina de la comunicación, Alsina añade que "[...]los modelos son construcciones racionales, constructos que para ser eficaces no sólo deben ser construidos para representar isomórficamente ciertos factores abstractos de un conjunto de fenómenos empíricos, sino que además deben corresponder a una teoría validada de este conjunto de fenómenos".

En este sentido, las teorías de la comunicación han ejercido su influencia en áreas como la economía, la política, la cultura, la educación, la bibliotecología, entre otras. Al respecto, Bustamante agrega que "[...]lo importante ya no es la producción del mensaje o el medio, sino reconocer que comunicarse es poner en común y, por lo tanto, el emisor, el mensaje y el canal de comunicación se enfrentan a un sujeto receptor con múltiples identidades, como individuo que interactúa y participa en un contexto social". ${ }^{6}$ En educación, los modelos comunicativos se ocupan generalmente de los medios para la presentación y la selección de contenidos, estrategias psicopedagógicas de aprendizaje, intercambio de conocimiento y de la interacción entre los actores del aprendizaje.

En cuanto al ámbito de la bibliotecología y la documentación, se han propuesto modelos que, por su naturaleza, se orientan a diversos aspectos del tratamiento de la información. En este contexto, Moreiro y Marzal han dicho que "[...]los modelos lingüísticos tienen como intención principal proponer normas, métodos y técnicas para eliminar la ambigüedad de las palabras, con el fin de precisar el contenido de documentos y potenciar la recuperación relevante de los mismos".7 Ellos también subrayan que los modelos cognitivos

5 Miguel Rodrigo Alsina. Los modelos de la comunicación, Barcelona: Tecnos, 1989, p. 18.

6 Hilda G. Bustamante Rojas. "Propuesta de un modelo de orientación educativa a distancia", en Educación y formación a distancia. Prácticas, propuestas y reflexiones,/coord. Rocío Amador Bautista, México: Universidad de Guadalajara, 2001, p. 174.

7 J.A. Moreiro González y M.A. Marzal García-Quismondo. "Modelos teóricos y elementos funcionales para el análisis de contenido documental: definición y tendencias", en Investigación Bibliotecológica: archivonomía, bibliotecología e información, jul./dic. 2001, vol. 15, no. 31, p. 126. 
"[...]proponen la utilización de procedimientos provenientes de distintas disciplinas cognitivas, empleados para unir estructuras textuales, estructuras de conocimiento, objetivos y metas de los servicios de información, intenciones y expectativas de analistas y usuarios, contextos de análisis y recepción de la información, estrategias, procesos y técnicas de representación y recuperación [de recursos informativos]". ${ }^{8}$ Sin embargo, la multitud de posibilidades que adoptan los modelos, atendiendo las diversas disciplinas que los generan, corresponde a este capítulo analizar lo concerniente a los modelos educativos y modelos académicos.

\section{LAS NOCIONES DE MODELO EDUCATIVO Y MODELO ACADÉMICO}

$\mathrm{Al}$ respecto, Fornaca afirma que los modelos educativos "[...]pueden definirse como un conjunto correlacionado, en específicas situaciones sociales e históricas, de fenómenos, de datos, de acontecimientos, de hechos, de situaciones, de instituciones, de mentalidad, tendientes a usar, promover, controlar conocimientos, informaciones, mitos, valores, capacidades, comportamientos, modalidades de enseñanza y de aprendizaje individual y comunitario".?

En este sentido, por ejemplo, el Sistema Universidad Abierta y a Distancia de la UNAM tiene como propósito extender la educación universitaria a grandes sectores de la población, utilizando métodos teórico-prácticos de transmisión y evaluación de conocimientos y la creación de grupos de aprendizaje. "Será un sistema de libre opción tanto para las facultades, escuelas y el Colegio de Ciencias y Humanidades como para los estudiantes; se impartirán los mismos estudios y se exigirán los mismos requisitos que cuentan en la UNAM, la que

8 Ibíd., p. 133.

9 R. Fornaca. Componentes epistemológicos en la reconstrucción histórica de los modelos educativos y pedagógicos (primera parte). en Cero en conducta, jul./oct. 1991, vol. 6 , nos. 26-27, p. 65. 
otorgará los mismos créditos, certificados, títulos y grados al nivel correspondiente". ${ }^{10}$

Por otra parte, el modelo educativo de la Universidad Virtual del ITESM se centra en la “[...]construcción del conocimiento a través del autoaprendizaje y el aprendizaje colaborativo que fomentan el desarrollo de habilidades, valores y actitudes, y el uso de tecnología avanzada. En este modelo destacan los valores y actitudes de independencia, autonomía, disciplina, respeto, aceptación de la diversidad, honestidad y cultura de calidad. El maestro facilita las condiciones para que el alumno aprenda por su cuenta, diseñando experiencias educativas significativas". ${ }^{11}$

Con base en lo anterior se puede decir que el modelo educativo toma como referentes principales los que se presentan enseguida, naturalmente que tales referentes conciernen de igual modo al modelo de la educación virtual:

- Misión social de la entidad educativa.

- Normatividad académica.

- Estructura académica.

- Perfil del egresado (valores, habilidades, conocimiento), procesos pedagógicos de enseñanza-aprendizaje.

- Perfil del tutor.

- Estructura académica.

- Sistema de administración académica.

Sobre la noción de modelo académico se ha dicho que hace especial énfasis en las características del currículum, debido a que este es determinante en la actividad académica, ya que constituye el marco en el que se definen las relaciones entre los actores del proceso educativo y la función que se le asigna a cada uno.

10 UNAM. Estatuto del Sistema Universidad Abierta y Reglamento del Estatuto del Sistema Universidad Abierta de la UNAM relativo al ingreso, la permanencia y los exámenes. Capítulo $1^{\circ}$. México: UNAM, Dirección General de Estudios de Legislación Universitaria, 1998, p. 1. La Coordinación de Universidad Abierta y Educación a Distancia es la responsable de coordinar diversos programas en la modalidad abierta y a distancia, [en línea] http://cuaed.unam.mx

11 Para mayores detalles sobre el modelo de la Universidad Virtual del Tecnológico de Monterrey, véase http://www.puc.cl/teleduc/acercade/modelo.htm 
Díaz Barriga indica que "[...]el currículum debe ser considerado como un aspecto fundamental en la definición y en el funcionamiento de la estructura académico-administrativa de las instituciones y derivarse del modelo educativo adoptado por la institución. Es decir, debe traducir su misión, sus fines y la concepción de las relaciones con la sociedad, el conocimiento, la enseñanza y el aprendizaje, aspectos que deben ser reflejados en el conjunto de las características normativas, organizacionales y académicas que definan tanto el diseno curricular como la estructura académico-administrativa". ${ }^{12}$ Arnaz coincide con lo anterior al señalar que "[...]el currículum es el plan que norma y conduce, explícitamente, un proceso concreto y determinado de enseñanza-aprendizaje". ${ }^{13}$ En relación con lo anterior, cabe delimitar que los modelos académicos con un uso amplio son el "[...]currículum rígido, currículum semiflexible, currículum flexible y currículum modular", ${ }^{14}$ que a continuación se describen.

Currículum rígido.

Se basa en la disciplina como criterio para seleccionar y ordenar los contenidos que cada asignatura aporta, independientemente del resto de las otras. Las materias requeridas para cursar un programa y obtener un título o grado están previamente determinadas y su secuencia temporal está claramente señalada en periodos de tiempo y ciclos escolares.

Currículum semiflexible.

En este modelo, los conocimientos requeridos para una carrera se organizan en etapas constituidas por grupos de asignaturas, que no necesariamente tienen una secuencia temporal obligatoria previamente definida. Por lo general, se organiza en tres niveles o etapas, conformadas por un grupo de cursos básicos de nivel general, comunes a todos los programas del área del conocimiento que corresponde; un segundo grupo de cursos, que responde a los

12 Ángel Díaz Barriga et al., "El diseño curricular en la UAM Xochimilco: un estudio exploratorio desde la práctica docente", en Revista de educación superior abr./jun. 1990, vol. 2, no. 74, pp. 51-94

13 José A. Arnaz, La planeación curricular, México: Trillas, 1983, p. 9.

14 M. D. Sánchez Soler, Modelos académicos, México: ANUIES, 1995. p. 33. 
requerimientos específicos del programa académico seleccionado y un tercer grupo de cursos que permiten profundizar en un área del programa de estudio o de un programa distinto. En alguna de las etapas, las asignaturas están organizadas por áreas.

Currículum flexible.

Permite que las actividades de aprendizaje se seleccionen considerando los requerimientos del programa y las características del estudiante. En este modelo no hay un listado predeterminado de materias a cursar o actividades escolarizadas definidas y secuenciadas. Se definen con precisión los objetivos del programa: el perfil de ingreso, las características de los académicos participantes y el perfil del egresado. La determinación y duración de los cursos, seminarios y actividades a desarrollar por los estudiantes se realiza generalmente por parte de un tutor asignado a cada estudiante o una instancia colegiada en la que participa el cuerpo docente asignado al programa, comúnmente el trabajo de investigación desempeña un papel preponderante en la definición de las actividades a desarrollar por el estudiante.

\section{Curriculum modular.}

Los contenidos del programa se encuentran organizados en módulos. Se entiende por módulo la unidad en sí misma que contempla, teórica y prácticamente, la totalidad de un proceso definido por un problema concreto, el cual constituye la base para el diseño de los contenidos del módulo e intenta integrar el conocimiento a través de la investigación de un problema eje y su repercusión en la sociedad. La función del tutor en este tipo de modelos es orientar y coordinar al estudiante en la adquisición del conocimiento, considerando el objeto de aprendizaje.

Con base en estos ejemplos de currículos se dice que la noción de modelo educativo trata de reconocer al alumno como el eje principal del aprendizaje, con valores de respeto, honestidad, responsabilidad, actitud crítica y compromiso social; habilidades de pensamiento, informativas y de aplicación del conocimiento. En consecuencia, se entiende que una formación virtual que garantice calidad en la enseñanza requiere la participación activa de los alumnos, capacidad de organización de su tiempo y actividades de aprendizaje para el 
cumplimiento oportuno de sus cargas académicas; aspectos a los que alude el modelo de la educación virtual.

En cuanto al modelo académico de la Especialización sobre organización de recursos informativos digitales, se adoptó la estructura modular por ser la que, con nuestra opinión, favorece la presentación lógica de los contenidos que se sugieren en dicha especialización y las particularidades de la tutoría. Asimismo, la presentación modular también se adopta en el desarrollo teórico del aula virtual. Sin embargo, el modelo propuesto considera otras características derivadas de la educación virtual y de los modelos instruccionales. Así, un modelo de esta naturaleza "[...]constituye [la estructura] procesal sobre la cual se produce la instrucción de forma sistemática y fundamentado en teorías del aprendizaje". ${ }^{15}$ En consecuencia, el conjunto de elementos presentados en la estructura del modelo académico de la especialización, se atiende a lo largo del siguiente apartado.

\section{MODELO ACADÉMICO PARA LA ENSEÑANZA VIRTUAL SOBRE LA ORGANIZACIÓN DE RECURSOS INFORMATIVOS DIGITALES: UNA ESPECIALIZACIÓN COMO EJEMPLO}

En el primer capítulo ${ }^{16}$ señalábamos que la educación a distancia es una "[...]metodología de enseñanza en la que las tareas docentes acontecen en un contexto distinto de las discentes, de modo que éstas resultan, respecto de las primeras, diferenciadas en el tiempo, en el espacio o en ambas dimensiones a la vez". ${ }^{17}$ "La educación a distancia es una metodología de enseñanza que se caracteriza por la

15 Gloria J. Yukavetsky, “¿Qué es el Diseño Instruccional?” [en línea] http://cuhwww.upr.clu.edu/ video/personal/facultad/yukavetsky/Tecnologia\% 20Ed/Lectura_3\%20.html [consultada: 28/01/03]

16 El marco teórico de la educación a distancia y las teorías de aprendizaje relacionadas se examinan ampliamente en el segundo capítulo de este libro. Por lo tanto, en este apartado sólo se remite parcialmente aspectos sobre el desarrollo de este rubro.

17 J. Sarramona, citado por Lorenzo García A., La educación a distancia: de la teoría a la práctica. España: Aries, 2001, p. 27. 
interposición de formas mediadoras entre docentes y estudiantes, para trascender las limitaciones de tiempo y espacio propios de la enseñanza directa o presencial, y abrir así el ámbito de influencia de la educación". ${ }^{18}$

En estos y otros aspectos teóricos del aprendizaje, se trata de precisar lo que implica la educación a distancia. Entre las dimensiones principales que la identifican, se halla la población masiva de estudiantes predominantemente adulta, puede haber separación física entre docente y estudiantes, acude planificadamente a contactos presenciales, atiende el desarrollo de materiales didácticos, hace uso de medios específicos de comunicación educativa, se orienta al aprendizaje centrado en el alumno, tiende al uso creciente de las TIC, utiliza redes académicas de aprendizaje y requiere de una institución sede, la cual debe reunir requisitos de infraestructura académica, administrativa y normativa. Tales dimensiones se presentan en el esquema.

Figura 6

Dimensiones esenciales del modelo de la educación a distancia

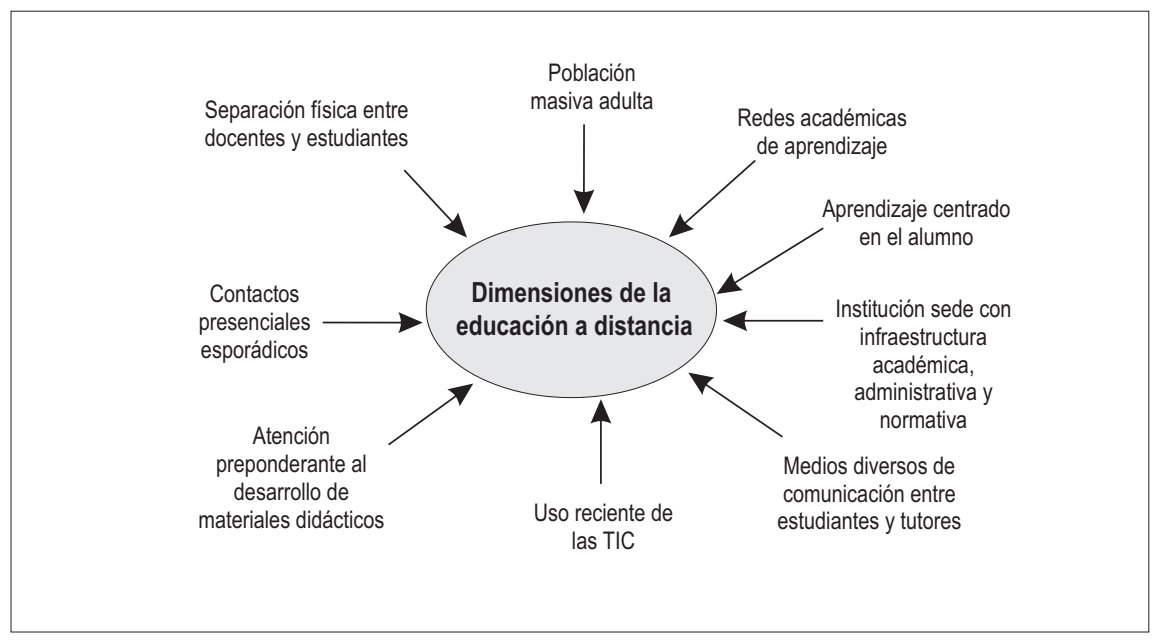

18 Peña Borrero, Op. cit., p. 9. 
Hoy la discusión sobre la educación a distancia como modelo alternativo adquiere relevante importancia en el marco mundial. Al respecto, la UNESCO reconoce el papel de la educación a distancia y de las TIC, en apoyo a los procesos educativos y de investigación. Destaca la manera como la tecnología ha modificado la elaboración, adquisición y transmisión del conocimiento, creando nuevos entornos pedagógicos capaces de sortear distancias y con sistemas que permitan una educación de alta calidad. ${ }^{19} \mathrm{~A}$ la vez puntualiza que se deberá generalizar, en la mayor medida posible, la utilización de tecnologías para "[...]reforzar el desarrollo académico, ampliar el acceso, lograr una difusión universal y extender el saber, y facilitar la educación durante toda la vida. Todo esto mediante la creación o reforzamiento de redes académicas, que permitan aprovechar las ventajas de la tecnología reconociendo las necesidades nacionales y locales". ${ }^{20}$

Por lo ya expuesto, cabe reconocer que en este milenio el desarrollo del conocimiento y de las TIC son fenómenos esenciales que enfrenta la educación superior en todos sus niveles y modalidades. En este sentido, cobertura y calidad continúan siendo retos para el modelo de la educación a distancia, acentuados con el uso de las TIC. Así, el desafío de las entidades de educación superior es participar en el diseño de modelos que indiquen, entre otros aspectos, la forma de hacer un uso más eficiente de los recursos humanos, las infraestructuras tecnológicas y los tiempos y espacios para aprender.

Asimismo, se tiene presente que la figura del tutor en "[...]el proceso de enseñanza-aprendizaje" 21 es determinante, dada su función de motivar y facilitar el aprendizaje. Por tanto, es necesario que el tutor se

19 La Educación Superior en el siglo XXI, Op. cit., pp. 1- 3.

20 Ibidem, p. 14.

21 Enseñanza, transmisión de conocimiento, técnica, normas a través de una serie de técnicas e instituciones. Su objetivo es promover aprendizaje eficazmente. El acto de enseñar recibe el nombre de acto didáctico, los elementos que lo integran son: $a$ ) un sujeto que enseña (docente), b) un sujeto que aprende (discente); c) el contenido que se enseña/aprende; d) un método, procedimiento, estrategia, por el que se enseña. Diccionario de las ciencias de la educación, p. 530. 
involucre con el modelo de la educación a distancia y, de manera especial, en la didáctica relacionada con ese modelo, principalmente la dirigida al desarrollo de materiales didácticos que respondan a los requerimientos de los estudiantes interesados en la especialización y en los métodos y medios de comunicación educativa, recordando las condiciones laborales, sociales y culturales de los alumnos, desde las que operan los sistemas bibliotecarios, documentales, bibliográficos y de información. Ello revela la necesidad de influir en el perfil de un egresado crítico y propositivo, por lo que, en el modelo planteado se acude a un proceso pedagógico constructivista, manifiesto como marco educativo general para sustentar la actividad educativa de la especialización, ya que en la corriente constructivista confluyen principalmente estos aspectos:

a) Postula la participación activa del alumno frente al objeto de conocimiento y al tutor como organizador y facilitador del aprendizaje, dependiendo del contexto social de que se trate.

b) Indica la necesidad de considerar procesos eminentemente interactivos en la construcción del conocimiento entre los actores del aprendizaje.

c) En los medios educativos se reconoce que el constructivismo es una teoría apropiada para aplicarla en proyectos basados en la educación a distancia.

d) Diversas propuestas a distancia en operación se apoyan en dicha teoría.

Para ahondar en lo anterior, se retoma lo señalado por Díaz Barriga de: la concepción constructivista del aprendizaje y la intervención educativa, que constituye la convergencia de las diversas aproximaciones psicológicas a estos problemas:

- El desarrollo psicológico del individuo, particularmente en el plano intelectual y en su intersección con los aprendizajes escolares.

- La identificación y atención a la diversidad de intereses, necesidades y motivaciones de los alumnos respecto del proceso enseñanza-aprendizaje.

- El replanteamiento de los contenidos curriculares, orientados a que los sujetos aprendan a aprender sobre contenidos significativos. 
- La búsqueda de alternativas novedosas para la selección, organización y distribución del conocimiento escolar, asociadas al diseño y promoción de estrategias de aprendizaje e instrucción cognoscitiva.

- La importancia de la promoción interactiva entre el docente y sus alumnos, así como entre éstos [...] a través estrategias de aprendizaje cooperativo.

- La revalorización del papel del docente, no sólo en sus funciones de transmisor del conocimiento, guía o facilitador del aprendizaje, sino más bien como mediador del mismo, resaltando el papel de la ayuda pedagógica que presta reguladamente al alumno. ${ }^{22}$

Se sabe que el principio de la actividad constructivista del alumno en la realización de los aprendizajes busca su participación en actividades intencionales, planificadas y sistematizadas conducentes a una actividad mental constructiva, en este sentido, en la estructura del modelo de la especialización sobre organización de recursos informativos digitales, también se incluye lo consecuente:

Es mediante la realización de aprendizajes significativos que el alumno construye significados, los cuales enriquecen su conocimiento del mundo físico y social, potenciando así su crecimiento personal. La filosofía educativa que subyace en estos planteamientos indica que la institución educativa debe promover el doble proceso de socialización y de individualización, permitiendo a los alumnos construir una identidad personal en el marco de un contexto social y cultural determinado. La finalidad última de la intervención pedagógica es desarrollar en el alumno la capacidad de realizar aprendizajes significativos por sí solo en una amplia gama de situaciones y circunstancias. 23

Varios teóricos discuten acerca de si el alumno construye conocimientos propios, requiere entonces relacionar contenidos didácticos con conocimientos previos, por lo cual tal tarea se vuelve necesaria en propuestas de educación virtual. Por esto también se contempla la postura constructivista de los principios de la instrucción y del material didáctico, orientado a sistemas a distancia, los cuales indican:

22 Frida Díaz Barriga, Op. cit., p. 24.

23 Ibid. 
El aprendizaje se facilita cuando los contenidos se presentan al alumno convenientemente organizados y siguen una secuencia lógica-psicológica apropiada. Es conveniente delimitar intencionalidades y contenidos de aprendizaje en una progresión continua que respete niveles de inclusividad, abstracción y generalidad. Esto implica determinar las relaciones de supraordenación-subordinación, antecedente-consecuente, que guardan los núcleos de información entre sí. Los contenidos $[\ldots]$ deben presentarse en forma de sistemas conceptuales (esquemas de conocimiento) organizados, interrelacionados y jerarquizados, y no como datos aislados y sin orden. La activación de los conocimientos y experiencias previas que posee el aprendiz en su estructura cognoscitiva, facilitará los procesos de aprendizaje significativo de nuevos materiales de estudio.

El establecimiento de puentes cognoscitivos (conceptos e ideas generales que permiten enlazar la estructura cognoscitiva con el material por aprender) puede orientar al alumno a detectar las ideas fundamentales, a organizar e integrarlas significativamente. Los contenidos aprendidos significativamente (por recepción o por descubrimiento) serán más estables, menos vulnerables al olvido y permitirá la transferencia de lo aprendido, sobre todo si se trata de conceptos generales integradores. Dado que el alumno en su proceso de aprendizaje, en virtud de ciertos mecanismos autorregulatorios, puede llegar a controlar eficazmente el ritmo, secuencia y profundidad de sus conductas y procesos de estudio, una de las tareas principales del docente será estimular la motivación y participación activa del sujeto y aumentar la significatividad potencial de los materiales académicos. ${ }^{24}$

En cuanto al aprendizaje adulto, que es la población meta a la que se dirige la educación virtual y en la que se inserta la especialización sobre la organización de recursos informativos digitales, se contempla el pensamiento de Reegel, relacionado con las operaciones dialécticas, cuya premisa es el cuestionamiento, por lo que el aprendizaje adulto se basa en contextos y acciones reales, debido a que se deben constituir procesos reflexivos, por ejemplo:

24 Ibíd., p. 33. 
1. La naturaleza del aprendizaje adulto implica un contexto cultural, social y económico que lo llevan a estar sujeto a los beneficios y dificultades de su vida en sociedad.

2. El adulto tiene una carga de experiencias que acumula una serie de alegrías, tristezas y responsabilidades familiares, que facilitan o dificultan su aprendizaje.

3. Las estrategias de enseñanza deben evitar "dar clases" como si el adulto fuera estudiante de primaria; se debe recurrir a otra manera de aprender y relacionarse, de preguntar y reflexionar.

4. El pensamiento creativo y crítico es preferible a la recepción acrítica del pensamiento de otros, porque de esa manera se favorece el desarrollo completo del adulto.

5. El pensamiento creativo y crítico es favorecido por sesiones de aprendizaje en grupo y aprendizaje autodirigido. ${ }^{25}$

De estos procesos se asume que las estrategias de aprendizaje estarán presentes a través de las actividades del programa académico en cuestión; en los objetivos y en la elaboración del currículum se toman en cuenta ya que a partir de su diseño se estructuran los objetivos y las actividades de aprendizaje relacionados directamente con la evaluación.

La estrategia de elaboración del programa tiene como intención ubicar el plan de estudios, con objetivos propios y una carga académica delimitada, representada por un conjunto de contenidos bien organizados para ser impartidos de manera lógica. En este contexto, se entiende por programa el "[...]proyecto de acción en el que aparecen explicitados con un orden secuencial y coherente los objetivos educativos, los contenidos de enseñanza, las actividades a realizar, etcétera, en función del tiempo y otros factores. El programa constituye el eje de la actividad escolar". ${ }^{26}$

25 Reegel, citado por H.G. Bustamante Rojas, "Propuesta de un modelo de orientación educativa a distancia”, Op. cit., p. 172.

26 Diccionario de las ciencias de la educación, p. 1141. 
En consecuencia, en el caso de la Especialización sobre la organización de recursos informativos digitales el programa se estructura en módulos de aprendizaje y se apoya en los siguientes tipos: "[...]programa científico, programa personal y programa realista", ${ }^{27}$ los cuales describo enseguida:

- Programa científico. En cuanto a que atiende la estructura lógica de cada módulo de aprendizaje y lo relaciona con el perfil de los alumnos, así como con otras variables.

- Programa Personal. Se diseña para grupos profesionales específicos. En este caso se toman en cuenta las características de profesionales en bibliotecología, documentación y de otros especialistas en activo y con intereses en la organización de recursos informativos digitales.

- Programa realista. Se determinan los objetivos-contenidos mínimos de cada módulo de aprendizaje recordando la utilidad directa que puedan tener para el alumno a distancia.

Igualmente se toman en cuenta los modelos pedagógicos, tecnológico, hermenéutico y crítico, en el entendido de que la especialización mencionada se identifica principalmente con el paradigma tecnológico, debido a que sus principios fundamentales inciden en diversas partes del modelo académico.

27 Ibid., p. 1141. 


\section{Modelos pedagógicos de uso en la educación a distancia}

\begin{tabular}{|c|c|c|c|}
\hline & TECNOLÓGICO & HERMENEÚTICO & CRITICO \\
\hline DOCENTE & $\begin{array}{l}\text { Diseñador de materiales y } \\
\text { experiencias. Estructura de } \\
\text { relación. } \\
\text { Relación de uno a muchos. } \\
\text { Individualización de la } \\
\text { enseñanza. } \\
\text { Decisional. } \\
\text { Profesional. } \\
\text { Busca la eficiencia. }\end{array}$ & $\begin{array}{l}\text { Organización informal. } \\
\text { Individualización. } \\
\text { Asume papel de líder. } \\
\text { Relación personal. } \\
\text { Importancia de la } \\
\text { comunidad. } \\
\text { Busca la comprensión. }\end{array}$ & $\begin{array}{l}\text { Actor implicado, } \\
\text { conocedor de la } \\
\text { realidad. } \\
\text { Orientado a la } \\
\text { comunicación. } \\
\text { Implicación de todos los } \\
\text { procesos. } \\
\text { Busca el desarrollo } \\
\text { personal. }\end{array}$ \\
\hline $\begin{array}{l}\text { DESARROLLO } \\
\text { CURRICULAR }\end{array}$ & $\begin{array}{l}\text { Racionalizador, } \\
\text { organización estructural, } \\
\text { funciones y papeles } \\
\text { formales. } \\
\text { El aprendizaje base de la } \\
\text { formación. }\end{array}$ & $\begin{array}{l}\text { Integrador, flexible, } \\
\text { definición informal de } \\
\text { responsabilidad y } \\
\text { funciones. } \\
\text { Se fundamenta en los } \\
\text { intereses. }\end{array}$ & $\begin{array}{l}\text { Negociador entre los } \\
\text { elementos que } \\
\text { intervienen. } \\
\text { Diálogo con la realidad. } \\
\text { Transformador. } \\
\text { Busca la emancipación } \\
\text { y la liberación. }\end{array}$ \\
\hline INVESTIGACIÓN & $\begin{array}{l}\text { Ciencia social como réplica } \\
\text { de la ciencia natural. } \\
\text { Objetividad. } \\
\text { Descriptiva-explicacional. } \\
\text { Obtención de normas. }\end{array}$ & $\begin{array}{l}\text { Intencional gobernada } \\
\text { por reglas. } \\
\text { Interpretativa, } \\
\text { contextual. } \\
\text { Busca conocimientos no } \\
\text { prescriptivos. }\end{array}$ & $\begin{array}{l}\text { Participativa, } \\
\text { sociocrítica, integrada } \\
\text { en contextos } \\
\text { ideológicos. } \\
\text { Desde la práctica, } \\
\text { Orientada a la acción. }\end{array}$ \\
\hline
\end{tabular}


En señanza virtual sobre la organización de recursos informativos digitales

\section{Modelos pedagógicos de uso en la educación a distancia \\ (Cont)}

\begin{tabular}{||l|l|l|l||}
\hline & TECNOLÓGICO & HERMENEÚTICO & CRITICO \\
\hline $\begin{array}{l}\text { FENÓMENO } \\
\text { EDUCATIVO }\end{array}$ & $\begin{array}{l}\text { Objetivo, mensurable. } \\
\text { Actividad racional } \\
\text { prediseñada. } \\
\text { Organización regulada. }\end{array}$ & $\begin{array}{l}\text { Subjetivo. } \\
\text { Importancia del } \\
\text { contexto. } \\
\text { Vital, personal y cultural. } \\
\text { Variabilidad. } \\
\text { Interactivo. }\end{array}$ & $\begin{array}{l}\text { Interpretado desde } \\
\text { condiciones históricas } \\
\text { y culturales. } \\
\text { constructivo, crítico y }\end{array}$ \\
\hline TEORÍA & $\begin{array}{l}\text { Describe, explica y } \\
\text { prescribe. } \\
\text { Se preocupa por los } \\
\text { procesos. } \\
\text { Transformación de la } \\
\text { realidad social. } \\
\text { Aplicación lineal. }\end{array}$ & $\begin{array}{l}\text { Interpretativa, } \\
\text { comprensiva, } \\
\text { contextual. } \\
\text { Aporta reglas (no leyes). } \\
\text { Como proceso de } \\
\text { interacción social, } \\
\text { horizontal y dialogante. }\end{array}$ & $\begin{array}{l}\text { Orientada a } \\
\text { transformar la } \\
\text { práctica, ilumina y } \\
\text { dinamiza la acción. } \\
\text { Concientiza y } \\
\text { emancipa en el plano } \\
\text { social e individual. }\end{array}$ \\
\hline
\end{tabular}

Fuente: A. J. Colom Cañellas, "Pedagogía tecnológica para la educación a distancia", en Los nuevos escenarios educativos y las transformaciones tecnológicas, p. 30.

De lo antes expuesto se asume que el modelo académico de la especialización toma en cuenta los elementos fundamentales de la educación a distancia, los principios del diseño curricular y fundamentos relevantes del constructivismo social. En cuanto a éste último, se destaca que "[...]durante los procesos y episodios de aprendizaje de conocimientos, habilidades y actitudes, mismos que, al visualizarse como procesos complejos se desarrollan en contextos sociales[...], determinados". ${ }^{28}$ Asimismo, el constructivismo "[...] aporta a los sistemas

28 Juan Carlos Miranda Arroyo, "El aprendizaje escolar y la metáfora de la construcción", en Revista Iberoamericana de Educación, [en línea] http://www.campus-oei.org/revista/deloslectores/630Miranda.PDF [consultada: 12/09/05] 
educativos al menos dos significados centrales: 1. ofrece pistas importantes para comprender los procesos humanos de creación, producción y reproducción de conocimientos y 2 . abre la posibilidad, con base en lo anterior, de desarrollar nuevos enfoques, aplicaciones didácticas y concepciones curriculares en cualquier ámbito de la educación [...]". ${ }^{29}$ En este contexto, la especialización que se propone toma como referentes sociales los distintos tipos de bibliotecas y los bibliotecólogos mexicanos que ejercen su profesión en éstas. En este sentido, el constructivismo social puede guiar el sustento de los ejes de preparación emergente para los bibliotecólogos

1. La formación práctica reflexiva centrada en los alumnos.

2. La investigación como una forma de enseñanza-aprendizaje.

3. La enseñanza y el aprendizaje de la disciplina bibliotecológica, con base en una nueva concepción didáctica $[\ldots] .{ }^{30}$

Cabe recordar que los rubros anteriores afectan a la bibliotecología en general, por lo tanto, se requiere enfatizar que los ejes fundamentales de la especialización sobre la organización de recursos informativos digitales serían los subsecuentes:

- Perfil del egresado.

- Proceso pedagógico.

- Estrategias de aprendizaje.

- Función del tutor.

- Estructura académica.

- Medios de comunicación e interacción.

- Institucionalización del programa.

Se entiende que estos elementos se reflejan en la estructura de la especialización aludida a lo largo del programa y sus objetivos, los módulos y sus contenidos temáticos. Enseguida se presentan las particularidades de esta especialización.

29 Jaime Ríos Ortega,. Op. cit., (versión en CD-ROM, 2000).

30 Ibid.. 


\section{TEMAS RELEVANTES PARA LA ENSEÑANZA VIRTUAL SOBRE LA ORGANIZACIÓN DE RECURSOS INFORMATIVOS DIGITALES}

\section{Avances del control bibliográfico y la normalización en los albores del siglo XXI}

Se contempla que la enseñanza virtual sobre el control bibliográfico abarque del siglo XX hasta los albores del siglo XXI, para responder al hecho de tener presente un marco de referencia sobre este tema, que presente hechos relevantes de la evolución de la organización documental y que explique el uso de la normalización en tareas de sistematización documental. En este sentido, cabe destacar que históricamente los propósitos de la normalización han sido constantes a lo largo de las épocas y en las sociedades, en consecuencia al inicio del siglo XXI, tales propósitos tienen vigencia. Su función primaria ha sido facilitar el acceso a la información y asegurar el control bibliográfico nacional y universal. Así, la normalización como proceso científico orientado a la organización documental se potencia y enriquece con el uso de las TIC, debido a que contribuyen a la normalización en la organización documental, propiciando un procesamiento más ágil, facilitando el control de calidad y posibilitando el intercambio de la información a las naciones que lo requieran.

Al respecto, Bereijo Martínez ha distinguido que "[...] la tecnología persigue la transformación creativa de la realidad. Sus logros [...] pueden ser evaluados para estimar su calidad, en función de su eficacia, esto es en relación con los objetivos buscados. También se tiene presente su eficiencia, cuando se establece la relación entre costos y efectos que llevan a una economía de medios". ${ }^{31}$ En este tenor, se diría que los sustentos de la eficacia y eficiencia han estado presentes en las actividades de la organización documental a lo largo de su historia. Al mismo tiempo, se ha acumulado un bagaje de conocimiento

31 Antonio Bereijo Martínez, Bases conceptuales del análisis documental: la calidad de objetivos, procesos y resultados, Madrid, Universidad Carlos III de Madrid, Boletín Oficial del Estado, 2002, p. 117. 
teórico e instrumental de gran valor para el diseño y desarrollo de sistemas de información modernos.

En su aspecto pragmático, el trabajo del control bibliográfico ha generado logros sustanciales de organización documental, lo cual se refleja principalmente en la generación de normas para la sistematización documental lograda hacia finales del siglo XIX, lo que favoreció el desarrollo del Control Bibliográfico Universal (CBU) durante el siglo XX, el cual se orientó a la sistematización normativa de la información bibliográfica y de la necesidad de rescatar y desarrollar teóricamente ese fenómeno.

$\mathrm{Al}$ conectar sistemas locales con sistemas mundiales las redes de teleproceso se vuelven más sensibles a factores de calidad normativa los productos documentales integrados en bases de datos bibliográficos, catálogos públicos en línea y, más recientemente, en bibliotecas digitales y sistemas de metadatos. También la realización de tareas documentales de índole descriptiva está condicionada por las limitaciones que ocasionarían las normas de gran complejidad, por ello, a finales del siglo XX y los principios del XXI se han desarrollado o gestado normas que garanticen la calidad en la descripción documental y normas genéricas que de igual manera las utilizarán autores de contenido (Núcleo de Dublín). Sus consecuencias están en vísperas de manifestarse.

La organización de la información digital representa un tema que ha suscitado un largo debate en los sectores sociales, cuya materia prima de trabajo es la información. Lo anterior a raíz de que el conocimiento publicado se ha convertido en elemento estratégico para la toma de decisiones y en la generación de nuevo conocimiento, por lo cual su efecto repercute en la economía, en los desarrollos científicos, tecnológicos, así como en las formas y medios de comunicación e interrelación social.

Tocante al desarrollo del control bibliográfico a lo largo del siglo XX, Gorman dice: “[...]la historia de la catalogación en el siglo XX es la historia de dos estructuras. La primera es la de los códigos y normas desde la cuarta edición de las reglas de Cutter en 1904 hasta el Red Book, ISBD (International Standard Bibliographic Description), MARC (Machine Readable Cataloging) y AACR2 (Anglo American Cata- 
loging Rules, 2nd ed.). La segunda es la de los medios por los cuales los registros son comunicados desde el catálogo en forma de libro y las tarjetas de inicios del siglo XX, hasta las microfichas, catálogos en línea y catálogos basados en la Web", ${ }^{32}$ idea que comparte Lafuente cuando agrega: "[...] ]actualmente, para satisfacer una buena parte de las necesidades de manejo documental (registro, organización y recuperación) que plantean diversas comunidades, se utiliza el proceso automatizado de datos, el cual está dominado por las tecnologías de las bases de datos y el hipertexto". ${ }^{33}$ Partiendo de esto, se advierte que ambas estructuras manifiestan el concurso de diversos fenómenos, los cuales han tenido su razón de ser a lo largo del siglo XX y lo que va del XXI.

Tal planteamiento se entiende por el desarrollo de la tecnología, como la inteligencia artificial o los sistemas expertos, que producen modelos de gestión de la información, con métodos en forma de bases de datos, catálogos públicos en línea, hipertextos y, muy recientemente, los sistemas de metadatos y bibliotecas digitales. Por la importancia de los aspectos ya señalados, estos temas han de atenderse en toda propuesta referida a la enseñanza virtual sobre la organización de recursos informativos digitales.

Ante este panorama, se señala que la normalización contempla una multiplicidad de conceptos y una variedad de fenómenos existentes o planeados, lo que determina límites de unificación y simplificación en la sistematización de la información. Por lo tanto, con la normalización es posible identificar las constantes de un fenómeno determinado para precisar su manejo consistentemente con el fin de identificar su solución de forma unívoca. En este sentido, organizar recursos informativos digitales en forma normalizada implica optimizar

32 M. Gorman, "Keynote address: from card catalogues to webPACs: celebrating cataloguing in the 20th Century, en Proceedings of the Bicentennial Conference on Bibliographic Control for the New Millennium: confronting the challenges of networked resources and the web (Washington, D.C. november 15-17, 2000) / ed. Ann M. Sandberg-Fox. Washington: Library of Congress, Cataloging Distribution Service, 2001, p. xix.

33 Lafuente y Garduño, Op. cit., p. ix. 
el uso de normas específicas, los procedimientos de análisis de contenido, el almacenamiento y recuperación de la información así como de su intercambio.

El estudio de la normalización es fundamental ya que también habrá que analizarlo a la luz de las leyes analógicas y las leyes de la información; por ejemplo, la ley de la entropía, la ley de la invarianza, la ley de la expansión del conocimiento científico y la ley de preservación de la invariabilidad del conocimiento científico, resumidas como sigue:

1. La Ley de la entropía define la dirección general en la investigación sobre la normalización, abarca la unificación de la información de un objeto particular y la conversión de esta información en conocimiento científico.

2. La Ley de la invarianza del conocimiento científico es la aspiración a un conocimiento básicamente estable en sus elementos principales. Implica que la normalización busca identificar un conocimiento científico estable, que es deseable recoger en normas, aunque haya cambios en las características del objeto [...].

3. La Ley de la expansión del conocimiento científico caracteriza el uso activo del conocimiento científico invariante, ley sin la cual la estandarización sería ineficiente: sólo desde el uso general del conocimiento fijado en la norma cabe proporcionar lugares propios para la investigación en la normalización.

4. La Ley de preservación de la viabilidad en el conocimiento científico delimita fronteras razonables a la normalización, sin permitir que dañe el desarrollo de la humanidad. Sin embargo, es necesario recordar que la normalización elimina la variedad y puede, en último término, conducir a una pérdida de información. ${ }^{34}$

En la actualidad, la discusión en cuanto a estas leyes ha generado serios debates, pues con el uso de las TIC en la normalización, las cosas se complican aún más. Por lo tanto, en cualquier propuesta educativa relacionada con la normalización de recursos digitales, se tendrá que atender, reflexionar y concluir sobre temas tan polémicos como los relacionados con tales leyes.

34 Bereijo Martínez, Bases conceptuales del ... Op. cit. p. 126. 
No obstante, ha de recordarse que los propósitos de la normalización han sido constantes en todas las épocas y pueden seguir siendo válidos en este siglo XXI. Algunos propósitos remiten a lo siguiente: “[...]la normalización es la actividad colectiva mediante la cual se establecen las normas. Una norma es una fórmula que tiene valor de regla, en general indicativa y a veces imperativa, por lo menos de hecho. Tiene por objeto definir las características que debe tener un objeto y las que debe tener su empleo, así como las de un procedimiento o de un método. ${ }^{35}$ Lafuente abunda sobre esto y argumenta: “[...]la intención primaria, básica, de la normalización es la introducción de un orden, fundamentado en principios unificadores libres de ambigüedad de todo tipo [...]. Por su misma naturaleza de búsqueda de acuerdos de intereses colectivos, la normalización es una actividad institucional efectuada por organismos nacionales, internacionales o regionales y no puede concebirse como una actividad autocrática o independiente del contexto internacional". ${ }^{36}$

En este contexto, se añade que la normalización contempla una multiplicidad de conceptos y una gama de fenómenos existentes o planeados, lo cual determina límites de unificación y simplificación en la sistematización de la información. Por lo tanto, a través de la normalización es factible identificar las constantes de un fenómeno dado para precisar su manejo consistentemente para identificar su solución de manera unívoca. Así, organizar recursos informativos digitales en forma normalizada implica mejorar el uso de normas específicas, los procedimientos del análisis de contenido, el almacenamiento de la información y las características de la navegación con propósitos de recuperación de objetos digitales.

Por otro lado, organismos internacionales como la UNESCO y la ISO continúan con la ardua labor de la normalización documental. Un aspecto sobresaliente tiene que ver con el programa de la

35 Claire Guincha y Michel Meneou, Introducción general a las ciencias y técnicas de la información y documentación. $2^{\mathrm{a}}$ ed, Madrid: CSIC, UNESCO. 1992, p. 446.

36 Ramiro Lafuente Lopez, "Anteproyecto de norma oficial mexicana (NOM): descripción bibliográfica y documental", en Documentación (nota preliminar), México: Comité Consultivo de Normalización, 1987, p. 1. 
UNESCO denominado Programa Información para Todos (PIT). ${ }^{37}$ Por la importancia de sus acciones para la ejecución de la normalización y del control bibliográfico en los inicios del siglo XXI, se alude al eje de acción 4, referente a la elaboración de instrumentos, sistemas de tratamiento y gestión de la información, que persigue estas acciones:

1. Realización de un análisis de las necesidades regionales y planificación de políticas sobre la creación de instrumentos de gestión de la información.

2. Preparación de un conjunto multilingüe, de libre acceso, de instrumentos de gestión de la información.

3. Preparación y ensayo de recopilaciones de las mejores prácticas y normas en materia de gestión de información.

El PIT tiene como propósito impactar en aspectos de mayor interés para los sectores bibliotecarios, debido, entre otros aspectos, a que el desarrollo tecnológico en este siglo ha generado expectativas en el mundo de la información, al considerar esquemas de metadatos orientados a la descripción y organización de recursos informativos digitales. No obstante, hasta ahora se observa que muchos esquemas se desarrollan para aplicarlos en determinada disciplina o para el manejo de un grupo limitado de recursos informativos. No obstante, el aumento en la generación de recursos digitales refleja el establecimiento de normas universales para su uso en el plano internacional. Por lo tanto, estos planteamientos requieren estudiarse en cualquier propuesta educativa sobre organización de recursos digitales.

37 Para mayor información sobre el PIT, véase http://www.unesco.org, [consultada: 16/11/03]. UNESCO, "Situación del programa General de Información (PGI) y del Programa Intergubernamental de Informática (PII) por un nuevo Programa Intergubernamental, Consejo Ejecutivo, 160a reunión, París, 2 de octubre de 2002. http://unesdoc.unesco/org/images/0012/001203/120374s.pdf [consultada: 16/11/03]. El informe final del PGI de la 25a reunión, 22-23 de junio de 1998, a cargo de la Mesa del Consejo Intergubernamental, se halla disponible en http://www.unesco.org/webworld/iip/rtf/pgi_25.rtf, [consultada: 16/11/03]. 


\section{Vigencia u obsolescencia de los formatos bibliográficos}

Para su enseñanza virtual, este tema requiere de la perspectiva creada a partir de 1966, que con la aparición de formatos bibliográficos, marcó un acontecimiento en los medios bibliotecarios, pues obligó a los especialistas de esta área a reorientar la aplicación de herramientas normativas tradicionalmente empleadas en tareas de organización bibliográfica. Los bibliotecarios observaron que utilizar una novedosa herramienta requería la adquisición de nuevos conocimientos para el desempeño de tareas de descripción documental, inducidas en la estructura de los formatos y en la aplicación de los paquetes de cómputo.

Desde los años sesenta, cada época ha determinado a los medios bibliotecarios sus requerimientos de conocimiento tecnológico y el desarrollo de habilidades para su manejo. El paradigma de los formatos bibliográficos tiene como intención fundamental señalar que un formato de esta naturaleza conlleva en la práctica un conjunto de decisiones semánticas y formales, relacionadas con el grupo de elementos usados para describir documentos específicos. Asimismo, destaca el método de organizar información bibliográfica, de tal manera que los elementos esenciales describan documentos para identificarlos en la computadora.

Las funciones de los formatos bibliográficos han sido nodales para las representaciones estructuradas de registros bibliográficos en ambientes automatizados para intercambiar estos registros entre unidades de información y para orientar el diseño de bases de datos bibliográficos. En consecuencia, el uso de formatos bibliográficos ha mostrado a las comunidades bibliotecarias y documentalistas que su aplicación en estas tareas exigen elementos que debían ser acordes con los intereses informativos de los sectores sociales (usuarios de bases de datos), por lo cual estos elementos demandan claridad, consistencia y univocidad, así pues facilitan su aplicación.

La experiencia adquirida por los bibliotecarios en el uso de formatos bibliográficos ha mostrado que, en lo que va del presente siglo se comprende con certeza que cada uno de los códigos y etiquetas de los formatos contienen elementos para codificar en forma 
unívoca y libre de ambigüedades, cualquier dato que requiera la organización bibliográfica automatizada. En consecuencia, las relaciones entre los elementos estructurales de un formato de esta naturaleza pueden ser de forma (con base en códigos y etiquetas) y de contenido (atendiendo al significado de los datos que cada código y cada etiqueta representan), relaciones que respaldan la base lógica para construir estructuras de almacenamiento y recuperación de información bibliográfica.

En consecuencia, un sistema bibliográfico automatizado se erige tomando como base la estructura de codificación para el almacenamiento y la recuperación de datos que muestren las relaciones de contenido lógico entre los distintos códigos. De esta manera, la estructura de codificación se hace explícita por medio de códigos de formato; en tanto que las relaciones lógicas se expresan en forma de índices o procesos de búsqueda. En este sentido, cualquier etiqueta, indicador o código de subcampo son vistos como códigos de formato cuya función obedece a las particularidades de contenido y de procesamiento de los registros bibliográficos.

En cuanto al uso de técnicas de automatización relacionadas con formatos los bibliográficos, desde sus inicios fue una propuesta novedosa para los sectores bibliotecarios, por tanto, el predominio de dichos formatos en la automatización de registros bibliográficos, en el diseño de bases de datos y en el intercambio de información, ha sido determinante para los medios bibliotecarios. Todo indica que en este milenio este tipo de formatos (principalmente MARC 21) continuará con una amplia aceptación en el desarrollo de las actividades comentadas. En consecuencia, la enseñanza a distancia de este tema lo consideramos de relevancia.

Otro aspecto importante tiene que ver con la escasa probabilidad, en lo que compete a la obsolescencia de los formatos bibliográficos, debido al cúmulo de experiencia adquirida en los sectores bibliotecarios, documentalistas e informáticos en cuanto a la automatización de información bibliográfica. Esta tarea se ha realizado y contado con el apoyo de normas internacionales y en la generación de bases de datos bibliográficos estructurados a partir de algún formato bibliográfico. Aun así, la reciente aparición de lenguajes de marcado para 
emplearlos, entre otras tareas, en la organización de documentos digitales, no será fácil que los medios bibliotecarios adopten rápidamente estos nuevos formatos, que aún se encuentran en sus etapas iniciales de aplicación y no han probado hasta hoy su eficacia en la sistematización normalizada de información digital de gran escala. Asimismo, este siglo perfila la consolidación y aparición de otras tecnologías, lo que indica que los especialistas en organización documental continuarán experimentando y aplicando nuevos desarrollos tecnológicos, relacionados con la sistematización documental. Esto último con el propósito de facilitar la integración de sistemas de información remotos y la intercomunicación de los sujetos que intervienen en los procesos del conocimiento publicado en cualquier medio físico. El estudio de los formatos bibliográficos, y de manera especial del formato MARC 21, se considera un tema relevante en el modelo de especialización propuesto.

Podemos decir que el estudio de los formatos bibliográficos es obligatorio principalmente en los medios bibliotecarios, documentalistas e informáticos, dadas sus repercusiones en las diversas tareas requeridas en la organización automatizada de recursos documentales. A lo largo del siglo XX y los pocos años del XXI, dichos formatos gozan de gran aceptación en los medios señalados gracias a que han mostrado los beneficios de su uso en la elaboración de bases de datos bibliográficos, catálogos públicos en línea e intercambio de registros entre diversas unidades de información. De los distintos formatos posteriores a 1960, MARC merece una mención especial pues su fuerte apoyo institucional y su adopción a nivel internacional incorpora constantemente los avances tecnológicos más recientes. Todo esto ha beneficiado la sistematización y recuperación automatizada de la información bibliográfica en el plano mundial.

También el desarrollo constante de las TIC obligan a reflexionar en la manera de describir y representar documentos y, recientemente, recursos informativos digitales, por lo tanto, el formato mencionado se convierte en un fenómeno de estudio permanente por sus implicaciones en las diversas disciplinas que se involucran y por sus posibles repercusiones en las distintas esferas sociales. Las recientes iniciativas para la representación de metadatos obligan a profundizar 
en el estudio de las implicaciones que éstas ocasionan frente al modelo que sustenta a los formatos bibliográficos.

\section{Bases de datos bibliográficos y catálogos públicos en línea (OPAC): ¿viejos problemas o soluciones novedosas?}

El estudio de la evolución de las bases de datos bibliográficos y de los catálogos públicos en línea es relevante por sus aportaciones en beneficio de las comunidades especializadas en organizar documentos y de las sociedades usuarias de información. Por lo tanto, tiene sentido indicar que la tecnología surgida en los años sesenta facilitó los primeros proyectos de organización documental automatizada, proyectos que, por lo general, presentaban rigidez, aspecto que trascendía en la obtención de productos con varias restricciones.

A partir de los años setenta, se empezó a gestar una transformación radical en la tecnología de la automatización. En esa época, surgieron dos de las principales tendencias en programación de computadoras, la programación lógica ${ }^{38}$ y la ingeniería del conocimiento. ${ }^{39}$ Ello propició que la computación se orientara sobre todo en el desarrollo de programas de cómputo para procesos de inferencia automatizada. La vertiginosa transformación de los principios de

38 La programación lógica es aquella en la que las sentencias representan proposiciones y predicados lógicos, implicaciones lógicas, etcétera. El lenguaje de programación de este tipo más extendido es PROLOG. en Antonio Vaquero y Luis Joyanes. Glosario de términos y siglas: diccionario inglés-españo-ingles, Madrid : McGraw-Hill, 1985, p. 31. La programación lógica parte del establecimiento de una base de datos de sentencias y reglas de inferencia que son declaradas por el programado. En Sergio Chapa Vergara, [en línea]

http://www.cscinvestav.mx/SC/publica/chapa/intro_lm/node $42 . h t m l$ [consultada: 18/04/03]

39 La ingeniería del conocimiento es una disciplina moderna que ayuda a construir aplicaciones y sistemas orientados al aprendizaje, apoyandonos en metodologías instruccionales y en tecnologías de computación y de telecomunicaciones. véase ángel Olivera, Ingeniería del conocimiento. [en línea] http://www.aldeaedu...com/aldea/Tareas 2 .asp.?which $=1386$, [consultada: 18/04/03] 
la computación, aunado a la popularización de compiladores de bajo costo, capaces de operar con los principios de programación lógica, como el lenguaje $\mathrm{C}++$ y Pascal, así como la comercialización de versiones de lenguaje Prolog para PC, motivaron la aparición de una abundante literatura sobre el tema.

La aplicación de la programación lógica al diseño de sistemas de información para el manejo documental evidentemente conformó una tendencia a seguir, no obstante, la infraestructura actual de automatización para el manejo de datos bibliográficos se opera con manejadores de bases de datos. Bastantes de los problemas del intercambio de datos y manejo estandarizado del procesamiento de datos bibliográficos derivan del desconocimiento de los principios básicos de las normas que rigen el procesamiento de datos en ambientes automatizados.

La computación ha desarrollado varios estándares de operación para el proceso de datos, uno de ellos el estándar PC IBM, compatible tanto con el hardware, como con el software. En el segundo, el estándar de mayor difusión es el DOS, norma que configura una plataforma de procesamiento de datos, que a su vez, permite la presencia de diversos estándares, como es el caso del manejo de bases de datos, el de mayor difusión es el Dbase, aunque existen otros, como el Paradox y el Oracle. Estos estándares han propiciado la aparición en el mercado de diversos productos, que configuran un ambiente de procesamiento de datos.

Los problemas técnicos de la normalización resultan relativamente fáciles de solucionar, empero, el mayor grado de dificultad radica en la experiencia para el manejo de las técnicas y en apreciar, en primer lugar, ventajas sobre poder transportar un archivo de datos no sólo entre una máquina y otra, sino entre un ambiente de proceso y otro. Desde luego, siempre persistirá el problema de la actualización que impone la presencia de nuevas normas en cuanto a la construcción de computadoras. Sin embargo, éste se puede controlar apelando a un buen diseño de la estructura de la base de datos en cuestión y al manejo de éstos conforme a los formatos y normas para la descripción bibliográfica. 
El meollo de la normalización radica en las metas de las personas o las instituciones al crear y manejar archivos de datos bibliográficos. Cada cual tiene diferentes necesidades y formas de entender lo que sería lo ideal para archivar y procesar datos bibliográficos, incluso distintos grados de conocimiento e ignorancia sobre el proceso de datos bibliográficos, situación que, aunada a la ausencia de manuales de referencia y textos explicativos de sistemas y procesos, ha generado no sólo el aislamiento en cuanto a la construcción de sistemas automatizados, sino también un considerable derroche de recursos.

En consecuencia, hasta ahora las normas y sistemas de reglas de catalogación no han logrado una convergencia universal en cuanto al procesamiento de datos bibliográficos. Un ejemplo de esto se halla en la constante generación de clones del formato MARC, denominados "marcoides", o la generación de diversas estructuras de bases de datos sustentadas en el formato CCF. No obstante, la sistematización y difusión de principios básicos del proceso de información bibliográfica conduciría a una "cultura" en cuanto a límites y posibilidades del procesamiento de datos bibliográficos, aspectos que tienen que rememorar en la enseñanza de la organización de recursos informativos digitales.

La experiencia indica que el diseño de registros y de bases de datos bibliográficos ha exigido un trabajo metódico, traducido en el tiempo de análisis de la información que se requiere automatizar, análisis de las herramientas normativas de apoyo y de los formatos de almacenamiento, de intercambio y en la elección del software de aplicación. Ciertos hechos más destacados sobre esto se citan enseguida. En los años sesenta y setenta, con la liberación del formato MARC (1966) se registra un incremento mundial en la automatización de actividades catalográficas. El diseño de bases de datos bibliográficos se fundamentó, principalmente, en módulos independientes; el software para el procesamiento de datos era limitado a secuencias de campo por campo. Los catálogos impresos en tarjetas fueron las herramientas primarias para el desarrollo de este tipo de bases, lo que determinó un predominio en tareas de conversión retrospectiva y el inicio de la desaparición del catálogo en tarjetas. También en esta 
época se generó el intercambio de registros bibliográficos en cinta magnética.

En la siguiente década de los ochenta, se perfeccionaron diversas actividades generadas en años precedentes, relacionadas con el desarrollo de bases de datos, la codificación y catalogación de información bibliográfica. Asimismo, se prestó mucha atención al software con mayores posibilidades de procesamiento.

La UNESCO publicó el Manual del Formato CCF (The Comon Communication Format), para incidir en el diseño de registros y bases de datos bibliográficos en diversos entornos geográficos. También se perfiló la posibilidad de la catalogación cooperativa, con una orientación eficientista, sin embargo, las expectativas con tal empresa no aportaron los resultados deseados.

En los años ochenta y noventa, cundió el desarrollo de software orientado al procesamiento integral de actividades bibliotecarias. Las tareas de organización documental se beneficiaron con la revisión y consolidación de la normalización orientada a la automatización de registros bibliográficos, así como con la inducción, en el diseño de software, del uso múltiple de llaves de recuperación. La distribución de catálogos bibliográficos recurre a la tecnología láser y aparecen los primeros catálogos públicos en línea (OPAC). Igualmente se prestó atención al desarrollo de interfaces para facilitar al usuario el acceso y la recuperación de la información.

Se observa que las instituciones públicas tienen escasa participación en la generación de software; en cambio, se genera una producción masiva de éste en la iniciativa privada. Se presenta el desarrollo en los medios bibliotecarios y documentalistas de una cultura en la aplicación de las TIC. El software, el equipo de cómputo y el formato de almacenamiento e intercambio de uso frecuente en este periodo fueron éstos: 
Elementos básicos para el diseño de un modelo para la enseñanza virtual ...

\begin{tabular}{|c|c|c|c|}
\hline SOFTWARE & HARDWARE & FOR A/l & ENTIDAD \\
\hline \begin{tabular}{|l} 
ADVANCED \\
INTEGRATED \\
LIBRARY SYSTEM \\
\end{tabular} & SUN, IBM RS6000 & MARC & Greac Company, Inc. \\
\hline ALEPH & UNIX, IBM, HP & MARC & $\begin{array}{l}\text { Univ. Hebrea de Jerusalem/ } \\
\text { Ex libris }\end{array}$ \\
\hline ALEXANDRIA & $\begin{array}{l}\text { IBM PC, } \\
\text { Macintosh }\end{array}$ & MARC & Companion Corporation \\
\hline ATHENA & $\begin{array}{l}\text { IBM PC } \\
\text {, Macintosh }\end{array}$ & MARC & Sagebrush Technologies \\
\hline AUTHEX PLUS & IBM PC, PS/2 & MARC & Reference Press \\
\hline BIBLUANL & DEC-VAX & MARC & UANL \\
\hline BYBLOS * & IBM PS80, MICRO VAX & MARC & ITM-Querétaro \\
\hline $\begin{array}{l}\text { CATALOG PLUS } \\
\text { UNISON }\end{array}$ & IBM PC, Pentium & MARC & Follest Software Co. \\
\hline DYNIX & HP, IBM, Unisys & MARC & Ameritech Library Derv. \\
\hline ENDNOTE & IBM PC, Apple Mach & MARC & ISI Research Soft \\
\hline GALAXY & DEC VAX, Alpha AXP & MARC & Gaylord Information Sis. \\
\hline HISTORY DATA BASE & IBM PC & MARC & History Comp. Proyect \\
\hline INMAGIC PLUS & IBM PC & MARC & Inmagic \\
\hline LASERCAT & IBM PC, Macintosh & MARC & OCLC-WLN \\
\hline LASERGUIDE & IBM PC & MARC & GRC International \\
\hline LOANET & IBM PC & MARC & Internet Systems \\
\hline LOGICAT & PC & MARC & Sistemas Lógicos \\
\hline MICROISIS & PC & MARC & UNESCO \\
\hline MICRO-VTLS & IBM PC & MARC & VTLS \\
\hline MITINET-MARC & IBM PC, Macintosh & MARC & Information Transfor \\
\hline MULTILIS & Digital Vax, IBM, UNIX & MARC & DRA Information \\
\hline PROCITE & IBM PC, Apple, Mach & MARC & ISI Research Soft \\
\hline SIABUC & PC & MARC & Universidad de Colima \\
\hline STAR & WIN NT, UNIX & MARC & Cuadra Associates \\
\hline UNICOR & WIN NT, UNIX & MARC & Sirsi Corporation \\
\hline
\end{tabular}


En la década de los noventa y primera del siglo XXI, aparecería la posibilidad tecnológica de estructurar metadatos y bibliotecas digitales. A mediados de 1990, fueron introducidos visualizadores web como una herramienta de navegación para acceder o localizar información, lo que determinó una tecnología novedosa en tareas de apoyo, entre otras actividades, las de organización de recursos documentales.

La experiencia revela que la adopción de normas y formatos compatibles diseñados para la codificación de la información bibliográfica facilita la interconexión entre los catálogos en línea a través del protocolo Z39.50. En consecuencia, se pone mayor atención al desarrollo de interfaces por medio de gráficos, primero en macintosh y después en windows o software similar, la intención de esto era lograr una mayor interacción en el uso de sistemas. También se comprende, con mayor certeza, que la adopción de normas y formatos bibliográficos compatibles diseñados para la codificación de la información bibliográfica facilita la interconexión y el intercambio de información entre bases de datos a gran escala.

En 1996, se diseñaron las primeras interfaces de visualización web para catálogos en línea (OPAC); las interfaces gráficas para catalogación incorporaron la interacción a través del ratón, para dar mayor movilidad de navegación al usuario a través de los módulos del sistema que requiera consultar. Además, las interfaces gráficas para usuarios de catálogos en línea incorporan patrones de búsqueda para facilitar la navegación y con posibilidades de modificar las estrategias de búsqueda.

Hoy las formas de comunicación y acceso a la información han influido en el desarrollo de catálogos en línea (OPAC), en este sentido, la normalización y la lengua en que se presentan los recursos informativos adquieren cada vez mayor importancia. El OPAC se ha vuelto una herramienta de suma utilidad, por lo cual el estudio en torno a estructuras, normalización, formas de indización, uso de software, capacidad en el uso de interfaces, relevancia en la recuperación y otras son determinantes en el ámbito de la organización de la información documental. El software, el equipo de cómputo, el formato de almacenamiento y de intercambio de uso frecuente en este periodo han sido los siguientes: 
Elementos básicos para el diseño de un modelo para la enseñanza virtual ...

\begin{tabular}{|l|l|l|l||}
\hline \multicolumn{1}{|c|}{ SOFTWARE } & \multicolumn{1}{|c|}{ HARDWARE } & \multicolumn{1}{c||}{ FOR All } & \multicolumn{1}{c||}{ ENTIDAD } \\
\hline MARC REVIEW & IBM PCS & MARC & The Marc Of Quality \\
\hline MARCVIEW & IBM PCS & MARC & System Planning \\
\hline NETCONNECT & SUN Internet Server & HTML, WEBPAC & $\begin{array}{l}\text { Ameritech Library } \\
\text { Sers. }\end{array}$ \\
\hline NETPAC2000 & $\begin{array}{l}\text { Cualquier equipo con } \\
\text { visualizador Web }\end{array}$ & MARC & $\begin{array}{l}\text { The Library } \\
\text { Corporation }\end{array}$ \\
\hline ONLINE CATALOG & Macintosh & MARC & Right on Programmes \\
\hline PAC2000 & IBM PC & MARC & $\begin{array}{l}\text { The Library } \\
\text { Corporation }\end{array}$ \\
\hline WEBCAT & IBM PC & $\begin{array}{l}\text { Portal-Web-Z39.50, } \\
\text { Unicorn }\end{array}$ & Sirsi Corporation \\
\hline
\end{tabular}

Se diría que las facilidades de los desarrollos tecnológicos, el uso de formatos bibliográficos y la normalización generada o adaptada para el proceso de datos automatizados han propiciado la generación de bases de datos y de catálogos públicos en línea. No obstante, las TIC perfilan, a principios del siglo en curso, nuevas posibilidades de repercusión en el desarrollo de sistemas de información más versátiles y con novedosas directrices en la organización de recursos digitales, como las propuestas de metadatos y bibliotecas digitales, las cuales conllevan el uso de lenguajes de marcado. Sin embargo, estas posibilidades exigen conocimiento y desarrollo de habilidades para manejarlas.

Por lo pronto, la identificación de las características de autores, de contenido y físicas de los recursos documentales, particularmente con el propósito de facilitar su localización, recuperación, intercambio y consulta, fue la meta de mayor importancia del control bibliográfico a lo largo del siglo XX, válida para los documentos digitales. En el incipiente siglo XXI, este fenómeno continúa manifestándose en la coexistencia de documentos impresos y digitales. 
La generación o adecuación de normas de catalogación y clasificación orientadas a la organización de recursos documentales en bases de datos y en catálogos públicos en línea, tienen que considerar que, la publicación digital consta de un conjunto de elementos bibliográficos comunes a cualquier otra presentación documental; sin embargo, “[...]tienen otra información específica relacionada con su naturaleza, como el entorno operativo, las formas de acceso y las condiciones de uso". 40

Al mismo tiempo, hoy en día, el catálogo en línea se ha convertido en una herramienta informativa utilísima, por lo que el estudio en torno a estructuras, normalización, formas de indización, uso de software, capacidad en el uso de interfaces, interacción, relevancia en la recuperación, etcétera, son determinantes en el ámbito de la organización de la información documental. En esta circunstancia, la orientación de las nuevas propuestas de normas tienen como propósito incidir en un alcance internacional en materia de organización documental e integrar sistemas de información, como bases de datos bibliográficos, catálogos públicos en línea, bibliotecas digitales y sistemas de metadatos.

\section{Promesas del paradigma de metadatos}

La importancia de la enseñanza virtual de este tema responde a ciertos planteamientos: el desarrollo tecnológico de los noventa trajo consigo la posibilidad de presentar y transmitir textos digitales por medio de redes de telecomunicación mundial. La facilidad de incorporar a este tipo de texto la presentación hipertextual, imagen, sonido y movimiento, a través de redes, son aspectos que generan otras formas de organizar los recursos informativos digitales. En este sentido, el uso de las TIC en los medios bibliotecarios continúa modificando diversas tareas relacionadas, entre otras actividades bibliotecarias, con la organización de documentos.

40 Ernesto Garcia Camarero y Luis Ángel García Melero, La biblioteca digital, Madrid: Arco Libros, 2002, p. 243. 
La búsqueda de organización del conocimiento colectivo para la recuperación eficiente de información en diferentes soportes sigue siendo una de las mayores preocupaciones de este siglo. Se advierte que las facilidades dadas por los desarrollos tecnológicos, el uso de formatos bibliográficos y la adaptación o generación de nuevas normas para el proceso de datos automatizados han propiciado el desarrollo de bases de datos y catálogos públicos en línea. Sin embargo, en el 2005 las TIC se perfilan hacia nuevas posibilidades que de atañer en el desarrollo de sistemas de información versátiles y con directrices novedosas en la organización de recursos digitales, como las propuestas de metadatos y las bibliotecas digitales y virtuales, que conllevan en su uso normas bibliotecarias y de lenguajes de marcado.

En este contexto cabe señalar que la red facilita el acceso múltiple a sistemas de información distribuida, aun así, la organización de recursos digitales requiere calidad y consistencia, sólo posible si se deriva en el desarrollo de investigaciones colectivas que creen, desarrollen y normalicen los instrumentos necesarios para la ejecución apropiada y el adecuado almacenamiento, búsqueda y recuperación de la información disponible en redes. En ese sentido, se observa que en los inicios del siglo XXI la investigación dirigida a la creación de sistemas de metadatos y bibliotecas digitales es prioritaria. También ocurre con la investigación orientada al modelo Resource Description Framework (RDF), como ha observado Gimeno Montoro: “[...] se propone facilitar la localización de información y potenciar la eficacia de los motores de búsqueda, por lo que toca a la relevancia en la recuperación de documentos". ${ }^{41}$ Se comprende de manera cabal que la teoría que subyace en los sistemas de metadatos indica que hay que tomar en cuenta las características y relación entre los elementos que describen documentos en general y los que representan información digital. Esto último ha inducido una línea de investigación que revisa el tratamiento de los

41 María José Gimeno Montoro, et al., Catalogación de recursos electrónicos accesibles en Internet: revisión de propuestas para una normativa [en línea] http://www.florida-uni.es/fesabid98/mj_gimeno.html [consultada:17/08/03] También proporciona otras ideas muy interesantes respecto al Resource Description Framework (RDF). 
documentos como objetos Document Like Objects (DLO). El objeto digital "[...] se asocia a las formas de representación de conocimiento y a los lenguajes de etiquetado [...]", ${ }^{42}$ y también conjuga variables que establecen la identificación única del objeto. La especialización en organización de recursos informativos digitales debe tomar muy en cuenta lo anterior.

Cabe admitir lo señalado por Gradmann en cuanto a que "[...]los registros catalográficos, tal como los han producido tradicionalmente los bibliotecarios, son bastante genéricos, en el sentido de que hacen pocas suposiciones sobre los usuarios potenciales de estos registros. El contexto futuro de uso (integración en un OPAC o colocación de las fichas impresas en un catálogo organizado secuencialmente) ha tenido hasta ahora muy poco impacto en la forma como esta información se crea en el proceso de catalogación y no ha influido demasiado la semántica (tal como está formalizada en los códigos de catalogación tipo AACR2)" . 43 Esta apreciación sería de mucho interés para las comunidades bibliotecarias porque constantemente se ha criticado la falta de orientación hacia el usuario final de la actividad catalográfica. Sin embargo, hoy estas comunidades son más conscientes de las desventajas de esta situación y por ello están obligadas a reconsiderar los principios de dicha actividad.

Lo anterior tiene sentido si se piensa en describir los elementos fundamentales sobre información digital, con el propósito de que su sistematización sea acorde con los requerimientos de los sujetos que la utilizarán con distintos propósitos: autores, editores, estudiantes, profesores, investigadores, bibliotecarios, documentalistas y demás. Conviene, pues, insistir en que los bibliotecarios enfrentan el reto de buscar o adecuar las herramientas normativas que garanticen la organización normalizada de recursos informativos digitales, para que el usuario final no se tope con barreras normativas que le impidan obtener la información apropiada a sus requerimientos. También

42 José Arias O., et al., Op. cit., p. 25.

43 Stefan Gradmann, "Catalogación versus metadata: ¿Vino viejo en odres nuevos?", en IFLA General Conference 64 (1998) [en línea]

http://ifla.inist.fr/IV/ifla64/007-126s.html [consultada:15/09/03] 
convendría tomar en cuenta que uno de los objetivos de los nuevos desarrollos tecnológicos se orienta hacia el diseño de herramientas versátiles y cada vez de más fácil utilización por parte de cualquier ciudadano. Así, la búsqueda de calidad en la organización de recursos digitales, en beneficio de los usuarios finales de la información pone de manifiesto la oportunidad de los sectores bibliotecarios y documentalistas para facilitar al usuario el acceso y uso de este tipo de recursos a través de sistemas de metadatos.

Los metadatos, señala Gradmann, "[...]son parte de una infraestructura de información técnica concreta, y esto es así, incluso hasta cierto punto en el nivel semántico, ya que en principio estaban pensados para ser independientes del contexto". ${ }^{44}$ También se ha señalado que el valor del registro metadatos lo determina en gran medida el buen funcionamiento de los puntos de acceso, los procesos de normalización relacionados con el URN (u otro identificador) y también el hecho de que los puntos de acceso cumplan los requisitos técnicos del software empleado para acceder a la información digital. Estos aspectos han propiciado álgidas discusiones en las reuniones realizadas por la Iniciativa Núcleo de Dublín Metadatos, que continúan sobre la mesa en este siglo.

Así, los metadatos no sólo pertenecen a un paradigma de producción diferente al de los registros bibliográficos, sino que también intentan ser parte de un contexto sobre un uso distinto de este tipo de registros; sin embargo, técnicamente los metadatos están conectados en gran medida con el contexto bibliográfico por la experiencia acumulada en esta área. Si bien esta afirmación simplifica enormemente las cosas (permitiendo el acceso directo al documento, a partir de métodos normalizados sobre puntos de acceso), paradójica y simultáneamente las cosas se complican. El papel de los registros de metadatos en la infraestructura de información digital depende de la evolución constante de las normas orientadas hacia la Internet, las cuales cambian y evolucionan constantemente.

44 Ibídem. 
Ciertamente que la catalogación-codificación de registros bibliográficos y la descripción de recursos digitales determinan dos enfoques distintos, orientados principalmente en función de las particularidades de las infraestructuras tecnológicas y de información a las que pertenecen. Un ejemplo son ciertos programas que utilizan o planean emplear catálogos en línea (OPAC), como pasarelas de acceso hacia infraestructuras de metadatos (OCLC, Biblioteca del Congreso de Estados Unidos, Biblioteca Británica). La riqueza de este enfoque radica en que, en su momento, ambas infraestructuras pueden ser complementarias en beneficio de los diversos usuarios de la información.

Por lo tanto, el hecho de ser consistentes en la descripción de metadatos de contenido, sería un requisito para su mayor aprovechamiento. En este sentido, los campos de autenticidad, resumen y temas, en tanto llaves de recuperación, se perfilan como determinantes en la producción de metadatos. Por esta razón, los bibliotecólogos y especialistas en lenguaje documental tendrán que conocer bien el acceso y la recuperación de la información en entorno digital y la consistencia normativa que se logre en este campo será determinante para las tareas referidas.

En cuanto a la consistencia para producir metadatos, los sectores de bibliotecarios contribuyen determinantemente, dada la experiencia adquirida a través de las épocas en la organización documental. No obstante, debe entenderse cabalmente que no se trata de realizar sistemas de metadatos que sólo impliquen una actividad de transferencia -como se hizo en diversos proyectos iniciados con la aparición de la computadora, que meramente transportaron el catálogo en tarjetas a un medio computacional-, sino de aprovechar otras posibilidades tecnológicas.

Al respecto, Weibel ha señalado:

[...]los metadatos son como tallos del paradigma de la información que difieren de otros que representan la actividad de la catalogación bibliotecaria y creo que las bibliotecas deberían sentirse invitadas a seguir intensamente su evolución y a no percibirlos como una 
amenaza, sino como una oportunidad de redefinir su papel en el contexto de los paradigmas de información emergentes. ${ }^{45}$

En nuestros días, los avances tecnológicos han generado propuestas de metadatos y la idea respecto a sí éstos se orientan a sustituir las normas de catalogación y los formatos bibliográficos utilizados en el siglo XX. En el XXI, el debate entre bibliotecarios, documentalistas e informáticos dificulta predecir el futuro de estos instrumentos normativos. Sin embargo, es evidente el requerimiento de la organización de las publicaciones digitales por los siguientes motivos:

- Son una manifestación más de la cultura y del desarrollo de las naciones, por lo que deben ser conservadas y puestas a disposición de la sociedad. Su recuperación y localización se facilitan mediante descripciones bibliográficas que las identifiquen y enlaces hipertextuales que permitan su acceso y consulta.

- El registro bibliográfico redactado a partir de un ejemplar recibido directamente del editor, por medio del depósito legal, es una medida de garantía de los derechos de la propiedad intelectual y un procedimiento que autentifica las características de la edición original. ${ }^{46}$

Por su parte, Owen y Walle argumentan en su informe, publicado por la Comisión Europea, las siguientes razones por las que las publicaciones digitales en línea deben sistematizarse:

- Los índices existentes en la red (Internet) son inadecuados; contienen insuficientes datos descriptivos y muestran falta de normalización de los datos y su presentación; a menudo resultan de poco valor para los usuarios y no está totalmente claro que se mantengan durante un periodo largo de tiempo.

- La naturaleza dinámica de los mecanismos de la red significa que no se guarda un registro de los recursos que se retiran de aquélla.

45 Stuart Weibel, citado por Stefan Gradmann, "Catalogación versus metadata: ¿Vino viejo en odres nuevos?”, en IFLA General Conference 64: (1998) [en línea] http://ifla.inist.fr/IV/ifla64/007-126s.html [consultada:15/09/03]

46 García Camarero, Op. cit., p. 240. 
- Los cambios frecuentes de los documentos y de las localizaciones conducen a cuestiones relacionadas con la autenticidad que sólo se puede resolver mediante un control bibliográfico formal.

- El control bibliográfico puede ayudar a proteger a los autores contra la piratería, en un entorno donde la información puede ser copiada y manipulada con facilidad.

- El depósito y el control bibliográfico contribuyen a realzar el estatus de las publicaciones electrónicas.

- La colección de depósito tiene que ser catalogada en cualquier caso para asegurar que las publicaciones puedan ser localizadas por las generaciones futuras. ${ }^{47}$

En este siglo se percibe que los desarrollos tecnológicos son de gran utilidad en la generación de sistemas de metadatos y en la gestión de nuevos servicios de información. Asimismo, en los medios bibliotecarios se plantea el requerimiento de aplicar normas de carácter universal con el fin de que se asegure la estructura, la descripción y el contenido de los metadatos. Lo anterior con el fin de que sean compatibles con el hardware y el software de gestión y lograr así eficacia en la recuperación de los mismos en beneficio de las sociedades usuarias de los documentos digitales.

Por lo ya mencionado el tema sobre metadatos es apasionante por su novedad y por las repercusiones que tendría en el ámbito internacional, por lo tanto, el estudio de dicho fenómeno debe dar respuesta a las siguientes interrogantes: ¿qué son los metadatos?, ¿qué tipos de metadatos existen?, ¿qué iniciativas de metadatos se han propuesto en los medios bibliotecarios y documentalistas?, ¿qué propone la iniciativa Núcleo de Dublín? ¿qué función tienen los lenguajes de marcado en la codificación de información digital y en el desarrollo de metadatos?, ¿cuáles son las tareas urgentes de los profesionales de la información en materia de metadatos?

47 J.S. Mackenzie Owen y J. V. D. Walle, citado por Ernesto García Camarero y Luis Ángel García Melero, La biblioteca digital, Madrid : Arco/Libros, 2001, p. 240. 
Elementos básicos para el diseño de un modelo para la enseñanza virtual ...

\section{El tesauro en la recuperación de documentos digitales}

Este fenómeno es relevante para la especialización propuesta, debido a que tiene que ver con la descripción de contenido, cuyo propósito es precisar el campo de conocimiento de que se trate, identificar y clasificar sin ambigüedad los diferentes temas que lo componen y expresar tales términos en lenguaje documental. En cuanto a este asunto, Naumis Peña señala: “[...]en la descripción de contenido está implícita entre otras cosas la agrupación [de documentos u objetos] de acuerdo a una clasificación". ${ }^{48}$ Se sabe que clasificar responde a tareas de organizar el conocimiento registrado de acuerdo con un orden sistemático.

Ella también afirma que:

[...]la clasificación temática se representa a través de términos normalizados, que se estructuran en un lenguaje de búsqueda y recuperación de información documental, de tipo descriptor que funcionan integrados en un sistema tesaural, dotando a esos términos de características propias, adecuadas a las necesidades del sistema de información del que forman parte. Los descriptores del tesauro documental serán alternados en la base de datos con palabras claves del título o de los resúmenes de los registros incluidos en el sistema y con identificadores de lugares, espacios, personajes, para una recuperación más integral. Los identificadores son listas de autoridades que aseguran el mismo uso para el mismo caso. ${ }^{49}$

Lo anterior tiene sentido si reflexionamos a partir de las búsquedas realizadas en Internet, que se basan en las palabras claves generadas automáticamente e incorporadas a listas y diccionarios de términos que, por lo general, no están normalizados. De ahí que los resultados de las búsquedas sean, en muchos casos, irrelevantes para el usuario final de la información. En consecuencia, el debate sobre la conveniencia de construir tesauros documentales está en pleno apogeo. Se piensa que el desarrollo de este tipo de herramientas será de mucha utilidad para las búsquedas en Internet, ya que debe res-

48 Catalina Naumis Peña, "Tesauro documental para la representación de contenidos educativos en videos”, en Investigación Bibliotecológica: archivonomía, bibliotecología e información ene./jun. 2003 vol. 34, no. 17, p. 157.

49 Ibid. 
ponder a: "[...]una estructura lingüística de clasificación temática o facetada, cuya organización básica está conformada por una relación de descriptores que representan o describen autoridades o contenidos semánticos, extraídos del lenguaje formal de una disciplina o área específica del conocimiento. ${ }^{50}$ Naumis Peña también señala que:

[...]se destacan en la integración del tesauro los descriptores que antes de su normalización para el sistema de información están validados por la comunidad de origen a través de la 'garantía literaria', es decir, su uso en documentos escritos por autores de prestigio que recogen la terminología de la especialidad. 51

Así, la búsqueda de una organización del conocimiento colectivo para la recuperación eficiente de información en la Internet sigue siendo una de las mayores preocupaciones en este tiempo, no sólo para la bibliotecología, sino para la documentación, la ciencia, la tecnología e incluso para la vida común del hombre.

Las estructuras de representación de la información se basan en la utilización del lenguaje controlado o natural, como intermediario hacia la recuperación y sobre la base teórica que la sustenta. La terminología es una rama de la lingüística aplicada, cuyo objeto de estudio son los términos y se ocupa de reconocer los vocabularios especializados, entenderlos y ubicarlos en el uso que hace de él la comunidad a la que sirve, además de normalizarlo para constituirlo en un vehículo efectivo de comunicación.

Es esencial contemplar que la terminología determina los fundamentos para la construcción de los lenguajes documentales. En consecuencia, en las tareas de diseño de herramientas terminológicas, se involucran especialistas en el ámbito temático específico en el que se necesita usarse, lo anterior garantiza la eficacia en la representación y recuperación de la información.

Es determinante atender la problemática derivada de la selección y recuperación de la información digital en Internet; se advierte que la

50 Catalina Naumis Peña, "Análisis de la confluencia entre término y descriptor en la elaboración de tesauros", en Investigación Bibliotecológica: archivonomía, blbliotecología e información, julio/diciembre de 2000, vol. 14, no. 29, p. 112.

51 Naumis Peña, Op. cit., p. 162. 
intervención de los sectores bibliotecarios deben orientarse principalmente en torno a los requerimientos para el acceso a la información y al conocimiento. En consecuencia, la enseñanza relacionada con la Internet y los tesauros debe proponer urgentemente la conveniencia de construir herramientas especializadas, dirigidas a sectores sociales específicos o abordar el diseño de herramientas globales. Asimismo, es necesario incidir en el desarrollo de interfaces para el uso de lenguajes documentales de fácil comprensión y con asociación de ideas múltiples para garantizar altos niveles de relevancia en la recuperación de la información.

\section{Redes de telecomunicación y transmisión de documentos digitales}

Algunos beneficios aportados al mundo bibliotecario es la generación de redes de telecomunicación y protocolos de comunicación para la integración de bases de datos; desarrollo de proyectos de adquisición y catalogación compartida; obtención de documentos en línea; intercomunicación de bibliotecas, autores, editores, y distribuidores; gestión de préstamos interbibliotecarios, servicios de resúmenes e indización; suministro de documentos electrónicos a usuarios finales de la información y servicios especializados para diversos tipos de comunidades (ejemplo, Campuswide Information Systems). Sin embargo, en la actualidad proliferan diversas bases de datos, redes de bibliotecas y servicios de información en línea, los cuales, generalmente, operan sobre técnicas de sistemas heterogéneos de información y a menudo resultan incompatibles; estos aspectos dificultan el uso compartido de recursos y provocan, en muchos casos, duplicidad de actividades.

Existen, en la actualidad más de seiscientos protocolos de comunicación para usar los recursos disponibles en la Internet, sin embargo, los servicios bibliotecarios, entre éstos los relacionados con la información digital, indican principalmente el uso de los siguientes: WWW, World Wide Web; HTTP. Hyper'Text Transport Protocol; Z39.50 (provee procedimientos normalizados para la conexión y transmisión de recursos de información en línea (OPAC); Telnet (TN3270); 
Wais, Wide Area Information Server; FTP, File Transportation Protocol y Mailing List Usenet.

Por lo anterior, se han generado programas cuyo propósito es reducir las barreras de la interconexión eficaz mediante el uso de las telecomunicaciones. Este aspecto se refleja en el programa UDT (Universal Dataflow and Telecomunications) de la IFLA, cuyas líneas principales de acción se refieren al desarrollo y experimentación de protocolos Open Systems Interconection (OSI) aplicados a la documentación; divulgación y promoción de protocolos OSI en bibliotecas, principalmente los relacionados con préstamos interbibliotecarios, recuperación de información digital, estructura y disponibilidad de redes teleinformáticas en el mundo y las formas en que pueden ser utilizadas para la transmisión de documentos digitales. Dicho programa contempla de igual manera la generación de sistemas de documentos digitales de texto completo, estudio de medios ópticos de almacenamiento y protocolos de comunicación como TCP/IP y normas teleinformáticas como X.400, X.500. El modelo OSI contempla un conjunto de estándares para facilitar la interconectividad de distintos equipos de cómputo, con el propósito de facilitar la transmisión remota de información. La OSI tiene su referente en la norma ISO 7498.

La problemática que plantea la enseñanza de la organización de recursos informativos digitales se incrementa ante el hecho de que las TIC cambian constantemente y ante la creciente demanda de bibliotecarios en cuanto a propuestas educativas que examinen fenómenos emergentes. Por ello es necesario repercutir en el modelo educativo, que concuerde con las características de lejanía y situación laboral de los potenciales alumnos. Así pues, se insiste en que la educación virtual, conforme a sus características y peculiaridades, puede ser idónea para sustentar el diseño de la especialización en los temas que se proponen en este documento.

Finalmente, se indica que el requerimiento de especialistas en diversos fenómenos inherentes a la bibliotecología es cada vez más evidente, debido, entre otros aspectos, al constante desarrollo de las TIC, las cuales continúan creando nuevas formas de generar información y conocimiento. Así, la sociedad reclamará con más énfasis la organización apropiada de la información digital, con la idea de tener 
el mayor éxito en los procesos que requieren su recuperación. Asimismo, los flujos de información interinstitucionales requieren de esa organización para los programas de cooperación relacionados con la organización documental.

En suma, es oportuno reflexionar sobre la enseñanza virtual de la organización de recursos informativos digitales, por las evidentes repercusiones, entre las que destacan las maneras de acceder y recuperar los recursos digitales disponibles a través de la Internet. Asimismo, se reconoce que dicha red ha generado nuevas formas para el diseño de escenarios virtuales de enseñanza-aprendizaje y, en consecuencia, en el aprendizaje basado en la interactividad y la navegación.

\section{FUNDAMENTO DE LA ESPECIALIZACIÓN SOBRE LA ORGANIZACIÓN DE RECURSOS INFORMATIVOS DIGITALES}

Para sustentar el diseño de esta especialización, se acudió principalmente a los referentes curriculares de la Maestría en Bibliotecología y Estudios de la Información de la UNAM; la Escuela Nacional de Biblioteconomía y Archivonomía de la SEP, en su modalidad a distancia y las áreas de investigación del Centro Universitario de Investigaciones Bibliotecológicas de la UNAM. Cabe señalar que estas instancias aportaron ideas y reflexiones muy importantes, no obstante, el área de conocimiento de la Maestría en Bibliotecología y Estudios de la Información de la UNAM, relacionada con la organización documental, influyó bastante en la estructuración del programa curricular de la especialización.

Sin duda, incidir en el diseño teórico de tal especialización, responde al requerimiento de tener referentes para el desarrollo de propuestas educativas a distancia que incidan en la preparación de cuadros altamente calificados, capaces de asumir tareas urgentes y emergentes, relacionadas con la organización de recursos digitales en pro de la sociedad. En otras palabras, se intenta contribuir con una propuesta teórica dirigida a la formación de bibliotecarios y documentalistas en activo, partiendo del estudio de fenómenos relevantes inherentes a la organización de recursos informativos 
digitales, entre otras razones, por las siguientes: la generación de documentos digitales crece significativamente, por lo que se precisa la formación de recursos humanos de alto nivel, con apropiación de la teoría, la aplicación de normas bibliotecarias pertinentes y desarrollo de competencias para el uso de las TIC que requiera la organización de recursos informativos digitales, con la idea de que influya en el desarrollo de sistemas de información orientados a la gestión de servicios documentales, acordes a los intereses informativos de la sociedad de hoy.

Con el surgimiento de las tecnologías de red, desde hace algunos años se han producido cambios sustanciales y vertiginosos en la organización, almacenamiento, acceso y producción de recursos digitales. En este sentido, la especialización se orienta al análisis de conceptos, procesos, métodos, instrumentos y fenómenos involucrados en la organización de recursos informativos digitales. Asimismo al desarrollo de habilidades y destrezas para recuperar, evaluar, describir y utilizar la Internet como fuente de documentos digitales. Para lograr todos estos, se propone un programa académico compuesto por módulos y contenidos de aprendizaje.

El programa académico ${ }^{52}$ de la especialización propuesta contempla cinco módulos, uno relativo a la preparación de un trabajo de investigación. A través de éstos se persigue que los alumnos adquieran conocimiento teórico y práctico de los problemas de la organización de recursos informativos digitales generados por las TIC. Algunos de esos fenómenos ya se examinaron capítulos antes.

Así, la estructura del programa se fundamenta en módulos de aprendizaje que agrupan el conjunto integrado de contenidos temáticos de esta especialización. La estructura en módulos de los fenómenos de estudio tiene como intención repercutir en un programa con una estructura flexible, para ejercer un control apropiado de los aprendizajes, los materiales didácticos y la evaluación. Los módulos se orientan a la enseñanza virtual de temas relativos a los recursos

52 Aquí se entiende por programa académico el conjunto de temas organizados lógicamente para orientar de manera metodológica el aprendizaje de los fenómenos involucrados en la organización de recursos informativos digitales. 
Elementos básicos para el diseño de un modelo para la enseñanza virtual ...

informativos digitales. Se presentan en forma lógica para incidir sistemáticamente en el desarrollo del aprendizaje.

Módulos del programa académico

\begin{tabular}{|l|c|}
\hline \multicolumn{1}{|c|}{ Módulos } & $\begin{array}{c}\text { Número de } \\
\text { créditos }\end{array}$ \\
\hline $\begin{array}{l}\text { Módulo I. Normalización de la información digital y gestión de contenido mediante } \\
\text { bases de datos, lenguajes de marcado e hipertexto }\end{array}$ & 8 \\
\hline $\begin{array}{l}\text { Módulo II. Formatos bibliográficos internacionales: MARC 21 y representación de } \\
\text { documentos digitales }\end{array}$ & 8 \\
\hline $\begin{array}{l}\text { Módulo III. Metadatos en la representación de recursos informativos digitales y } \\
\text { acceso a la información vía Internet }\end{array}$ & 8 \\
\hline Módulo IV. El tesauro en el medio digital & 8 \\
\hline Módulo V. Elaboración de un trabajo de investigación de carácter monográfico & 10 \\
\hline Total & 42 \\
\hline
\end{tabular}

La especialización se acredita con 42 créditos, definidos a partir de su importancia temática dentro del módulo, la profundidad del aprendizaje requerido, las cargas de las actividades de aprendizaje y los requerimientos de trabajo final de investigación. Este total de créditos se basa en el Reglamento General de Estudios de Posgrado de la $U N A M^{3}$ ya que en éste se fundamentan diversas especializaciones presenciales y a distancia en distintas facultades, y por ser la universidad nacional tiene una mayor especificidad normativa sobre la enseñanza de especializaciones. A continuación se describen los artículos normativos de más relevancia.

53 El reglamento vigente lo aprobó el Consejo Universitario en su sesión del 14 de diciembre de 1995 y se publicó en la Gaceta UNAM el 11 de diciembre de 1996. 


\section{UNIVERSIDAD NACIONAL AUTÓNOMA DE MÉXICO}

\section{Normas para la obtención del diploma de especialización Artículos normativos del Reglamento General de Estudios de Posgrado}

Artículo 1. Son estudios de posgrado los que se realizan después de los estudios de licenciatura y tienen como finalidad la formación de académicos y profesionistas del más alto nivel. Al término de los estudios de posgrado se otorgará el grado de maestro, grado de doctor o diploma de especialización. Estarán organizados en forma de programas de estructura flexible y procurarán la participación conjunta de las entidades académicas que cultivan disciplinas o ramas afines del conocimiento.

El mismo Reglamento en el Título III, capítulo único. De las características y Organización de los Estudios de Especialización señala lo siguiente:

Artículo 40.- Los estudios de especialización tienen como objetivo profundizar y ampliar los conocimientos y destrezas que requiere el ejercicio profesional en un área específica. Los planes de estudios de una especialización deberán tener cuando menos cuarenta créditos.

Artículo 41.- En los programas de especialización se podrá constituir un comité académico, cuya conformación y atribuciones quedarán definidas en las normas operativas. Cuando un programa no considere la integración de un comité académico, los consejos técnicos determinarán, en las normas operativas, la instancia que asumirá las atribuciones del comité académico previstas en este reglamento.

Artículo 42.- Para cada programa de especialización, los directores de las entidades académicas participantes designarán a un coordinador cuyas funciones serán definidas por los consejos técnicos respectivos, en las normas operativas correspondientes.

Artículo 43.- Cuando se justifique y requiera, los alumnos de especialización contarán con tutoría. Las funciones y requisitos académicos de los tutores deberán quedar definidos en las normas operativas correspondientes.

Artículo 44.- La permanencia en los estudios de especialización se sujetará a los plazos previstos en el plan de estudios.

Artículo 45.- Para obtener el diploma de especialización será necesario haber cubierto los créditos del respectivo plan de estudios, y cumplir los demás requisitos establecidos.

Fuente: Reglamento General de Estudios de Posgrado de la UNAM. 
Para sustentar el programa académico de esta especialización, se contemplaron distintos aspectos de este reglamento. Enseguida se muestra cuáles son.

\section{MÓDULOS DE LA ESPECIALIZACIÓN}

El programa de la especialización tiene como objetivo general analizar conceptos, procesos y fenómenos involucrados en la organización de recursos informativos digitales para que los alumnos, a través de la modalidad virtual, reafirmen su conocimiento previo en torno a la organización documental, adquieran nuevo conocimiento sobre los fenómenos de estudio comprendidos en la especialización, además de que desarrollen habilidades y destrezas en el manejo de las TIC disponibles para organizar y recuperar documentos digitales.

Se asume que, con base en los contenidos de los módulos propuestos, así como con la elaboración de un trabajo de investigación, se cubre la enseñanza de los temas contemplados en dichos módulos requeridos para el estudio de la Especialización sobre la organización de recursos informativos digitales. No obstante, la estructura modular se muestra con principios de flexibilidad para que, en su momento, se incorporen otros temas de estudio que exijan la actualización y el enriquecimiento de esta propuesta. En principio, se plantean los cursos optativos siguientes: Organización de la publicación electrónica, Organización y gestión de recursos digitales en bibliotecas especializadas y Organización de la biblioteca digital y de sus servicios de información. Los módulos referidos se presentan en seguida. 


\section{Módulo I. Normalización de la información digital y gestión de contenido mediante bases de datos, lenguajes de marcado e bipertexto}

\begin{tabular}{|c|c|}
\hline $\begin{array}{c}\text { Módulo I } \\
\text { Normalización de la información digital y gestión de } \\
\text { contenido mediante bases de datos, lenguajes de } \\
\text { marcado e hipertexto }\end{array}$ & Objetivc \\
\hline $\begin{array}{l}\text { Unidad 1. Control bibliográfico y normalización en el siglo } \\
\text { XX y los albores del siglo XXI } \\
\text { Contenido } \\
\text { Modelo creado con la aparición de formatos bibliográficos } \\
\text { Bases de datos y catálogos públicos en línea (OPAC). } \\
\text { Paradigma creado con la aparición de lenguajes de marcado } \\
\text { para la representación de recursos digitales } \\
\text { - Lenguaje HTML (Hypertext Markup Language = Lenguaje } \\
\text { de Marcado para Hipertexto). } \\
\text { - Lenguaje SGML (Standard Generalized Markup Language = } \\
\text { Lenguaje Estándar Generalizado de Marcado). } \\
\text { - Lenguaje XML (eXtensible Markup Language = Lenguaje } \\
\text { Generalizado de Marcado). } \\
\text { - Hipertexto y metadatos. } \\
\text { Unidad 2. Organismos Internacionales en materia de } \\
\text { control bibliográfico y normalización } \\
\text { 1. Federación Internacional de Asociaciones de Bibliotecas } \\
\text { (IFLA) y el Programa Información para todos sobre Control } \\
\text { Bibliográfico Universal MARC Internacional (CBUIN). } \\
\text { 2. Seminario Internacional sobre Control Bibliográfico } \\
\text { Universal: el Control bibliográfico en América Latina y el } \\
\text { Caribe hacia el Tercer Milenio. } \\
\text { 3. Organización de las Naciones Unidas para la Educación, la } \\
\text { 4. Organización Internacional de Normalización (ISO). } \\
\text { 5. Uso social de la organización de recursos digitales en los } \\
\text { albores del siglo XXI }\end{array}$ & $\begin{array}{l}\text { - Analizar el desarrollo del } \\
\text { control bibliográfico durante el } \\
\text { siglo XX y principios del XXI, a } \\
\text { fin de identificar los } \\
\text { paradigmas para la } \\
\text { organización documental } \\
\text { aparecidos con las } \\
\text { tecnologías de información y } \\
\text { comunicación. } \\
\text { - Analizar la evolución de los } \\
\text { formatos bibliográficos y } \\
\text { valorar si constituyen } \\
\text { herramientas normativas que } \\
\text { faciliten el intercambio de } \\
\text { registros bibliográficos entre } \\
\text { unidades de información } \\
\text { - Estudiar sobre los metadatos } \\
\text { y el hipertexto a fin de valorar } \\
\text { su función en tareas de } \\
\text { organización de recursos } \\
\text { informativos digitales. } \\
\text { - Analizar la función de } \\
\text { organismos internacionales } \\
\text { representativos en la } \\
\text { normalización documental y } \\
\text { en el control bibliográfico. } \\
\text { - Reflexionar sobre la } \\
\text { importancia que tiene la } \\
\text { normalización en la } \\
\text { organización y recuperación } \\
\text { de recursos informativos y su } \\
\text { utilidad para la sociedad } \\
\text { actual. }\end{array}$ \\
\hline
\end{tabular}


Elementos básicos para el diseño de un modelo para la enseñanza virtual ...

\section{Módulo II. Formatos Bibliográficos Internacionales: MARC 21 y representación de documentos digitales}

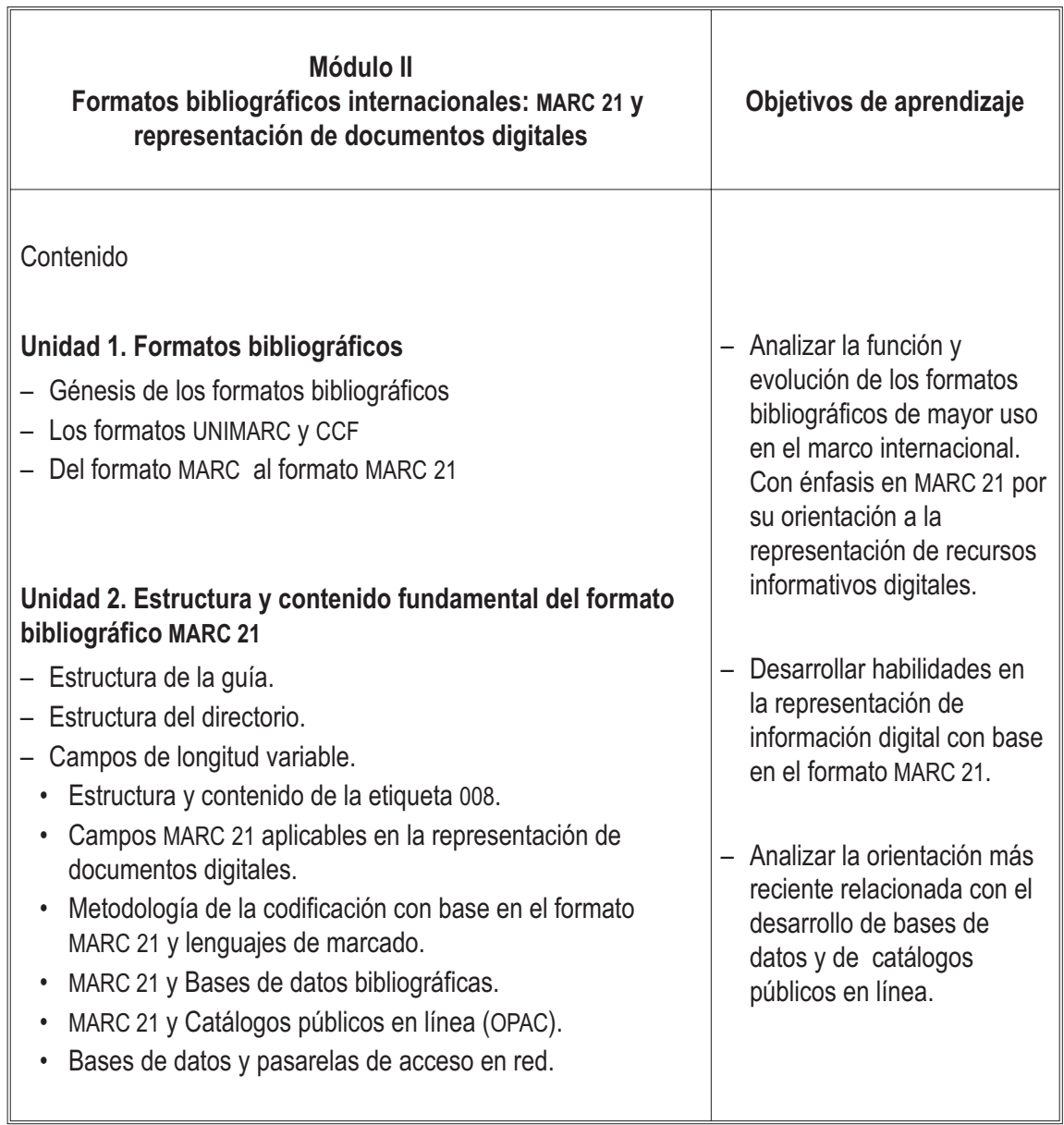




\section{Módulo III. Metadatos en la representación de recursos informativos digitales y acceso a la información vía Internet}

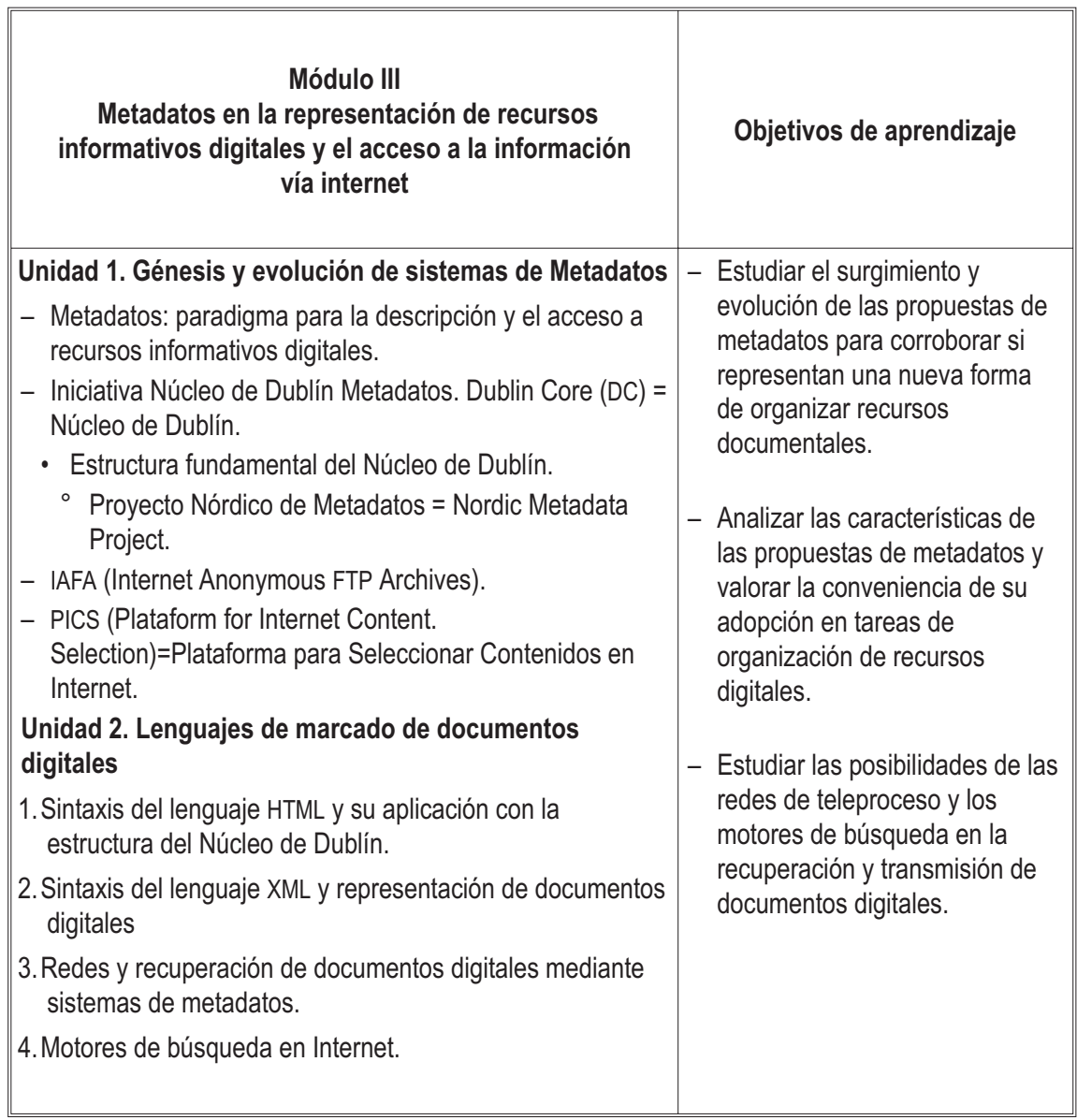


Elementos básicos para el diseño de un modelo para la enseñanza virtual ...

\section{Módulo IV. El tesauro en el medio digital}

\begin{tabular}{|c|c|}
\hline $\begin{array}{c}\text { Módulo IV } \\
\text { El tesauro en el medio digital }\end{array}$ & Objetivos de aprendizaje \\
\hline $\begin{array}{l}\text { Contenido } \\
\text { Unidad 1. Tesauros en entornos de red } \\
\text { 1. Tecnologías de red y ambientes digitales en la } \\
\text { construcción de tesauros. } \\
\text { 2. El análisis de contenido en la construcción de tesauros } \\
\text { 3. Sustento teórico de los tesauros. } \\
\text { 4. Normas para la construcción de tesauros. } \\
\text { 5. Métodos para la construcción de relaciones tesauruales. } \\
\text { 6. Tecnologías de información y comunicación de apoyo en } \\
\text { la construcción de tesauros para ambientes digitales. } \\
\text { 7. Funcionamiento del tesauro en red. } \\
\text { 8. Mapas de navegación para la Web }\end{array}$ & $\begin{array}{l}\text { - Discutir los convenientes e } \\
\text { inconvenientes teóricos y } \\
\text { aplicados en cuanto al uso de } \\
\text { las TIC en el desarrollo de } \\
\text { tesauros. } \\
\text { - Explicar que es, para que se } \\
\text { usa y como se construye una } \\
\text { clasificación temática para } \\
\text { representar el conocimiento, } \\
\text { imágenes y saberes implícitos } \\
\text { en documentos digitales } \\
\text { sustituyéndolo por términos } \\
\text { normalizados que permitan } \\
\text { localizar el documento que } \\
\text { contiene una información en } \\
\text { una masa de documentos y su } \\
\text { funcionamiento en red. } \\
\text { Asimismo analizar las } \\
\text { posibilidades de los mapas de } \\
\text { navegación. }\end{array}$ \\
\hline
\end{tabular}


En señanza virtual sobre la organización de recursos informativos digitales

\section{Módulo V. Elaboración de un trabajo de investigación}

\begin{tabular}{||l|l||}
\hline \multicolumn{1}{|c|}{ Trabajo de investigación } & \multicolumn{1}{c||}{ Objetivos de aprendizaje } \\
\hline $\begin{array}{l}\text { Elaboración de un trabajo de investigación de carácter } \\
\text { monográfico }\end{array}$ & \\
$\begin{array}{l}\text { 1. La investigación en la planificación de proyectos sobre } \\
\text { organización de recursos informativos digitales. }\end{array}$ & $\begin{array}{l}\text { El trabajo final tiene como } \\
\text { propósito rescatar el }\end{array}$ \\
$\begin{array}{l}\text { 2. Orientación de la investigación en organización del } \\
\text { conocimiento significativo que }\end{array}$ \\
$\begin{array}{l}\text { 3. Estudios de caso. } \\
\text { El trabajo final de la especialización deberá incidir en la } \\
\text { propuesta de un sistema de metadatos para ser desarrollado } \\
\text { en la unidad de información que mejor convenga a los } \\
\text { intereses del alumno. } \\
\text { El alumno lecturas y de las } \\
\text { actividades de aprendizaje de } \\
\text { cada módulo. Por tanto, se } \\
\text { las actividades de aprendizaje de cada módulo, con el } \\
\text { propósito de facilitar el desarrollo de su trabajo final. Es } \\
\text { conveniente que el alumno enriquezca el contenido, acudiendo las tareas } \\
\text { a documentos en texto completo almacenados en la biblioteca } \\
\text { digital de apoyo a la especialización. } \\
\text { A cada alumno virtual se le asignará un tutor atendiendo a la } \\
\text { orientación de su trabajo final. }\end{array}$ & $\begin{array}{l}\text { realizadas, las reflexiones y las } \\
\text { conclusiones personales } \\
\text { deberán reflejarse en dicho } \\
\text { trabajo. Para apoyar el } \\
\text { desarrollo del mismo se propone } \\
\text { el desarrollo de los rubros } \\
\text { descritos. }\end{array}$ \\
\hline
\end{tabular}

\section{Requisitos y figuras del programa académico}

En este rubro sólo se ejemplifican los elementos más relevantes, por lo que lo relativo al desarrollo de materiales didácticos, métodos de estudio, normas para la presentación de actividades de aprendizaje deben considerarse cuando se desarrollen e implementen propuestas de esta naturaleza, ya que dichos elementos han de responder a esos objetivos y a las características de la plataforma tecnológica de apoyo. A continuación se presentan esos elementos de la especialización. 
Elementos básicos para el diseño de un modelo para la enseñanza virtual ...

\section{Requisitos de ingreso}

Para ingresar a esta especialización conviene que el aspirante cuente con estos requisitos:

- Contar con licenciatura en bibliotecología, biblioteconomía, ciencias de la información, ciencias de la documentación u otro título afín.

- Tener otra profesión e interesarse en cursar la especialización a distancia y que laboren en áreas relacionadas con la organización documental o bien que tengan experiencia en tareas bibliotecarias.

- Presentar al Comité Académico de la especialización una solicitud conforme lo estipula la convocatoria que se emita.

\section{Mecanismos de Admisión}

Una vez cubiertos los requisitos, el Comité Académico evaluará la solicitud, el currículum y resolverá si acepta o no al aspirante.

Requisitos de egreso

- Haber aprobado los módulos de especialización.

- Haber elaborado y entregado el trabajo final.

Perfil del egresado

Los contenidos de los módulos del programa de la especialización darán elementos al egresado para:

- Participar en el diseño y desarrollo de sistemas de información utilizando la normalización internacional, según los requerimientos de los ámbitos en que se apliquen.

- Proponer alternativas orientadas al uso de las TIC como apoyo a las tareas propias de la organización, principalmente de recursos documentales de carácter digital.

\section{Requisitos de permanencia}

- Cumplir con las actividades de aprendizaje indicadas en cada módulo, en las fechas previstas en el calendario de la especialidad.

\section{Comité Académico}

La especialización contará con un Comité Académico, cuyas funciones básicas serán:

- Atender cualquier asunto que exija el buen funcionamiento de la especialización.

- Llevar a cabo la selección de los alumnos.

- Participar en la acreditación de éstos. 
- Intervenir en la evaluación del trabajo final para la acreditación de la especialización.

\section{Coordinadores y tutores}

Cada módulo tendrá un coordinador y los tutores que requieran las unidades de aprendizaje. Durante la especialización, el alumno contará con el apoyo y seguimiento de estas figuras, mediante una plataforma (aula virtual) en la que se recurra al correo electrónico, así como consultorías telefónicas.

\section{Actividades presenciales}

El Comité Académico y los tutores de módulo determinarán la conveniencia de las actividades presenciales, en cuanto a socialización del conocimiento adquirido en esta especialización. Con base en el análisis de algunos modelos a distancia se recomendaría la programación de por lo menos dos encuentros presenciales con los alumnos. Algunas actividades a desarrollar serían las siguientes:

1. Una sesión al inicio de la especialización, en la que se contemple la presentación del Comité Académico y de los tutores de módulo, las particularidades del currículum académico, características generales del material didáctico, interacción con el aula virtual e interacción con la biblioteca digital.

2. Una sesión al final de la especialización para socializar el conocimiento adquirido a lo largo de la especialización, discutir los convenientes e inconvenientes en cuanto a la atención de los coordinadores y la oportunidad de las tutorías, la calidad de los materiales didácticos y de las actividades de aprendizaje, uso del aula virtual y utilidad de la biblioteca digital, solucionar dudas sobre la elaboración del trabajo final, etcétera.

\section{Mercado laboral del egresado}

Los especialistas en organización de recursos informativos digitales prestarían sus servicios en cualquier unidad de información ubicadas en entidades educativas públicas y privadas, gubernamentales, instituciones de investigación públicas o privadas. Algunas de sus tareas profesionales serían:

- Representación normalizada de información documental en diversos medios.

- Transferencia de información documental vía redes de teleproceso. 
Elementos básicos para el diseño de un modelo para la enseñanza virtual ...

- Participación en el diseño de bases de datos y de catálogos públicos en línea.

- Participación en el diseño de sistemas de metadatos y bibliotecas digitales.

\section{Duración de los estudios}

La duración máxima prevista es de doce meses, organizados como se enuncia: dos meses y medio para cada módulo y dos meses para el desarrollo del trabajo final, una prórroga de tiempo para el desarrollo de esta tarea se acordaría con el tutor correspondiente, sin exceder de cinco meses. Para cumplir en lo posible con este tiempo, se tiene en mente el inicio del trabajo final por lo menos a los cinco meses de iniciada la especialización, por lo que conviene inducir al alumno a elegir a su tutor, atendiendo el tema de su interés y que se relacione con las temáticas vistas en la especialización. Asimismo, los cinco módulos se planean con base en dos semestres en los cuales el alumno cursaría dos o tres módulos el primero y dos más en el segundo; se entiende que el módulo correspondiente al desarrollo del trabajo final se realizará en el segundo semestre.

\section{Requisitos para obtener el diploma}

Para obtener el diploma de esta especialización es necesario aprobar los cuatro módulos que la integran y elaborar un trabajo final de investigación que corresponde al quinto módulo, cuyas características son éstas:

- El trabajo final para la obtención del diploma debe realizarse individualmente.

- El aspirante a la especialización elaborará un trabajo monográfico sobre temas de la especialización. Se tiene que considerar un capítulo en el que se plantee la aplicación de una propuesta relacionada con la organización de recursos digitales y su beneficio social, propuesta que se aplicaría en la unidad de información que elija el alumno.

- La supervisión del trabajo debe estar a cargo de un tutor.

- En las sesiones de tutoría, el alumno presentará al tutor los avances en el desarrollo de su trabajo y discutirá con él todos los problemas derivados. El tutor, por su parte, proporcionará al alumno orientación bibliográfica, teórica y metodológica para su investigación. La 
consecución de estas actividades se hará de preferencia a través del aula virtual, utilizando el correo electrónico.

\section{Objetivos terminales}

Al finalizar la especialización los participantes deberán:

- Incrementar su conocimiento tecnológico, orientado principalmente a los diversos fenómenos involucrados en la organización documental.

- Desarrollar habilidades y destrezas para diseñar y usar sistemas de metadatos y bibliotecas digitales.

- Representar recursos de información digital con base en normas internacionales.

- Comprender y manejar estructuras de lenguajes de marcado más usuales.

- Estructurar sistemas de metadatos y bibliotecas digitales.

- Conocer los últimos avances tecnológicos en la gestión de recursos digitales.

\section{Características del temario}

1. Es recomendable que cada módulo esté a cargo de un coordinador y cada unidad de aprendizaje, de un tutor. Esto garantiza un mayor control del programa, de las actividades de aprendizaje y la participación de tutores, lo cual enriquece la orientación y puntos de vista de alumnos y tutores, además de que evita el exceso de actividades para un solo asesor o tutor.

2. Los módulos incluyen diversas actividades de aprendizaje, que se sugiere se cubran en un periodo de tres meses, tomando en cuenta los tiempos de la institución educativa interesada en ofrecer este tipo de cursos.

3. Los requisitos de evaluación de cada módulo comprenden:

¿ Un examen por módulo de opción múltiple.

- Ejercicio(s), según lo amerite el módulo. Los criterios los definirán los tutores de los módulos.

$\varpi$ Participación del grupo en foros de discusión en cada módulo.

• Participación en grupo o en forma individual en chats sobre temas específicos, según lo exija el módulo, el grupo o el alumno individualmente.

Desarrollo de un ensayo escrito por cada módulo. 
Elementos básicos para el diseño de un modelo para la enseñanza virtual ...

\section{Materiales didácticos}

Los materiales didácticos deben contener el conocimiento fundamental para el aprendizaje de los fenómenos incluidos en el currículum académico, con el fin de complementar y profundizar el conocimiento, se proporcionarán a los estudiantes, según el caso, documentos digitales y bibliografías para ampliar el estudio de rubros específicos. Para fines de esta especialización, se recomienda la Internet como medio primordial para integrar los materiales didácticos. En el segundo capítulo se revisan los elementos relativos al desarrollo de materiales didácticos. Así, en cada módulo se proporcionará a los alumnos a distancia los materiales didácticos correspondientes, que serían:

- Textos de aprendizaje desarrollados ex profeso en multimedios.

- Antologías digitalizadas.

- Artículos relevantes digitalizados.

- Cuestionarios para evaluar los avances académicos de cada alumno. Métodos de estudio

Se recomienda a los alumnos de la especialización pensar en las siguientes indicaciones, con el fin de llevar a buen término sus actividades de aprendizaje:

- Realizar las lecturas de los módulos correspondientes.

- Formular preguntas relevantes al tutor específico y enviarlas al buzón correspondiente.

- Participar activamente en las sesiones de chat y en los foros de discusión.

- Enviar las actividades de aprendizaje para su evaluación correspondiente a cada módulo, en las fechas preestablecidas.

- Remitir al coordinador del módulo específico el trabajo final correspondiente.

Dedicar un promedio de doce horas de estudio a la semana. Si se cumple este promedio, el número aproximado de horas dedicadas a la especialización sería de 576 hrs.

Es conveniente que el alumno participe en su proceso de aprendizaje, tenga facilidad para el estudio independiente y el estudio colaborativo y creatividad para organizar el tiempo-horas que dedicará al estudio de cada módulo. 


\section{Criterios de evaluación}

Los criterios de evaluación para otorgar una calificación a los trabajos de los alumnos serán los académicamente aceptados en las actividades de enseñanza-aprendizaje de estos temas:

1. La evaluación se hará por módulo.

2. Elaboración de un trabajo de carácter monográfico en el que se muestre la apropiación de conocimiento relacionado con alguna temática estudiada durante la especialización, dicho estudio será teórico o práctico y será objeto de análisis por parte del Comité Académico. Aprobado lo anterior, el alumno se hará acreedor del diploma en el que se indicará que cuenta con especialización sobre la organización de recursos informativos digitales, que acreditará la institución sede.

\section{Institucionalización de la especialización}

En el desarrollo de programas educativos a distancia es mejor conocer las características de la institución sede, las necesidades educativas que resolverá, las características de los estudiantes a los que se quiere hacer llegar la propuesta educativa, los recursos humanos que la apoyarán y la infraestructura de recursos humanos y tecnológicos disponibles.

En la literatura consultada se observa que toda propuesta educativa a distancia responde, en principio, a la misión de la institución educativa oferente, los valores que sustenta, así como su compromiso con la sociedad. Debido a que para esta especialización se propone como sede a la UNAM, se hace referencia a su misión, consistente en:

Formar recursos humanos de calidad, preparados para enfrentar los retos de una competencia internacional basada en la ciencia y la tecnología, capaces de actuar de manera solidaria en una sociedad que aún tiene carencias e injusticias, y con una formación humanista que les permita encontrar sentido y razón a su vida y a su práctica profesional. Investigar para ampliar las fronteras del conocimiento, buscando el máximo beneficio para la sociedad mexicana, en términos de formación de recursos humanos, creación de una cultura propia y solución de los problemas nacionales. Preservar y difundir 
la cultura nacional, así como los grandes valores de la cultura universal, en beneficio de la sociedad mexicana. ${ }^{54}$

Debido a lo determinante que es la institucionalización de programas en propuestas educativas virtuales, la teoría recomienda que la institución responsable debe reunir una serie de condiciones sobre su:

- Infraestructura administrativa.

- Infraestructura académica.

- Infraestructura de información documental (biblioteca).

- Infraestructura tecnológica.

En consecuencia, el diseño de una propuesta educativa de esta naturaleza, determina que la dependencia sede designe uno o varios coordinadores académicos, quienes por regla general son nombrados por los cuerpos colegiados de la institución responsable del programa. La coordinación tendrá como prioritarias las siguientes funciones:

1. Programar el presupuesto para operar la propuesta educativa, lo cual implica inversión en el desarrollo de material didáctico, personal académico dedicado a garantizar el buen funcionamiento del currículum, los apoyos tecnológicos requeridos y demás.

2. Contar con personal especializado, principalmente en bibliotecología, pedagogía, comunicación, y TIC.

3. Coordinar el diseño curricular de la especialización, lo que implica el conocimiento del proceso de enseñanza-aprendizaje en sistemas a distancia, teorías del aprendizaje y sistemas de evaluación.

4. Desarrollo de materiales didácticos de apoyo al proceso de enseñanza-aprendizaje.

5. Evaluar el programa, antes, durante y después de su liberación.

Respecto de la institucionalización en México del programa de la Especialización sobre organización de recursos informativos Digitales, las entidades académicas idóneas serían la Facultad de Filosofía y Letras, a través de su Programa de Posgrado en Bibliotecología y Estudios de la Información, así como el Centro Universitario de Investigaciones

54 Para mayor información al respecto, véase http://www.matem.unam.mx/avisos/97/barnes/plan97.html 
Bibliotecológicas. Asimismo consideramos que sería conveniente la participación de la Coordinación de Universidad Abierta y Educación a Distancia (CUAED) y de la Dirección General de Cómputo Académico (DGSCA), entidades que también pertenecen a la UNAM.

Lo oportuno de que las primeras actúen como responsables del programa de la especialización responde a la exigencia de contar con la infraestructura de recursos humanos y tecnológicos, experiencia en la educación superior en bibliotecología y en la investigación bibliotecológica, por tener la Facultad y el CUIB a su cargo la conducción del programa de Maestría y Doctorado en Bibliotecología y Estudios de la Información, entre otros aspectos. Asimismo, su participación como entidades tiene reconocimiento legal según lo establecido en el Artículo $1^{\mathrm{O}}$ del Reglamento General de Estudios de Postgrado de la UNAM. ${ }^{55}$

\section{REPRESENTACIÓN GRÁFICA DE LA ESPECIALIZACIÓN}

Con base en toda la información anterior, a continuación se presenta el esquema de la Especialización sobre la organización de recursos informativos digitales, tomando en cuenta las dimensiones alumno, tutor, teoría del aprendizaje, materiales, medios, etcétera. El esquema se estructura atendiendo el enfoque de sistemas, por lo tanto, contempla que la noción de teoría de sistemas "[...]concibe a un sistema como un conjunto de elementos que se relacionan entre sí y con el medio, es decir, un correlato conceptual de ciertos rasgos universales de objetos observables e interrelacionados". ${ }^{56}$

En este sentido, las dimensiones institución, comité académico, alumnos y otros se entienden como conjuntos relacionados en subsistemas.

55 Reglamento General de Estudios de Postgrado. Artículo 1. "Al término de los estudios de postgrado se otorgará el grado de maestro, grado de doctor o diploma de especialización. Estarán organizados en forma de programas de estructura flexible y procurarán la participación conjunta de las entidades académicas que cultivan disciplinas o ramas afines del conocimiento".

56 Von Bertalanffi, citado por H.G. Bustamante Rojas, "Propuesta de un modelo de orientación educativa a distancia”, en Educación y formación a distancia.... Op. cit., pp. 165-167. 
Un subsistema puede, a su vez, observarse como un sistema del cual se derivan otros de naturaleza subordinada, con propiedades específicas de sus componentes determinadas por sus interrelaciones.

La estructura del sistema se relaciona con los diferentes subsistemas para incidir en la retroalimentación y mantener una visión de conjunto. A continuación se muesra dicha estructura de la especialización en organización de recursos informativos digitales.

Figura 7

Sistema de la Especialización sobre la organización de recursos informativos digitales

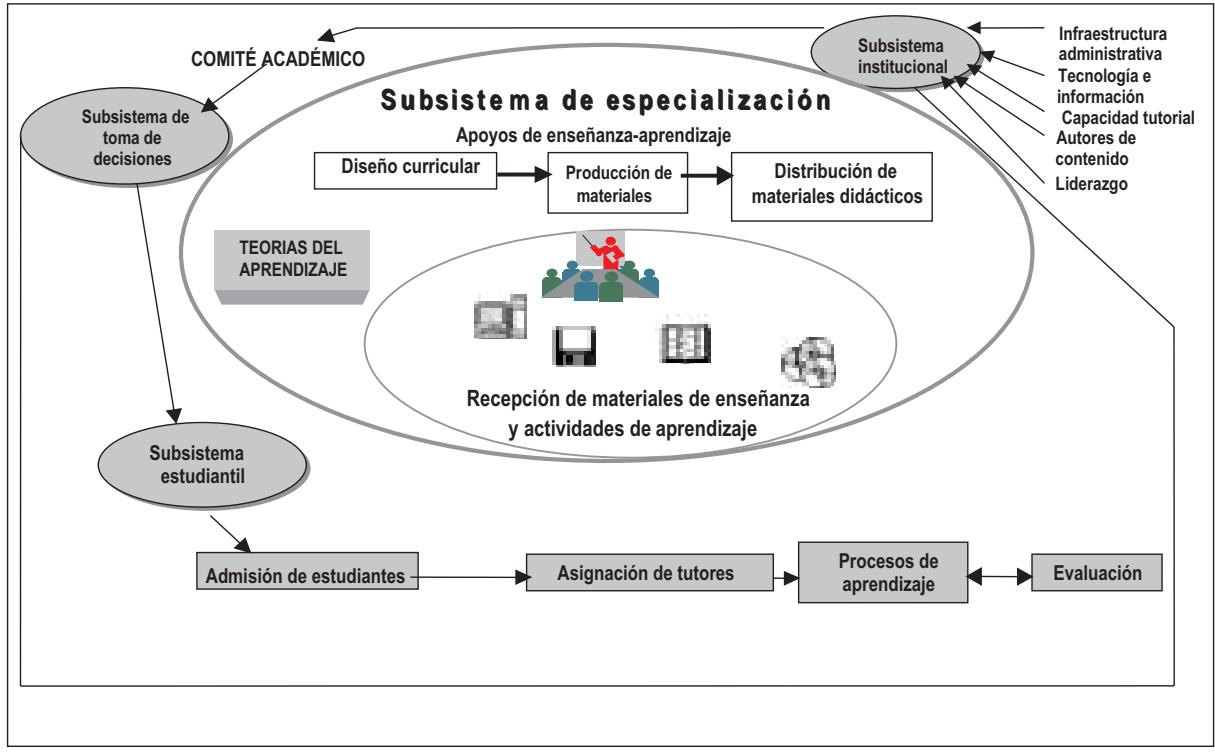

Sistema de la especialización sobre organización de recursos informativos digitales. En el esquema anterior se aprecia que el sistema de la especialización se estructura en subsistemas y en cada cual se identifican responsabilidades y actividades específicas. Cabe subrayar que la teoría de sistemas indica el requerimiento de su constante interacción, a fin de lograr su retroalimentación y de esta manera incidir, si se requiere, en la reestructuración de alguno para reorientar su estructura sin afectar al sistema en su conjunto. 
Subsistema de la especialización. Al centro del esquema se encuentra el subsistema de la especialización, que contempla el diseño curricular (modular), la producción de materiales didácticos, las teorías de aprendizaje y su distribución, a través de diversos medios. En esta especialización, la distribución de contenidos y la interacción entre los actores del aprendizaje sería vía Internet.

Subsistema institucional. Sin embargo, para que se pueda desarrollar y ejecutar, se requiere que la institución sede reúna condiciones como estas: infraestructura administrativa, tecnológica, de recursos humanos preparados en los temas de la especialización, autores de contenidos y tener reconocimiento de liderazgo en el marco nacional e internacional. Asimismo, de otorgar la certificación correspondiente.

Subsistema comité académico. Las funciones del Comité Académico serían atender cualquier asunto que asegure el buen funcionamiento de la especialización, llevar a cabo la selección de los alumnos, intervenir en la evaluación del trabajo final y, participar en la acreditación de los alumnos.

Subsistema estudiantil. Este subsistema se orienta principalmente a las actividades académico-administrativas, las cuales comprenden el registro de alumnos, asignación de tutores que faciliten los procesos de aprendizaje, asesoría permanente a los alumnos y evaluaciones.

Finalmente, destaca que la estructuración de modelos académicos requiere investigar las diversas variables que se relacionan con propuestas educativas de esta índole. Las variables derivadas del modelo de la educación a distancia que se emplean en la educación virtual son vitales para guiar propuestas educativas como la aquí expuesta.

Por otra parte, sobresale el hecho de que el modelo teórico presentado se implementaría en cualquier organismo educativo que se interese en ofrecer tal especialización, empero se dirige principalmente a la UNAM, debido a que a partir de su reglamentación e infraestructura académica y tecnológica se fundamentaron diversos aspectos de ésta. No obstante, ahora conviene preguntar icómo aplicar la especialización en forma virtual? La respuesta se halla en el siguiente capítulo. 


\section{V}

Plataforma de apoyo a la enseñanza virtual sobre la organización de recursos informativos digitales 



\section{INTERNET EN LA EDUCACIÓN VIRTUAL}

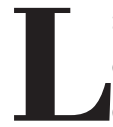

a enseñanza virtual es un campo privilegiado para comprender los desafíos que hoy tienen las sociedades en cuanto a la explicación de los fenómenos y procesos suscitados a raíz de la aparición de las TIC en nuestros días. En el terreno educativo es indispensable comprender la repercusión del uso de la Internet en la educación a distancia, las propuestas teóricas que se discuten ahora en cuanto a interactividad y navegación, las perspectivas sociales e institucionales que se tienen de la educación virtual del siglo en curso.

Así, se observa que la posibilidad tecnológica en cuanto al desarrollo de aulas virtuales en soporte Intranet-Internet es un fenómeno reciente, sin embargo, ha generado interés de diversos organismos nacionales e internacionales para concentrarse en propuestas educativas virtuales, las cuales se han incrementado desde 1994. Lo anterior debido, entre otras cosas, a la visión tecnológica del futuro, imaginando un mundo en el que las computadoras y las redes de telecomunicación respaldarán cualquier actividad humana y en el que las universidades virtuales serán el común denominador de los sistemas educativos del siglo XXI.

Esta visión exige reflexionar en los fenómenos que se prevén para que tal afirmación sea realidad. Uno de los aspectos urgentes se refiere a un cambio cultural que incida en la apropiación de las TIC para que la sociedad haga un uso correcto de aquellas, tomando en cuenta que 
representan un medio que facilita la adquisición de conocimiento. Las consecuencias pueden extenderse hasta la vida cotidiana y al ejercicio profesional. En suma, la Internet ofrece a profesores y estudiantes un medio innovador de comunicación, ágil y económicamente accesible, lo que ha ocasionado una elevada demanda de sistemas de correo electrónico, chat y videoconferencia. En consecuencia, uno de los retos de la enseñanza virtual es el diseño de herramientas de interacción orientadas a que el alumno a distancia tenga más posibilidades de aprendizaje al combinar las ventajas que cada canal de comunicación le ofrezca.

Una de las dimensiones relevantes de la EAD se refiere a los medios en que se ofrecerá la propuesta educativa específica. En este sentido, la Internet representa un medio de sumo valor, entre otras, por las siguientes razones:

1. El reconocimiento de gobiernos de diversas naciones respecto de las posibilidades que tiene la educación virtual en la sociedad de la información y del conocimiento.

2. La orientación generalizada en instituciones educativas al incremento de propuestas vía Internet.

3. El desarrollo constante de plataformas tecnológicas orientadas a la educación virtual.

4. La visión de estudiosos que consideran que las computadoras y las redes de telecomunicación formarán la infraestructura tecnológica de escuelas y universidades virtuales del siglo XXI.

Esto se hace con el propósito de potenciar nuevas aplicaciones en la educación y ampliar el alcance de uso social. No obstante, conviene recordar que el usuario común no siempre realizará una gran inversión en infraestructura de telecomunicaciones, software y equipos de cómputo; en este sentido, proyectar el uso de la Internet en tareas educativas virtuales requiere retomar este señalamiento. Por lo demás, se observa que cualquier resultado posterior de las innovaciones tecnológicas, el Internet seguirá siendo muy atractivo para las instituciones educativas, ya que posibilita el acceso remoto a un cúmulo de información, cuyo incremento es constante y también por ser un medio inédito para la comunicación remota. 
Varios críticos han señalado que la Internet es sólo una muestra del potencial de la infraestructura real de la información del futuro que se generará por la sociedad mundial. En este sentido, la enseñanza virtual tiene grandes retos en relación con la información disponible en la red, así como con las innovaciones tecnológicas actuales y las que vendrán.

Se observa que la Internet ha influido en el panorama actual de la EAD principalmente en dos vertientes: 1. en las maneras de comunicación y 2. en la forma de hacer llegar los recursos didácticos para el aprendizaje. En suma, la Internet ofrece a profesores y estudiantes un ágil e innovador medio de comunicación. El panorama actual indica que se amplía el uso de otros sistemas de comunicación interpersonal más complejos que el correo electrónico, como la videoconferencia y el aula virtual. En consecuencia, uno de los retos de la enseñanza virtual consistirá en diseñar las posibilidades de interacción orientadas a que el alumno tenga mayores facilidades para realizar su aprendizaje.

Otro aspecto interesante para la educación consiste en que la Internet también se caracteriza por ser un enorme depósito de información, cuyo potencial de uso para la enseñanza virtual en cuanto a recursos didácticos, se refiere será de enorme valor. Sin embargo, los autores de materiales de instrucción deben programar la mediación pedagógica apropiada entre el estudiante, el currículum y los contenidos del aprendizaje; en consecuencia, una actividad primordial del tutor a distancia es la de fungir como intermediario entre los estudiantes y los contenidos informativos disponibles en la Internet entendida ésta como la orientación para dar respuesta a preguntas como:

- ¿Dónde y cómo se localiza la información específica del aprendizaje determinado?

- ¿Cómo realizar su análisis para seleccionar la más relevante de los temas de estudio?

- ¿Cómo se incide en el descubrimiento de información relevante adicional a los materiales didácticos desarrollados para determinado curso? 
- ¿Cómo se logra que esa información redunde en conocimiento significativo para el sujeto del aprendizaje? Y en su momento, ¿para qué y cómo recrearla?

En este sentido, diversas universidades y bibliotecas nacionales, especializadas y públicas, representativas en el ámbito mundial, mantienen a través de la Internet sus bases de datos bibliográficos, de texto completo y catálogos públicos en línea. Sin embargo, tal riqueza informativa se tiene que hacer llegar al estudiante con una planeación apropiada a los objetivos del aprendizaje; de lo contrario, dichos recursos sumados a la información disponible en Internet, significarían para el alumno un alud de información que redundaría, ante tal copiosidad, en una escasa utilidad. En consecuencia, es preferible cuidar que los recursos informativos estén suficientemente identificados, seleccionados, depurados y organizados, de tal forma que sean más bien un complemento de los objetivos y de la base de conocimiento (contenidos didácticos) fundamentales del programa o curso en cuestión.

La incorporación a Internet de recursos informativos de calidad para el apoyo a la educación virtual es una responsabilidad compartida de organismos y centros de educación e investigación, de docentes, de bibliotecarios y documentalistas. Igualmente los autores de contenidos interesados en publicar y difundir en la Internet los hallazgos de su conocimiento, también contribuirían a la búsqueda de alternativas viables para la educación, relacionadas con los derechos de propiedad, ya que en la actualidad ha habido serios debates respecto de los derechos de autor en la red. De hecho, la tendencia para dar a tal problema una solución tecnológica ya a mostrado inconsistencias operativas y económicas, por lo que es un fenómeno que requiere de una mayor investigación que contemple, entre otras posibilidades, los beneficios para la educación virtual.

En la actualidad, se observa un uso frecuente de la Internet en el ámbito de la enseñanza virtual, en la generación de la oferta y distribución de cursos en diversos niveles educativos, en los que las posibilidades son múltiples. Algunas de éstas se encuentran en operación y muestran ciertos rasgos que permiten identificar sus características principales. Al respecto Tiffin señala que se resumen en "[...] sistemas 
mixtos y sistemas completos. Los sistemas mixtos combinan canales tradicionales de enseñanza a distancia con el uso de Internet para fines complementarios o puntales". ${ }^{1}$ Es decir, determinado curso a distancia que se basa principalmente en materiales didácticos impresos o audiovisuales, que valoran la importancia de la tutoría telefónica o por correo electrónico beneficiaría a los actores del aprendizaje si utilizan estos canales para la interacción académica. También señala que “[...] en los sistemas completos, el sistema de enseñanza a distancia reposa en su totalidad en el uso de Internet, tanto para los mecanismos de tutorización, como para la impartición de contenidos utilizando productos o dispositivos intermedia". ${ }^{2}$

Así, en el caso de los sistemas completos, la Internet se usa como canal de comunicación absoluto y como medio para la distribución de materiales didácticos. Lo anterior se percibe en la incorporación de tecnologías en instituciones y centros de educativos basados en el modelo presencial. En algunos de éstos ya operan diversos programas educativos que se clasifican en alguna de las categorías citadas, como es el caso de la UNAM, el ITESM y el IPN. En España destaca la Universidad Nacional de Educación a Distancia, la Universitat Oberta de Cataluya ${ }^{3}$ y la Universitat Pompeau Fabra. ${ }^{4}$ En el campo de la bibliotecología, México cuenta con la Escuela Nacional de Biblioteconomía y Archivonomía de la SEP, donde se imparten dos licenciaturas a distancia, y el TEC de Monterrey, que ofrece la Maestría en Bibliotecología y Ciencias de la Información en su modalidad virtual.

Con toda seguridad, las instituciones educativas referidas han experimentado la complejidad y riesgos del cambio, o la reestructuración de su modelo académico y de los métodos de trabajo. Sobre esto, Perriault afirma: "Las barreras a la definitiva adopción de sistemas mixtos son múltiples, desde los costes de la transición de un sistema tradicional a otro mixto, hasta las eventuales reticencias de

1 John Tiffin y Lalita Rajasingham, Op. cit. p. 242.

2 Ibid., p. 242.

3 Para mayor información, sobre la UOC véase http://www.uoc.es/.

4 Para mayor información sobre la Universitat Pompeau Fabra, véase http://www.upf.es/ 
usuarios, tanto de profesores como de estudiantes". ${ }^{5}$ No obstante, se percibe que diversas instituciones educativas, cuyo modelo académico ha sido presencial, se orientan hacia propuestas educativas a distancia, debido a las facilidades que ofrecen las TIC sí como para evitar el riesgo de quedar en el nivel de mercados educativos residuales.

De ahí que se advierta que las ofertas de esta naturaleza crezcan cada día, y proceden casi siempre de dos sectores: "De instituciones de nueva creación concebidas ya desde su inicio para consagrarse por entero a impartir formación, utilizando exclusivamente sistemas completos y [...] de instituciones tradicionales de formación presencial, singularmente universidades y centros de formación empresarial". 6 Lo anterior debido quizá a que tales organismos se han percatado de que los sistemas completos tienen enormes posibilidades a futuro, por el desarrollo constante de las TIC, aspecto que se traduce en oportunidades para incidir en propuestas educativas virtuales, en pro de amplios sectores sociales.

Los diseñadores de programas a distancia también se han dado cuenta de que el uso de multimedios digitales, en la educación virtual son fenómenos y realidades tecnológicas que requieren tomarse en cuenta en el diseño de ofertas educativas de esta clase; por lo cual precisan de investigación permanente centrada en los medios y las estrategias de aprendizaje propios de la temática educativa que se quiera ofertar. La educación apoyada en Internet requiere una atención especial, cuyo propósito principal es la creación de universidades virtuales y, en consecuencia, de aulas virtuales en las cuales los alumnos y tutores se comuniquen de manera remota, recurriendo a multimedios que permitan combinar texto, sonido e imágenes, con la computadora como soporte.

Actualmente es muy notorio que estos elementos estarán presentes con más énfasis en la educación del presente siglo, debido a las diversas posibilidades del uso de tecnologías de red. Sobre ello, Lafuente opina: “[...]se advierte que las tecnologías más recientes ofrecen diversas posibilidades de comunicación con el alumno,

5 J. Perriault. citado por Tiffin y Rajasingham, Op.cit., p. 242.

6 Ibid. p. 243. 
controles académicos versátiles, diseño de materiales didácticos basados en estructuras de hipertexto e hipermedio". ${ }^{7}$ A lo que se suma después de 1995, el uso de la videoconferencia, el correo electrónico, la biblioteca digital y los sistemas de metadatos. Asimismo, se observa la generación de servicios de diseminación selectiva de la información, mediante las telecomunicaciones y la transferencia de documentos digitales como apoyos de la educación virtual.

Por todo esto, las TIC ofrecen diversas y ricas posibilidades para el diseño y desarrollo de modelos educativos y de materiales didácticos dirigidos a la docencia y a la investigación. Un logro importante de las propuestas didácticas actuales de la educación virtual se relaciona con un alto grado de control administrativo, con la difusión masiva vía Internet de cursos en diversos niveles, con facilidades de interacción entre alumnos- tutores y con la posibilidad de consultar en la red diversas fuentes documentales. En este sentido, la convergencia tecnológica en la Internet pone de manifiesto la posibilidad de construir modelos integrales e integrados en línea. No obstante, conviene enfatizar que en paradigmas de esta naturaleza debe tenerse un cuidado especial para diseñar actividades como éstas:

- Desarrollo de materiales didácticos que faciliten al alumno reconstruir su conocimiento previo, con el fin de que generen nuevas estructuras de conocimiento.

- Diseño de ambientes de estudio que contemplen el conjunto de actividades de aprendizaje, experiencias y recursos documentales de apoyo a la reconstrucción de conocimientos.

- Infraestructuras de comunicación remota que faciliten la interacción no presencial entre tutores y alumnos, mediante discusiones en tiempo real, discusiones en tiempo diferido, intercambio de ensayos, referencias bibliográficas, materiales de lectura y visita de sitios web relativos a los temas de los cursos específicos.

7 Ramiro Lafuente López y Roberto Garduño Vera. "Enseñanza a distancia de la Bibliotecología y Estudios de la Información", en Investigación Bibliotecológica, jul./dic. 1999. vol. 13, no. 27 p. 16. 
- Construcción de foros de discusión virtuales que faciliten la comunicación asíncrona, cuyo propósito sea enriquecer las reflexiones entre alumnos en cualquier área geográfica en que se encuentren.

Un tema relevante es el diseño de seminarios virtuales para intercambiar información relevante que propicie la reflexión sobre asuntos específicos en los que la comunicación entre los alumnos sea desde distintos lugares y, mediada por sistemas de telecomunicación, programas y reglas para ordenar la información que transferir. El seminario virtual se utilizaría en actividades de larga duración, y de ahí la conveniencia de que en su diseño se contemplen ciertos aspectos:

- Inclusión de bases de conocimiento elaborados con fundamento en teorías del aprendizaje, apropiadas a los contenidos informativos multimedia.

- Contemplar formalidades, conceptos y finalidades que orienten la inclusión de información y pláticas en tiempo real, ya sea por chat o en videoconferencia.

- Definir explícitamente los objetivos iniciales y terminales del seminario.

- Determinar el perfil de los participantes, considerando, además, sus capacidades de infraestructura tecnológica.

- Inclusión de enlaces a recursos informativos disponibles en la Internet (bases de datos, catálogos en línea, páginas web y bibliotecas digitales de contenidos relevantes para el curso en cuestión).

\section{INTERNET Y LOS NUEVOS PROCESOS EN LA EDUCACIÓN VIRTUAL}

La aplicación de las TIC en la teleenseñanza y el teleaprendizaje han repercutido en la transformación de diversos procesos y prácticas tradicionales relativos a los diversos procesos educativos, así como las formas y medios para socializar el conocimiento. En este sentido, la Unesco señala que:

[...]la convergencia tecnológica de las redes telemáticas en la teleenseñanza y el teleaprendizaje induce a la integración de diversas tecnologías de información, la diversificación de los sistemas de 
comunicación y la apertura de fuentes de información que no reconocen fronteras geopolíticas. ${ }^{8}$

La importancia de la convergencia tecnológica dada por medio de las redes radica en la posibilidad de realizar comunicaciones y diálogos remotos entre individuos o grupos, y facilidades para la distribución de flujos de información y conocimiento. Por ello, es factible decir que el concepto de red se ha convertido en el núcleo de la convergencia tecnológica. Bankis opina sobre esto que "[...]la primera acepción de red corresponde a la infraestructura física que posibilita la integración de diferentes TIC en un sistema de telecomunicación o red telemática".?

En este aspecto, se subraya que la convergencia tecnológica ha inducido la generación de ciberespacios y espacios virtuales, en consecuencia, ha propiciado la idea de interactividad entre máquinas y humanos, así, los sujetos que enseñan y los que aprenden se mantienen en una comunicación interactiva, propiciando nuevas formas de transmitir la información, el conocimiento y el saber. Amador observa que "[...]del texto escrito y los audiovisuales didácticos, a los programas vía satélite y a las redes informatizadas, la convergencia de los audiovisuales, la informática y las telecomunicaciones trajeron como consecuencia la creación de redes telemáticas". ${ }^{10}$ De lo que se infiere que los nuevos escenarios virtuales se configuran a partir de la convergencia tecnológica, dan sentido a los actores del aprendizaje quienes se comunican mediante las computadoras, situación que

8 UNESCO, Rapport mondial sur la communication, citada por Rocío Amador Bautista, "Nuevos procesos educativos en el medio digital," El medio digital en el siglo XXI: retos y perspectivas para los bibliotecólogos, investigadores, educadores y editores, México : CUIB, UNAM,, [es ed. en CD-ROM]. "Ponencia presentada en el XVIII Coloquio Internacional de Investigación Bibliotecológica.

9 Henry Bankis, "Les reseaux et leurs enjeux socialux", citado por Rocío Amador Bautista. Nuevos procesos educativos en el medio digital. Op. cit. En El medio digital en el siglo XXI... [Editado en CD-ROM]. Trabajo presentado en el XVIII Coloquio Internacional de Investigación Bibliotecológica.

10 Amador Bautista, Rocío. Nuevos procesos educativos en el medio digital. En El medio digital en el siglo XXI..., [Editado en CD-ROM, 2001]. Trabajo presentado en el XVIII Coloquio Internacional de Investigación Bibliotecológica. 
propicia una novedosa modalidad de interacción entre los sujetos del aprendizaje.

En consecuencia, Amador advierte que la interactividad se presenta cuando coexisten estas condiciones: "Interactividad entre máquinas [...], interactividad entre humanos [...] formas de producción [de] documentos digitales $[. .$.$] , formas de almacenamiento [...] formas de dis-$ tribución mediante redes telemáticas $[\ldots]$ y formas de acceso“. ${ }^{11}$

Con lo anterior en mente, se observa que la enseñanza virtual necesita generar estrategias tecnológicas y pedagógicas orientadas a los actores de los aprendizajes, además enfrentar los retos de la innovación y la convergencia tecnológica, inducida por los sistemas de comunicación y la información existentes en Internet. Respecto de la convergencia tecnológica, la interactividad y su aplicación en el aprendizaje virtual, recientemente surgieron propuestas orientadas a incidir su máximo aprovechamiento. Algunas enfatizan incluso los entornos de la hipertextualidad, la interacción, la conectividad, cambio social y la web. En este sentido, Derrick de Kerckhove agrega: "Con las redes de comunicación, el acceso a los procesos digitales tiene el potencial de la ubicuidad". ${ }^{12}$ Asimismo, los desarrollos tecnológicos recientes de las interfaces dinámicas, cada vez más fáciles de operar, han propiciado un aumento exponencial de usuarios de la Internet, muchos de ellos interactúan y navegan en diversos cursos en línea. Al referirse a la formación virtual, Capdevila señala: "Su tasa de crecimiento anual en Europa se sitúa en 96\%, a finales del 2004, 50\% de la formación (en informática) será ofrecida a través de Internet". ${ }^{13}$

Sobre la interacción, Derrick de Kerckhove opina: "La creciente efectividad de la interacción sensorial en los multimedia, los hipermedia y la realidad virtual, [...] presagia el cambio de énfasis del estatismo de los medios basados en la memoria, a los medios del proceso

\section{Ibid.}

12 Derrick de Kerckhove, Inteligencias en conexión: hacia una sociedad de la web. España: Gedisa, 1999, p. 174.

13 Irene Capdevila."Grandes ingresos en el e-learning europeo", [en línea] http://www.laempresa.net/noticias/2001/0101/20020222_07.htm [consultada: 5/10/2003]. 
dinámico basados en la inteligencia". ${ }^{14}$ En cuanto a la conexión, también afirma que "[...]el incremento en las interacciones humanas, personales, sociales e institucionales, a través de las redes integradas, está concentrando y multiplicando la energía mental humana”. ${ }^{15}$

Las observaciones citadas inducen, sin duda, a un cúmulo de reflexiones sobre la convergencia tecnológica y su aplicación en distintas actividades educativas virtuales. En este sentido, se deduce que las posibilidades tecnológicas para la educación virtual son potencialmente infinitas, situación que determina la preparación constante de grupos de profesionistas que asuman la responsabilidad y la exigencia requerida por el diseño y desarrollo de modelos educativos virtuales, mediante tecnologías de vanguardia. Por ello se reconoce que el medio digital, la interactividad en red, la convergencia tecnológica y contenidos en web constituyen fuentes de investigación sustantivas para la informática, la psicología, la pedagogía, la bibliotecología, la documentación y, en general para todas las disciplinas, ya que son fenómenos que competen a todas, debido a sus repercusiones en la educación virtual del presente siglo.

\section{LO VIRTUAL EN LA EDUCACIÓN}

Hoy es muy común hablar de universidad virtual, educación vía Internet, educación virtual, aprendizaje virtual, entornos virtuales de aprendizaje y otros. Sin embargo, conviene preguntar ¿qué es lo virtual? Se dice que virtual es lo que está implícito, lo que es de facto. Se define así: "Virtual, frecuentemente en oposición a efectivo o real; que tiene existencia aparente y no real". ${ }^{16}$ En este mismo sentido, lo virtual también se define como "[...] efectivo, aparente, irreal. Que existe en esencia o en sus efectos, aunque no en forma real y verdadera". ${ }^{17}$ Por otro lado, Maestre Yenes aclara: lo virtual es la "[...]forma de funcionar

14 Derrick de Kerckhove, Op. cit. p. 174.

15 Ibid. p. 175.

16 Diccionario de la Lengua española, p. 2095.

17 Diccionario enciclopédico de términos técnicos, p. 1709. 
basada en las tecnologías de la información y de las comunicaciones en las que se simula el mundo real, dando una serie de prestaciones y funcionalidades que permiten en gran medida obtener los mismos servicios y prestaciones que se obtendrían en aquel [...] utilizando las posibilidades que proporciona Internet". ${ }^{18}$

Con estas definiciones, resumiríamos, que lo virtual es la acción que produce efectos a la sociedad en forma no presencial, situación que nos conlleva a la simulación, a lo simbólico.

Cabe advertir que en estos tiempos la dimensión simbólica está sobredimensionada, en particular desde que los medios masivos de comunicación comienzan a ocupar un lugar destacado en la sociedad y elaboran discursos que explican los hechos, interpretan situaciones y acciones de los seres humanos. ${ }^{19}$

La educación virtual trata de influir en el uso creciente de las TIC, alimentar el interés de los tutores al ofrecer un novedoso modelo de gestión educativa centrado en el aprendizaje de los alumnos. Ello implica fomentar el estudio independiente y el estudio colaborativo, la interacción académica efectiva entre tutor-alumno, alumno-tutor, el desarrollo de habilidades cognoscitivas en los alumnos, capacidad de análisis y, síntesis y en la formulación de juicios de valor. En consecuencia, el tutor se convierte en facilitador de los aprendizajes, diseñador de estrategias de autoaprendizaje inculcando el aprendizaje interactivo y el análisis crítico, como bases fundamentales del trabajo en equipo, asume el papel de observador y se convierte en uno de los diversos recursos de consulta por medio de asesorías personalizadas o colectivas; desarrolla materiales didácticos, selecciona contenidos y sugiere lecturas complementarias, fomenta el aprendizaje cooperativo mediante la asignación de proyectos o casos de estudio que generen discusiones en equipos, sea presencial o virtualmente.

Así, en este contexto de virtualidad educativa, cada alumno es el eje del proceso educativo, gestor de su propio crecimiento intelectual y profesional, organizador de su tiempo de estudio, lo cual implica

18 Pedro Maestre Yenes. Op. cit. p. 240.

19 Delia Crovi Druetta. "Virtudes de la virtualidad: algunas reflexiones desde la educación”, Tecnología y Comunicación Educativa 13, no. 29 (1999), p. 75. 
oportunidades para ser creativo, reflexivo y analítico. Por lo tanto, se persigue que los alumnos a distancia desarrollen una actitud crítica para la asimilación de nuevos conocimientos y para la investigación.

Este tipo de alumno debe participar activamente en discusiones colectivas en temas de debate, confrontar ideas, mostrar interés por su propio proceso de aprendizaje, realizar investigación bibliográfica de calidad para complementar la información proporcionada por el tutor, con miras a enriquecer sus conocimientos, adoptando una actitud permanente de avidez investigativa que le aporte conocimiento sobre la selección de la información relevante, en un entorno social en el que constantemente, se genera información, ésta inútil o innecesaria para el curso en cuestión, desarrollar habilidades en el uso extensivo de las TIC que requiera utilizar.

Lo virtual ha propiciado la generación de comunidades que en este siglo franquean fronteras nacionales e internacionales, se desbordan contextos institucionales y culturales, se evidencian cambios en las formas de comunicación a través de redes académicas. Sin embargo, procede cuestionar: "[...] ¿cuál es el entorno social en el que surge y se afianza este concepto de virtualidad? En principio, $[\ldots]$ se trata de un entorno que va mucho más allá de las posibilidades creadas por la tecnología. O dicho en otros términos, la tecnología sola no lo explica". ${ }^{20}$ En este sentido, se diría que la comunidad virtual se vuelve realidad si existen afinidades temáticas, académicas o intereses investigativos en común, aspectos que redundan en la aparición de escenarios con interacciones sociales y telemáticas.

Una comunidad virtual, según Crovi Druetta, es “[...]el núcleo de atención y también de unión e interacción que se ubica en el interés por un tema o asunto. Es una comunidad que realiza sus intercambios por medio de la red, o sea virtualmente. Trabaja de manera desterritorializada y sin la presencia física [...], no hay un aquí y ahora, no se oponen a lo real sino a lo actual". ${ }^{21}$

Lo virtual conlleva a la conectividad y a la interactividad, la primera requiere de la unión de diversas tecnologías de red; a esta posibilidad

20 Ibid. p. 76.

21 Ibíd. p. 80. 
se ha denominado convergencia tecnológica, pues posibilita la confluencia de diversas tecnologías. Así, la convergencia y la interactividad tienen sentido cuando la sociedad utiliza para su beneficio los flujos de la información que se transmiten por medio de las tecnologías de red. La velocidad en el traslado de la información, la rapidez de la comunicación y transmisión de grandes volúmenes de datos repercuten en lo educativo, en la construcción de conocimiento y en lo laboral. El espacio se afecta por expresiones como navegar, ciberespacio, cibernauta, cibercultura.

Al respecto, Crovi Druetta señala que "[...]el común denominador que subyace en estos cambios es una nueva concepción del tiempo y el espacio surgido del concepto de virtualidad". ${ }^{22}$ En este tenor, "[...]se ha dicho con acierto que a partir de los nuevos medios y su manejo del tiempo/espacio hemos pasado de la lectura a la navegación; de la transmisión a la inclusión; del texto al hipertexto". ${ }^{23}$

Sin duda, la virtualidad que favorece la convergencia tecnológica de estos tiempos induce, cuando se trata de procesos educativos, a situaciones de visibilidad-invisibilidad. Los sujetos del aprendizaje se ocultan en determinados momentos; en otros, aparecen virtualmente acudiendo a la dimensión espacio-tiempo para discutir, preguntar, opinar o desmentir. Nos encontramos ante un escenario novedoso para la educación virtual, en el que destacan estos elementos.

1. Convergencia de tecnologías, modelos educativos y modelos de comunicación.

2. La relación entre la institución, el tutor, el alumno y el material de instrucción han sufrido cambios significativos frente a la virtualidad.

3. Los contenidos de apoyo al proceso de enseñanza-aprendizaje experimentan cambios sustantivos al aplicar teorías del aprendizaje, la digitalización y el uso de hipermedios en red. Los grupos interdisciplinarios adquieren especial importancia para asegurar un adecuado aprovechamiento de los recursos didácticos, los conocimientos e infraestructuras tecnológicas.

22 Ibid. p. 80.

23 Ibid. p. 82. 
4. La recuperación vía Internet de la información de apoyo a los aprendizajes ha mostrado a los actores del proceso educativo su inestabilidad y la dificultad para su cotejo en términos de veracidad y autenticidad.

Las necesidades del mercado de trabajo y de los egresados que buscan incorporarse a éste, han hecho que las instituciones educativas vean en la educación virtual una estupenda oportunidad. Pocos dudan de ello, sin embargo, es menester recordar que se trata de un desafío que exige asumir compromisos investigativos, de estudio y de reflexión. Todo ello dirigido a conseguir propuestas novedosas y de amplio alcance para el mejor aprovechamiento de la virtualidad en la educación.

\section{INTERACTIVIDAD EN LA WEB Y EDUCACIÓN VIRTUAL}

La interactividad en la educación virtual se ha convertido en una de las variables que condicionan la enseñanza de este tipo, por lo cual se han generado líneas de investigación orientadas principalmente a buscar los marcos teóricos y aplicados que permitan incidir en una interactividad de calidad en la Internet y en los actores del aprendizaje. Igualmente, se ha pronunciado el requerimiento de influir en propuestas que contemplen la selección y organización de los recursos informativos digitales disponibles en la red con el fin de que sean útiles en programas educativos virtuales. Tales propósitos adquieren cada vez mayor sentido, pues una realidad actual de la interactividad se relaciona con la posibilidad de acceder a bases de datos, bibliotecas virtuales, bibliotecas digitales y sistemas de metadatos, todas éstas fuentes de información necesarias para acceder a contenidos y conocimiento.

En cuanto a la interacción como parte del proceso pedagógico, Amador Bautista afirma que se necesita importar en "[...]la enseñanza y el aprendizaje asincrónicos, con base en una pedagogía flexible, abierta y libre en el uso del espacio y del tiempo, y una nueva relación cooperativa y de participación entre interlocutores". ${ }^{24}$ En este

24 Rocío Amador Op. cit. . 
mismo sentido, Habermas afirma: "Desde nuestro punto de vista, la perspectiva del modelo de acción comunicativa nos permite comprender que todo proceso educativo a distancia se funda, inicialmente, en un proceso de interacción social a través del lenguaje y la acción". ${ }^{25}$ En este mismo tenor, Fainholc advierte:

[...]la noción de interactividad pedagógica, real o virtual, se refiere a la intervención de acciones didácticas para la elaboración de conceptos o el desarrollo de competencias, los que permitan comprender y transferir a la acción la esencia de los objetos implicados a fin de actuar apropiadamente. ${ }^{26}$

Con base en esto, es factible señalar que esta comunicación es un proceso de interacciones sociales en determinado contexto. El concepto de acción comunicativa se sustenta en un modelo de cooperación social, basado en situaciones de relación e interacción, entre los actores del aprendizaje y los modos de actuar en un proceso educativo a distancia. En este sentido, las TIC constituyen la infraestructura para producir, almacenar, distribuir información y conocimiento, con el fin de lograr una interacción de alta calidad.

Se puede decir que "[...]la interacción social y la interactividad pedagógica, mediadas por tecnologías y lenguajes artificiales de comunicación, se producen por la acción simbólica de los lenguajes artificiales de las máquinas, los metalenguajes de los discursos científicos y la capacidad de interpretación de los sujetos". ${ }^{27}$ Con base en lo anterior, es factible apreciar que hoy la Internet facilita la convergencia y, en consecuencia, el uso de diversas tecnologías, cuyo propósito principal es incidir en procesos interactivos entre los sujetos del aprendizaje. Así, la tecnología CU-SeeMe ${ }^{28}$ se ha orientado a compartir datos visuales como diagramas, fotografías y dibujos en forma directa y en tiempo real.

25 Habermas, citado por Rocío Amador Bautista Ibiíd.

26 Fainholc, citado por Rocío Amador Bautista Ibíd.

27 Ibid.

28 El $C U$-SeeMe es un programa que permite realizar videoconferencias a través de la red conversaciones e imágenes en tiempo real. 
Por otra parte, la videoconferencia se perfila como un medio integrador de diversas tecnologías y contenidos en distintos formatos, aspectos que resultan ser muy atractivos para la educación virtual, pues se advierte que la telepresencia ha creado nuevas formas de interacciones sociales. Este fenómeno ha sido ampliamente estudiado por Smith, a quien los críticos consideran uno de los maestros de la videoconferencia en el ámbito mundial. Este autor ha logrado la convergencia tecnológica al adaptar su máquina "Telepresencia al concepto de Supply Student, en donde se coloca una cámara de vídeo en un aula de colegio que permite ser controlada por un estudiante a distancia". ${ }^{29}$

No obstante, los grandes desarrollos tecnológicos y la existencia de diversas propuestas educativas por medio o basadas en la Internet, advierten los estudiosos la necesidad de una mayor atención al estudio teórico de las nuevas formas de enseñar y de aprender a través de tecnologías de red utilizando la Internet. El uso reciente de ésta como medio para la educación virtual ha evidenciado, el requerimiento de replantear el proceso de enseñanza-aprendizaje en diversos aspectos, debido a las posibilidades de diseñar escenarios virtuales de aprendizaje orientados a la educación virtual. Éstos han generado, a su vez, la necesidad de investigar sobre los fenómenos que se involucran en el aprendizaje en red, situación que determina un aprendizaje que emplea la navegación como principal recurso, Tiffin ha dicho que "[...]uno de los principales escollos con los que se ha enfrentado el desarrollo de nuevos sistemas de enseñanza a distancia basados en Internet es la ausencia de un marco teórico adecuado". ${ }^{30}$ Lo anterior revela que las instituciones educativas se enfrentan con diversos problemas al afrontar los cambios o ajustes de sus modelos académicos, métodos y procedimientos requeridos en propuestas educativas virtuales.

La importancia de la teoría apropiada para la educación virtual a través de Internet debe indicar los riesgos de entender dicha educación como sustitución de la enseñanza presencial, con el propósito de evitar en lo futuro el porcentaje de fracaso de los estudiantes; de ahí la necesidad de analizar si es pedagógicamente conveniente dejar

29 Smith Graham, citado por Tiffin y Rajasingham, Op. cit. p. 233.

30 Tiffin y Rajasingham, Op. cit. p. 243. 
al estudiante la responsabilidad del éxito o fracaso de su aprendizaje, Ésto traería como consecuencia el requerimiento de investigar permanentemente sobre el aprendizaje virtual del adulto, utilizando la navegación y la interacción en Internet.

Algunos estudiosos en educación coinciden en que, con el advenimiento y uso de las TIC en la educación virtual, es necesario incidir en una teoría abierta, aplicable a cualquier escenario de aprendizaje, y que por lo menos reconozca la especificidad de la educación virtual para construir modelos didácticos genuinos y eficaces. De nuevo, Tiffin señala que una teoría de esta naturaleza debe contar con:

- Un marco adecuado para comprender el aprendizaje y, singularmente, el aprendizaje de personas adultas en escenarios virtuales.

- Unos principios que orienten la disposición de las distintas ayudas pedagógicas que en este tipo de entornos suelen ofrecerse, de acuerdo con la tecnología disponible que se juzgue más conveniente en cada caso. ${ }^{31}$

No obstante, el debate suscitado respecto de la búsqueda de marcos teóricos acordes a la educación virtual, se aprecia que en esencia los supuestos anotados se aplicarían en diferentes espacios de aprendizaje. Sin embargo, un escenario virtual tiene implicaciones que no necesariamente se darían en un espacio presencial. La diferencia más obvia se relaciona con el canal de comunicación, la interacción en tiempo real y diferido, las circunstancias personales del alumno, las posibles interacciones entre tutor-estudiante, estudiante-tutor, estudiante-estudiante, tutor-tutor y la ausencia del currículum oculto. Con todo esto se deduciría que el reto de las instituciones educativas y de las disciplinas en cuanto al uso de las TIC en la educación virtual determina compromisos con el desarrollo de modelos orientados a alcanzar el máximo aprovechamiento y las potencialidades de las TIC en el entorno educativo, así como maximizar el uso de medios de comunicación e interacción de la navegación en red.

31 Ibid. p. 244. 
Para los próximos años se proyectan expectativas de la Internet orientadas a optimizar su utilidad e incorporar mayores posibilidades de recursos multimedia. Un indicador interesante es el concepto intermedia, consistente en lograr materiales didácticos de alta calidad que faciliten su combinación multimedia y propicien conexiones múltiples con bibliotecas digitales y sistemas de metadatos a través de la Internet.

Una investigación en proceso a fín con lo antes señalado es una de las tareas del proyecto denominado EVA (Espacios Virtuales de Aprendizaje). ${ }^{32}$ "Este megaproyecto incluye un ambiente personalizado cooperativo de enseñanza en la web y un conjunto de herramientas". ${ }^{33} \mathrm{El}$ ambiente visual para el desarrollo de materiales didácticos se denomina POLilibros, con los cuales se pretende que el alumno genere material didáctico acorde a las materias de estudio. Así, un POLilibro se estructura con base en unidades de material didáctico y actividades de aprendizaje; con éstos el alumno participa en el desarrollo de actividades en colaboración, genera tareas, realiza evaluaciones y recibe asesoría virtual de los tutores. El cúmulo de conocimientos tecnológicos innovadores de dicho proyecto redundará en beneficio de la sociedad mexicana y de la educación virtual en general.

La Universitat Oberta de Catalunya (Universidad Virtual) ha incursionado en propuestas educativas por Internet. Hoy cuenta con el desarrollo de su campus virtual, mediante el cual el estudiante accede desde cualquier latitud a su experiencia de aprendizaje dinámicamente. Se le reconoce como el centro del proceso formativo y lo asesora un equipo docente acreditado, asimismo, cuenta con los recursos didácticos y servicios más innovadores. "A partir del uso intensivo de las nuevas tecnologías, en la UOC rompemos las barreras del

32 El proyecto EVA se desarrolla desde el 2000 en el IPN, en colaboración con el CENIDET, ambos organismos mexicanos.

33 Leonid, Sheremetov, "Espacios Virtuales de Aprendizaje: experiencia y prospectiva". En El medio digital en el siglo XXI", Op.cit. 
espacio y del tiempo y ofrecemos un modelo de formación basado en Internet". 34

La Universidad Pompeau Fabra incursiona desde 1988 en el uso de las TIC. Su propósito ha sido colaborar en una renovación profunda de sus formas de enseñanza y de aprendizaje, recurriendo a las TIC mediante su uso se propone lograr un mayor control de los procesos de aprendizaje, influir en una mejoría de autoaprendizaje y favorecer nuevos tipos de éste, posibilitar el desarrollo de materiales didácticos con una mayor interactividad y buscar un mayor nivel de comunicación remota entre los actores del aprendizaje.

La UPF cuenta con su campus global (CG) a través del cual es factible acceder a todos sus servicios educativos. El CG es una red de computadoras interconectadas en redes locales o por Internet.

El Campus Global es también, y principalmente, el proyecto de innovación docente que la Universidad ha iniciado a través del concepto Aula Global, se configura primordialmente como una herramienta didáctica al servicio del proyecto pedagógico de cada centro y de cada equipo docente. 35

\section{ESTRUCTURA DEL AULA VIRTUAL DE APOYO A LA ESPECIALIZACIÓN SOBRE LA ORGANIZACIÓN DE RECURSOS INFORMATIVOS DIGITALES}

Con la tendencia actual de la generación de propuestas educativas virtuales, la formación vía Internet ha ingresado en las instituciones educativas, que se han percatado de la necesidad de considerar que toda propuesta de esta indole requiere pensar en las dimensiones

34 UOC, "La Universidad Virtual", Dimensión universal, [en línea]

http://www.uoc.es/web/esp/universidad/01home.html , [consultada: 17/6/2003].

35 "El Campus Global de la Universitat Pompeau Fafra como instrumento al servicio de la innovación docente" [en línea] http://www.upf.es/cont3.htm?a $=$ http://www.upf.es/usice/cg/cast/innova.html [consultada: 17/6/2003]. 
teóricas de la educación a distancia y seleccionar el soporte tecnológico $^{36}$ apropiado. Así, aunado a las experiencias de distintas universidades que ya utilizan determinadas tecnologías para ofrecer propuestas educativas por Internet, recientemente han aparecido plataformas orientadas a la educación virtual. En los ámbitos tecnológicos se entiende por plataforma el "[...] sistema constituido por un conjunto de elementos físicos y de elementos lógicos, incluyendo el [software] de base y más concretamente el sistema operativo". ${ }^{37}$ Así, la plataforma constituye un asunto tecnológico de sumo interés, pues se relaciona con el software (programas de computadora de aplicación) y el hardware (procesador, memoria principal y secundaria, etc.). Éstos, a su vez, son controlados por un conjunto de instrucciones derivadas del sistema operativo. Cuando existe el requerimiento de realizar comunicación remota, como ocurre en la educación virtual, la plataforma incluye tecnologías de red, lo cual implica el uso de protocolos de comunicación.

Una búsqueda bibliográfica reciente, respecto de la existencia de tecnología orientada al E-Learning, arrojó 59 distintas plataformas, las cuales ofrecen principalmente aulas virtuales, módulos para el ingreso de material didáctico y módulos para evaluaciones. Sin embargo, las plataformas WebCT y Blackboard: Bb Learning, son algunas de las que ofrecen más servicios integrados. WebCT es un software para el desarrollo de material didáctico mediante el uso de tecnología web. "Los profesores podrán publicar los contenidos del curso, realizar evaluaciones, asignar tareas, comunicarse con los alumnos en forma individual y colectiva, etcétera". 38 Por otra parte, se afirma que Blackboard: Bb Learning fue creado "[...]para transformar Internet en un poderoso entorno de formación a distancia". 39

36 E-learning: soluciones de e-learning. Formación a Distancia [en línea] http://e-learning.bankhacker.com/ [consultada: 8/5/2003]. En esta fuente se diceque la Instrucción Asistida por Computadora (CAI) ha evolucionado al nuevo WBT/IBT (Web Based Training/Internet Based Training), válido en entornos Intranet o Internet, nociones involucradas con la educación virtual.

37 Pedro Maestre Yenes. Op. cit. p. 187-188.

38 Ibid.

39 Ibíd. 
Así, en el diseño de determinada aula virtual conviene tener en cuenta la evaluación de distintas plataformas, analizar diversos modelos en operación, como los de las universidades ya citadas. Sin embargo, en el caso que nos ocupa, se concluyó que tenía sentido abordar el desarrollo de un aula virtual a través de la exploración de software libre, por las posibilidades de adquirir conocimiento y experiencia al respecto, cuyos resultados serían benéficos para la investigación bibliotecológica, la educación virtual en bibliotecología, y en su momento, para profesionistas en educación interesados en la educación virtual.

Al considerar los aspectos antes descritos, así como los diversos retos que presupone el diseño de un ambiente de aprendizaje en red, se concluyó que tal ambiente ha de contener un aula virtual y una biblioteca digital. La complejidad del desarrollo de esas herramientas presuponía sustentar su diseño recordando los fenómenos relacionados con la Internet y principalmente los vinculados con la educación virtual y la biblioteca digital.

Aquí se entiende por aula virtual el espacio simbólico de investigación, estudio y actualización en técnicas y metodologías propias de la enseñanza virtual, para aplicarlas en propuestas educativas a distancia en varios niveles, tomando como base las redes telemáticas como la vía fundamental para la comunicación, la interacción entre los actores del aprendizaje y la entrega de materiales didácticos.

En este sentido, se contempló que la aplicación de redes en la enseñanza a distancia ha repercutido en la transformación de diversos procesos y prácticas tradicionales relacionadas con las formas y los medios para socializar el conocimiento. Se pensó que las particularidades de la convergencia tecnológica de las redes telemáticas induciría a la integración de las TIC y posibilitaría almacenar y acceder a múltiples fuentes de información útiles para la formación. En el ámbito educativo, estos aspectos tienen gran valor, pues la convergencia tecnológica posibilita que la educación virtual emita y reciba información, dialogue, converse y distribuya información y conocimientos a lo largo de grandes distancias. En consecuencia, en el diseño del aula virtual se pensó que debía cubrir, entre otros, estos: 
- Facilitar la convergencia de los actores fundamentales de la enseñanza, como los tutores y alumnos.

- Permitir el ingreso, consulta y transmisión de material simbólico desarrollado en los contenidos didácticos para su aprendizaje.

- Facilitar el diálogo y la retroalimentación a distancia entre los actores del aprendizaje y el objeto del conocimiento.

- Permitir la interacción en el tiempo y el espacio para favorecer la comunicación bidireccional y multidireccional entre tutores y alumnos, es decir, comunicación asíncrona que no requiere la presencia simultánea de los alumnos y tutores a través de aplicaciones de correo electrónico, foros de discusión, pizarra electrónica, grupos de noticias, u otros; o comunicación síncrona, que requiere la presencia simultánea a distancia de los actores del aprendizaje mediante aplicaciones como el chat y la videoconferencia.

- Organizar el grupo de alumnos en comunidad virtual (aprendizaje colaborativo) para producir bienes colectivos e intercambiar ideas en torno a los fenómenos de estudio.

- Facilitar la realización y el control de la evaluación del alumno, del tutor y del programa académico.

- Facilitar la instrumentación de la administración escolar.

- Permitir los flujos de información en cualquier formato digital como aplicaciones de World-Wide Web (Www), File Transfer Protocol, (FTP)

En el diseño teórico del aula virtual, además de los requerimientos anteriores, se retomaron los lineamientos de las técnicas didácticas de Paulsen propuestas para la educación en línea, las cuales se orientan a los emisores y receptores de la comunicación educativa, entre cuyas características más relevantes se hallan:

\section{Técnicas de uno-solo}

Se basan en aplicaciones cliente/servidor y se fundamentan en el paradigma de la recuperación de información (information retrieval). Los estudiantes buscan y recuperan información pertinente al 
objeto de estudio en un servidor ad hoc o mediante las herramientas necesarias para el acceso a Internet. ${ }^{40}$

Un ejemplo de esto sería que en, determinada actividad de aprendizaje de algún módulo de la Especialización sobre la organización de recursos informativos digitales, se buscaría en la Internet la información específica para resolver actividades de aprendizaje determinadas. De esta manera, la información complementaria al material didáctico se orienta a la búsqueda en bases de datos bibliográficas, catálogos públicos en línea, bibliotecas digitales, sistemas de metadatos y direcciones especializadas en la web.

La ventaja de este tipo de diseños es que permiten reunir en un solo sitio todas las facilidades y recursos a disposición de los actores del aprendizaje. El servidor sería la plataforma para la presentación y discusión de los trabajos de los estudiantes, abierta a toda la Internet, si así lo requiere la propuesta educativa.

\section{Técnicas de uno-a-uno}

La comunicación se establece fundamentalmente entre dos personas (tutor-alumno, alumno-alumno). El paradigma actual de este tipo de tecnología es el correo electrónico para la comunicación asíncrona e Internet Relay Chat (IRC) en la comunicación síncrona. ${ }^{41}$

Esta técnica indica que la comunicación es individual y se busca que el modelo del aula virtual en desarrollo contemple una localidad para que todo lo discutido por los actores del aprendizaje quede almacenado y se recupere posteriormente para su uso, por ejemplo, como complemento de alguna evaluación. Esta técnica tiene amplia aceptación con el uso de herramientas de la internet más modernas, ligada a la ampliación de los anchos de banda, a la optimización de las técnicas de compresión de datos en tiempo real y a la disponibilidad de estaciones de trabajo potentes a precios reducidos. En ese

40 M.F. Paulsen. "The Online Report on Pedagogical Techniques for Computer-Mediated Communication." en NKI Oslo, Noruega, 1995, [en línea]

http://www.hs.nki.no/ morten/cmcped.html [consultada: 5/10/2003].

41 Ibid. 
sentido, la videoconferencia se proyecta como el medio que permitirá emplear la riqueza expresiva de la imagen y la voz en la comunicación entre tutores y estudiantes o entre estudiantes.

\section{Técnicas de uno-a-muchos}

Se basan en aplicaciones como el correo electrónico y los servidores de listas de distribución o videoconferencia. Permiten la comunicación entre el profesor y un grupo de alumnos numeroso. ${ }^{42}$

El típico uso didáctico de esta forma de comunicación es el pánel de discusión. Uno o varios expertos realizan presentaciones, individualmente o interactuando entre sí. Normalmente, los estudiantes sólo reciben y leen los materiales didácticos preparados por los expertos, pero en ocasiones se presenta la posibilidad de preguntar o comentar dentro de un periodo de tiempo, a las que el experto responde.

Técnicas de muchos-a-muchos. Todos los actores del aprendizaje tienen oportunidad de participar en la interacción y, por lo tanto, de observar las aportaciones de los tutores, alumnos, invitados. "Las técnicas de mayor uso son los debates, las simulaciones, el estudio de casos, grupos de discusión, los foros de discusión y los grupos de proyectos". 43

Con base en lo anterior, se diría que las técnicas orientadas a la educación virtual muestran la diversidad de recursos y orientaciones que admite aquélla. En este contexto, el diseño teórico del aula virtual dirigida a la Especialización propuesta tomó en consideración los aspectos descritos líneas atrás. Asimismo, su desarrollo tecnológico se fundamentó en la utilización de software libre. El uso de éste en el diseño del aula virtual y de la biblioteca digital requirió probar y comprobar que no contuviera "hoyos de seguridad", con la finalidad de no poner en riesgo la integridad del aula debido a que el principal acceso a los servicios fue la Internet, lo cual requirió tomar las medidas de seguridad necesarias. Asimismo, la generación de claves de acceso

42 Ibid.

43 Ibid. 
protegidas da por resultado una mayor garantía de integridad y seguridad de la información elaborada por cada actor del aprendizaje.

\section{SOFTWARE Y DESARROLLO DEL AULA VIRTUAL Y DE LA BIBLIOTECA DIGITAL DE APOYO}

La elección de las herramientas tecnológicas se basó en la evaluación de un grupo de éstas. Después de analizar las posibilidades existentes, se decidió emplear herramientas que permitieran el desarrollo de un aula versátil y que fueran útiles a la especialización, pero también a otro tipo de cursos en línea. Así, entre las herramientas evaluadas se encuentran éstas:

- Phronesis. Modelo de biblioteca digital desarrollado por el Tecnológico de Monterrey.

- Hot-Potatoes. Herramienta para la elaboración de evaluaciones de los alumnos.

- Mayordomo. Servidor de listas de correos.

- Enterprice Server. Servidor web.

> NetMeeting. Chat con video.

- Mnogo Search. Motor de búsqueda de texto completo que reconoce metadatos en estructura Núcleo de Dublín.

- Prospector 1.0. Calendario en línea con interfaz web.

- Dforum. Herramienta dirigida a foros de discusión en línea con interfaz web.

Finalmente, el aula se desarrolló a partir de software de licencias públicas genéricas GPL (Generic Public Licence) y con software libre (Open Source Software), aspecto que evitó la inversión en software comercial. Así, el utilizado fue el siguiente:

- Postgre SQL. Administrador de bases de datos relacionales.

- Perl. Lenguaje de programación.

- Apache. Servidor web.

- Linux ReadHat. Sistema operativo UNIX. 
La programación se fundamentó en comando de interfaz puente CGI (Command Gateway Interfaz), JavaScripts y HTML dinámico. En cuanto a medidas de seguridad, se previeron los siguientes elementos:

- Login y password; este último viaja a través de la red encriptado, utiliza un desarrollo propio.

- El sitio es protegido desde cualquier punto de acceso, es decir, si se requiere acceder a la biblioteca digital, desde una página visitada anteriormente y no se ha ingresado el login y el password, el sitio no permite el acceso.

- El servidor utiliza un disco espejo como respaldo de seguridad inmediata.

- Respaldos continuos del servidor, en equipo externo, el cual permite detectar la entrada de virus informático en la biblioteca digital.

- Actualización de bug's de seguridad en el servidor para evitar la presencia de intrusos.

Previniendo las diversas dimensiones teóricas de la educación virtual, así como otros aspectos ya citados, el diseño lógico del aula virtual se estructuró de acuerdo a los objetivos de la especialización propuesta, a los sujetos del aprendizaje, a los actores administrativos del aula y a las tecnologías de aplicación.

\section{ESTRUCTURA LÓGICA DEL AULA VIRTUAL}

La estructura del aula contempla tres módulos principales: opciones generales, tutores y alumnos. Las opciones generales contienen un directorio de alumnos y tutores, una lista de sus correos, la biblioteca digital, sitios de interés relevantes para los temas de la especialización, ingreso a sus módulos, dudas y comentarios tanto de alumnos como de tutores, pánel de discusión y posibilidades de formalizar chats para promover el aprendizaje colaborativo.

El espacio de tutores incluye las diversas opciones requeridas por el aprendizaje, como el ingreso de temarios, envío de material didáctico, envío de actividades de aprendizaje, evaluaciones, acceso a los trabajos realizados por los alumnos, entre muchas otras. El área de alumnos contempla el acceso a los temarios del curso, a los materiales 


\section{didácticos, a la biblioteca digital, facilidades para el envío de activida- des de aprendizaje y trabajos requeridos por los tutores. Para ilustrar esto, en seguida se presentan algunos esquemas.}

Figura 8

Estructura lógica del aula virtual

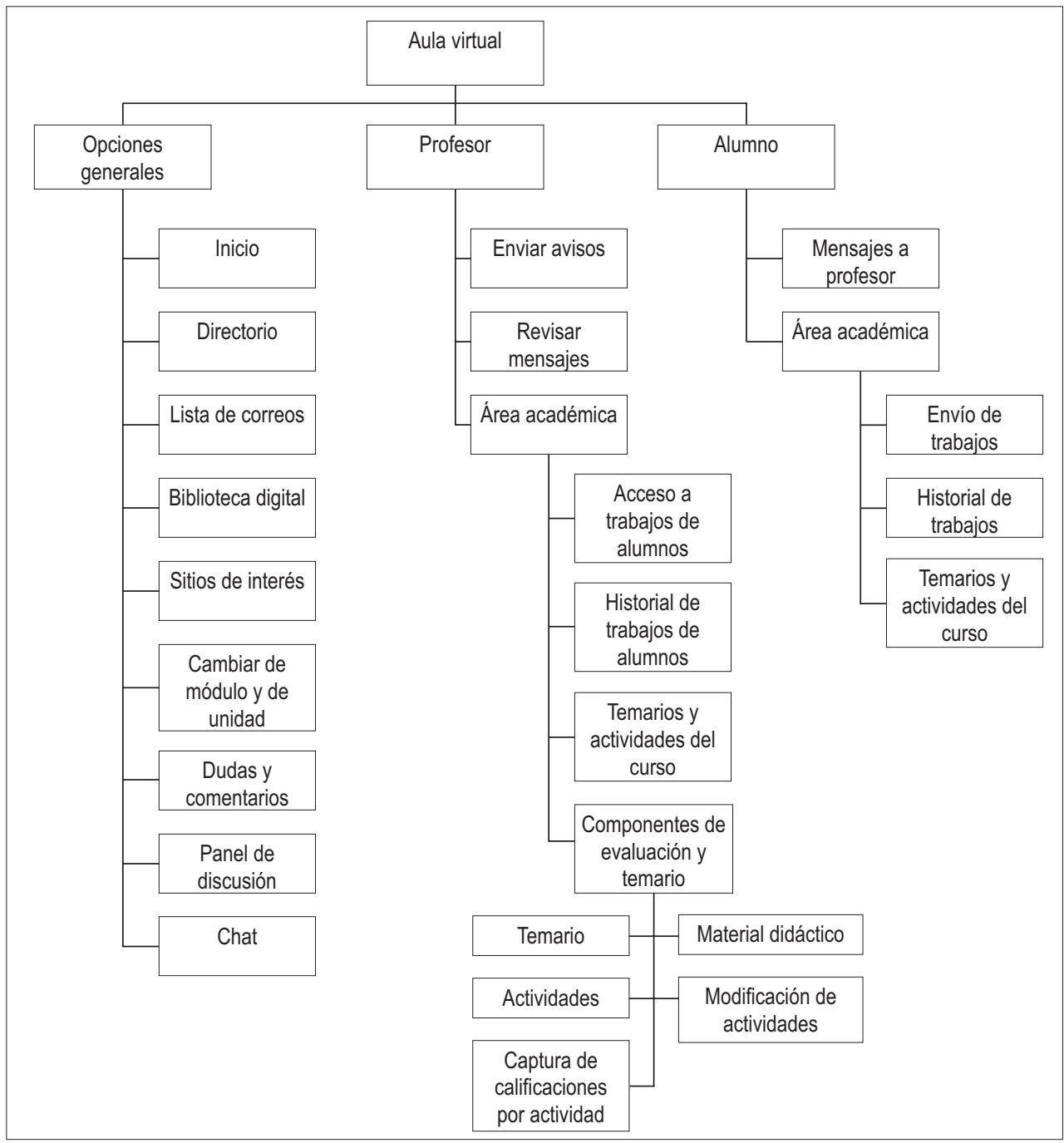


Destaca que la estructura lógica ${ }^{44}$ orienta el desarrollo computacional de determinada propuesta educativa virtual, contempla los parámetros necesarios previendo los diversos aspectos requeridos por los sujetos del aprendizaje. Por lo tanto, en seguida, se muestran sólo como ejemplo las pantallas principales, que contienen diversas variables de la estructura lógica del esquema anterior relacionadas con: opciones generales, tutores y alumnos.

\section{opciones generales}

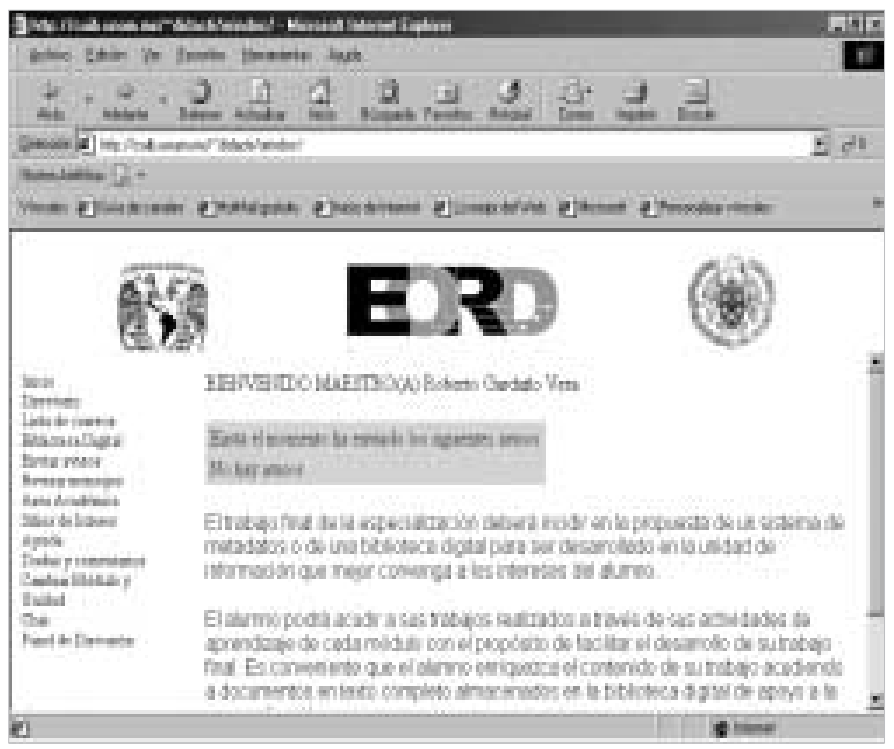

\section{Aprendizaje colaborativo a través de chat}

El objetivo de este espacio es brindar a los alumnos y tutores una herramienta para la interacción en tiempo real. Antes de iniciar una sesión, se dan los siguientes datos: nombre del alumno, correo electrónico y página personal web (cuando cuente con ella).

44 El desarrollo integral se explica con detalle en: Roberto, Garduño Vera, “ Modelo para la enseñanza vía Internet de una especialización en organización de recursos informativos digitales", Universidad Complutense de Madrid, 2002, pp. 362-412 (Tesis de doctorado en Ciencias de la Información). 


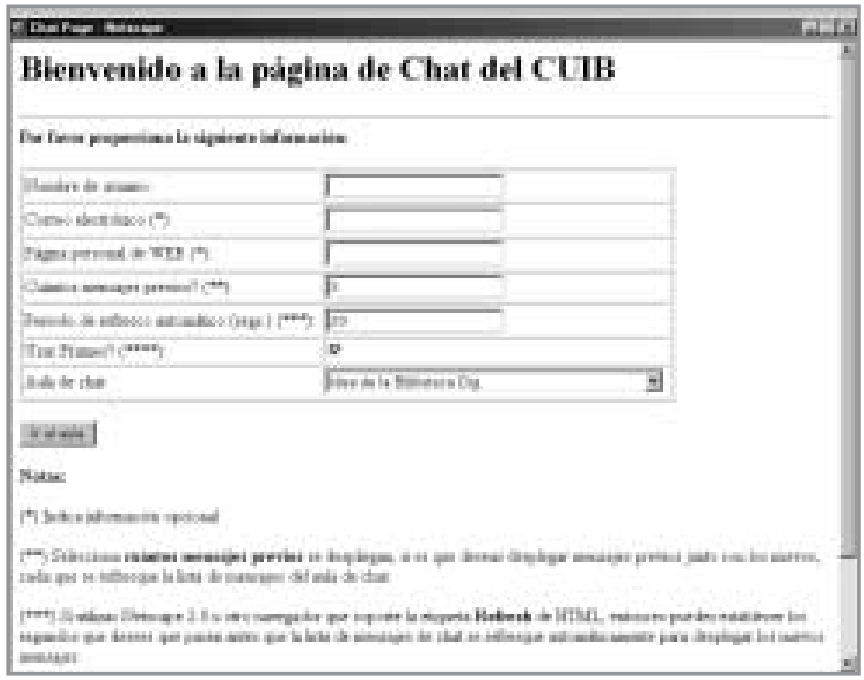

\section{Tutores (área académica del tutor)}

Esta opción es muy valiosa, ya que los tutores a distancia pueden apoyarse en este espacio para realizar sus actividades académicas de mayor relevancia, como las descritas en la pantalla siguiente:

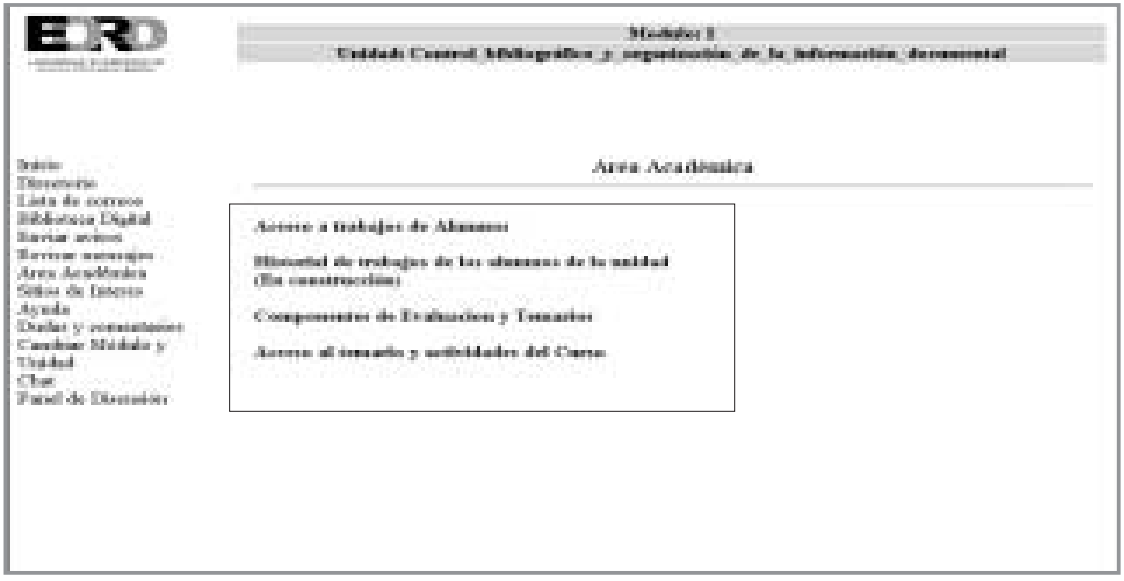


Tutores (bistorial de trabajos de alumnos)

La siguiente opción permite consultar el conjunto de trabajos de los alumnos inscritos por lo que la pantalla que a continuación se muestra contiene lo siguiente: lista de alumnos inscritos en el módulo indicado, actividades de aprendizaje y vínculos a los trabajos enviados por los alumnos al tutor a distancia.

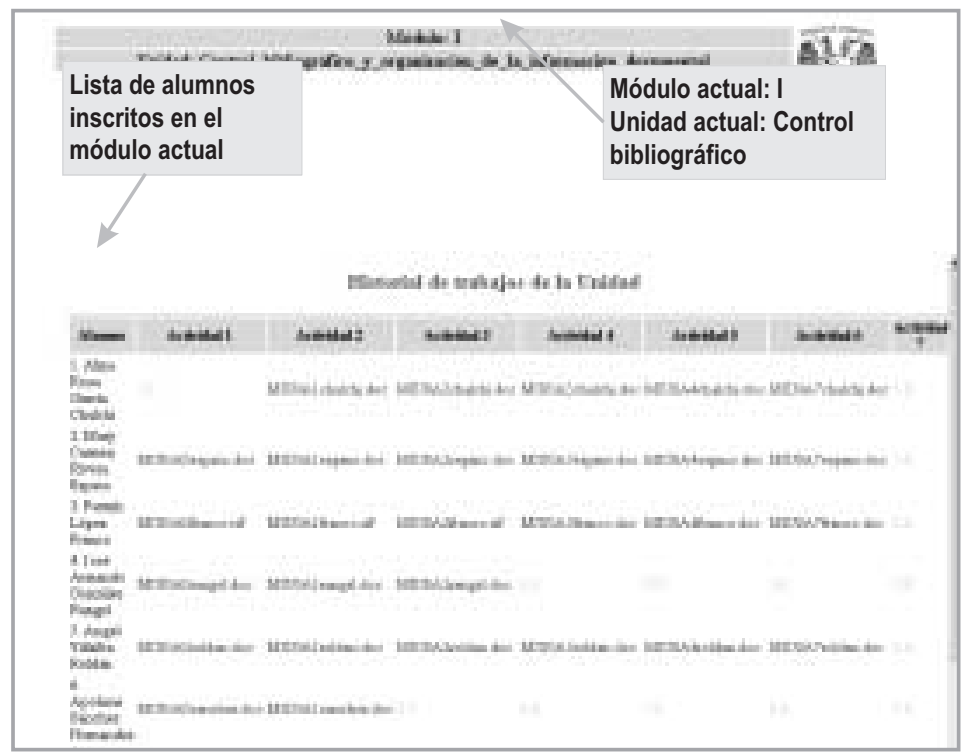

\section{Tutores (material didáctico)}

La siguiente opción permite ingresar y guardar los archivos que contienen el material didáctico correspondiente al módulo en operación. La presentación del material puede ser en texto o en multimedia. 


\section{Captura de material didáctico}

\begin{tabular}{|c|c|c|}
\hline & Dates del naterial & \\
\hline Material Didicticec & 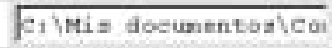 & Drawse \\
\hline
\end{tabular}

\section{Opinma para Continur}

\section{Tutores (bistorial de calificaciones)}

Los datos que se muestran en la pantalla son la lista de alumnos inscritos, lista de actividades definidas en esa unidad, valores que se pueden asignar en la evaluación de los aprendizajes, los cuales van de una escala de 0 al 10; y S.T. valor para los alumnos que no entregaron trabajo y, S.C. sin calificación.

\begin{tabular}{|c|c|c|c|c|c|c|c|c|c|}
\hline \multicolumn{10}{|c|}{ Calififaciones zundades del ahume } \\
\hline Suma & Aetisitat & $\begin{array}{c}\text { Artinthet } \\
t\end{array}$ & Artinitat & $\begin{array}{c}\text { Artiviend } \\
4\end{array}$ & Artinhtul & Antinitat & Artwibued & $\begin{array}{c}\text { Artirital } \\
8\end{array}$ & Prameas \\
\hline $\begin{array}{l}\text { Carma Cholts } \\
\text { Abra Kan }\end{array}$ & S.T & v & 9 & $\theta$ & ab & 10 & s.t. & 5.T & 7 \\
\hline 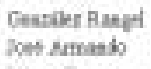 & 9 & v & 9 & s.t & s.t & s.t & 8.r. & s.t & 3 \\
\hline $\begin{array}{l}\text { Lper frare: } \\
\text { Verat }\end{array}$ & 10 & 10 & 10 & 10 & 36 & 10 & s.t & 5.7 & 8 \\
\hline $\begin{array}{l}\text { Rerer Boptos } \\
\text { Magr Comes }\end{array}$ & 9 & v & v & $\bullet$ & 0 & " & $\operatorname{sit}$ & 5.T & $\rightarrow$ \\
\hline $\begin{array}{l}\text { Surbez } \\
\text { Herrants } \\
\text { Apeleng }\end{array}$ & 9 & 9 & S.T & \&T & S.T & \&.T & 8.1 & S.T & 2 \\
\hline $\begin{array}{l}\text { Torred Marter } \\
\text { lava Crisa: }\end{array}$ & 110 & to & 10 & $\bullet$ & 9 & s.t & 8.1 & 5.1 & T \\
\hline $\begin{array}{l}\text { Vouta soditue } \\
\text { Nogel }\end{array}$ & 10 & 10 & 30 & 10 & 30 & 10 & s.t & 5.7 & 8 \\
\hline 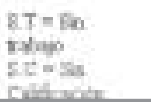 & & & & & & & & & \\
\hline
\end{tabular}


También, la estructura integral del aula virtual refleja las particularidades de la plataforma, de las herramientas tecnológicas, de los actores del aprendizaje, de las funciones del alumno, y las funciones del tutor, las funciones del bibliotecario que proveerá contenidos en la biblioteca digital y las funciones del administrador del aula. Por lo tanto, la plataforma y las herramientas tecnológicas de base estarán relacionadas con los actores del proceso de enseñanza-aprendizaje y sus respectivas funciones. A continuación se ilustran:

Figura 9

Plataforma del aula virtual

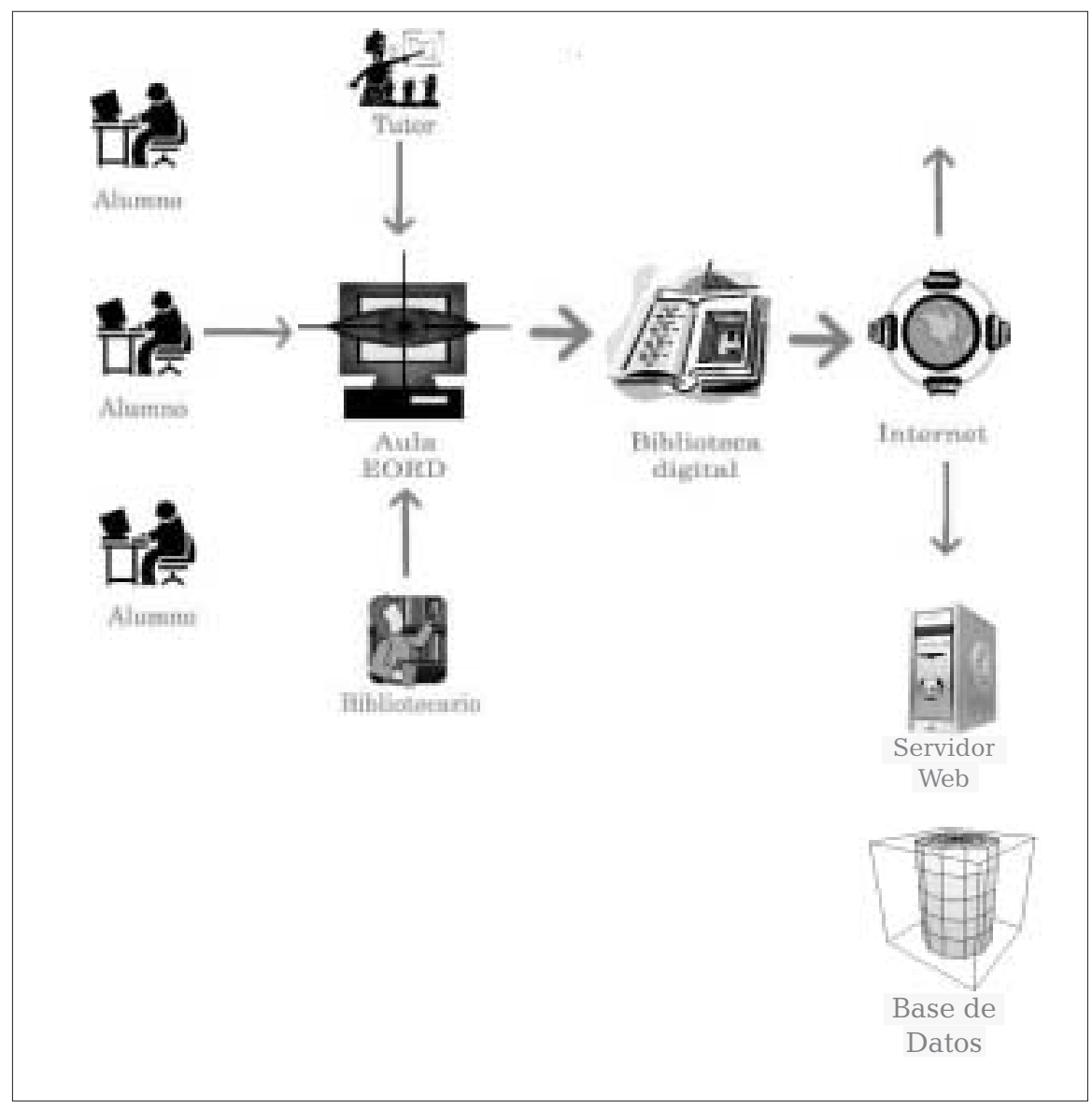


Figura 10

Herramientas del aula virtual

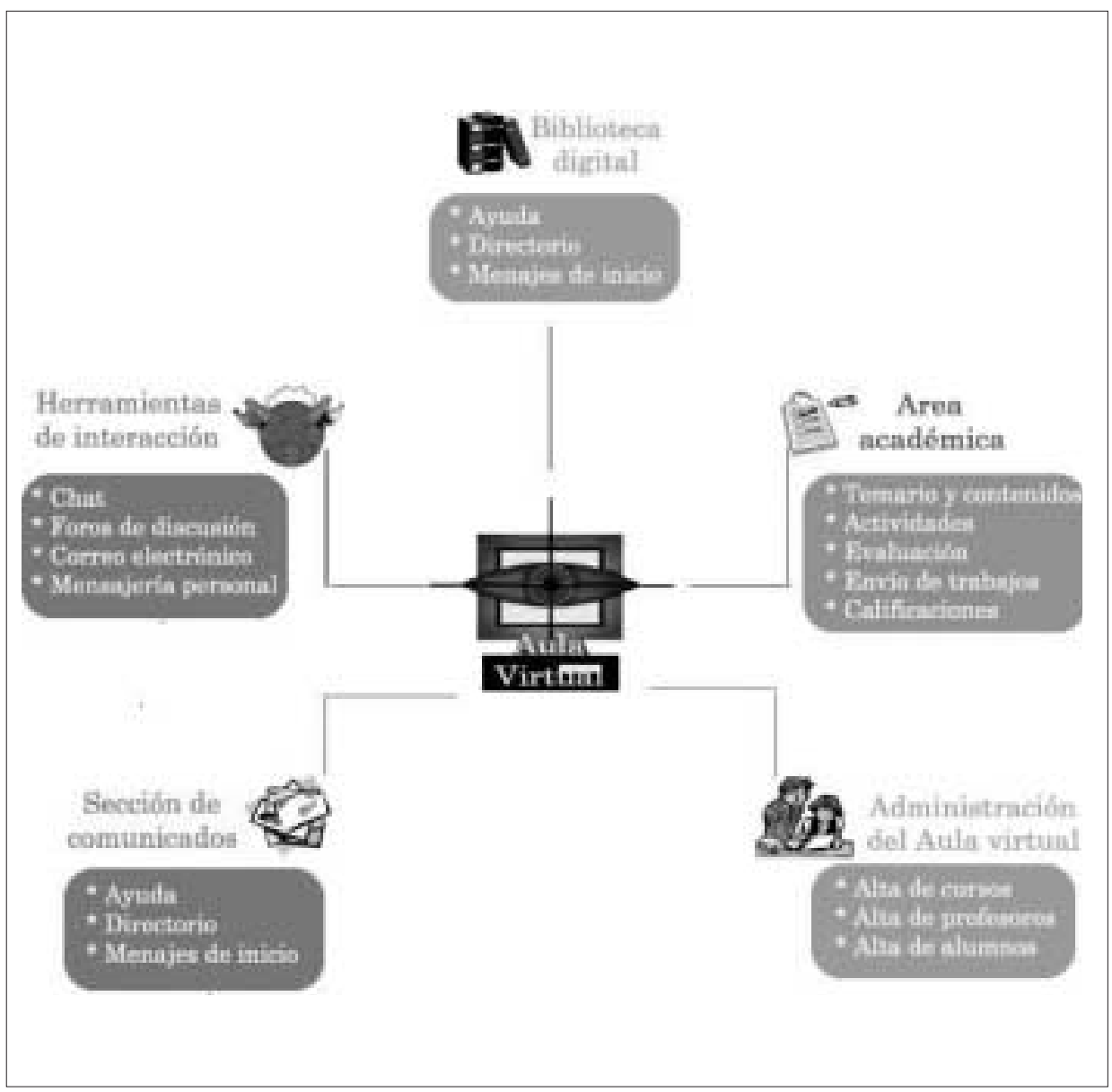


Figura 11

Actores del aprendizaje a través del aula

virtual y figuras complementarias

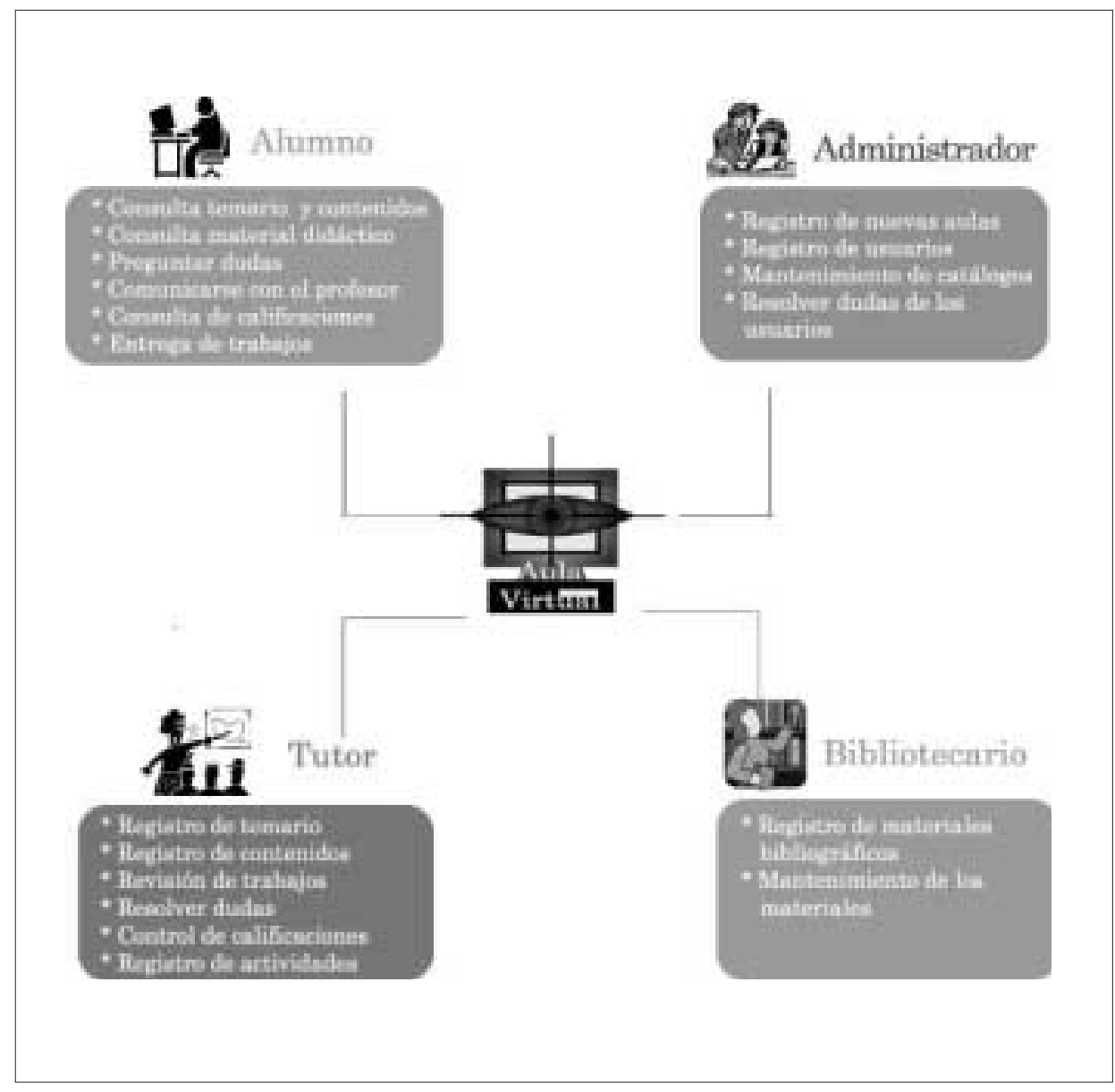


Figura 12

Funciones del alumno a distancia

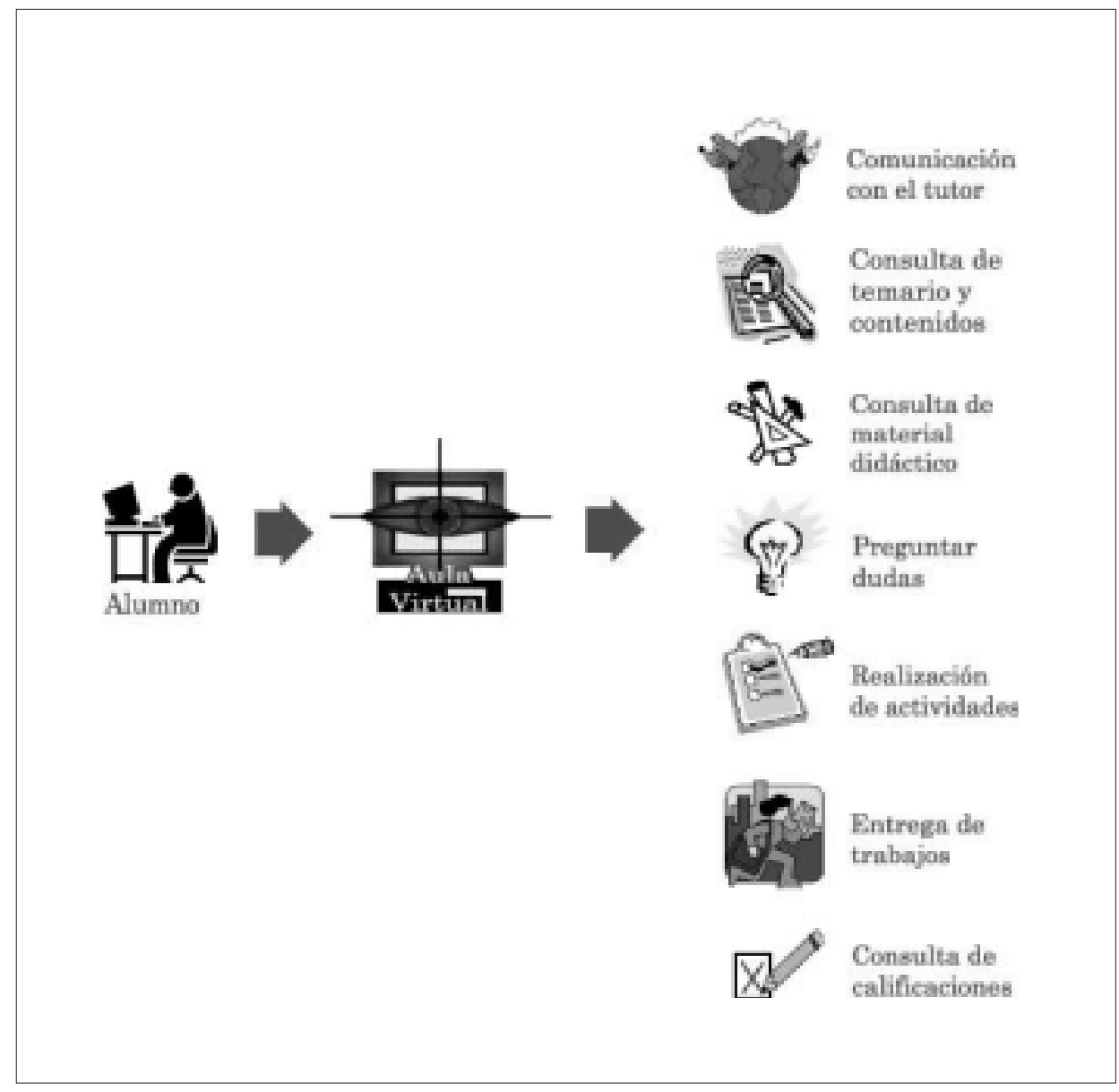


Figura 13

Funciones del tutor a distancia

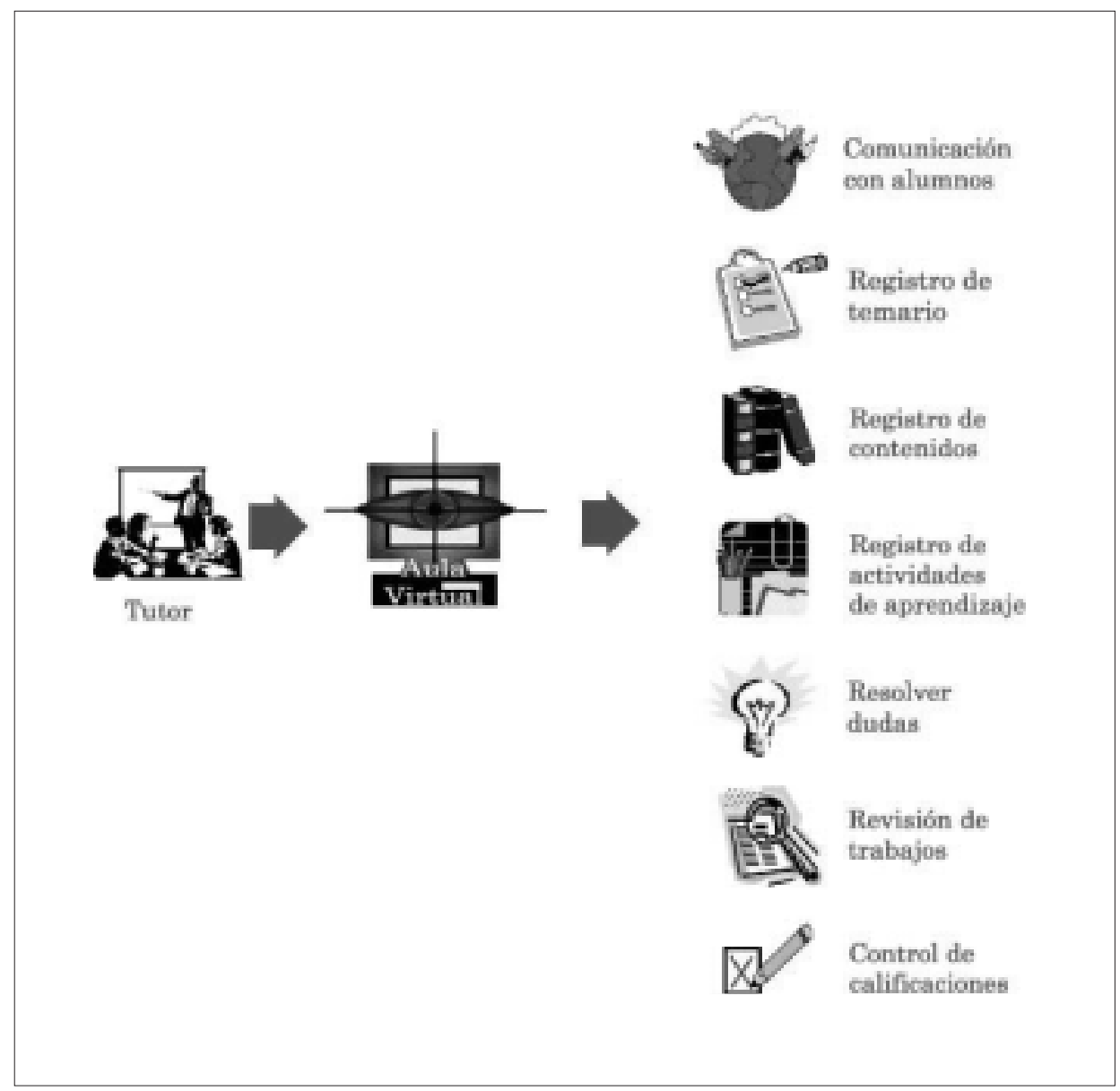


Figura 14

Funciones del bibliotecólogo en

la educación virtual

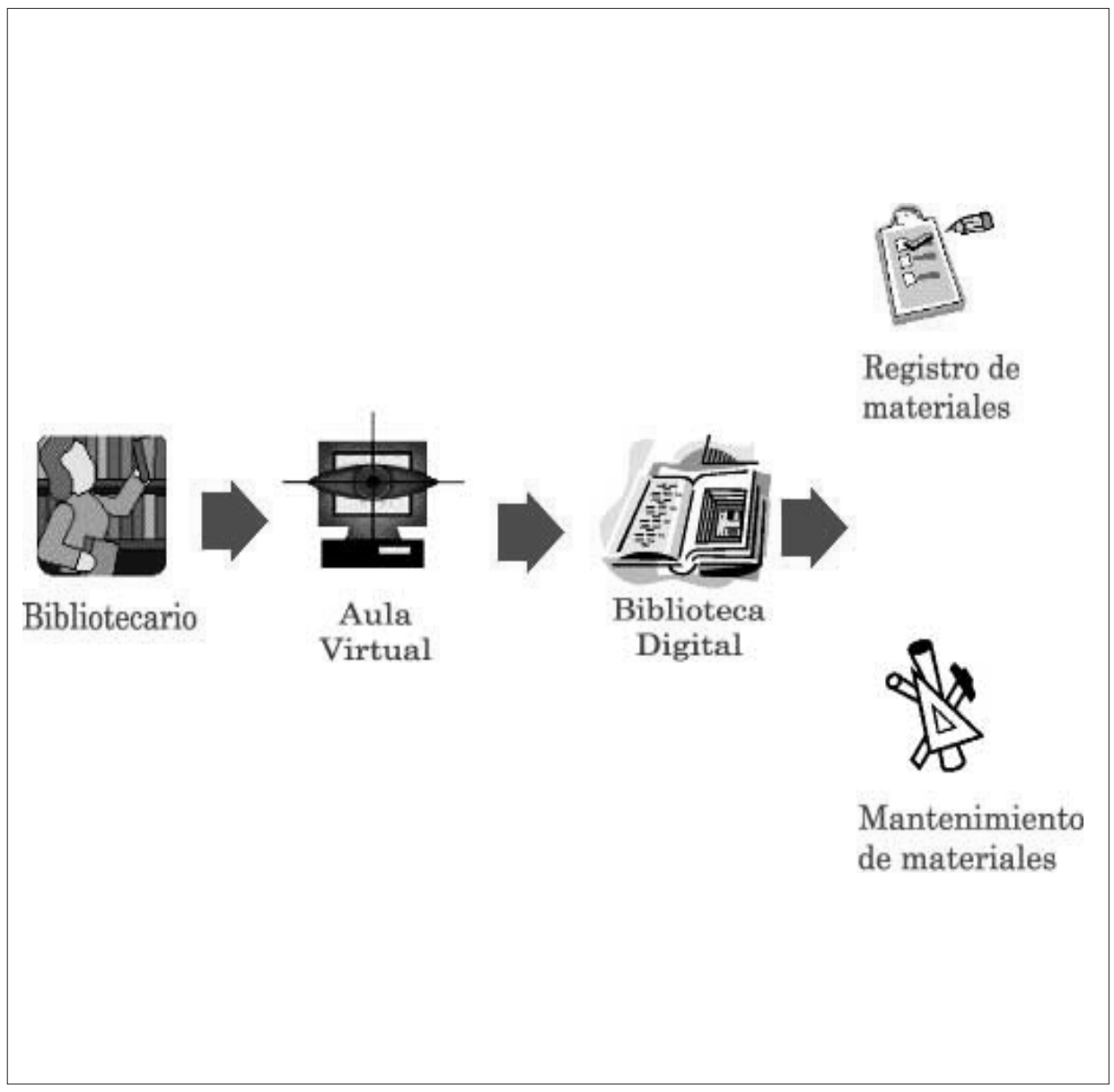


Figura 15

Funciones del administrador

del aula virtual

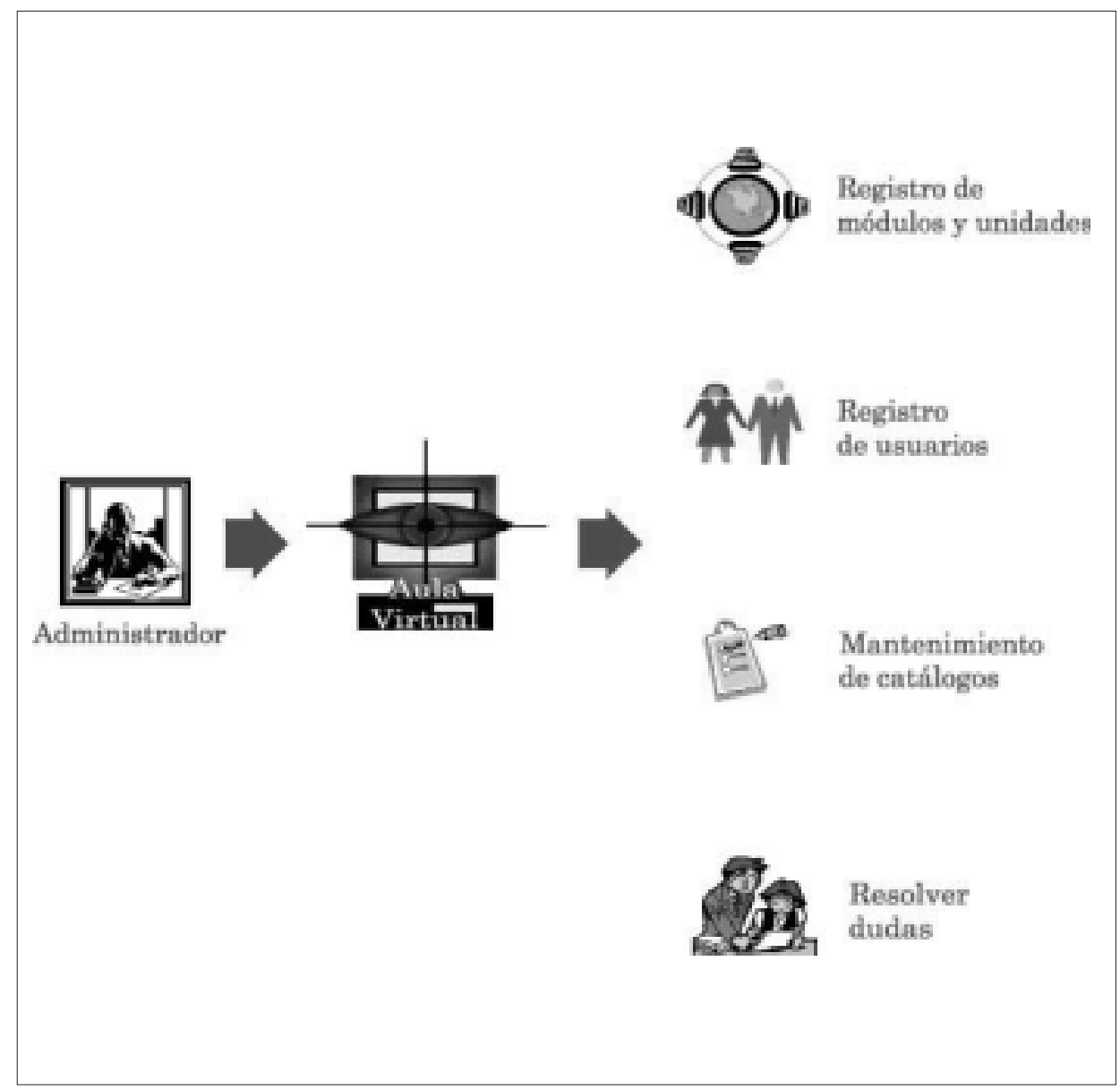


Otro aspecto importante sobre el diseño del aula virtual es la organización de temarios, contenidos de los materiales didácticos y de las actividades de aprendizaje. En el modelo educativo descrito en el capítulo anterior se adopta una organización curricular, basada en módulos, puesto que respeta los aspectos de la EAD se concluyó que la estructura en módulos de aprendizaje incide en un buen control de: programa académico, material didáctico, actividades de aprendizaje, evaluaciones y la navegación por parte de los actores del proceso de enseñanza-aprendizaje.

\section{ESTRUCTURA LÓGICA DE LA BIBLIOTECA DIGITAL Y SUS SERVICIOS EN LA EDUCACIÓN VIRTUAL}

En el diseño de la biblioteca digital de apoyo documental para esta especialidad se contemplaron elementos ya descritos y fundamentalmente éstos: la orientación actual del uso del Internet para el almacenamiento y recuperación de recursos informativos digitales, la lejanía de los alumnos, el nivel de la propuesta educativa planeada, el perfil de los alumnos y los materiales fundamentales de instrucción. Al mismo tiempo, se pensó que la comunicación en red integra los procesos de escrituras, edición, publicación y generación de documentos y acervos digitales simultáneamente. Esta situación en la educación virtual adquiere un nuevo sentido, lo que genera la necesidad de replantear la función de la biblioteca en la educación virtual, sus servicios y el perfil del profesional que la atiende.

A fines del siglo XX y principios del siglo XXI se ha incrementado el interés por la investigación relacionada con los servicios que otorga la biblioteca digital en la educación virtual; sin embargo, hasta hoy se puede afirmar que muy poco se ha avanzado en novedosas propuestas teóricas y prácticas que sustenten modelos de servicios bibliotecarios para la educación de esta naturaleza.

La ausencia de un modelo tal, validado para los servicios de información de la biblioteca digital en la educación virtual ha dado lugar a la generación de servicios digitales aislados, con escaso fundamento teórico. Por lo tanto, en toda propuesta de servicios de esta índole se 
precisa pensar en los servicios de la biblioteca tradicional, los cuales corresponden a un modelo reconocido. Por ejemplo, el servicio de diseminación selectiva de la información, generado en la biblioteca tradicional; en la biblioteca digital se contempla su eficiencia y el uso de tecnologías que faciliten la interactividad con el alumno, a fin de que éste desarrolle sus estrategias de búsqueda y estructure servicios personalizados de diseminación selectiva.

Paulatinamente, la educación virtual reconoce que la biblioteca digital es el núcleo informativo de toda propuesta educativa de esta naturaleza por el apoyo informativo que brinda a los alumnos a distancia. Por ello, diversas asociaciones de profesionales discuten la función de la biblioteca y del bibliotecario en el entorno que propicia la educación virtual, lo cual incluye la formación de usuarios en el uso de servicios bibliotecarios en línea, desarrollo de colecciones digitales, su organización dinámica y la sistematización normalizada de documentos digitales existentes en sitios web. Así, los servicios bibliotecarios para la educación virtual se dinamizan a partir del acceso vía redes a documentos digitalizados, documentos digitales, imágenes, fotografías, catálogos públicos en línea de texto completo, sitios web, etc. En consecuencia, la biblioteca digital resulta favorecida al convertir o incorporar organizadamente a sus colecciones este tipo de documentos, a fin de crear nuevos servicios bibliotecarios que en verdad apoyen propuestas educativas virtuales. Al mismo tiempo, la biblioteca digital prevé, como parte de sus servicios, ofrecer herramientas tecnológicas (software y plataformas) que faciliten a los actores del aprendizaje el desarrollo de métodos apropiados para la investigación, el estudio independiente y el estudio colaborativo.

Asimismo, se tomó en cuenta la creencia de que el desarrollo de colecciones de la biblioteca digital se realizará principalmente dentro de la institución de la que dependa la biblioteca. En consecuencia, se piensa que autores de contenido, tutores e investigadores producirían documentos de calidad para la educación virtual, los cuales formarían las colecciones básicas de la biblioteca digital. De igual modo, el libro electrónico y los objetos de aprendizaje se perfilan como servicios importantes de la biblioteca digital. 
También, hay que considerar que “[...]la rápida socialización y comercialización de las redes de telecomunicación, principalmente en el caso de Internet, ha generado un alud de información acerca de los cambios que induce la tecnología de la información en la biblioteca". ${ }^{45}$ Esto ha motivado a que en el desarrollo de la biblioteca digital recalquen los beneficios que una infraestructura tecnológica suscita en la organización y recuperación de recursos informativos digitales.

Hoy las bibliotecas digitales son el punto de interés de diversas áreas de investigación, por lo cual se puede señalar que es un fenómeno emergente. No obstante, se han propuesto varias características fundamentales que tienen que reunir este tipo de bibliotecas. Sin embargo, se advierte que hasta hoy no existe un modelo de biblioteca digital generalizado, por lo que cada organismo que incide en el diseño de este tipo de entidades proporciona a su modelo un sello propio. Sobre esto, Nabil indica "[...]diferentes proyectos han añadido variadas perspectivas para estudiar y caracterizar el paradigma de una biblioteca digital". ${ }^{46}$

Al profundizar en el diseño y experimentación de modelos de organización de documentos digitales, en cuestiones de software, de servicios o bien en la construcción y transferencia de documentos digitales, proporcionó elementos para influir en el diseño de la biblioteca digital, orientada principalmente a apoyar la enseñanza virtual sobre la organización de recursos informativos digitales. En su diseño se consideró que debía enfocarse en lograr los aspectos siguientes:

- Sistemas, procesos y servicios relacionados.

- Una organización y administración flexible orientada al control de la calidad de la información y de los servicios.

- Un cuidadoso diseño de interfaz de usuario, intuitiva y normalizada de fácil aprendizaje para la recuperación de la información.

- Capacidad para el ingreso de documentos de texto completo.

45 Georgina Araceli Torres Vargas. "La biblioteca virtual: algunas reflexiones en torno a su contexto conceptual. "En Ciencias de la Información (junio de1994), 25, no. 2, p.p. 54-60.

46 R. Adam Nabil et al. Digital libraries: research and technology advances. Berlín: Springer, 1996. 290 p. 
- Presencia de servicios en los que existe una separación física entre el bibliotecario y los actores del aprendizaje.

- Creación de colecciones de documentos digitales que sirvan como instrumento para la navegación y consulta de los contenidos de la biblioteca digital.

- Facilidades para la transferencia de documentos digitales vía telecomunicaciones, que permitan la disponibilidad inmediata del documento de texto completo.

- Cuidar los derechos de autores y editores para lograr la libre circulación de los documentos contenidos en la biblioteca digital.

La estructura lógica de la biblioteca digital se desarrolló a partir de los 15 campos fundamentales del Núcleo de Dublín, las normas de descripción relacionadas con estos campos son las reglas de catalogación angloamericanas, capítulo 9, Archivos de Computadora y las normas ISBD(ER) (International Standard Bibliographic Description, Electronic Resources. Los campos que formalizan la estructura de la biblioteca digital se presentan en seguida.

\begin{tabular}{||l|l|l||}
\hline \multicolumn{1}{||c||}{$\begin{array}{c}\text { Elementos y directrices de la biblioteca digital de apoyo a la enseñanza virtual sobre la } \\
\text { organización de recursos informativos digitales }\end{array}$} \\
\hline \multicolumn{1}{|c|}{ Elemento } & \multicolumn{1}{|c||}{ Descripción } & \multicolumn{1}{c||}{ Asiento } \\
\hline $\begin{array}{l}\text { Autor } \\
\text { Este elemento puede } \\
\text { ser utilizado en todas } \\
\text { las hojas de trabajo. }\end{array}$ & $\begin{array}{l}\text { La(s) persona(s) e } \\
\text { institucion(es) } \\
\text { responsable(s) del } \\
\text { contenido intelectual del } \\
\text { objeto } \\
\text { Este elemento puede ser } \\
\text { la(s) persona(s) e } \\
\text { institución (ciones) del } \\
\text { contenido intelectual del } \\
\text { objeto }\end{array}$ & $\begin{array}{l}\text { Un autor puede presentarse bajo una gran } \\
\text { variedad de formas y por ello debe ser } \\
\text { normalizado al ser uno de los principales } \\
\text { puntos de acceso. Se asienta el apellido(s) } \\
\text { separado(s) por una coma (,), a } \\
\text { continuación el (los) nombre(s) de pila. } \\
\text { Lafuente López, Ramiro. En este elemento } \\
\text { se pueden asentar hasta tres autores. Cada } \\
\text { autor debe separarse con un signo de } \\
\text { pesos (\$). Ej. Lafuente López, } \\
\text { Ramiro\$Garduño Vera, Roberto. Cuando } \\
\text { existan más de tres autores, éstos se } \\
\text { asentarán en el elemento otro agente. }\end{array}$ \\
\hline
\end{tabular}




\begin{tabular}{|c|c|c|}
\hline \multicolumn{3}{|c|}{$\begin{array}{l}\text { Elementos y directrices de la biblioteca digital de apoyo a la enseñanza virtual sobre la } \\
\text { organización de recursos informativos digitales } \\
\text { (Cont.) }\end{array}$} \\
\hline Elemento & Descripción & Asiento \\
\hline $\begin{array}{l}\text { Correo del/los } \\
\text { autor (es) } \\
\text { Este elemento se puede } \\
\text { utilizar en todas las } \\
\text { hojas de trabajo, } \\
\text { excepto la de } \\
\text { Listas de discusión. }\end{array}$ & Correo electrónico & $\begin{array}{l}\text { Cuando se conozcan las direcciones } \\
\text { electrónicas del autor(es) se indicarán en el } \\
\text { campo correspondiente. }\end{array}$ \\
\hline $\begin{array}{l}\text { Título } \\
\text { Es indispensable que } \\
\text { este elemento se } \\
\text { incluya en todas las } \\
\text { hojas de trabajo. }\end{array}$ & $\begin{array}{l}\text { Nombre que identifica al } \\
\text { objeto que se requiere } \\
\text { describir. }\end{array}$ & $\begin{array}{l}\text { El asiento del título es otro de los } \\
\text { principales puntos de acceso a un } \\
\text { documento y cuando no incluye autor se } \\
\text { constituye en el elemento principal de } \\
\text { acceso que lo identifica formalmente. Se } \\
\text { anotará exactamente tal como aparezca en } \\
\text { la fuente original incluyendo el subtítulo; } \\
\text { este último separado del título por dos } \\
\text { puntos (:). Ej. Diversificación de actividades: } \\
\text { habilidades y funciones catalográficas en la } \\
\text { era digital. }\end{array}$ \\
\hline $\begin{array}{l}\text { Otro Agente } \\
\text { Este elemento puede } \\
\text { utilizarse en todas las } \\
\text { hojas de trabajo, con } \\
\text { excepción de artículos } \\
\text { de periódico y listas de } \\
\text { discusión. }\end{array}$ & $\begin{array}{l}\text { La(s) persona(s) como } \\
\text { editores, traductores e } \\
\text { ilustradores que hayan } \\
\text { hecho una contribución } \\
\text { intelectual significativa al } \\
\text { contenido. }\end{array}$ & $\begin{array}{l}\text { En la mención de responsabilidad, después } \\
\text { del título y de una diagonal (I), se asientan } \\
\text { por apellido(s) y nombre(s) las personas } \\
\text { con aportación secundaria que hicieron } \\
\text { alguna contribución importante al contenido } \\
\text { intelectual del documento. Ej. Garduño } \\
\text { Vera, Roberto, trad. Las abreviaturas } \\
\text { normalizadas las proporciona el propio } \\
\text { sistema para seleccionar la que } \\
\text { corresponda. }\end{array}$ \\
\hline
\end{tabular}




\begin{tabular}{|c|c|c|}
\hline \multicolumn{3}{|c|}{$\begin{array}{l}\text { Elementos y directrices de la biblioteca digital de apoyo a la enseñanza virtual sobre la } \\
\text { organización de recursos informativos digitales } \\
\text { (Cont.) }\end{array}$} \\
\hline Elemento & Descripción & Asiento \\
\hline $\begin{array}{l}\text { Fuente } \\
\text { Este elemento se puede } \\
\text { utilizar en todas las } \\
\text { hojas de trabajo con } \\
\text { excepción de las de } \\
\text { carácter monográfico. }\end{array}$ & $\begin{array}{l}\text { Documento original, } \\
\text { impreso o digital, del cual } \\
\text { se deriva el documento } \\
\text { digital. }\end{array}$ & $\begin{array}{l}\text { Incluye datos del (los) autor(es) y el título } \\
\text { del documento fuente: partes de libro; título } \\
\text { de la publicación periódica, y/o nombre de } \\
\text { la reunión, etc., así como cualquier otro } \\
\text { dato considerado importante para identificar } \\
\text { el documento que sirvió de base al } \\
\text { documento actual. Ej. de un artículo de } \\
\text { revista: Morales Campos, Estela. "El fin de } \\
\text { siglo, la globalización y la infodiversidad". - } \\
\text { En : Investigación Bibliotecológica : } \\
\text { archivonomía, bibliotecología e información. }\end{array}$ \\
\hline $\begin{array}{l}\text { Edición } \\
\text { Este elemento se puede } \\
\text { utilizar en las hojas de } \\
\text { trabajo de monografías, } \\
\text { analíticas de } \\
\text { monografías y } \\
\text { documento genérico. }\end{array}$ & $\begin{array}{l}\text { Mención de la edición } \\
\text { relacionada con los } \\
\text { cambios que ha tenido el } \\
\text { documento digital }\end{array}$ & $\begin{array}{l}\text { Transcribir la edición concerniente a un } \\
\text { documento orignal que presente diferencias } \\
\text { con respecto a otras ediciones. Ej. Ed. Rev.; } \\
2 \text { ed. }\end{array}$ \\
\hline $\begin{array}{l}\text { Lugar y editor } \\
\text { Este elemento se puede } \\
\text { utilizar en todas las } \\
\text { hojas de trabajo } \\
\text { exceptuando las de } \\
\text { artículo de periódico y } \\
\text { listas de discusión. }\end{array}$ & $\begin{array}{l}\text { Sitio geográfico y } \\
\text { el agente o agencia que } \\
\text { tiene los derechos de } \\
\text { distribución y es } \\
\text { responsable de hacer } \\
\text { accesible el objeto. }\end{array}$ & $\begin{array}{l}\text { Transcribir el lugar de publicación, } \\
\text { distribución, etc., en la forma en que } \\
\text { aparece en el documento. También se } \\
\text { anotará la empresa editorial o el distribuidor } \\
\text { tal y como aparece en el documento, y se } \\
\text { omitirán las abreviaturas de carácter } \\
\text { comercial tales como Inc., Cía., Ltda., etc. } \\
\text { antecediéndoles dos puntos (:), Ej. México: } \\
\text { UNAM, Centro Universitario de } \\
\text { Investigaciones Bibliotecológicas. } \\
\text { Para las tesis en el campo del editor se } \\
\text { anotarán las siglas del nombre y apellido(s) } \\
\text { del autor. }\end{array}$ \\
\hline
\end{tabular}




\begin{tabular}{|c|c|c|}
\hline \multicolumn{3}{|c|}{$\begin{array}{l}\text { Elementos y directrices de la biblioteca digital de apoyo a la enseñanza virtual sobre la } \\
\text { organización de recursos informativos digitales } \\
\text { (Cont.) }\end{array}$} \\
\hline Elemento & Descripción & Asiento \\
\hline Año & & \\
\hline $\begin{array}{l}\text { Este elemento se puede } \\
\text { utilizar en todas las } \\
\text { hojas de trabajo. }\end{array}$ & $\begin{array}{l}\text { Refiere a la fecha de } \\
\text { publicación. }\end{array}$ & $\begin{array}{l}\text { El año de publicación se anotará siempre } \\
\text { con números arábigos. }\end{array}$ \\
\hline Sección & & \\
\hline $\begin{array}{l}\text { Este elemento se utiliza } \\
\text { en la hoja de trabajo } \\
\text { Artículo de periódico. }\end{array}$ & $\begin{array}{l}\text { Nombre de la sección del } \\
\text { periódico a la que } \\
\text { corresponda el artículo } \\
\text { analizado. }\end{array}$ & $\begin{array}{l}\text { Transcribir el título de la sección tal y como } \\
\text { aparece en el periódico. }\end{array}$ \\
\hline Día & & \\
\hline $\begin{array}{l}\text { Este elemento se utiliza } \\
\text { en la hoja de trabajo } \\
\text { Artículo de periódico. }\end{array}$ & $\begin{array}{l}\text { Día y fecha en que } \\
\text { apareció publicado en el } \\
\text { periódico el artículo. }\end{array}$ & $\begin{array}{l}\text { Se anotará el día y la fecha de publicación } \\
\text { del periódico. }\end{array}$ \\
\hline Volumen (es) & & \\
\hline $\begin{array}{l}\text { Este elemento se puede } \\
\text { utilizar en la hoja de } \\
\text { trabajo Analítica de } \\
\text { revista y en Documento } \\
\text { genérico. }\end{array}$ & $\begin{array}{l}\text { La denominación de } \\
\text { volumen de una } \\
\text { publicación seriada } \\
\text { puede aparecer con } \\
\text { otras denominaciones } \\
\text { como: año y tomo. }\end{array}$ & $\begin{array}{l}\text { Siempre se indicará esta denominación con } \\
\text { números arábigos. }\end{array}$ \\
\hline Número(s) & & \\
\hline $\begin{array}{l}\text { Este elemento se puede } \\
\text { utilizar en la hoja de } \\
\text { trabajo Analítica de } \\
\text { revista y en Documento } \\
\text { genérico. }\end{array}$ & $\begin{array}{l}\text { En una publicación } \\
\text { seriada es el número(s) } \\
\text { asignado(s) a cada uno } \\
\text { de los fascículos }\end{array}$ & $\begin{array}{l}\text { Se indica el número o rango de números } \\
\text { que abarque el fascículo. Cuando indica } \\
\text { más de un número, éstos se separan con } \\
\text { un guión. }\end{array}$ \\
\hline Mes (es)/estacion(s) & & \\
\hline $\begin{array}{l}\text { Este elemento se puede } \\
\text { utilizar en la hoja de } \\
\text { trabajo Analítica de } \\
\text { revista y en Documento } \\
\text { Genérico. }\end{array}$ & $\begin{array}{l}\text { Corresponde a los } \\
\text { meses y/o estaciones del } \\
\text { año en que se publica un } \\
\text { fascículo. }\end{array}$ & $\begin{array}{l}\text { Se indica el nombre del mes(es) y/o } \\
\text { estación(es) así como el periodo que } \\
\text { abarquen, separados por un guión. Cuando } \\
\text { un fascículo abarca dos o más meses se } \\
\text { incorporan dos campos para indicar el mes } \\
\text { de inicio y el mes de término del periodo. }\end{array}$ \\
\hline
\end{tabular}




\begin{tabular}{|c|c|c|}
\hline \multicolumn{3}{|c|}{$\begin{array}{l}\text { Elementos y directrices de la biblioteca digital de apoyo a la enseñanza virtual sobre la } \\
\text { organización de recursos informativos digitales } \\
\text { (Cont.) }\end{array}$} \\
\hline Elemento & Descripción & Asiento \\
\hline $\begin{array}{l}\text { Páginas } \\
\text { Este elemento se puede } \\
\text { utilizar en todas las } \\
\text { hojas de trabajo, con } \\
\text { excepción de } \\
\text { Fotografías y Listas de } \\
\text { discusión. }\end{array}$ & $\begin{array}{l}\text { Refiere a las páginas o } \\
\text { equivalente en medio } \\
\text { digital. }\end{array}$ & $\begin{array}{l}\text { Se anotará el número total o parcial de } \\
\text { páginas que abarque el documento. }\end{array}$ \\
\hline $\begin{array}{l}\text { Descripción física de } \\
\text { imágenes } \\
\text { Este elemento se utiliza } \\
\text { en la hoja de trabajo } \\
\text { Documento genérico. }\end{array}$ & $\begin{array}{l}\text { Designación específica } \\
\text { del material documental. }\end{array}$ & $\begin{array}{l}\text { Se incluyen detalles físicos, como color, } \\
\text { dimensiones, etc. }\end{array}$ \\
\hline $\begin{array}{l}\text { Serie } \\
\text { Este elemento se puede } \\
\text { usar en las hojas de } \\
\text { trabajo de carácter } \\
\text { monográfico, analíticas } \\
\text { de monografías, } \\
\text { fotografías y genérica. }\end{array}$ & $\begin{array}{l}\text { Conjunto de material } \\
\text { documental con su título } \\
\text { propio cada uno, y } \\
\text { agrupados por un título } \\
\text { colectivo. }\end{array}$ & $\begin{array}{l}\text { Se anotará entre paréntesis el título de la } \\
\text { serie y el subtítulo si lo tiene, seguido del } \\
\text { número de la serie correspondiente. Ej. } \\
\text { (Sistemas Bibliotecarios de Información y } \\
\text { Sociedad; 1). } \\
\text { Se utiliza también para fotografías cuando } \\
\text { se quiere indicar la serie que asignó el autor } \\
\text { o grupo documental al que pertenece la } \\
\text { fotografía. }\end{array}$ \\
\hline Nota de tesis & & \\
\hline $\begin{array}{l}\text { Este elemento se utiliza } \\
\text { en la hoja de trabajo de } \\
\text { Tesis. }\end{array}$ & $\begin{array}{l}\text { Comprende el tipo de } \\
\text { trabajo recepcional, el } \\
\text { título o grado alcanzado } \\
\text { y el nombre de la } \\
\text { institución que otorga el } \\
\text { nivel académico. }\end{array}$ & $\begin{array}{l}\text { Los datos relacionados con el tipo de } \\
\text { trabajo presentado, el nivel académico } \\
\text { alcanzado y la institución otorgante, se } \\
\text { extraen del mismo trabajo analizado. Ej. } \\
\text { Tesis (Doctor en Pedagogía) —UNAM. } \\
\text { Facultad de Filosofía y Letras, División de } \\
\text { Estudios de Posgrado. }\end{array}$ \\
\hline
\end{tabular}




\begin{tabular}{|c|c|c|}
\hline \multicolumn{3}{|c|}{$\begin{array}{l}\text { Elementos y directrices de la biblioteca digital de apoyo a la enseñanza virtual sobre la } \\
\text { organización de recursos informativos digitales } \\
\text { (Cont.) }\end{array}$} \\
\hline Elemento & Descripción & Asiento \\
\hline \multirow{4}{*}{$\begin{array}{l}\text { Resumen } \\
\text { Este elemento puede } \\
\text { ser utilizado en todas } \\
\text { las hojas de trabajo }\end{array}$} & \multirow{4}{*}{$\begin{array}{l}\text { Descripción textual del } \\
\text { contenido: resúmenes, } \\
\text { tablas de contenido, } \\
\text { notas relevantes, etc. }\end{array}$} & \\
\hline & & $\begin{array}{l}\text { El resumen debe sintetizar el contenido } \\
\text { sustancial del documento en forma clara, } \\
\text { concisa y fiel. }\end{array}$ \\
\hline & & $\begin{array}{l}\text { Podrán usarse hasta } 1000 \text { caracteres para } \\
\text { el resumen. }\end{array}$ \\
\hline & & También puede incluirse texto completo. \\
\hline \multirow{2}{*}{$\begin{array}{l}\text { Tema } \\
\text { Este elemento se debe } \\
\text { utilizar en todas las } \\
\text { hojas de trabajo. }\end{array}$} & & \\
\hline & $\begin{array}{l}\text { Asunto(s) tratado(s) en } \\
\text { documento electrónico, } \\
\text { definido(s) a partir de } \\
\text { sistemas de clasificación: } \\
\text { CDU, DDC,LCSH. }\end{array}$ & $\begin{array}{l}\text { Para la asignación de descriptores se usará } \\
\text { el Tesauro Latinoamericano en } \\
\text { Bibliotecología y Ciencia de la Información. } \\
\text { Se utilizarán como máximo cinco } \\
\text { descriptores. Cuando el término buscado no } \\
\text { se encuentre se podrá asignar el que } \\
\text { decida el analista utilizando el campo } \\
\text { destinado a término candidato. }\end{array}$ \\
\hline \multicolumn{3}{|l|}{ Identificador } \\
\hline \multirow{2}{*}{$\begin{array}{l}\text { Este elemento se puede } \\
\text { utilizar en todas las } \\
\text { hojas de trabajo con } \\
\text { excepción de listas de } \\
\text { discusión. }\end{array}$} & $\begin{array}{l}\text { Serie o número usado } \\
\text { como identificador único } \\
\text { del objeto. }\end{array}$ & $\begin{array}{l}\text { Los materiales existentes en red incluyen } \\
\text { los URLs, = Uniform Resource Locator = } \\
\text { Localizador Uniforme de los Recursos. }\end{array}$ \\
\hline & & $\begin{array}{l}\text { Además se pueden incluir los ISBN y los } \\
\text { SIN. }\end{array}$ \\
\hline \multicolumn{3}{|l|}{ Relación } \\
\hline $\begin{array}{l}\text { Este elemento se puede } \\
\text { utilizar en todas las } \\
\text { hojas de trabajo. }\end{array}$ & Sitios web relacionados. & Ligas a otros sitios de interés. \\
\hline \multicolumn{3}{|l|}{ Idioma } \\
\hline $\begin{array}{l}\text { Este elemento se utiliza } \\
\text { en todas las hojas de } \\
\text { trabajo. }\end{array}$ & $\begin{array}{l}\text { Idioma del contenido } \\
\text { intelectual. }\end{array}$ & $\begin{array}{l}\text { Se indica en forma completa el idioma en } \\
\text { que está escrito el documento. } \\
\text { Seleccionándolo del menú que proporciona } \\
\text { el sistema. }\end{array}$ \\
\hline
\end{tabular}




\begin{tabular}{|c|c|c|}
\hline \multicolumn{3}{|c|}{$\begin{array}{l}\text { Elementos y directrices de la biblioteca digital de apoyo a la enseñanza virtual sobre la } \\
\text { organización de recursos informativos digitales } \\
\text { (Cont.) }\end{array}$} \\
\hline Elemento & Descripción & Asiento \\
\hline $\begin{array}{l}\text { Derechos de autor } \\
\text { /Propiedad intelectual } \\
\text { Este elemento se puede } \\
\text { utilizar en todas las } \\
\text { hojas de trabajo con } \\
\text { excepción de Listas de } \\
\text { Discusión }\end{array}$ & $\begin{array}{l}\text { Mención sobre el manejo de los } \\
\text { derechos }\end{array}$ & $\begin{array}{l}\text { Indicar las condiciones del derecho } \\
\text { de autor como: Restricciones para } \\
\text { el uso de los documentos; } \\
\text { derechos de autor concedidos y } \\
\text { fechas de la concesión; libre de } \\
\text { derechos de autor, etcétera. }\end{array}$ \\
\hline $\begin{array}{l}\text { Formato } \\
\text { Este elemento se utiliza } \\
\text { en todas las hojas de } \\
\text { trabajo. }\end{array}$ & $\begin{array}{l}\text { Manifestación física del objeto, } \\
\text { como: PostScript, HTML, SGML, } \\
\text { XML, Archivo ejecutable en } \\
\text { Windows. }\end{array}$ & $\begin{array}{l}\text { Indicar nombre, tipo y formato del } \\
\text { archivo, así como sistema operativo } \\
\text { empleado. }\end{array}$ \\
\hline $\begin{array}{l}\text { Colección } \\
\text { Este elemento se puede } \\
\text { utilizar en todas las } \\
\text { hojas de trabajo. }\end{array}$ & $\begin{array}{l}\text { Nombre que recibe en cada } \\
\text { Unidad de Información, un } \\
\text { conjunto de materiales que son } \\
\text { agrupados por su temática o } \\
\text { características especiales. }\end{array}$ & $\begin{array}{l}\text { Se anota el nombre de la colección } \\
\text { a la cual pertenece el documento } \\
\text { digital analizado. }\end{array}$ \\
\hline $\begin{array}{l}\text { Unidad propietaria } \\
\text { Este elemento se puede } \\
\text { utilizar en todas las } \\
\text { hojas de trabajo. }\end{array}$ & $\begin{array}{l}\text { Nombre de las unidades de } \\
\text { información o instituciones que } \\
\text { poseen el material. }\end{array}$ & $\begin{array}{l}\text { Se anotarán las siglas o } \\
\text { abreviaturas que identifiquen a la } \\
\text { unidad de información y/o } \\
\text { instituciones }\end{array}$ \\
\hline $\begin{array}{l}\text { Tipo de medio } \\
\text { Este elemento se utiliza } \\
\text { en todas las hojas de } \\
\text { trabajo. }\end{array}$ & $\begin{array}{l}\text { Describe categorías generales } \\
\text { de los medios en los que se } \\
\text { puede encontrar almacenado el } \\
\text { documento. }\end{array}$ & $\begin{array}{l}\text { Se deberá seleccionar una de las } \\
\text { opciones del menú } \\
\text { correspondiente. }\end{array}$ \\
\hline
\end{tabular}




\begin{tabular}{|c|c|c|}
\hline \multicolumn{3}{|c|}{$\begin{array}{l}\text { Elementos y directrices de la biblioteca digital de apoyo a la enseñanza virtual sobre la } \\
\text { organización de recursos informativos digitales } \\
\text { (Cont.) }\end{array}$} \\
\hline Elemento & Descripción & Asiento \\
\hline $\begin{array}{l}\text { Archivo de } \\
\text { bibliografia } \\
\text { Este elemento se } \\
\text { utiliza en todas las } \\
\text { hojas de trabajo. }\end{array}$ & $\begin{array}{l}\text { Seleccionar el archivo físico } \\
\text { del documento que se } \\
\text { almacenará en la Biblioteca } \\
\text { digital. }\end{array}$ & $\begin{array}{l}\text { Este campo será llenado } \\
\text { automáticamente por el sistema, una vez } \\
\text { que se halla seleccionado el archivo } \\
\text { físico oprimiendo el botón archivo. Se } \\
\text { desplegará una ventana con la estructura } \\
\text { organizacional de directorios del disco } \\
\text { duro. A través de dicha estructura podrá } \\
\text { seleccionar el archivo que deseé enviar a } \\
\text { la Biblioteca Digital. Sólo podrá } \\
\text { seleccionar un archivo a la vez. }\end{array}$ \\
\hline $\begin{array}{l}\text { Listas de discusión } \\
\text { Denominación que } \\
\text { recibe esta hoja de } \\
\text { trabajo en particular. }\end{array}$ & $\begin{array}{l}\text { Para esta hoja de trabajo los } \\
\text { elementos diferentes que se } \\
\text { utilizan son: el nombre y } \\
\text { correo electrónico del } \\
\text { administrador de la lista, el } \\
\text { nombre de la lista y su } \\
\text { dirección electrónica. }\end{array}$ & $\begin{array}{l}\text { Los datos se transcribirán tal y como } \\
\text { aparecen en las listas de discusión }\end{array}$ \\
\hline
\end{tabular}

Finalmente, retomando aspectos teóricos y prácticos para el desarrollo de bibliotecas digitales y recordando los elementos de la biblioteca digital, se presenta su estructura gráfica, la cual se observa en los esquemas que aparecen luego. 
Figura 16

Estructura fundamental de la

biblioteca digital

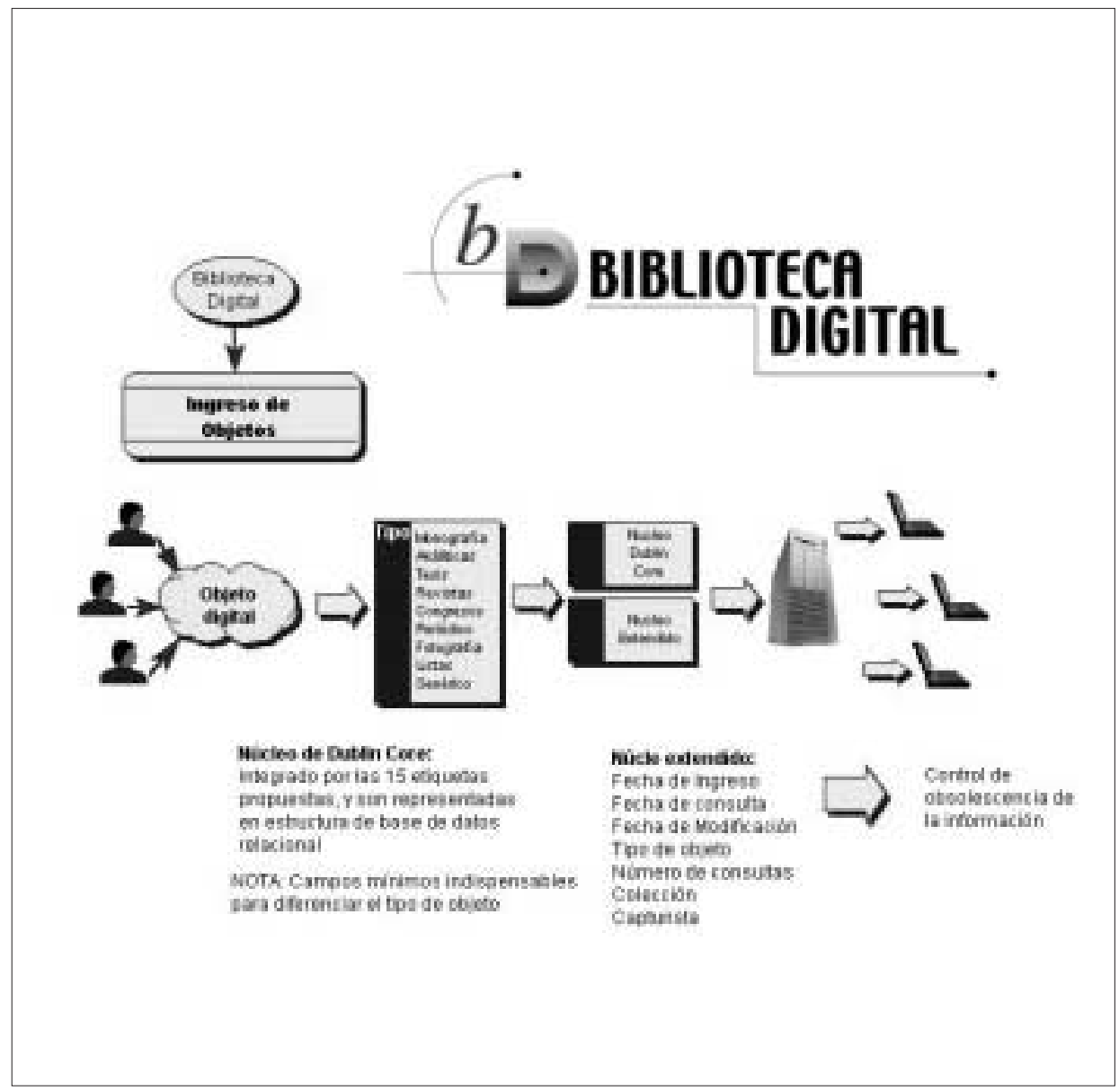


Figura 17

Recuperación de la información digital (documento-objeto)

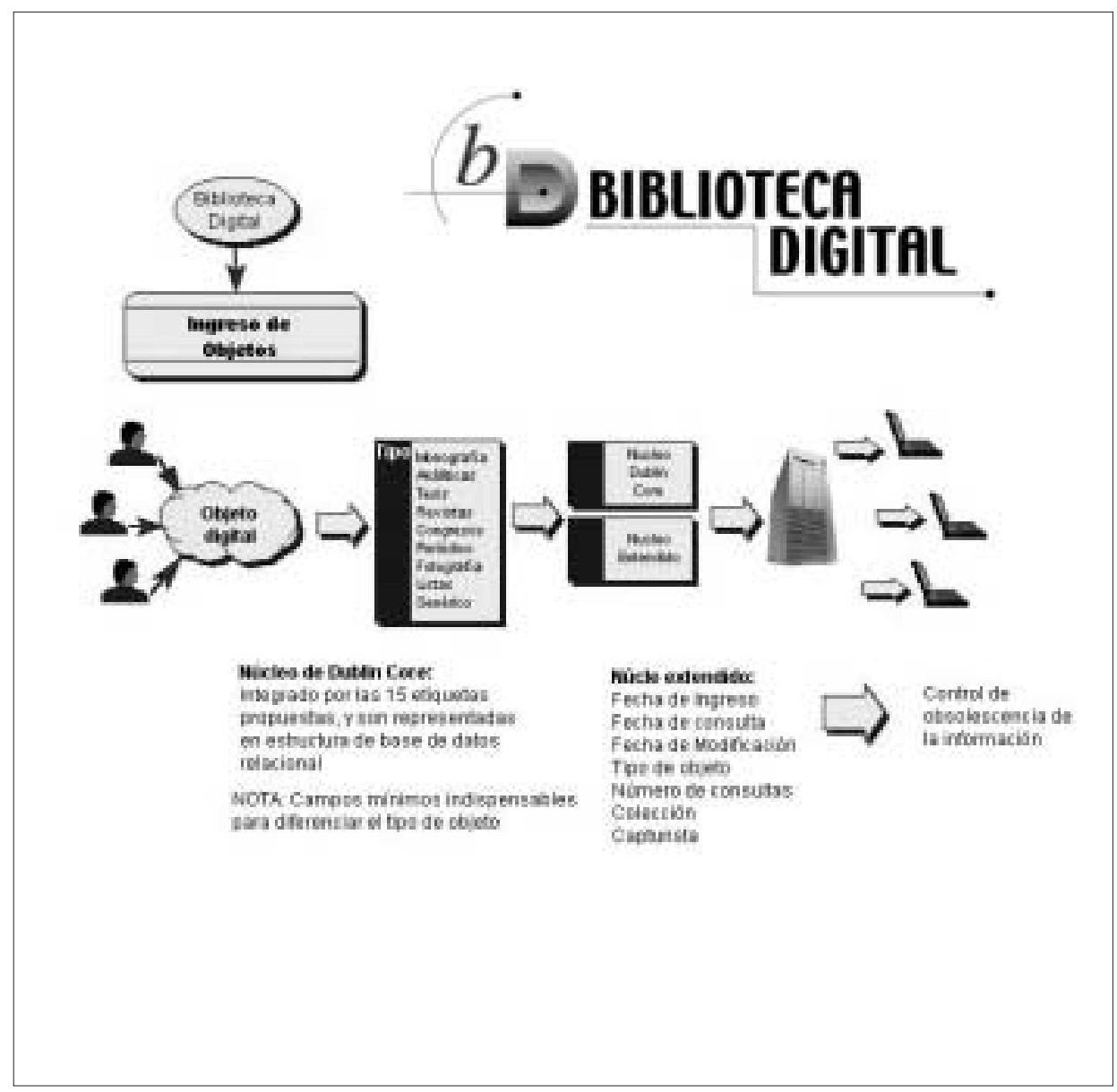

Fuente: Roberto Garduño Vera, y Elsa Ramírez Leyva, "Diplomado a distancia en biblioteca digital" Foro Internacional de Bibliotecas Digitales: Interfaces. Colima, 2001 [ed. en Cd-Rom]. 
En cuanto a la proyección de los servicios de la biblioteca digital, se tomó en cuenta la orientación actual del uso de Internet respecto del almacenamiento, recuperación de recursos informativos digitales, lejanía de los alumnos, nivel de la propuesta educativa planeada, perfil de los alumnos y los materiales fundamentales de instrucción. En este incipiente siglo XXI ha incrementado el interés por la investigación de los servicios que debe otorgar la biblioteca digital en la educación virtual, sin embargo, hasta nuestros días, muy poco se ha avanzado hoy en propuestas teóricas y prácticas que sustenten modelos de servicios bibliotecarios de vanguardia para la EAD.

Así, la ausencia de un modelo general y validado de servicios de la biblioteca digital para la educación virtual ha promovido la generación de servicios bibliotecarios digitales dispersos, con escaso fundamento teórico. Por lo tanto, en toda propuesta de servicios de esta naturaleza se requiere incluir a los sujetos del acto educativo, elegir las tecnologías apropiadas que faciliten la interactividad con el alumno a distancia, así se lograría que este pudiese desarrollar sus estrategias de búsqueda y estructurarse servicios personalizados de diseminación selectiva de la información para el crecimiento de sus actividades de aprendizaje. En este sentido, tutores, alumnos y bibliotecarios tienen mucho que aportar en la generación de servicios bibliotecarios en red, en pro de los actores que necesariamente se involucran en propuestas de educación virtual en este siglo.

En suma, se dice que en los años recientes toda propuesta educativa debe realizarse en función del fenómeno de la globalización, ya que ha generado una serie de complejos factores. Lo global se relaciona con las tendencias del mundo actual, en cuanto a eliminar barreras de comunicación para facilitar los flujos de información, impulsados principalmente por la tecnología electrónica, la informática y las telecomunicaciones. A la vez, es factible señalar que la educación virtual posee cualidades inherentes a los aspectos de globalización cuando la sociedad requiere el acceso a propuestas educativas distintas a la presencial. Por lo tanto, el Internet es un medio con mucha potencia en el que convergen los constantes desarrollos tecnológicos que propician el diseño de programas en línea. En este sentido, educadores y 
diseñadores de modelos a distancia requieren apropiarse de las TIC que puedan ser más útiles para la educación en el siglo que corre.

Por otra parte, los contenidos informativos digitales representan un rubro de suma importancia para la educación virtual. Esto se evidencia a partir de la orientación de programas relacionados con la edición y organización digital de datos, cuya intención es integrar globalmente a los actores de conocimiento publicado, con las unidades de servicios informativos y las instituciones y organismos usuarios de información. Lo anterior intenta reducir las barreras tecnológicas que se presentan en las telecomunicaciones y facilitar el uso de normas internacionales en el campo de la comunicación de información digital. En este contexto, la posibilidad de generar y transmitir flujos de información en un marco global reclama forzosamente la estandarización tecnológica requerida para acceder a la Internet. Lo anterior es determinante en la educación virtual del presente siglo. Así, en la actualidad se advierte la existencia de una demanda generalizada respecto del uso del Internet en las diversas áreas del conocimiento, siendo la educación superior en la que se revela un alto grado de esa demanda. Asimismo, se advierte el propósito de gobierno en consolidar infraestructuras tecnológicas que permitan la conexión a la Internet, dedicando importantes sumas monetarias. En cuanto a las sociedades de los países industrializados, se hace patente su permanente interés de procurarse conexiones a la Internet. En cuanto a los países en vías de desarrollo, se sigue una tendencia creciente para acceder a dicha red. Sin embargo, esto ha generado conmoción para superar obstáculos tecnológicos, financieros y cognitivos requeridos por las sociedades latinoamericanas.

A esto habría que agregar el fenómeno de la sociedad de la información y la sociedad del conocimiento, en las que las denominadas TIC y la información misma han propiciado cambios significativos y constituyen la base material. En el caso de la educación virtual, el uso apropiado de la información relevante para los aprendizajes orientará cada vez más a los educadores a modificar los hábitos de estudio, analizar y recrear la información disponible en redes para fines docentes. 


\section{REFLEXIONES FINALES}

La sociedad de la información y la sociedad del conocimiento han propiciado cambios sustanciales que han afectado a la sociedad en su conjunto. En el campo educativo, las TIC han generado nuevos escenarios de comunicación, relación y acción que han influido en las disciplinas y en el ejercicio profesional. En este contexto, un aspecto importante para el éxito de propuestas educativas virtuales estriba en que las naciones se comprometan a preparar cuadros profesionales especializados en educación virtual y en el manejo y aplicación de tecnologías orientadas a la educación de esta naturaleza. También, los diseñadores de propuestas a distancia, autores de contenido y tutores, deben cuestionar los alcances de los modelos que diseñen, el uso apropiado de las TIC, la conveniencia y relevancia de los contenidos educativos y las prácticas pedagógicas que se quieran emplear.

Hoy en día, la Internet representa una realidad tecnológica relevante en el diseño de propuestas educativas virtuales para cualquier disciplina, por ello resulta conveniente tener en mente diversos aspectos de su desarrollo y de su aplicación en la educación en el nuevo siglo. En este contexto, el desarrollo del conocimiento y la tecnología son fenómenos fundamentales que la educación ha de enfrentar en todos sus niveles.

El creciente desarrollo tecnológico, de información y de conocimiento ha generado necesidades educativas relacionadas con la formación e instrucción de los sujetos, a fin de hacerlos competentes en la aplicación de tecnologías y en la operación de procesos derivados de éstas. No obstante, aunque se adopten tecnologías de vanguardia en las instituciones educativas, sólo se avanza en propuestas de calidad si existe interés por desarrollar tareas de gestión educativa a distancia que incluyan el aprendizaje innovador, la formación de autores de contenido, de tutores preparados para la interacción virtual y el abatimiento de costos. Así, en el nuevo siglo la universidad virtual ha de considerar que si sólo se limita a activar por Internet modelos académicos presenciales, no tendrá mucho que aportar. Por lo tanto, conviene atender un compromiso de incluir innovaciones pedagógicas en sus planes y programas de estudio para su enseñanza 
virtual y alentar la responsabilidad individual de alumnos y tutores, como sujetos que conforman la comunidad académica.

Los medios de comunicación propician un cambio radical porque la información digital elaborada en línea o digitalizada y distribuida a través de tecnologías de redes integrará cada vez más al alumno como especialista o como usuario conocedor de cierta disciplina. Por lo tanto, son asuntos que la bibliotecología debe atender, puesto que los sujetos del acto educativo requieren de servicios de información ágiles y relevantes, basados en los intereses de los tutores y de los alumnos a distancia. Al mismo tiempo, la incorporación a la Internet de recursos documentales de calidad para apoyar la educación virtual es una responsabilidad compartida de organismos educativos, centros e institutos de investigación, docentes, bibliotecólogos y documentalistas.

La enseñanza virtual y las TIC plantean nuevos fenómenos de estudio para la bibliotecología, debido, entre otras razones, a las transformaciones tecnológicas operadas en el campo de las telecomunicaciones y la computación, las cuales han generado cambios en las sociedades respecto de las formas de trabajo, los modos de interacción y comunicación de grandes sectores sociales y las necesidades en cuanto al uso de información.

Las TIC han propiciado que el documento adquiera dimensiones inéditas, por ello, en nuestros días, suelen denominárseles objetos digitales, debido a que se generan en forma distinta a los impresos. Proporcionan datos para su organización, administración, comprensión de contenido, facilidades para ser relacionados con otros objetos digitales, característica que propicia la comunicación interactiva entre los objetos y sus usuarios. Las normas bibliográficas para organizar documentos digitales muestran que su aplicación recurriendo a las TIC no es del todo simple, debido a que su empleo requiere del conocimiento de una gran variedad de contextos y conceptos. Uno de éstos se refiere a la homologación del documento digital con otros similares, desde el punto de vista temático o a partir de otras variables con el finde intercambiarlo y transferirlo como parte de una red de información. 
Las alternativas de solución a los problemas de la organización y el uso de documentos digitales no se halla en el mercado de software y hardware. Sin embargo, no se trata de prescindir de la innovación tecnológica, más bien se necesita conocer la problemática del diseño y la construcción de documentos digitales, comprender la tecnología de su arquitectura, estudiar las normas propuestas para su organización y difusión conocer las propuestas de los metadatos y las bibliotecas digitales como soportes de esa organización y difusión. Así, generar alternativas de solución a los problemas que nos plantea la organización y el uso de documentos digitales exige soluciones para evaluar y meditar, ya que la tecnología pronto se vuelve obsoleta, por razones de rentabilidad del mercado tecnológico. En consecuencia, tendremos que buscar alternativas para el mayor provecho de la organización documental y garantizar una adecuada relación costo-beneficio para las instituciones que los generen.

La Especialización sobre la organización de recursos informativos digitales expuesta en esta obra, busca identificar los fenómenos que requieren ser estudiados, agruparlos en un modelo académico y explicar teóricamente los requerimientos de una plataforma tecnológica en un ambiente de red que sustente la propuesta de dicha especialización. Con lo anterior, se quiere colaborar con ideas y reflexiones para prever la preparación de cuadros altamente calificados que asuman tareas sociales urgentes y necesarias, relativas a la organización de documentos digitales.

Asimismo, se persigue intervenir en el fomento de la profesionalización del bibliotecólogo, a partir del estudio de temas inseparables de la organización de recursos informativos digitales, cuya base principal son fenómenos de actualidad, relevantes, que genera las TIC. Al mismo tiempo, se busca alentar la investigación bibliotecológica en diversos temas examinados en este libro.Un ejemplo de tal propósito sería explicar las diferencias entre catalogar registros bibliográficos y representar documentos digitales (objetos digitales), para ser incorporados en sistemas de metadatos o en bibliotecas digitales. Sería un propósito fundamental para reorientar el estudio teórico y las tareas bibliotecarias de los modelos generados a partir de las TIC, que estarían sujetos a cambios constantes que afectan las 
actividades requeridas por la sistematización documental, cuyo propósito sigue siendo facilitar la recuperación y el uso de la información a las sociedades usuarias.

La teoría subyacente en la $\mathrm{EAD}$ y que ha heredado la educación virtual tiene mayor sentido cuando se le conduce hacia propuestas educativas específicas, con la idea de corroborar la pertinencia de las dimensiones sustantivas de esta modalidad. En consecuencia, el modelo académico y la plataforma tecnológica presentados en esta obra corroboran que es necesario tener conocimiento interdisciplinario en el que se elabora la propuesta educativa y ser especialista en organización documental para poder estructurar un currículum y el material didáctico que respondan a los fenómenos adecuados para atenderlos en la enseñanza. También es indispensable contar con conocimiento sobre TIC, a fin de estructurar la lógica de un modelo académico y relacionarlo con determinada plataforma tecnológica.

Para diseñar un modelo de la educación virtual en bibliotecología o en otras disciplinas conviene valorar la pertinencia de agruparlo modularmente. Si es el caso, cada módulo debe contener su propio material didáctico, la bibliografía complementaria, ligas a sitios web relevantes, de acuerdo con los temas de cada módulo y las actividades de aprendizaje. De esta manera, el alumno a distancia navegará a través del curso en cuestión, bajo un orden secuencial, organizado en un aula virtual, o navegando en forma aleatoria a través de cualquier módulo. En teoría, la organización curricular en módulos y su correspondiente material de instrucción permiten al alumno un alto grado de navegación, de interactividad y de autoaprendizaje.

Así, la interactividad y la navegación en redes son fenómenos de gran interés para diversos organismos internacionales y estudiosos de la educación virtual dada a su novedad, y los pocos avances que se han logrado en este terreno hasta el día de hoy. Los diseñadores de aulas virtuales, para operarlas a través de Internet, analizan detenidamente las necesidades de la programación requerida para la interactividad y la navegación en los procesos de aprendizaje, vía redes de teleproceso. Esto exige a los bibliotecarios que colaboren en proyectos de esta naturaleza, que conozcan los fundamentos de tal programación para lograr tener una comunicación profesional apropiada 
con el equipo de cómputo. Por otra parte, los autores de contenido requieren de una alta especialización en los temas en que generen los contenidos de aprendizaje y contar con conocimiento sobre las posibilidades de los multimedia, el software educativo y el hipertexto para desarrollar materiales didácticos adecuados para el aprendizaje en escenarios virtuales. Lo anterior determina una colaboración inter y multidisciplinaria.

Es indispensable que en las tareas de diseño, desarrollo y puesta en operación de aulas virtuales y de bibliotecas digitales de apoyo a la educación virtual se acuda a la teoría subyacente en el modelo de la educación a distancia, la necesidad de atender el desarrollo de materiales didácticos, una tutoría que armonice con el aprendizaje virtual y con los procesos de evaluación. La biblioteca digital tiene que analizar los servicios que históricamente ha otorgado la tradicional, con la idea de incidir en nuevas propuestas de servicios para la educación virtual.

En las propuestas de educación virtual en bibliotecología han de tenerse en mente que es necesario establecer las condiciones humanas y tecnológicas para incidir en el diseño y desarrollo de propuestas educativas virtuales exitosas. Atender la necesidad del aprendizaje de los sectores bibliotecarios que requieran conocer las nuevas propuestas y el nuevo conocimiento en torno a la disciplina, generar modelos académicos y tecnológicos de amplio espectro útiles para diseñar programas educativos virtuales en distintos niveles de la educación en bibliotecología. En consecuencia, estos niveles servirían de base para estructurar propuestas de esta clase en otras disciplinas. Definir estructuras de materiales de apoyo a los aprendizajes cuyo contenido tome en cuenta metodologías y teorías del aprendizaje típicas de los entornos virtuales. Dichas estructuras serían de utilidad para los interesados en desarrollar materiales de instrucción orientados a la educación virtual. 
Finalmente, quiero señalar que los avances científicos y tecnológicos repercuten en el mundo de la información y las transformaciones se han propiciado en el ámbito de la disciplina bibliotecológica y en su ejercicio; asimismo, han repercutido en las formas de organizar recursos de información digital, retomando los soportes materiales y el uso de la información. Sin embargo, y contra algunas previsiones muy optimistas, considero que estamos lejos, sobre todo en los países subdesarrollados, de un convencimiento social pleno acerca de las posibilidades que otorga la educación a distancia y mucho más lejanos de la educación virtual. En consecuencia, se necesita de un trabajo más intenso y de participación entre los sectores bibliotecarios interesados en compartir las diversas modalidades educativas que atraviesan por plena gestación. 


\section{BIBLIOGRAFÍA}

ACHINSTEIN, Peter. Los modelos teóricos / trad. Madaleno Sancho. México: UNAM, Coordinación de Humanidades, 1987. 27 p.

ALSINA, Miguel Rodrigo. Los modelos de la comunicación. Barcelona: Tecnos, 1989. $138 \mathrm{p}$.

AMADOR BAUTISTA, Rocío. "Educación y formación a distancia en México. Crónica de una historia no escrita", en Educación y formación a distancia. Prácticas, propuestas y reflexiones / coord. Rocío Amador Bautista, México: Universidad de Guadalajara, 2001, pp. 15-49.

- - . "Nuevos procesos educativos en el medio digital", en El medio digital en el siglo XXI: retos y perspectivas para los bibliotecólogos, investigadores, educadores y editores. México: UNAM, CUIB, 2001. [Editado en CD-ROM] (Trabajo presentado en el XVIII Coloquio Internacional de Investigación Bibliotecológica).

ANUIES. Plan Maestro de Educación Superior Abierta y a Distancia Líneas estratégicas para su desarrollo. Documento aprobado, en lo general por la XXXI Asamblea General Ordinaria en su sesión del 16 de octubre de 2000 en la Universidad Autónoma de Nuevo León, [en línea] http://www.anuies.mx/pdf/Plan\%20Maestro1.pdf [consultada: 15/07/03].

Aprender en la virtualidad / comp. Joseph M. Duart y Albert Sangrá. Barcelona: Gedisa, 2000. 253 p.

ARIAS O., José, M. Hernández Cruz y Martha Arango de V. "El desarrollo de las estructuras de la biblioteca digital", en Taller de Bibliotecas Digitales. Santafé de Bogotá: Pontificia Universidad Javeriana, 2000. h. 19-45. 
ARNAZ, José A. La planeación curricular. México: Trillas, 1983. 74 p.

ATHERTON, Pauline. Manual para sistemas y servicios de información. París: UNESCO, 1978. [p. v.]

BARBERÁ, Elena. [et al.]. La incógnita de la educación a distancia. Barcelona: ICE; Universitat Barcelona, Horsori, 2001. 245 p. (Cuadernos de educación; 35).

BARBERENA BLÁSQUEZ, Elsa. "Desafíos para la Bibliotecología", en $L a b i$ bliotecología en el México actual y sus tendencias. México: UNAM, DGB, 1992. pp. 189-190.

BATES, A. W. La tecnología en la enseñanza abierta y la educación a distancia. México : Trillas, 1999. 334 p.

BEAR, John y Mariah Bear. College degrees by mail: and modem 100 acredited schools that other bachelor's, master, doctorates and law degrees by home study. Berkeley, Cal.: Ten Speed, 1999. 203 p.

BELANGER, France y Dianne H. Jordan. Evaluation and implementation of distance learning: technologies, tools and techniques. London: Idea Group Publishing, 2000. 246 p.

BEREIJO MARTÍNEZ, Antonio. Bases conceptuales del análisis documental: la calidad de objetivos, procesos y resultados. Madrid: Universidad Carlos III de Madrid, Boletín Oficial del Estado, 2002. 319 p.

BERMÚDEZ, Guillermo. "Biblioteca y derechos de autor en el nuevo mundo digital", en Revista Mexicana del Derecho de Autor 2003, vol. 3, no. 7, 2003. pp. 20-24.

BESTOUGEF, H. y J.P. Pargette. Enseñanza y computadoras. España: Gedisa, 1986. 221 p.

La biblioteca del futuro / coord. Estela Morales Campos y Adolfo Rodríguez Gallardo. México: UNAM, DGB, 1996. 333 p.

BOOCH, Grady. Object solution:managing the object oriented project. California : Addison-Wesley, 1996. 323 p.

BUSTAMANTE ROJAS, Hilda G. "Propuesta de un modelo de orientación educativa a distancia", en Educación y formación a distancia. Prácticas, propuestas y reflexiones / coord. Rocío Amador Bautista. México: Universidad de Guadalajara, 2001. pp. 168-179. 
CABRERO ALMENARA, Julio. "Nuevas Tecnologías, comunicación y educación", en EDUTEC Revista electrónica de tecnología educativa núm.1, [en línea] http://uib.es/depart/gte/revelec1.html/ [consultada: 20/10/03].

El Campus Global de la Universitat Pompeau Fabra como instrumento al servicio de la innovación docente [en línea], http://www.upf.es/usice/cg/cast/innova.html [consultada: 17/06/05].

CAPDEVILA, Irene. "Grandes ingresos en el e-learning europeo", [en línea] http://www.laempresa.net/noticias/2001/0101/ 20020222_07.htm [consultada:05/08/05].

CARROLL, C.E. The professionalization of library education. Metuchen, N.J.: Scarecrow Press, 1970. [p.v.].

CASAS ARMEGOL, Miguel Ángel. Universidad sin clases: educación a distancia en América Latina. Caracas: Kapeluz; OEA-UNA, 1987. 20 p.

CASTELLS, Manuel. "La era de la información: economía, sociedad y cultura”, en La Sociedad Red. México: Siglo XXI, 1999. 590 p.

CODINA, Lluís. "El libro digital y la WWW". Madrid: Tauro, 2000. 274 p. (Comunicación y lenguajes).

- - . "El libro digital y la www", en Revista Española de Documentación Científica 2000, vol. 23, no.1, pp. 61-92.

COHEN, M. L. "Education for law librarianship", en Library Trends, jan. 1963, no. 11, pp. 306-314.

COLOM CAÑElLAS, Antonio J. "Pedagogía tecnológica para la educación a distancia", en Los nuevos escenarios educativos y las transformaciones tecnológicas / comp. Patricia Ávila Muñoz. México. ILCE, 1998. pp. 25-40.

COLLIS, B. Tele-learning in a digital world: the future of distance learning. London: International Thompson Computers Press, 1996. $651 \mathrm{p}$. 
CONTRERAS MAYÉN, Rita. "Reflexiones en torno al uso de la tecnología de la información en el terreno educativo", en Soluciones avanzadas: tecnologías de información y estrategias de negocios, jun. 1997, vol. 5, no. 46, pp. 10-15.

Copyright issues in Digital Distance Education, [en línea]

http://www.tbr.state.tn.us/general_counsel/ip/Copyrigth\% in\%20in\%DE.htm [consultada:09/03/04].

CROSLAND, D.M. "Georgia tech and the NSF Study Grant for Training Personnel for Scientific and Technical Libraries", en Special Libraries dec. 1962 , no. 53 , pp. 590-594.

CROVI DRUETTA, Delia. "Virtudes de la virtualidad: algunas reflexiones desde la educación", en Tecnología y Comunicación Educativa 1999, vol. 13, no. 29, pp.75-86 .

CHAN NUÑEZ, M. E. [ et al.]. "Guía para la elaboración del paquete de materiales didácticos orientados al aprendizaje independiente", en Estudio Independiente. México: ILCE, 1997. pp. 259-282.

CHAPA VERGARA, Sergio. Programación lógica. [en línea] http://www.cscinvestav.mx/SC/publica/chapa/intro_lm/node 42.html [consultada: 18/04/03].

DANIEL, John. "¿Va a ser la macro-universidad el modelo de formación académica superior en el nuevo milenio?”, en La educación a distancia en tiempos de cambios: nuevas generaciones, viejos conflictos / coord. Eustaquio Martín Rodríguez y Manuel Ahijado Quintillán. Madrid: Ediciones de la Torre, 1999. pp. 27-42.

DEEGAN, Malilyn y Simon Tanner. Digital futures: strategies for the information age. London: Library Association Publishing, 2002. 245 p.

Derecho de autor e industrias culturales, Barra Mexicana, Colegio de Abogados A.C. [en línea] p. 266.

http://www.google.com.mx/search?q= cache: $\mathrm{hg} 6 \mathrm{mX} 54 \mathrm{OJscJ}$ :www.bma.org.mx/publicaciones/ediciones/nuevas/derecho/derechode.html + dietz + derecho + autor\&hl $=$ es\&ie $=$ UTF-8 [consultada: 12/03/04].

DÍAZ BARRIGA, Ángel [et al.]. "El diseño curricular en la UAM Xochimilco: un estudio exploratorio desde la práctica docente", en Revista de Educación Superior abr./jun. 1990. vol. 2, no. 74, pp. 51-94. 
En señanza virtual sobre la organización de recursos informativos digitales

DÍAZ BARRIGA, Frida. "El aprendizaje significativo desde una perspectiva constructivista", en EDUCAR oct./dic. 1993. pp. 23-35.

Diccionario de las ciencias de la educación. México: Santillana, 1995. $1431 \mathrm{p}$.

Diccionario Enciclopédico de términos técnicos inglés-español, español-inglés. México: McGraw-Hill, 1980. 3.v.

Diccionario de la lengua española / Real Academia Española. $22^{\mathrm{a}}$ ed. Madrid: Real Academia Española, 2001. 1180 p.

DIDOU AUPETIT, Sylvie. Sociedad del conocimiento e internacionalización de la educación superior en México. México: ANUIES, 2000. 397 p. (Biblioteca de la Educación Superior, Investigaciones).

DISCENZA, Richard, Caroline Howard y Karen Schenk. The design and management of effective distance learning programs. London : Idea Group Publishing, 2002. 299 p.

La educación a distancia en tiempos de cambios: nuevas generaciones viejos conflictos / coord. Eustaquio Martín Rodríguez y Manuel Ahijado Quintillán. Madrid: Ediciones de la Torre, 1999. 222 p.

La Educación Superior en el Siglo XXI -Líneas estratégicas de desarrolloUna propuesta de la ANUIES. Documento aprobado en la XXX Sesión Ordinaria de la Asamblea General, Universidad Veracruzana e Instituto Tecnológico de Veracruz, Ver, 1999. [p.v.].

EDUCADIS. "Materiales y medios didácticos. Servicios asociados para la educación a distancia” [en línea]. Argentina, 2000. http://www.educadis.com.ar/mymath.htm [consultada:25/09/03].

"E-learning: soluciones de e-learning. Formación a Distancia", [en línea], http://e-learning.bankhacker.com/ [consultada: 08/05/03].

Elementos introductorios a la educación abierta y a distancia. México: UNAM, SUA, 1994. $402 \mathrm{p}$.

Enciclopedia de pedagogía. España: Espasa, 2002. 1115 p.

FAINHOLC, Beatriz. La interactividad en la educación a distancia. Barcelona: Paidós, 1999. 172 p. (Cuestiones de educación). 
FERNÁNDEZ HERNÁNDEZ, Patricia. "Transferencia de información y educación a distancia", en $X$ Encuentro internacional de educación a distancia: hacia la construcción de la sociedad del aprendizaje. México: [en prensa] 2003.

La formación continuada de bibliotecarios y documentalistas: bases para una evaluación. Informe elaborado por Ángel Villagrá Rubio [et al.]. Madrid: Federación Española de Sociedades de Archivística, Biblioteconomía y Documentación, 1996. 135 p.

"Formando teleformadores: diseño y desarrollo de un curso online utilizando WebCT" [en línea] http://s.es/idea/mie/pub/marcelo/ Formando\%20Teleformadores.pdf [consultada: 15/04/03].

FORNACA, R. "Componentes epistemológicos en la reconstrucción histórica de los modelos educativos y pedagógicos (primera parte)", en Cero en conducta, jul./oct. 1991, vol. 6, no. 26-27, pp. 64-73.

FREI, H.P. y D. Stieger. "The use of semantic links in hypertext information retrieval", en Information Processing and Management, jan./feb. 1995, vol. 31, no. 1, pp. 1-13.

FREIXAS FLORES, R. "SEP e ILCE en la educación a distancia", [en línea], http://www.ciberhabitat.com.mx/escuela/sep_ilce/textos/texto _sepilce.htm [consultada:28/08/05].

FUNDESCO. Teleformación: un paso más en el camino de la formación continua. Madrid: FUNDESCO, 1998. 212 p.

GALLOWAY, Alex. “¿Qué son los estudios digitales?”, [en línea] http://aleph-arts.org/pens/digitalstud.html [consultada: 15/05/03].

GARCÍA ARETÍO, Lorenzo. La educación a distancia: de la teoría a la práctica. España: Aries, 2001. 328 p.

GARCÍA CAMARERO, Ernesto y Luis Ángel García Melero. La biblioteca digital. Madrid: ArcoLibros, 2002. p. 243.

GARCÍA MARCO, Francisco Javier y Vannevar Bush. "El hipertexto y el futuro del documento", en Tendencias de la investigación en documentación / ed. Jesús Tramullas, España: Seminario TID, 1996. 150 p. 
GARCÍA OLVERA, Guillermo. "Propuesta para elaborar programas de actualización a distancia para egresados de escuelas mexicanas de bibliotecología". México: El Autor, 2001. 312 p. Tesis (Maestría en Bibliotecología) UNAM, FFyL, Posgrado en Bibliotecología.

GARCÍA PÉREZ, Jesús Francisco. "Los derechos de autor, el entorno digital $y$ los usuarios”. México: UNAM, FFyL, 2004. [en proceso] (Tesis. Maestría en Bibliotecología).

GARDUÑO VERA, Roberto y Elsa Ramírez Leyva. "Diplomado a Distancia en Biblioteca Digital". en Foro Internacional de Bibliotecas Digitales INTERFACES. Colima: Universidad de Colima, 2001. [Edición en CD-ROM].

GIMENO MONTORO, María José [et al.]. "Catalogación de recursos electrónicos accesibles en Internet: revisión de propuestas para una normativa" [en línea].

http://wg328 ww.florida-uni.es/ fesabid98/mj_gimeno.html [consultada: 17/08/03].

GOLSTEIN, Paul. El copyrigth en la sociedad de la información / Int. y trad. María Luisa Llobregat Hurtado. Alicante: Publicaciones Universidad de Alicante, 1999. 203 p.

GONZÁLEZ, Juliana. "La UNAM y su magisterio”, en Los Universitarios, nueva época, jun. 2003, no. 33.

GORMAN, M. Keynote address: from card catalogues to webPACs: celebrating cataloguing in the 20th Century, en Proceedings of the Bicentennial Conference on Bibliographic Control for the New Millennium: confronting the challenges of networked resources and the web (Washington, D.C. november 15-17, 2000) / ed. Ann M. Sandberg-Fox. Washington: Library of Congress, Cataloging Distribution Service, 2001. pp. xix-xxvii.

GRADMANN, Stefan. "Catalogación versus metadata: ¿Vino viejo en odres nuevos?" [en línea], en IFLA General Conference (64:1998, Amsterdan, Hol.) http://ifla.inist.fr/IV/ifla64/007-126s.html [consultada:15/09/03].

GRINBERG, Gabriel. "Educación digital: un desafío histórico”, en Política Digital feb./mzo. 2002, no. 2. 
GUINCHAT, Clare y Michel Menou. Introducción general a las ciencias y técnicas de la información y documentación. $2^{\mathrm{a}}$ ed. corregida y aumentada por Marie-French Blanquet. España: CINDOC; UNESCO, $1992.555 \mathrm{p}$.

GURI-ROSENBLIT, Sarah. Distance and campus universities: tension and interactions. A comparative study of five countries. [s.1.]: UNESCO, International Association of Universities and Elsevier Science Ltd., 1999. pp. 240-242 (Trad. del capítulo final, por Tito Mejía Esparragoza).

HANNAFIN, M.J. y K. L. Peck. The design, development and evaluation of instructional software. New York: Macmillan-Collier Macmillan, 1988. 89 p.

HRICKO, Mary. Design and implementation of web-enabled teaching tools. London : Information Science Publishing, 2003. 265 p.

INSTITUTO MEXICANO DE LA PROPIEDAD INDUSTRIAL. Informe Anual 1999. México: El Instituto, 2000. 125 p.

ISO. Standarization and Documentation: an introduction for documentalists and librarians. Switserland: ISO, 1983.98 p.

ISO. [en línea]. http://www.iso.ch [consultada: 10/04/03].

JAMESIME, F. "La computadora en la enseñanza: una retrospectiva”, en Perspectivas: revista trimestral de educación 1987, vol. 7, no. 63, pp. 395-398.

KENNY, J. y M. Reid. Training interventions. London: Institute of Personnel Management, 1986. 198 p.

KEOGH, A. "Advanced library training for research workers", en ALA Bulletin jul. 1919, no. 13, pp. 165-167.

KERCKHOVE, Derrick de. Inteligencias en conexión: hacia una sociedad de la Web. España: Gedisa, 1999. 214 p.

KOUKI, Rafa y David Wright. Telelearning via the internet. Hershey, Penn: Idea Group Publishing, 1999. 197 p. 
En señanza virtual sobre la organización de recursos informativos digitales

LAFUENTE LÓPEZ, Ramiro. "Anteproyecto de norma oficial mexicana (NOM): descripción bibliográfica y documental", en Documentación (nota preliminar). México: Comité Consultivo de Normalización, $1987.79 \mathrm{~h}$.

- - - Biblioteca digital y orden documental. México: UNAM,CUIB. 1999. $100 \mathrm{p}$.

- - - y Estela Morales Campos. "Reflexiones en torno a la enseñanza de la bibliotecología", en Investigación Bibliotecológica: archivonomía, bibliotecología e información, ene./jun. 1992, vol. 6, no. 12, pp. $25-33$.

- - - y Roberto Garduño Vera. "Enseñanza a distancia de la Bibliotecología y Estudios de la Información”, en Investigación Bibliotecológica : archivonomía, bibliotecología e información, jul./dic. 1999. vol. 13 , no. 27 , pp. 153-179.

- - - y Roberto Garduño Vera. Lenguajes de marcado de documentos digitales de carácter bibliográfico. México: UNAM, CUIB. 2001. 280 p. (Sistematización de la Información Documental).

$---[$ et. al.]. Conocimiento y uso de las nuevas tecnologías de la información y la comunicación. Cuba: UNESCO, CRESALC, 1996. 54 h. (Documento Central, Comisión 4).

LANDESHEERE, Gilbert de. Diccionario de la evaluación y de la investigación educativa. México: Oikos-Tau, 1985. 491 p.

LAUTERBACK, R. y K. Frey. "Los programas de informática. Balance y perspectivas", en Perspectivas: revista trimestral de educación, 1987, vol. 17 , no. 63 , pp. $423-428$.

Ley Federal del Derecho de Autor [en línea] http:/www.impi.gob.mx/web/docs/marco_j/index_marco_j.html [consultada: 15/03/04].

LÓPEZ GUZMÁN, Clara. "El derecho de autor y el desarrollo de colecciones digitales", en Biblioteca Universitaria jul./dic. 2003, vol. 6, no. 2, pp. 103-107.

LÓPEZ YEPES, José. Fundamentos de información y documentación. Madrid: EUDEMA, 1990. 485 p. 
LOYO VARELA, C. y V. G. Sánchez. "La telemática y la educación a distancia" [en línea], en Soluciones Avanzadas: tecnologías de información $y$ estrategias ago. 1995, vol. 4, no. 24. http://www.lania.mx/nivel2/ divulgacion.html [consultada en: 10/01/04].

MAESTRE YENES, Pedro. Diccionario de gestión del conocimiento e informático. Madrid: Fundación Dintel, 2000. 268 p.

MARTÍN RODRÍGUEZ, Eustaquio. "Dilemas y supuestos teórico-prácticos del desarrollo institucional de la educación a distancia", en La educación superior en tiempos de cambios: nuevas generaciones viejos conflictos. Madrid: Ediciones de la Torre, 1999. pp. 193-221.

MCKNIGHT, Cliff. Hypertext in context. Cambridge: Cambridge University Press, 1991. 166 p.

MIRANDA ARROYO, Juan Carlos. "El aprendizaje escolar y la metáfora de la construcción", en Revista Iberoamericana de Educación, [en línea] http://www.campus-oei.org/revista/deloslectores/ 630Miranda.PDF [consultada: 12/09/05].

MIRAS, Mariana e Isabel Solé." La evaluación del aprendizaje y la evaluación en el proceso de enseñanza", en Desarrollo psicológico y educación / comp. César Coll, Jesús Palacios y Alvaro Marchesi. Madrid: Alianza Psicología, 1993. 508 p.

MIRELES CÁRDENAS, Celia. "Del documento al objeto digital", en Investigación Bibliotecológica: archivonomía, bibliotecología e información, ene./jun. 2003, vol. 34, no. 17, pp. 88-103.

MONEREO, Carlos. Macroestrategias de enseñanza: aplicación en la preparación de servicios de información. España: Universidad de Barcelona, [2000]. [mimeo].

MORALES CAMPOS, Estela. Infodiversidad, globalización y derecho a la información. Buenos Aires: Sociedad de Investigaciones Bibliotecológicas, 2003. 203 p.

MOREIRO GONZÁLEZ, J.A. y M. A. Marzal García-Quismondo. "Modelos teóricos y elementos funcionales para el análisis de contenido documental: definición y tendencias", en Investigación Bibliotecológica: archivonomía, bibliotecología e información, jul/dic. 2001, vol. 15 , no. 31 , pp. 125-162. 
En señanza virtual sobre la organización de recursos informativos digitales

NABIL R., Adam [et al.]. Digital libraries: research and technology advances, Berlín: Springer, 1996. 290 p.

National Council on Quality Continuing Education for Information, Library and Media Personnel. A program for quality in continuing education for information, library and media personnel: policy statement and criteria for quality. Washington: Continuing Library Education Network and Exchange, 1980. 213 p.

NAUMIS PEÑA, Catalina. "Análisis de la confluencia entre término y descriptor en la elaboración de tesauros", en Investigación Bibliotecológica: archivonomía, bilbliotecología e información, jul/dic. 2000, vol. 14, no. 29, pp.95-113.

- - . "Tesauro documental para la representación de contenidos educativos en videos", en Investigación Bibliotecológica: archivonomía, bibliotecología e información, ene./jun. 2003, vol. 34, no. 17, pp. 144-174.

Objetivos de aprendizaje. México: UNAM, ENEP-Zaragoza, Departamento de Tecnología Educativa, 1994. [p. v.].

OLIVERA, Ángel. "Ingeniería del conocimiento", [en línea] http://www.aldeaedu.com/aldea/Tareas2.asp.?which $=1386$ [consultada: 18/04/03].

PAGLIARIO, L.A. "The history and development of CAI: 1926-1971 an overview", en The Alberta Journal of Educational Research, march 1983, vol. 29, no. 1, pp. 75-79.

PAULSEN, M.F. The online report on pedagogical techniques for computer-mediated communication, [en línea] NKI Oslo, Noruega, 1995, http://www.hs.nki.no/ morten/cmcped.html [consultada:15/10/03].

PEÑA BORRERO, Luis Alberto. Planeación de programas de universidad abierta y a distancia: factores críticos para la toma de decisiones. Colombia: ICFES, Ministerio de Educación Nacional, 1983. 66 p.

PÉREZ GUTIÉRREZ, Mario. El fenómeno de la información. Una aproximación conceptual al flujo informativo. Madrid: Trotta, 2000. 333 p. (Estructuras y Procesos. Ciencias Sociales). 
PÉREZ PAZ, Nahúm. "La modalidad de educación abierta y a distancia de la Escuela Nacional de Biblioteconomía y Archivonomía", en Jornadas Mexicanas de Biblioteconomía (28:1997: Cocoyoc, Mor.), México: AMBAC, 1998. pp. 122-131.

PLUMMBER, M.W. "Specialization and grading in library schools" en $A L A$ Bulletin, jun. 1913, no. 7, pp. 343-347.

Problemas sobre teoría y epistemología de la ciencia bibliotecológica y de la información: discusión y análisis / comp. Miguel Ángel Rendón Rojas. México: UNAM, CUIB, 2000. 79 p. (Teoría y métodos; 1).

POZO, Juan Ignacio. "Estrategias de aprendizaje", en Desarrollo psicológico y educación. / comp. César Coll, Jesús Palacios y Alvaro Marchesi, Madrid: Alianza Psicología, 1993. 508 p.

PRESCHEL, Barbara M. "Education of the information professional: what employers want", en Journal of the American Society for Information Science, 1988, vol. 39, no. 5, p. 358-361.

RANKIN, R. "Training for the special librarian", en Special Libraries nov. 1926 , no. 17 , p. $329-330$.

RAYWARD, B. "Library and information science: an history perspective", en Journal of Library History, spring 1985, no. 20, pp. 120-136.

Report on copyright and digital distance education. Washington, D.C.: Library of Congress, Copyright Office, 1999. 4 vols.

Reunión de Investigadores y Educadores de Iberoamérica y el Caribe en el área de la Bibliotecología y Ciencia de la Información / comp. Elsa M. Ramírez Leyva, Martha A. Añorve Guillén y Ma. del Rocío Graniel Parra. México: UNAM, CUIB, 1996. 387 p. (Memorias; 9).

Reunión Nacional de Educación Abierta y a Distancia (5). México: UNAM, SEP, 1994. $432 \mathrm{p}$.

RICO, Mary. Design and implementation of web-enabled teaching tools. London : Information Science Publishing, 2003. 265 p. 
RÍOS ORTEGA, Jaime. "Modelos en conflicto en la formación del bibliotecólogo mexicano", en El medio digital en el siglo XXI: retos y perspectivas para los bibliotecólogos, investigadores, educadores y editores, México: UNAM, CUIB, 2001 [Editado en CD-ROM]. (Trabajo presentado en el XVIII Coloquio Internacional de Investigación Bibliotecológica).

RODRÍGUEZ GALLARDO, J. A. Formación humanística del bibliotecólogo: bacia su recuperación. $2^{\mathrm{a}}$ ed. México: UNAM, CUIB, 2003. 327 p. (Sistemas Bibliotecarios de Información y Sociedad).

ROSAS, L. El cómputo en la enseñanza: la computadora en actividades docentes. México: UNAM, DGSCA, 1998. 33 p.

ROSS, Paul. "Hacia una autonomía del alumno: nueva pauta para medir los logros de una institución de enseñanza abierta", en La educación a distancia en tiempos de cambios: nuevas generaciones, viejos conflictos. Madrid: Ediciones de la Torre, 1999. p. 43-60.

RUMBLE, G. On defining distance education. En usos de las nuevas tecnologías en la educación. México: UNAM, CISE, 1995. pp. 63-77.

SÁNCHEZ SOLER, M.D. Modelos académicos, México: ANUIES, 1995. 83 p. (Temas de Hoy en la Educación Superior; 8).

SÁNCHEZ VEGAS, Saadia y Estrella Pérez. "Reflexiones sobre la formación de recursos humanos de cuarto nivel en el área de las ciencias de la información", en INFOLAC oct./dic. 1996, vol. 9, no. 4, pp. 3-7.

SANZ PRIETO, Mariano. "Teleeducación entornos de aula virtual”, en Temas. [s.1.] : [s.a.]. pp.12-20.

SCHAMBER, Linda. "What is the document? Rethinking the concept in uneasy and times", en Journal of the American Society for information Science, 1996, v.47, no.9, pp. 669-671.

SHERA, J. H. Los fundamentos de la educación bibliotecológica / trad. Surya Peniche de Sánchez Mcgregor. México: UNAM, CUIB, 1990. 520 p. (Monografías; 9). 
SHERA, J. H. "The present state of education and training in documentation, information science, and special librarianship in the United States", en Proceedings of the 1965 Congress, International Federation for Documentation. Washington: American Documentation Institute and Macmillan and Co., [1966]. [p. v.].

- - - "Training for specials: a prologue to revision", en Special Libraries mayo/jun. 1937, no. 28, pp. 139-144.

- - - y D.B. Cleveland. "History and foundations of information science", en Annual Review of Information Science and Technology, 1977, no. 12, pp.111-151.

SHEREMETOV, Leonid. "Espacios virtuales de aprendizaje: experiencia y prospectiva", en El medio digital en el siglo XXI: retos y perspectivas para los bibliotecólogos, investigadores, educadores y editores, México: UNAM, CUIB, 2001. [Editado en CD-ROM]. (Trabajo presentado en el XVIII Coloquio Internacional de Investigación Bibliotecológica).

Sistema Universidad Abierta: mejor educación. México: UNAM, Sistema de Universidad Abierta, 1994. 59 p.

SLAMECKA, V. "Graduate programs in information science at the Georgia Institute of Technology", en Special Libraries apr. 1968, no. 59, pp. 246-250.

STOJANOVIC, Lily. "Teoría en la educación universitaria a distancia de América Latina: exploración sobre la utilización de bases teóricas en la producción de materiales de instrucción", en Revista de Tecnología Educativa 1988, vol. 10, no. 4, pp. 273-290.

TAUBE, M. "Implications for professional organization and training", en American Documentation aug. 1953, no. 4, pp. 122-125.

TIFFIN, John y Lalita Rajasingham. En busca de la clase virtual: la educación en la sociedad de la información. Barcelona: Paidós, 1997. $312 \mathrm{p}$.

TORRES VARGAS, Georgina Araceli. "La biblioteca virtual: algunas reflexiones en torno a su contexto conceptual", en Ciencias de la Información, jun. 1994, vol. 25, no. 2, pp. 54-60. 
UNAM. Centro Universitario de Investigaciones Bibliotecológicas [en línea] http://cuib.unam.mx [consultada: 24/01/04].

UNAM. Centro Universitario de Investigaciones Bibliotecológicas [Folleto de difusión], [1999]. $18 \mathrm{p}$.

UNAM. Estatuto del Sistema Universidad Abierta y Reglamento del Estatuto del Sistema Universidad Abierta de la UNAM relativo al ingreso, la permanencia y los exámenes, capítulo $1^{\circ}$. México: UNAM, Dirección General de Estudios de Legislación Universitaria, 1998. 1415 p.

UNAM. Programa de Maestría en Bibliotecología y Estudios de la Información [en línea]. México: UNAM, Consejo Técnico de Humanidades, 1998.

http://www.filos.unam.mx:80/POSGRADO/programa/biblio.htm [consultada: 17/06/03].

Universidad Virtual del Instituto Tecnológico de Estudios Superiores de Monterrey, [véase http://www.puc.cl/teleduc/acercade/modelo.htm].

UNESCO. Consejo Ejecutivo. Contribución de la UNESCO a la cumbre mundial sobre la sociedad de la información. París: UNESCO, 2003. 5 p.

UNESCO. Situación del Programa General de Información (PGI) y del Programa Intergubernamental de Informática (PII) por un nuevo Programa Intergubernamental. Consejo Ejecutivo, $160^{\mathrm{a}}$ reunión. París, 2 de octubre de 2002. http://unesdoc.unesco/org/images/0012/001203/120374s.pdf [consultada: 16/11/03]. El informe final del PGI de la 25a reunión, 22-23 de junio de 1998, a cargo de la Mesa del Consejo Intergubernamental se puede consultar en http://www.unesco.org/webworld/iip/rtf/pgi_25.rtf) [consultada: 16/11/03].

Unidad de autoenseñanza: redacción de objetivos de aprendizaje. México: UNAM, [1998]. [p.v.].

UOC. La Universidad Virtual. Dimensión universal [en línea] http://www.uoc.es/web/esp/Universidad/01home.html [consultada: $17 / 06 / 03$ ]. 
VANN, S. K. Training for librarianship before 1923: education for librarianship, prior to the publication of Williamson's report on training for library service. Chicago: American Library Association, 1961. $242 \mathrm{p}$.

VAQUERO SÁNCHEZ, A. Las TIC para la enseñanza, la formación y el aprendizaje" [en línea], en Novática 132: monografía sobre las TIC en la educación, http://www.ati.es/PUBLICACIONES/novatica/1998/132.html [consultada: $18 / 06 / 03$ ].

- - y Luis Joyanes. Glosario de términos y siglas: diccionario inglés-españo-ingles. Madrid: McGraw-Hill, 1985. p. 31.

WILLIAMS, Robert V. y Martha Jane K. Zachert. "Specialization in library education: a review of the trends and issues", en Journal of Education for Library and Information Science, spring 1986, vol. 26, no. 4, pp. 215-231.

WRIGHT, H. C. "Shera as a bridge between librarianship and information science", en Journal of Library History, spring 1985, no. 20, pp. 137-156.

YUKAVETSKY, Gloria J. “¿Qué es el Diseño Instruccional?”, [en línea] http://cuhwww.upr.clu.edu/ video/personal/facultad/yukavetsky/ Tecnologia\%20Ed/Lectura_3\%20.html [consultada: 28/01/04].

ZETINA AGUIRRE, I. "Experiencias del sistema de educación a distancia de la Universidad Pedagógica Nacional”, en Divulgación Científica 1989, vol. 1, no. 1, pp. 21-26. 

Eseñanza virtual sobre la organización de recursos informativos digitales. La edición consta de 500 ejemplares. Coordinación editorial, Ignacio Rodríguez Sánchez. Formación editorial y revisión de pruebas, Carlos Ceballos Sosa. Corrección de estilo Hugo Espinoza Rubio. Centro Universitario de Investigaciones Bibliotecológicas/ UNAM. Fue impreso en papel cultural ahuesado de 90 gr. en Desarrollo Gráfico Editorial, S. A. de C. V., ubicados en Municipio Libre 175, Nave Principal, Col. Portales, México D.F. Se terminó de imprimir en el mes de diciembre de 2005. 